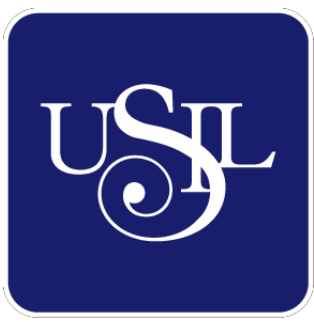

UNIVERSIDAD

SAN IGNACIO

DE LOYOLA

ESCUELA DE POSTGRADO

Maestría en Ciencias Empresariales

\title{
NEGOCIOS DE UN RESTAURANTE CON INSUMOS SALUDABLES Y ORGANICOS PARA EJECUTIVOS DEL CENTRO FINANCIERO EMPRESARIAL SAN ISIDRO
}

Trabajo de Investigación para optar el grado de Maestro en Ciencias Empresariales con Mención en Gestión de Pequeñas y Medianas Empresas

\section{LIZBETH JULIA CHACON ROJAS}

Asesor:

Dr. Edmundo Rafael Casavilca Maldonado

Lima - Perú

2019 

NEGOCIOS DE UN RESTAURANTE CON INSUMOS SALUDABLES Y ORGÁNICOS PARA EJECUTIVOS DEL CENTRO FINANCIERO EMPRESARIAL SAN ISIDRO 


\section{RESUMEN EJECUTIVO}

El presente Proyecto Gerencial Aplicado se centra en demostrar que la idea de Negocio de un restaurante de comidas con insumos saludables y orgánicos para ejecutivos de oficina del centro financiero empresarial de San Isidro es factible y rentable.

El tema elegido es producto de la visión de la autora por poner en marcha una fuente alterna de ingresos enfocado en brindar un servicio de alimentación saludable a los ejecutivos del Centro Financiero Empresarial de San Isidro.

Por ello se va a ofrecer un servicio cuyo valor agregado se centra en el hecho de utilizar insumos saludables y orgánicos, en su totalidad con la supervisión permanente de un nutricionista en todo el proceso de elaboración de las comidas.

La Organización de las Naciones Unidas para la Agricultura y la Alimentación considera como saludable: "Elegir una alimentación que aporta todos los nutrientes esenciales y la energía que cada persona necesita para mantenerse sana. Los nutrientes esenciales son: proteínas, hidratos de carbono, lípidos, vitaminas, minerales y agua" (Alimentación y estilos de vida saludable, FAO (2010).

Según el Ministerio de Ambiente considera como alimentos orgánicos: "Aquellos que han crecido libres de pesticidas, agro tóxicos, hormonas y antibióticos. Son producidos a escalas pequeñas (no industriales), y procuran establecer una relación de armonía con el ambiente. Tienen un sabor más auténtico" (MINAM, 2014). 
Considerando que hoy en día este público es más exigente e informado, alternativa que actualmente dada la conciencia por gozar de buena salud ha despertado el interés por introducir cambios en los hábitos alimenticios en parte de la población, la cual carece de ofertas con estas características, no contando con los estándares de calidad en los locales de restaurantes o comidas rápidas del mismo rubro ubicados en el distrito de San Isidro.

Se ha realizado un análisis del contexto actual y esperado del entorno de los sectores Político - Gubernamental, económico, legal, cultural, tecnológico y ecológico; así como el análisis de la industria, la investigación de mercado, la misma que no ha permitido realizar un estudio de mercado el cual está basado en la confirmación de aceptación del producto por parte del segmento escogido, así como la preferencia de estos por los servicios adicionales que se pretende ofrecer.

Se ha desarrollado la estructura organizacional y administrativa de la empresa, la cual es sencilla y flexible orientada a maximizar las utilidades y brindar un servicio orientado al cliente, objetivos que hacen necesario establecer un grato ambiente laboral basado en una cultura organizacional.

Respecto al plan de marketing se ha realizado la formulación de estrategias respecto al producto, precio, distribución, promoción y publicidad, acompañando del correspondiente plan de ventas y presupuesto de ventas.

En el aspecto Legal se ha presentado las condiciones necesarias para optar formar una empresa como una Sociedad Anónima Cerrada (SAC), de acuerdo a la ley general de sociedades. 
Por último, en cuanto al análisis financiero, se ha evaluado las fuentes de financiamiento se ha calculado el presupuesto de inversión y los costos fijos y variables de operación, se ha estimado el ingreso por ventas, para posteriormente elaborar los estados financieros, así como los indicadores necesarios que nos permita ver la viabilidad del proyecto, siendo atractivo frente a cualquier tasa pasiva que el sistema financiero pueda remunera. 


\section{ÍNDICE}

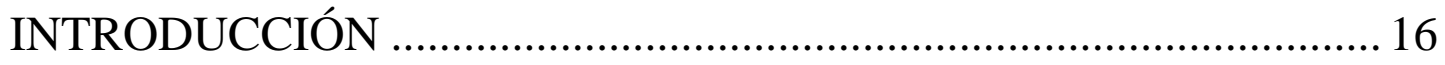

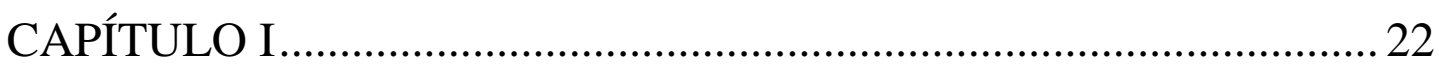

1. FORMULACIÓN DE LA IDEA DE NEGOCIO ........................ 22

1.1 Descripción general de la idea y modelo de negocio. ................. 22

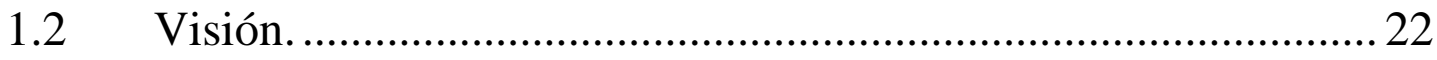

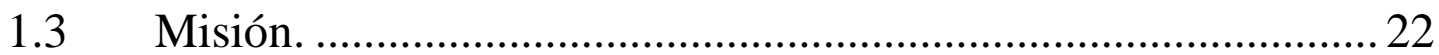

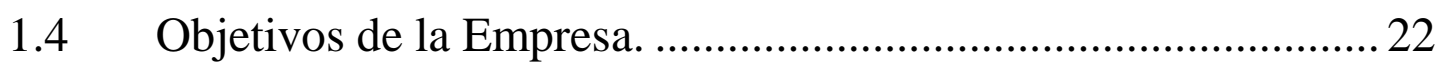

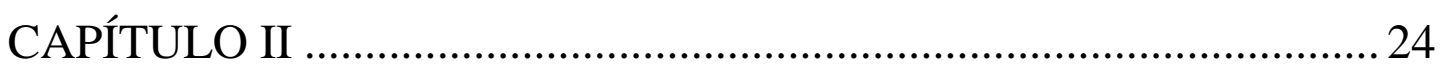

2. ANÁLISIS DE LA INDUSTRIA Y DEL MERCADO ............. 24

2.1 Análisis de la Industria............................................................... 24

2.1.1 Análisis del Sector Industrial.................................................. 24

2.1.2 Análisis de los Factores Externo.................................................. 26

2.1.3 Evaluación de Factores Externos............................................... 44

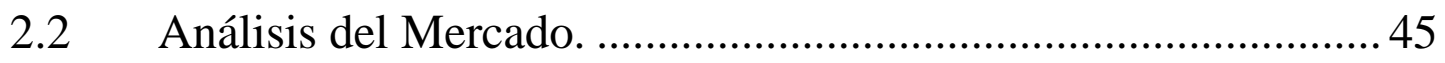

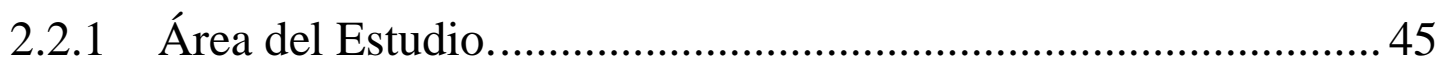

2.2.2 Perfil del Consumidor............................................................... 48

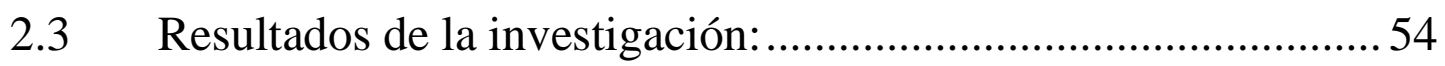

2.4 Sobre la Evaluación del concepto de negocio .............................. 57

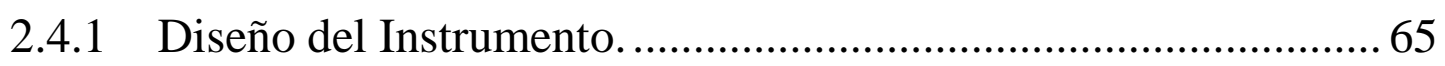

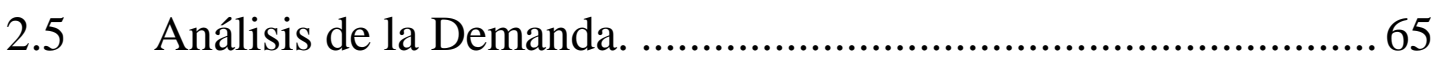

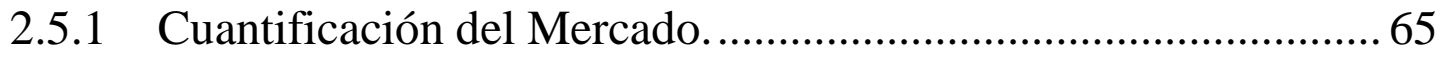

2.6 Análisis de la Competencia......................................................... 70

2.6.1 Identificación de los Competidores............................................. 70

2.6.2 Participación de Mercado. ............................................................ 73

2.7 Análisis de la Cadena de Valor.................................................. 74

2.7.1 Actividades Primarias ................................................................ 75

2.7.2 Actividades y Perfil del Personal para el Negocio. ..................... 77 


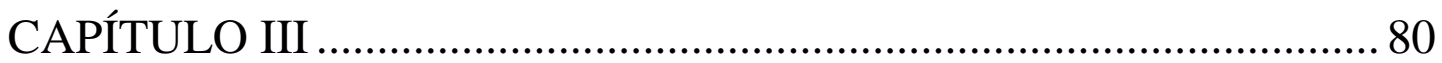

3. PLAN DE MARKETING Y VENTAS ..................................... 80

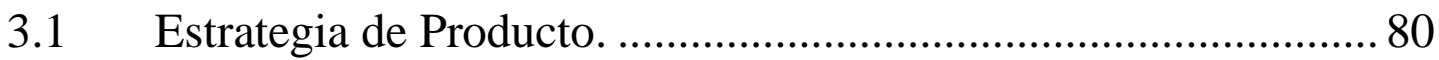

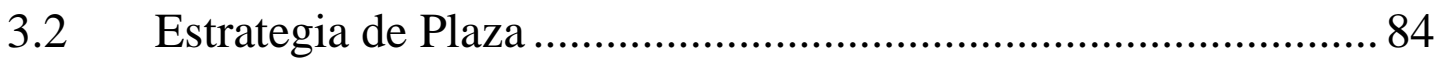

3.2.1 Determinación de la capacitad operativa..................................... 86

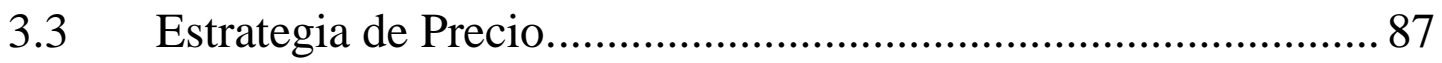

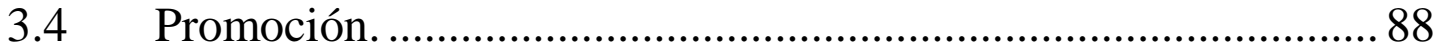

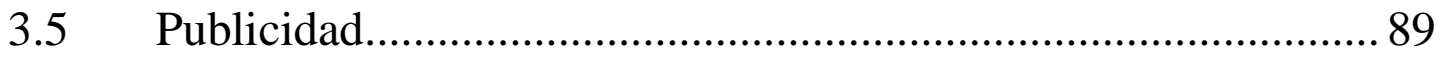

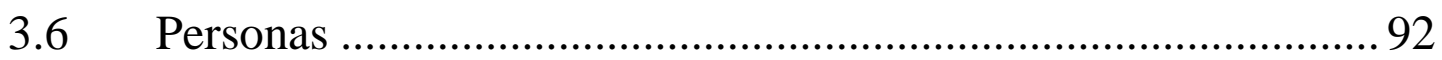

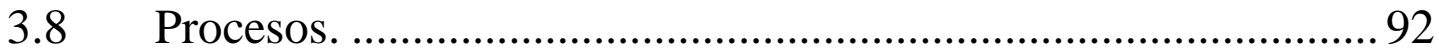

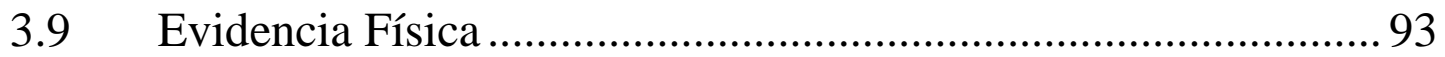

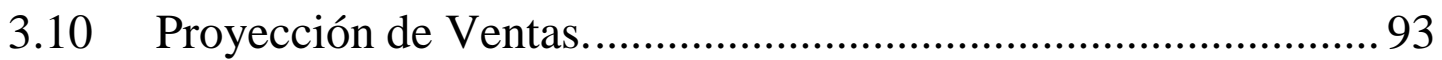

3.10.1 Proyección de ventas propuestas .................................................. 93

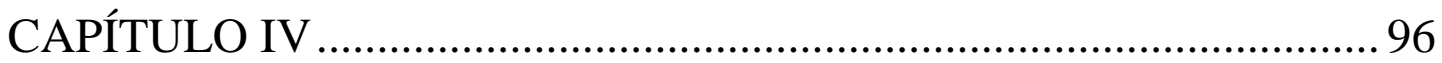

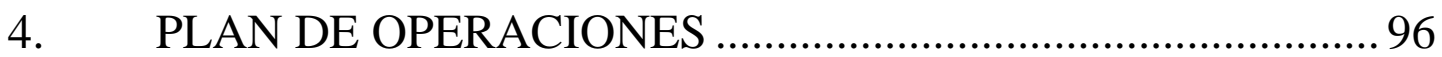

4.1 Ubicación geográfica. ..................................................................96

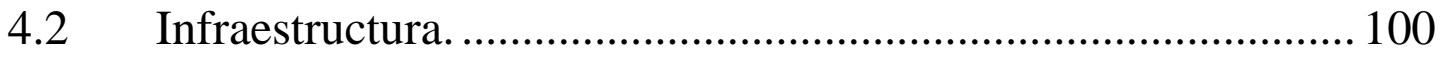

4.2.1 Diseño y composición de interiores........................................ 100

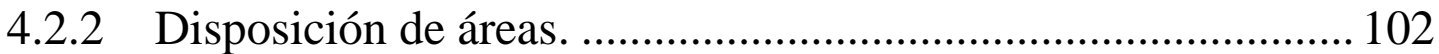

4.2.3 Capacidad instalada de atención a los clientes.......................... 104

4.3 Proceso Productivo. ................................................................... 106

4.3.1 Proceso de compras de insumos y materias primas.................... 106

4.3.2 Proceso de Producción de Alimentos. ......................................... 108

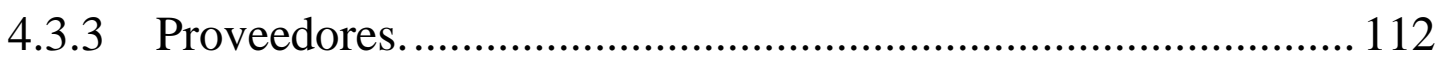

4.3.4 Ambiente Físico y Presentación del Restaurant. ....................... 114

4.4 Regulaciones de Licencias y Políticas ....................................... 116

4.4.1 Constitución de la empresa....................................................... 116

4.5 Costos de producción................................................................ 120

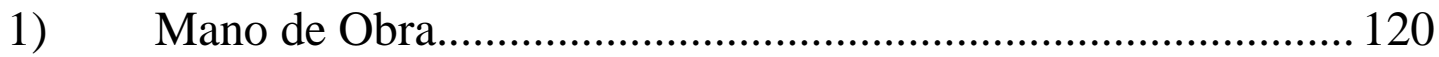




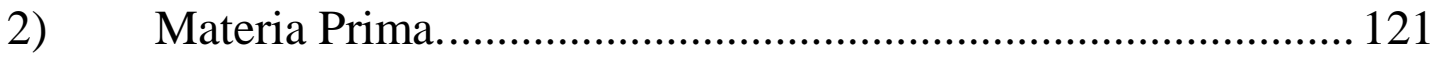

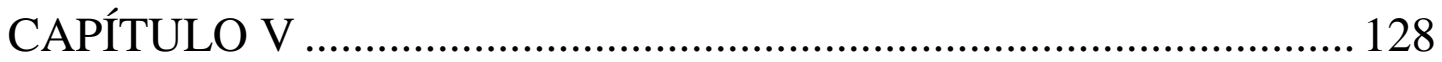

5. PLAN DE RECURSOS HUMANOS ................................... 128

5.1 Organización Funcional........................................................ 128

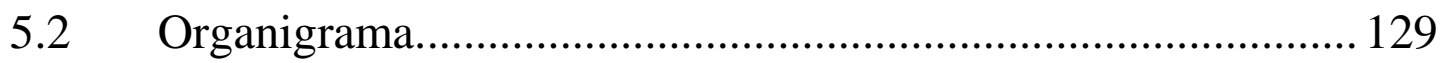

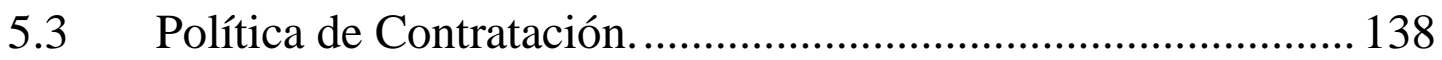

5.3.1 Legislación Laboral. ................................................................. 138

5.4 Política Salarial .................................................................. 140

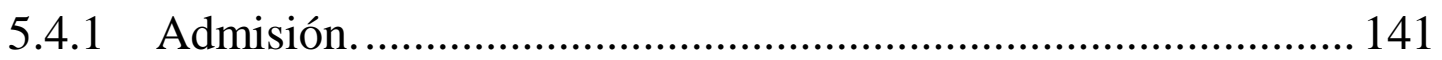

5.4.2. Derechos, obligaciones y prohibiciones del trabajador.............. 142

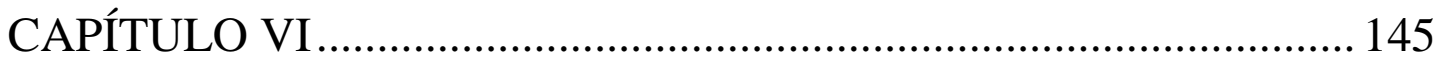

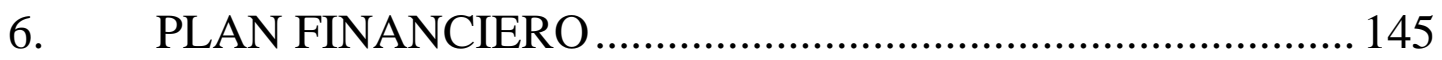

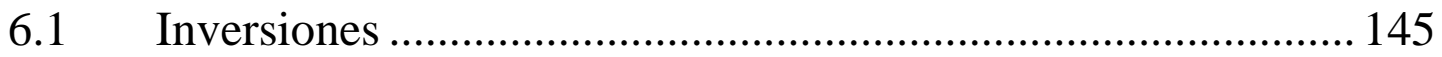

6.1.1 Inversiones en Activo Fijo..................................................... 145

6.1.2 Inversión de Capital de Trabajo................................................ 149

6.1.3 Inversiones en activos Intangibles ........................................... 151

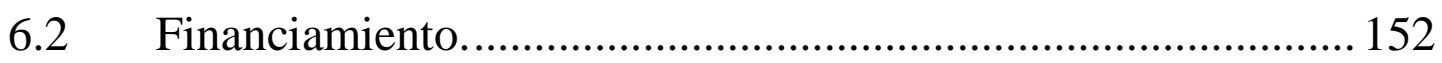

6.2.1 Costo de Oportunidad. ........................................................... 155

6.2.2 Costo Promedio del Capital. ..................................................... 158

6.2.3 Determinación del WACC.-.................................................. 159

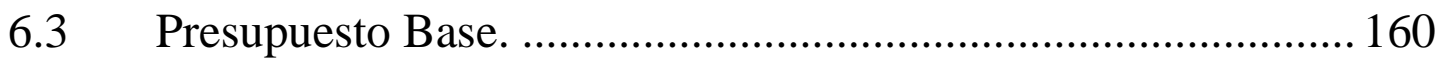

6.3.1 Presupuesto de Ventas. ............................................................. 160

6.3.2 Presupuesto de Compras.......................................................... 160

6.4 Estados Financieros Proyectados................................................ 163

6.4.1 Estado de Pérdidas y Ganancias ................................................ 163

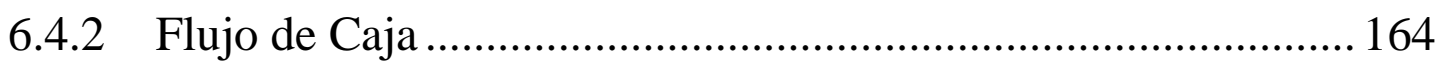

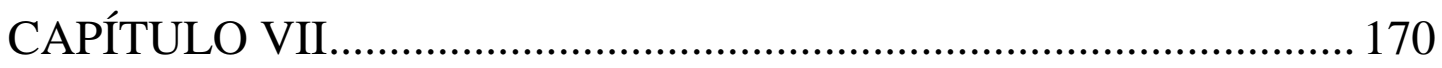

7. CONCLUSIONES Y RECOMENDACIONES ....................... 170

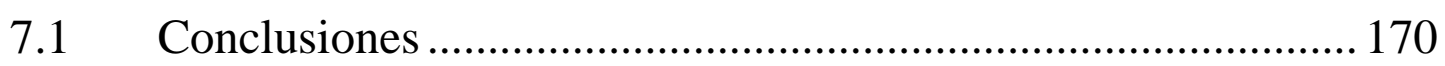




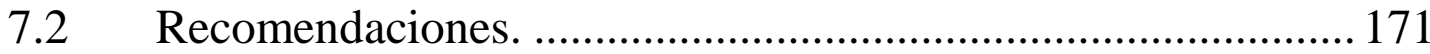

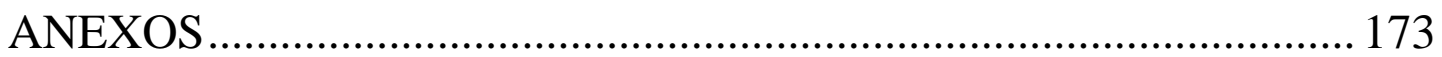

ANEXO 1. CARACTERÍSTICAS Y PROPUESTAS......................... 173

ANEXO 2. COSTOS UNITARIOS POR PLATO DE MENÚ............. 178

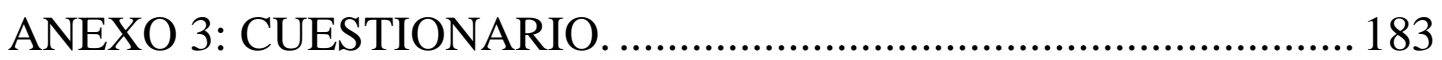

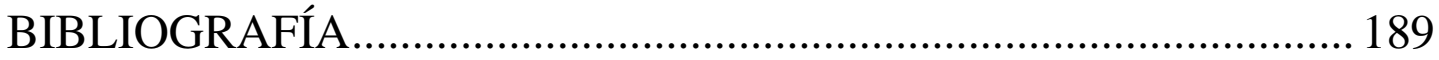

REFERENCIAS ELECTRÓNICAS ................................................... 191 


\section{ÍNDICE DE IMAGEN}

Imagen $N^{\circ} 2$ 1: Evolución mensual de la Actividad de Restaurante

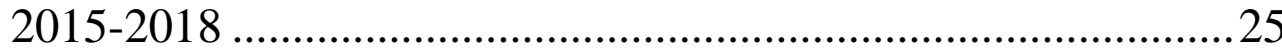

Imagen $\mathrm{N}^{\circ} 2$ 2: Licencias de Apertura de Restaurantes 2014_................26

Imagen $\mathrm{N}^{\mathrm{o}} 2$ 3: Evolución del Producto Bruto Interno.............................29

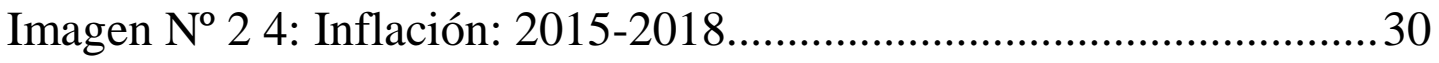

Imagen $\mathrm{N}^{\circ}$ 2.5: Análisis de las 5 Fuerzas de Porter .................................4

Imagen $\mathrm{N}^{\mathrm{0}} 2$ 6: Ubicación Geográfica del local .....................................47

Imagen $N^{\circ} 2$ 7: Población Flotante San Isidro por Sector ........................49

Imagen $\mathrm{N}^{\mathrm{o}} 2$ 8: Perfil de la Población Flotante San Isidro .......................49

Imagen $\mathrm{N}^{\circ} 2$ 9: Fórmula que estimará nuestro mercado potencial .........50

Imagen $\mathrm{N}^{\mathrm{o}} 2$ 10: Mapeo y registro geográfico de restaurantes.................70

Imagen $\mathrm{N}^{\mathrm{o}} 2$ 11: Análisis de la Cadena de Valor......................................79

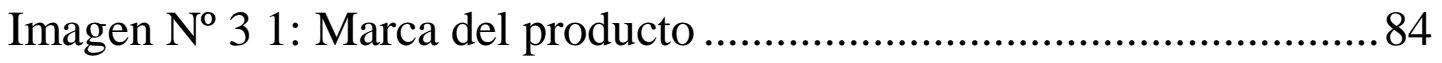

Imagen $\mathrm{N}^{\mathrm{o}} 3$ 2: Panorama de local - Restaurant en San Isidro Centro

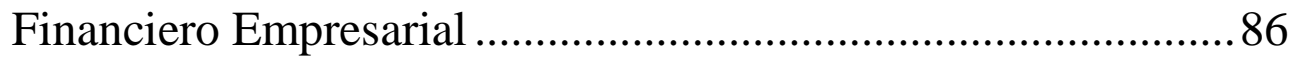




\section{ÍNDICE DE CUADROS}

Cuadro $\mathrm{N}^{\circ}$ 2.1: Matriz General Concluyente de las Fuerzas de Porter 41

Cuadro No 2.2. Evaluación de Factores Externos - EFE....................... 44

Cuadro $N^{\circ}$ 2.3: División Geográfica del distrito de San Isidro............ 46

Cuadro Nº 2.4: Determinación del Mercado Potencial......................... 67

Cuadro $\mathrm{N}^{\mathrm{o}}$ 2.5: Interés frente a la nueva idea del negocio .................... 68

Cuadro $\mathrm{N}^{\mathrm{o}}$ 6: Intención de consumo frente a la nueva propuesta de

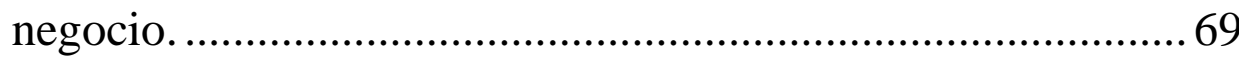

Cuadro No 7: Proyección mercado objetivo........................................... 69

Cuadro $N^{\circ}$ 2.8: Restaurantes asemejan a la nueva propuesta de negocio 72

Cuadro $N^{\circ}$ 2.9: Competencia indirecta por la cercanía ........................ 73

Cuadro No 2.10: Participación de Mercado.......................................... 74

Cuadro No 3 1: Información del distrito de San Isidro ......................... 85

Cuadro $N^{\circ} 3$ 2: Determinación de la capacidad operativa .................... 87

Cuadro $N^{\circ} 3$ 3: Cuadro comparativo de precios promedio de Menú.. 88

Cuadro No 3 4: Determinación de la proyección de ventas .................. 94

Cuadro No 3 5: Proyección de venta propuesta por platos................... 94

Cuadro $N^{\circ} 3$ 6: Resumen de la proyección de venta propuesta en

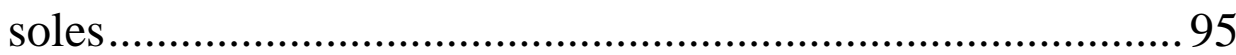

Cuadro $N^{\circ} 6$ 1: Relación de Activo Fijo - Maquinarias....................... 147

Cuadro No 6 2: Relación de Activo Fijo - Muebles y Equipos........... 148

Cuadro $N^{\circ} 6$ 3: Depreciación de Activo Fijo Maquinaria y Equipos 148

Cuadro $N^{\circ} 6$ 4: Amortización Intangibles ......................................... 149

Cuadro $N^{\circ} 6$ 5: Método del máximo Déficit Acumulado ..................... 150

Cuadro $N^{\circ} 6$ 6: Activos Intangibles - Gastos de Inversión .................. 151

Cuadro $\mathrm{N}^{\circ} 6$ 7: Programación del financiamiento................................ 152 
Cuadro $N^{\circ} 6$ 8: Cronograma de pagos de Capital de Trabajo.

Cuadro $N^{\circ} 6$ 9: Propuesta de Financiamiento de Capital de Trabajo. 155

Cuadro $N^{\circ} 6$ 10: Propuesta entidades Bancarias................................... 155

Cuadro $\mathrm{N}^{\circ} 6$ 11: Indicadores y datos financieros ................................. 156

Cuadro $N^{\circ} 6$ 12: Proyección de Ventas ................................................ 160

Cuadro $N^{\circ} 6$ 13: Costos de producción-Materia Prima ......................... 161

Cuadro $\mathrm{N}^{\circ} 6$ 14: Determinación de los costos de producción por plato 162

Cuadro No 6 15: Estados de Ganancias y Pérdidas............................... 164

Cuadro N 6 16: Flujo de Caja Operativa Proyectado.......................... 165

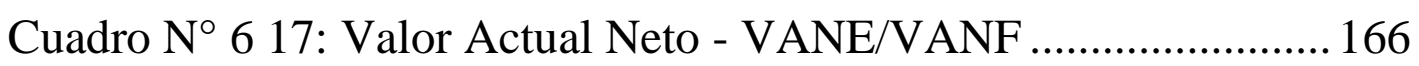

Cuadro No 6 18: Tasa interna de retorno Económico - TIRE.............. 167

Cuadro $\mathrm{N}^{\circ} 6$ 19: Tasa interna de retorno financiera- TIRF ................. 167

Cuadro $N^{\circ} 6$ 20: Valor Actual de la empresa en Periodo Continuo ... 169

Cuadro Nº 6 21: Determinación del Punto de Equilibrio ...................... 169 


\section{ÍNDICE DE GRÁFICOS}

Gráfico $\mathrm{N}^{\mathrm{o}} 2$ 1: Tipo de comida que come la población flotante

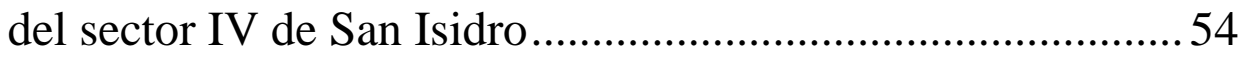

Gráfico No 2 2: Disponibilidad de pago................................................55

Gráfico $\mathrm{N}^{\circ} 2$ 3: Tipo de comida que come la población flotante

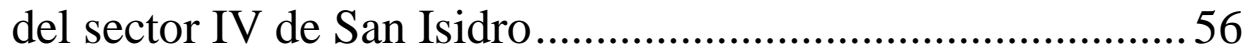

Gráfico $\mathrm{N}^{\mathrm{o}} 2$ 4: Interés frente a la nueva propuesta de negocio...........58

Gráfico $\mathrm{N}^{\mathrm{o}} 2$ 5: Nivel de agrado de atributos .....................................59

Gráfico $\mathrm{N}^{\circ} 2$ 6: Intención de consumo según NSE ............................... 60

Gráfico No 2 7: Evaluación según las opciones de almuerzo .............. 61

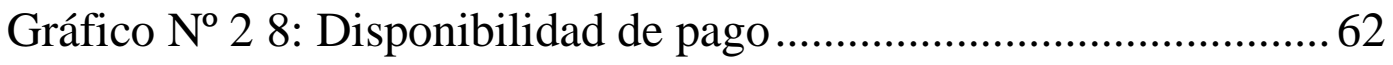

Gráfico No 2 9: Frecuencia de compra.................................................... 63

Gráfico No 2 10: Medios de información.............................................. 64

Gráfico No 2 11: Distribución de Ventas de la competencia ............... 74 


\section{ÍNDICE DE FIGURAS}

Figura $N^{\circ} 4$ 1: Ubicación geográfica por sector según el distrito .......96 Figura $N^{\circ} 4$ 2: Divisiones del sector según el distrito de San Isidro .. 97 Figura $N^{\circ} 4$ 3: Ubicación del local comercial - Restaurant.................. 99 Figura $\mathrm{N}^{\mathrm{o}} 4$ 4: Distribución del Restaurant ......................................... 106 Figura $N^{\circ} 4$ 5: Flujograma de atención a proveedores........................ 107 Figura $N^{\circ} 4$ 6: Diagrama de Flujo del área de la cocina .................... 110 Figura No 4 7: Diagrama de Flujo de Atención al Cliente .................. 111 Figura $N^{\circ} 5$ 1: Organigrama de la empresa ....................................... 129 


\section{INTRODUCCIÓN}

Este Plan de negocio nace de la idea de crear una nueva alternativa de alimentación dirigida a ejecutivos de oficina que diariamente por la necesidad natural de alimentarse acuden a restaurantes, fast food, comidas por delivery, entre otros. Aprovechando la acogida que tiene la comida peruana en estos últimos años a nivel nacional e internacional, se plantea realizar el análisis que potencia el modelo de empresa de un Restaurante de Comidas con Insumos Saludables y Orgánicos para Ejecutivos del Centro Financiero Empresarial de San Isidro

Por ello se propone un lugar confortable donde podamos ofrecer a los ejecutivos que laboran diariamente en el Centro Financiero Empresarial del Distrito de San Isidro, una alimentación especializada preparada con insumos saludables y orgánicos (siendo estos proveídos por instituciones certificadas y de garantía ) con un ambiente agradable, cómodo y la atención enfocado al servicio del cliente, bajo la supervisión de un especialista en nutrición y para la atención de los pedidos y reservas se utilizara un sistema de tecnología sofisticada como el uso de los IPad que se encuentren conectados a un sistema integrado tecnológico en línea que permitirá agilizar la elaboración de los pedidos.

Perú fue elegido como mejor Destino Culinario de Sudamérica según la edición regional de los World Travel Awards 2016 (WTA) obteniendo el galardón por quinta vez consecutiva. Además, Lima fue elegida como Mejor Destino para Turismo de Reuniones según los World Travel Awards Sudamérica 2016.

El distrito de San Isidro es una de las áreas urbanas de la ciudad de Lima, considerado como uno de los centros financieros importantes, sede central 
de los mayores bancos del país y sede de empresas nacionales y transnacionales. Según fuentes del INEI e información de la municipalidad distrital de San Isidro, este distrito cuenta con más de 5,075 empresas jurídicas dentro de ella se encuentran las empresas bancarias, corredoras de seguros, notarias, clínicas, empresas mineras, oficinas administrativas, actividades inmobiliarias, restaurantes con diferentes calidades de comida para diferentes tipos de cliente, que van desde los quioscos, fast food y food court de los centros comerciales.

Por otro lado, según el Informe Técnico de consulta mixta de expertos de la Organismo Mundial de la Salud y la Organización de las Naciones Unidas para la agricultura y la alimentación Dieta, Nutrición y prevención de Enfermedades Crónicas, 2003 indican que; “La promoción de dietas y modos de vida saludables para reducir la carga mundial de ENT (Enfermedades no Transmisibles) requiere un enfoque multisectorial y, en consecuencia, la participación de los diversos sectores pertinentes de la sociedad. Los sectores agropecuario y alimentario son un componente destacado en esta empresa y merecen ser tenidos debidamente en cuenta en toda consideración de la promoción de dietas saludables para los individuos y los grupos de población”. OMS/FAO (2003).

En el informe se concluye que una dieta con poco consumo de grasas saturadas, azúcar y sal, y mayor consumo de hortalizas y frutas, además de la práctica regular de alguna actividad física, contribuirá a reducir las altas tasas de muerte y enfermedad mencionadas, en consecuencia podemos indicar que hay una promoción de consumo de alimentos saludable, informe que es la base para la elaboración de nuestro Proyecto de Negocio y promoción del consumo de una alimentación saludable, con hábitos sano para satisfacer las demandas y afrontar los retos planteados. 
Según Natalia Ida del Greco (noviembre 2010, pág. 4), "Estudio sobre tendencias de consumo de alimentos", menciona que en los últimos años hubo muchos factores como las exigencias laborales actuales, el stress, la crisis global, la seguridad, la limitación del tiempo disponible, influyeron en los cambios de hábitos de la vida cotidiana y estos impactaran en distintos aspectos de la alimentación en el siglo XXI.

Según indica los nuevos estilos de cocina hay un concepto al abandono de la obligación de cocinar, concentrándose solo en determinados momentos y de forma rápida, el aumento del consumo de alimentos naturales y la mayor disposición a consumir platos preparados fuera del hogar.

En la columna de semana económica según Javier Masías, (Enero, 2016), indica que hay una búsqueda por el consumidor de productos tan naturales como le sea posible, sin aditivos ni colorantes, lo que obliga a restaurantes y empresarios a implementar los cambios en la medida de lo posible.

En el reporte titulado Global Food and Drink Market (2016), la consultora internacional Mintel: el rechazo a lo artificial es la tendencia más establecida en todo el planeta.

Mediante la observación directa se ha identificado en el distrito de San Isidro, alta concurrencia de comensales en días laborables de semana que buscan alimentarse saludablemente, pero por factor de tiempo en su búsqueda y poca oferta de ello se ven limitados a consumir comidas fast $\mathrm{o}$ restaurantes cercanos a sus oficinas, esto responde a la necesidad de los ejecutivos del Distrito de San Isidro, que tienen el tiempo limitado para almorzar o ingerir algún tipo de alimento con insumos saludables y tendencia orgánica ofrecida. 
En base a este marco de referencia y la falta de empresas que brinden este servicio de calidad, creemos que la necesidad de almorzar saludablemente es nuestra clave de éxito y sobre todo en un ambiente cómodo y un excelente servicio de atención al cliente. Es por ello que se ha decidido crear un plan de negocios que va dirigido a ejecutivos de negocios ofreciendo nuestro producto de un restaurante que utilice insumos saludables y orgánicos.

Por consiguiente, en el presente plan de negocios se va a realizar un análisis de mercado, evaluar servicios similares en el mercado, examinar las competencias y diseñar una propuesta de valor; la cual nos va a permitir identificar clientes potenciales, proyectar los aspectos económicos y financieros.

En los siete capítulos del trabajo se desarrollan el diseño completo de las actividades del Plan de Negocios del restaurante con insumos saludables y tendencia orgánica, con la finalidad de brindar un panorama general se describen brevemente los temas de cada en cada capítulo:

Primer Capítulo; Se precisa la formulación y la idea del negocio, se describe de manera general como se va a desarrollar el negocio, en que consiste, cual es el modelo a seguir, así como la visión, misión y los objetivos principales que delinearan a la empresa.

Segundo Capítulo; Esta enfocado a desarrollar el análisis de la industrial del rubro de servicios de restaurante, comprende un estudio completo de los factores económicos, político, legal, ecológico y tecnológico; así como el análisis del mercado, como se encuentra la demanda en este momento, la conformación de las competencias directas e indirectas y la cadena de valor.

Tercer Capítulo; en el plan de marketing se exponen las cuatro estrategias necesarias como son producto, precio, distribución y promoción, así como 
los canales adecuados para desarrollar una proyección de ventas adecuada al mercado.

Cuarto Capítulo; se describe el plan de operaciones, esto es como va a operar el negocio, la ubicación geográfica, infraestructura, sus divisiones y áreas, así como el proceso productivo de los alimentos, atención a los cliente y proveedores.

Quinto Capítulo; se desarrolla el plan de recursos humanos, como va a organizarse funcionalmente, las funciones, actividades, reclutamientos según las áreas y organigramas de la empresa, con sus respectivas normas, procedimientos, evaluación del desempeño y sistemas de remuneración.

Sexto Capítulo; en este punto se desarrolla el análisis financiero de la empresa por medio de lineamientos que permitan evaluar la rentabilidad del negocio, las proyecciones de compras y ventas, los estados de ganancias y pérdidas, el flujo de caja, la fuente de financiamiento entre otros.

Séptimo Capítulo; finalmente se realiza una sección de conclusiones y recomendaciones, sintetizando la viabilidad económica del negocio para el inversionista.

Las principales características de la propuesta de valor de este producto que permita su diferenciación y genere una ventaja competitiva son:

- Rapidez en el servicio de atención desde el ingreso al establecimiento, con ayuda tecnológica sofisticada en la toma de pedidos.

- Alimentos con insumos saludables y tendencia orgánica cuidando la calidad en la elaboración de los alimentos. 
- Constante capacitación del personal especializado en los procesos de elaboración.

- Permanente supervisión de un nutricionista en la elaboración de los alimentos.

- Permitir la reserva de las mesas a través de nuestra atención en línea y aplicativos. 


\section{CAPÍTULO I}

\section{FORMULACIÓN DE LA IDEA DE NEGOCIO}

\subsection{Descripción general de la idea y modelo de negocio.}

La idea del negocio consiste en la creación de un restaurante que brinde un servicio de comidas con insumos saludables y orgánicos, enfocado a una atención de calidad en el servicio al cliente, a un costo asequible supervisado por un nutricionista, los insumos a utilizar van a ser oriundos del Perú proveídos de los productores agrícolas en su mayoría saludables y orgánicos. El servicio de comida se brindará en el horario de almuerzo a los clientes que se encuentren en el ámbito geográfico del distrito de San Isidro manteniendo el compromiso de un servicio puntual y rápido.

\subsection{Visión.}

Ser líderes en Lima Metropolitana en el servicio de alimentación con insumos saludables y orgánicos orientados a conseguir un buen estado de salud de nuestros clientes a la hora del almuerzo.

\subsection{Misión.}

Ser considerados como una empresa que brinda a los ejecutivos una alimentación saludable, equilibrada en el almuerzo del día, promotores del uso productos saludables, y orgánicos.

\subsection{Objetivos de la Empresa.}

Desarrollar un plan de negocios para un Restaurante de Comidas con Insumos Saludables y orgánica para Ejecutivos del Centro Financiero Empresarial de San Isidro para hombres y mujeres que trabajan 
dentro del centro empresarial de San Isidro, en un ambiente acogedor, cálido y con un excelente servicio enfocado al cliente en el menor tiempo posible.

Con esta iniciativa se espera concentrar la actual oferta gastronómica a través de una página web que permita a las personas realizar sus pedidos de comidas y una central telefónica que tomara sus pedidos en línea. 


\section{CAPÍTULO II}

\section{ANÁLISIS DE LA INDUSTRIA Y DEL MERCADO}

\subsection{Análisis de la Industria.}

\subsubsection{Análisis del Sector Industrial.}

Actualmente el Perú muestra un contexto macroeconómico favorable debido al crecimiento económico en diversos sectores de la economía en especial el sector Restaurantes, según el Instituto Nacional de Estadística e Informática (2018), Boletín estadístico Encuesta mensual del Sector Servicios en junio 2018 el sub sector restaurantes creció en 1,86\%. Este resultado se sustentó en la evolución favorable de la actividad de restaurantes en 1,62\%, otras actividades de servicio de comidas en $3,52 \%$, servicio de bebidas en $1,71 \%$; contrariamente, decreció suministro de comidas por encargo en $-1,57 \%$.

El sector restaurantes registró una variación acumulada de 2,75\%.

Para seguir examinando la actividad de este sector, en la imagen 2.1 vemos un crecimiento decreciente durante el segundo semestre del 2018, a pesar de ello el sector restaurante cuenta con mucho potencial para seguir siendo explotado con mucha probabilidad de éxito para las empresas de este sector. 
Imagen $\mathrm{N}^{\mathrm{o}} 2$ 1:

Evolución mensual de la Actividad de Restaurante 2015-2018

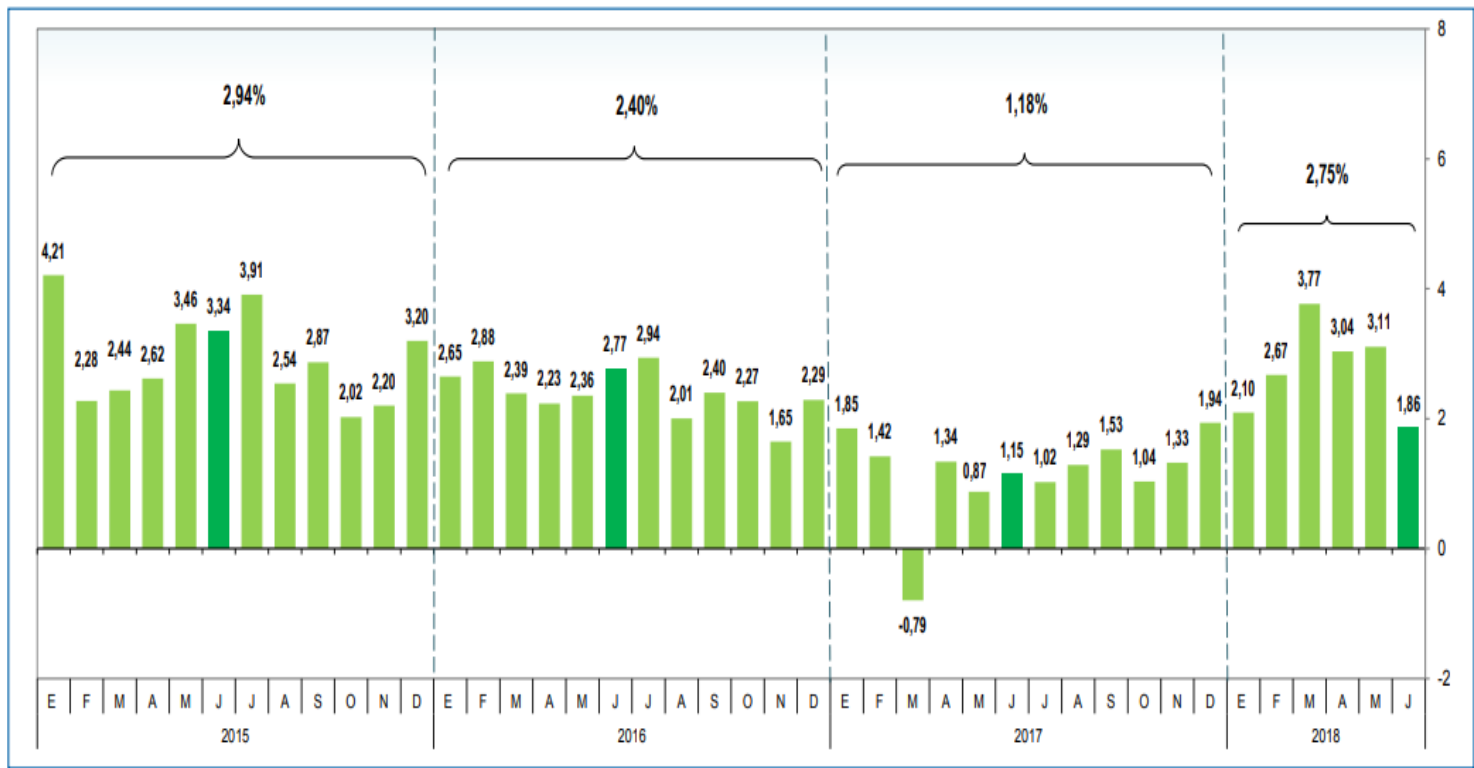

Fuente: Instituto Nacional de Estadística e Informática INEI.

“Durante el año 2014 se aperturó más de 47 mil restaurantes en todo Lima Metropolitana", de acuerdo al documento presentado por el INEI, Una Mirada a Lima Metropolitana (Pag.40), divididos en Lima Norte, Lima Centro, Lima Sur, Lima Este y la Provincia Constitucional del Callao, siendo San Juan de Lurigancho el distrito que concentra el mayor número de restaurantes seguida del Cercado de Lima y San Martin de Porres.

Diariamente en Lima, inician actividades 20 restaurantes y se cierran 5, de acuerdo al informe del Instituto Nacional de Estadística e Informática. 
Imagen $\mathrm{N}^{\mathrm{o}} 2$ 2:

Licencias de Apertura de Restaurantes 2014.

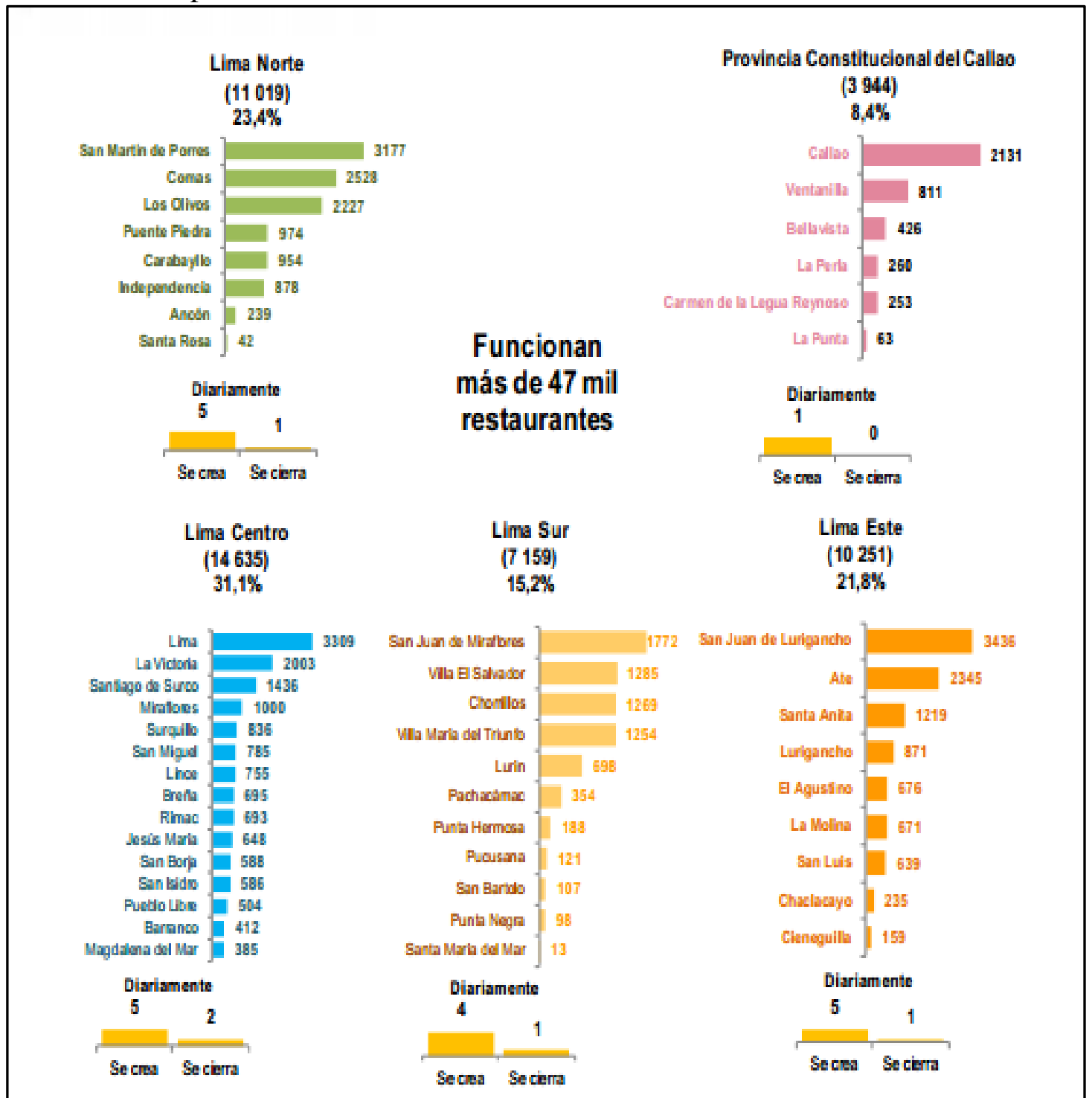

FUENTE: Instituto Nacional de Estadística - Directorio Central de Empresas y Establecimientos 2014.

\subsubsection{Análisis de los Factores Externo.}

\section{Análisis PESTEL.}

Mediante este análisis vamos a estudiar el entorno en el que se ubica la empresa a través de los diferentes factores.

La palabra PESTEL trata de un acrónimo en inglés, y las siglas que lo conforman hacen referencia a los seis factores que influirán en 
nuestro plan de negocios desde el exterior, pero que están fuera del control de la misma. Estos son: Políticos, Económicos, Socioculturales, Tecnológicos, Ecológicos y Legales. Cabe destacar que estos factores no son independientes entre sí, muchos de ellos están relacionados. A medida que cualquiera de estos factores cambie, dicha variación afectará al entorno competitivo en el que se moverá nuestro negocio. Los resultados que obtengamos de este estudio nos servirán para conocer qué podemos aprovechar del entorno y a que elementos nos tendremos que enfrentar.

\section{1) Análisis Político.}

Según el diario Perú 21 (abril, 2017) "Ante los resultados de las elecciones en Estados Unidos y en el marco del Foro sobre el Desarrollo y Promoción de la Infraestructura de la Alianza del Pacífico, el ministro de Economía y Finanzas, se mostró optimista ante los posibles efectos que generarían la elección de Donald Trump como presidente de la potencia mundial sobre la economía peruana y aseguró que los indicadores peruanos están estables.

El mes de Setiembre del 2016 el congreso aprobó la ley que permite al poder ejecutivo la facultad de legislar en materia de reactivación económica y formalización, seguridad ciudadana y lucha contra la corrupción, agua y saneamiento y reorganización de Petroperú S.A.

Dentro de ella destaca la simplificación de la estructura tributaria empresarial, fomentar el desarrollo de mercado de capitales con el fin de incrementar la competencia en el sistema 
financiero, modificar la Ley del Impuesto a las ventas e Impuesto Selectivo al Consumo a fin de reducir en un punto porcentual la tasa del Impuesto General a las Ventas a partir del 1 ro de Enero del 2017; estas medidas son puntos favorables que van a permitir a nuestro proyecto de negocio desarrollarse eficientemente con un escenario político a futuro estable y con tendencia a seguir haciendo suponer que no se suscitara eventos que atenten con la viabilidad y continuidad de nuestro negocio.

\section{2) Análisis Económico.}

Según el informe del Banco Mundial indica que el Perú se ubica en el puesto 54 entre 190 economías evaluadas en el ranking "Doing Business 2017: Igualdad de Oportunidades para Todos" elaborado por el Banco Mundial, una caída de cuatro posiciones frente a la lista del año pasado. El Banco Mundial concluyó que abrir una empresa en América Latina lleva ahora un promedio de 32 días, en comparación con los 55 días de hace cinco años. BM (2017).

De acuerdo al informe del Banco Mundial (2015), el Perú ha destacado como una de las economías de más rápido crecimiento en la región, con una tasa de crecimiento anual promedio de 5,9\% en un entorno de baja inflación (2,9\% en promedio). Un contexto externo favorable, políticas macroeconómicas prudentes y reformas estructurales en diversos ámbitos convergieron para dar lugar a este escenario de alto crecimiento con baja inflación. BM (2015). 
De acuerdo con el informe técnico No 03 agosto 2018 (INEI), El Producto Bruto Interno a precios constantes de 2007, registró un crecimiento de 5,4\%, incidiendo en este resultado la evolución favorable de la demanda interna, dinamizada por el incremento del consumo y la inversión, en un contexto internacional de crecimiento de las economías de nuestros principales socios comerciales.

Imagen $\mathrm{N}^{\circ} 23$ :

Evolución del Producto Bruto Interno

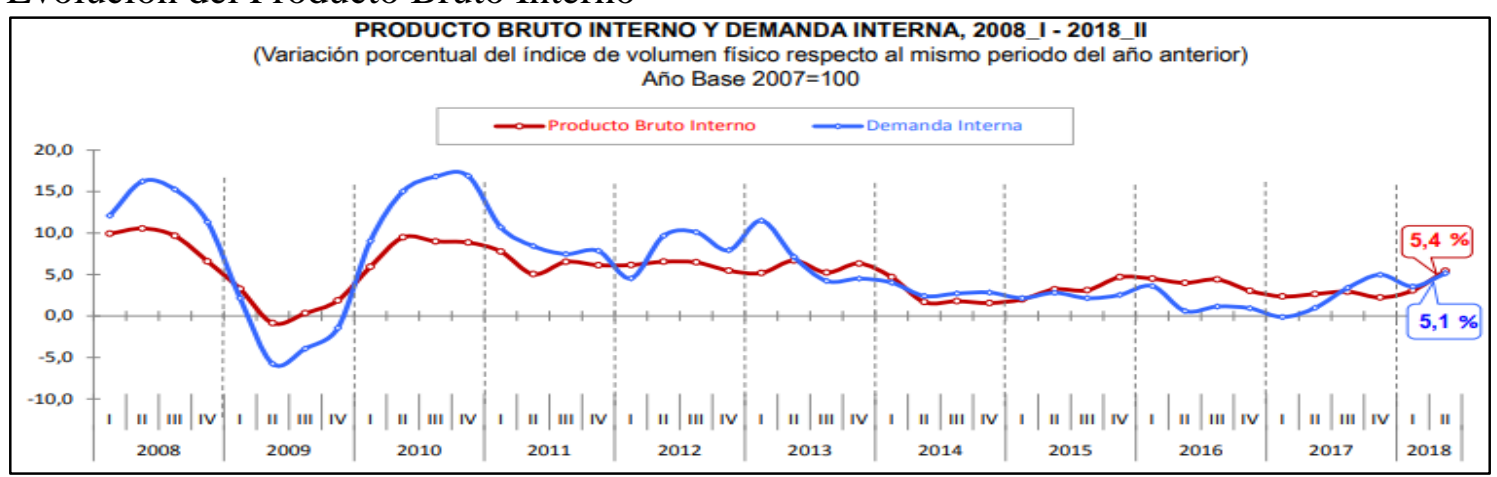

Fuente: Instituto Nacional de Estadística e Informática INEI.

La inflación general, después de llegar a un punto máximo de $4,6 \%$ a principios de año, disminuyó nuevamente y se encontraba en $2,9 \%$ en agosto de 2016, justo por debajo del límite superior del rango meta. La reducción de la inflación se debió a una menor presión por depreciación de la moneda nacional y a la normalización de las condiciones del clima que ejercieron presión sobre los precios de los alimentos en los meses anteriores. 
Imagen $\mathrm{N}^{\circ} 24$ :

Inflación: 2015-2018

Inflación

(Variación porcentual 12 meses)

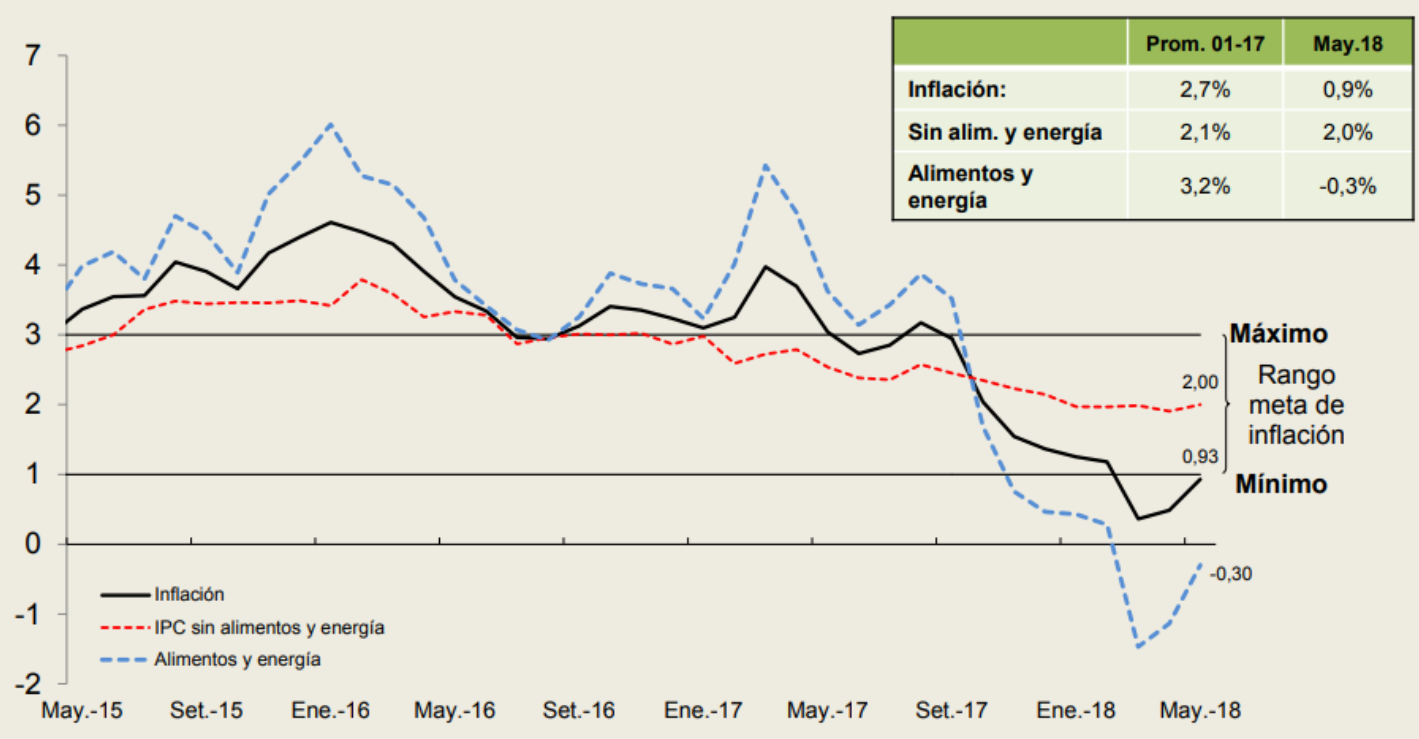

Fuente: Instituto Nacional de Estadística e Informática INEI.

En el frente externo, los principales factores que pueden impactar en el crecimiento económico son:

- La caída de los precios de las materias primas, estrechamente vinculada a la desaceleración de la economía mundial.

- Un eventual período de volatilidad financiera, vinculado al alza esperada de las tasas de interés en Estados Unidos.

En el frente interno, las proyecciones en cuanto al crecimiento del PBI son vulnerables a lo siguiente:

- Impacto del fenómeno de El Niño en la economía real.

- Un gran porcentaje de la población sigue siendo vulnerable a los choques o remezones y podría volver a caer en la pobreza. 


\section{3) Análisis Sociocultural}

Los factores socioculturales son aquellos que desde la perspectiva de las tendencias y cambios de la sociedad y comportamiento de los individuos que la forman pueden influir en el plan de negocios. Estos son básicamente los cambios demográficos (Tanto cuantitativos y cualitativos), los factores de conciencia social que afectan a la ética empresarial, y los aspectos "Psicosociales", como son las modas y los comportamientos colectivos.

Actualmente, los cambios en el estilo de vida, hace que existan factores que lleven a las personas a consumir alimentos fuera del hogar y que influirían en nuestro plan de negocios, entre los que podemos enumerar:

- Mayor participación de la mujer en la fuerza laboral.

- Hogares conformados por familias sin hijos o solteros.

- Nuevos segmentos poblacionales con nuevas costumbres con tendencias a alimentarse saludablemente.

\section{4) Análisis Tecnológico.}

La tecnología orientada al servicio de los clientes en los restaurantes se convertirá continuamente en la norma ya que los consumidores se vuelven más cómodos con ella y los propietarios de restaurantes trabajan cada día para reducir sus costos laborales y aumentar su eficiencia. 
Aplicar nueva tecnología en los restaurantes, es uno de los factores que más cambios ha tenido en los últimos años en el mundo, con el objetivo de facilitar la vida al cliente y sabiendo que el cliente que nos visita tendrá siempre a la mano un dispositivo móvil, entonces se le brindará wifi gratis durante su estadía.

Para nuestro proyecto de negocio tenemos determinado la utilización de dispositivos móviles como los iPad en la mesa al momento de tomar los pedidos de los clientes, estos serán manejados por todo el personal - Meseros - que tome los pedidos de los clientes, la información o pedidos estarán conectados con un Sistema Integrado Tecnológico proporcionada por la empresa Revolution Sistem, la cual estarán interconectados en línea con todas las áreas vinculadas en el proceso productivo y de ventas con la finalidad de agilizar los proceso de producción de los alimentos y la facturación de los consumos al finalizar el proceso de atención a un cliente.

\section{5) Análisis Ecológico.}

En los últimos años, hemos notado una creciente toma de conciencia con respecto a los problemas ambientales que afectan a nuestro planeta. Los gobiernos han dictado normas para la protección del medio ambiente; y en cuanto a los consumidores, hemos ido cambiando nuestros hábitos para optar por productos eco amigable.

Ello ha ocasionado, en consecuencia, la aparición y el desarrollo de nuevos mercados, y para conocer mejor cuáles son las características de las personas interesadas en productos que no 
dañan el medio ambiente, así como la introducción de estos en el mercado, las empresas deben orientar su gestión hacia el cuidado ambiental y diseñar estrategias en el ámbito del márketing verde". (Antonieta Hamann Pastorino, 2013, Pág. 3).

Algunas medidas básicas se utilizan para contrarrestar el impacto negativo de los restaurantes en el medioambiente:

- Implantar medidas de ahorro de los recursos escasos y agotables.

- Establecer políticas de compra amigable con el medioambiente.

- Capacitar al personal en cuanto a la clasificación de los desechos y formas de reciclaje.

- Cumplir los planes de mantenimiento y reposición de las tecnologías en uso.

\section{6) Análisis Legal.}

Uno de los aspectos más importantes para el desarrollo de nuestro negocio son las regulaciones normativas y legales que tiene nuestro país para la apertura de un negocio. En nuestro país la libertad de empresa es un derecho constitucional reconocida por el Artículo 59, Capítulo I Título III de la Constitución Política del Perú de 1993, promoviendo de esa manera la inversión privada. 
Para el inicio de operaciones de un negocio como requisito básico es obtener la licencia de funcionamiento, estas son autorizaciones dadas por las municipalidades de cada distrito o gobiernos locales. Se encuentra regulada por la ley marco de licencia de funcionamiento - LEY 28976, antes de la licencia de funcionamiento, todo inmueble pasa por una inspección por parte del Instituto Nacional de Defensa Civil - INDECI, una vez que el INDECI declara a un local apto para abrir, la municipalidad debe emitir el permiso para operar en un plazo no mayor a las 24 horas de acuerdo con la ley marco de licencia de funcionamiento antes mencionado.

Otro componente, es la autorización de DIGESA que como órgano técnico normativo del MINSA (Ministerio de Salud), regula los aspectos relacionados al saneamiento básico, salud ocupacional, higiene alimentaria, zoonosis y protección del ambiente Articulo 25 de la Ley del Ministerio de Salud, Ley 27657.

Finalmente, se debe considerar la regulación que se exige a cualquier empresa que se dedique a la producción, comercialización o prestación de servicios, que va desde la constitución de la empresa, régimen tributario y normativas laborales.

\section{Conclusiones del análisis PESTEL}

Realizando el análisis del contexto actual y esperado, se ha podido determinar cuáles son las conclusiones que nuestro Plan de Negocios de Comida Saludable con Insumos Saludables y 
Orgánicos puede tener las oportunidades, de esta manera elaborar estrategias favorables de respuesta, como son:

- El PBI por habitante aumentó 2,1\%, tasa menor al promedio de los últimos cinco años (3,6 \%). La inflación pasó de 3,2\% en el 2014 a 4,4\% en el 2015.

- La rama de otras actividades de servicio de comidas creció $3,02 \%$, impulsada por el rubro de concesionarios de alimentos, que mostró dinamismo por la continuidad de eventos y nuevas tenciones, apertura de contratos y mejora del servicio con amplio equipo logístico para asegurar altos estándares de calidad.

- Óptima política monetaria que repercute favorablemente en los niveles de consumo e inflación. una política monetaria prudente consolidada con una fuerte acumulación de reservas. En este sentido, la prudencia fiscal ha sido bien administrada en años anteriores, lo que le permite mantener una trayectoria macroeconómica estable.

- Población económicamente activa en crecimiento, lo cual se traduce en mayor consumo. Es importante mencionar que el crecimiento de la producción nacional está estrechamente relacionado con el empleo formal en la economía nacional.

- La prudencia fiscal ha sido bien administrada en años anteriores, lo que le permite mantener una trayectoria macroeconómica estable ante la actual caída de las materias primas. 
- Las personas dentro de nuestra sociedad, se encuentran en la tendencia de preocuparse por seguir una Alimentación Saludable y mejorar su apariencia física.

- Medios digitales de publicidad permiten segmentación. nuestro mercado objetivo.

- El acceso a la información a través del internet, los avances en tecnología y sistemas de información, el desarrollo acelerado de las comunicaciones y energía; el equipamiento y maquinaria de tecnología de punta, favorecen el desarrollo del país y sus regiones.

- Tendencia al cuidado del medio ambiente y uso de empaque ecológicos de papel reciclado.

\section{Las cinco fuerzas competitivas de Porter.}

Esta herramienta nos proporciona un marco de reflexión estratégica para determinar la rentabilidad de nuestro sector específico, y evaluar el valor de la proyección futura de nuestra empresa o unidad de negocio para operan en el sector restaurantes.

Es por tanto una herramienta esencialmente estratégica. Vamos a utilizarla en la elaboración de nuestro plan de negocios, con el objetivo de tener un enfoque analítico de nuestro sector, nos ayudará a complementar el análisis del sector previamente desarrollado. 
El Análisis Porter toca las 5 fuerzas de Porter: los proveedores, clientes, competidores, productos sustitutivos y nuevos competidores.

\section{a) Rivalidad entre Empresas Competidoras.}

La rivalidad entre empresas es existente y la más poderosa, esta fuerza analiza los restaurantes que vamos a encontrar en nuestro entorno del negocio, como se encuentra distribuido el mercado actual en el sector restaurante y las influencias directas e indirectas para nuestro plan de negocios.

En el entorno de nuestro mercado no contamos con una competencia directa que ofrece esta propuesta de negocio por ello se ha identificado a restaurantes que se asemejan a nuestra propuesta de negocio como son Qumara y Saladbar Green is Better quienes en su propuesta ofrecen alimentación saludable y como competidores indirectos tenemos a Restaurantes como Malabar, Maras y Aguaymanto, ofreciendo una a alimentación saludable utilizando productos organicos,

Como podemos ver la rivalidad con la competencia actual es media, debido a que tenemos una semejanza de tener propuesta de negocio que ofrece el uso de insumos saludables y orgánicos. Dentro de todas las competencias hay una baja oferta relacionada a nuestro producto y precio, sobre todo en la diferenciación de contar con un nutricionista que supervisara el procesos productivo

\section{b) Ingreso Potencial de Nuevos Competidores.}

En esta fuerza se ha identificado que el ingreso de nuevas empresas en nuestro mercado es Media debido a los siguientes puntos: 
- Necesidad de inversión inicial, que fácilmente puede ser adquirida con un financiamiento, así como la compra o alquiler del local, la reforma, son acciones necesarias que requieren un gran capital para poder ser llevadas a cabo antes de poner en marcha el negocio.

- Encontrar una ubicación buena y económica. Los lugares más rentables no suelen estar disponibles y, de estarlo, requieren rentas elevadas que no todos los posibles competidores están dispuestos o pueden pagar.

- La diferenciación. Ésta es una opción muy valiosa para posicionarse y consolidarse en el mercado, por tanto, nuestra propuesta de negocio representa una fuerte barrera de entrada para nuevos competidores.

\section{c) Desarrollo Potencial de Productos Sustitutos.}

La amenaza de esta fuerza va a provenir de la capacidad de satisfacer la necesidad del cliente de consumir alimentos saludable y la necesidad de satisfacer su alimentación diaria con el poco tiempo que tiene para consumir sus alimentos que por lo general son de una hora a hora y media, haciendo que esa necesidad se vea sustituida por comidas rápidas ubicadas en el Food Court de Saga Falabella, pollerías o chifas cercanas a sus centro de trabajo, ofreciendo ensaladas y carnes blancas al paso en un ambiente no muy confortable, aunque son comidas que difieren de nuestra propuesta por encontrarse procesadas y no ser naturales. 
Frente a esta Fuerza se ha visto que tenemos una barrera de entrada media, debido a que dentro del centro Financiero Empresarial que no están enfocadas a ofrecer una alimentación saludable, pero pueden ofrecer productos que sustituyan en parte el concepto de alimentación.

\section{d) Capacidad de Negociación de los Proveedores.}

Los proveedores tienen un bajo poder de negociación puesto que los insumos a utilizar en el proceso de elaboración de los alimentos no son únicos, hay gran cantidad de proveedores que ofrecen estos productos en el Mercado Mayorista de Santa Anita así como en el mercado de Productores; a la vez tener la posibilidad de realizar convenios con el ministerio de agricultura y el Ministerio del medio ambiente con sus programas sociales de realizar convenios con los agricultores para proveer de insumos y productos orgánicos. Siendo posible obtener mejores condiciones de negociación y precios para el negocio.

Contamos con un gran número de proveedores que ofrecen los insumos exigidos para nuestro negocio, donde se presenta una lista de proveedores de productos orgánicos proveídos por SENASA, garantizando la calidad de los alimentos, además este mercado está empezando a darse a conocer, no se corre el riesgo de que estos proveedores tengan un gran número de clientes que puedan generar un desabastecimiento.

\section{e) Capacidad de Negociación de los Clientes.}

En esta fuerza los clientes tienen la capacidad de reducir los precios, exigir la calidad en los productos y servicios prestados, así 
como los mejore beneficios y calidad esperada, en esta fuerza el poder de negociación del cliente es alta.

Frente a este poder se va a trabajar en la fidelización del cliente a través del seguimiento constante de sus preferencias, sugerencias, presenciales o a través de nuestra página web o nuestras redes sociales, por ello nuestro foco principal se desarrollará en la calidad de atención al cliente. 
Cuadro $\mathrm{N}^{\mathrm{o}} 2.1$ :

Matriz General Concluyente de las Fuerzas de Porter

\begin{tabular}{|c|c|}
\hline FUERZAS & SECTOR RESTAURANTE \\
\hline \multirow{6}{*}{$\begin{array}{l}\text { 1. Empresas } \\
\text { competidores } \\
\text { (Rivalidad). }\end{array}$} & Media/Baja \\
\hline & 1.1. Número de competidores con recursos y capacidades similares. \\
\hline & 1.2. Tasa de crecimiento del sector industrial alimentación saludable. \\
\hline & 1.3. Oferta de productos y precios diferenciados. \\
\hline & 1.4. Escasa oferta de alimentación saludable. \\
\hline & 1.5. Oferta de alimentación saludable con precios altos. \\
\hline \multirow{5}{*}{$\begin{array}{l}\text { 2. Nuevos Competidores } \\
\text { (Amenaza). }\end{array}$} & Baja \\
\hline & 2.1. Fuerte inversión Inicial (Alquileres, mobiliario, etc.) \\
\hline & 2.2. Dificultad para encontrar una buena ubicación. \\
\hline & 2.3. Altos alquileres para buenas ubicaciones. \\
\hline & 2.4. Oferta diferenciada que representa una barrera de entrada. \\
\hline \multirow{4}{*}{$\begin{array}{l}\text { 3. Amenazas de } \\
\text { sustitutos. }\end{array}$} & Media \\
\hline & 3.1. Existen productos sustitutos - Comida rápida \\
\hline & 3.2. Ambientes poco confortables \\
\hline & 3.3. Precios altos por productos de calidad media a baja \\
\hline \multirow{5}{*}{$\begin{array}{l}\text { 4. Poder de negociación } \\
\text { de los proveedores. }\end{array}$} & Baja \\
\hline & 4.1. Gran cantidad de proveedores. \\
\hline & 4.2. Posibilidad de realizar alianzas / convenios. \\
\hline & 4.3. Opciones de precios y calidades de productos. \\
\hline & $\begin{array}{l}\text { 4.4. La industria de restaurantes es un cliente importante para los } \\
\text { proveedores. }\end{array}$ \\
\hline \multirow{5}{*}{$\begin{array}{l}\text { 5. Poder de negociación } \\
\text { de los clientes }\end{array}$} & Media \\
\hline & 5.1. El cliente está concentrado en el centro financiero empresarial. \\
\hline & 5.2. Diversas de opciones de alimentación \\
\hline & 5.3. Pocas opciones de alimentación saludable. \\
\hline & 5.4. Exigen productos o servicios de calidad. \\
\hline
\end{tabular}

FUENTE: Elaboración propia.

\section{Conclusiones de las Cinco Fuerzas de Porter}

La configuración de las 5 fuerzas de Porter permite distinguir el poder de la competencia que se da en un área delimitada de una industria, de cuyo análisis se logra establecer la estrategia futura de 
una organización que al final debe resultar en la obtención de los beneficios deseados.

Considerando la situación del sector gastronómico desarrollado en el sector IV dentro del distrito de San Isidro, se pueden hacer algunas reflexiones finales de estas fuerzas.

Entre las empresas competidoras contamos con una ventaja amplia con mucha probabilidad del éxito de nuestro negocio por las condiciones descritas en este análisis orientan el desarrollo del plan de negocios tomando en cuenta la estrategia genérica de diferenciación y enfoque

Amenaza de sustitutos, vemos la oportunidad de posicionarnos como una empresa que ofrece alimentación con insumos saludables y organicos determinando nuestra ventaja frente a la competencia que ofrece similar oferta de nuestra propuesta.

Como conclusión del análisis de las 5 fuerzas de Porter se ha obtenido que la propuesta del Plan de Negocios a desarrollarse en el sector restaurante, tiene una atractividad alta de la industria, existen condiciones

que permiten el desarrollo y éxito de un nuevo concepto basado en la diferenciación de la oferta existente, orientándose al grupo de clientes que buscan la opción de alimentación saludable. 
Imagen $\mathrm{N}^{\mathrm{o}} 2.5$ :

Análisis de las 5 Fuerzas de Porter

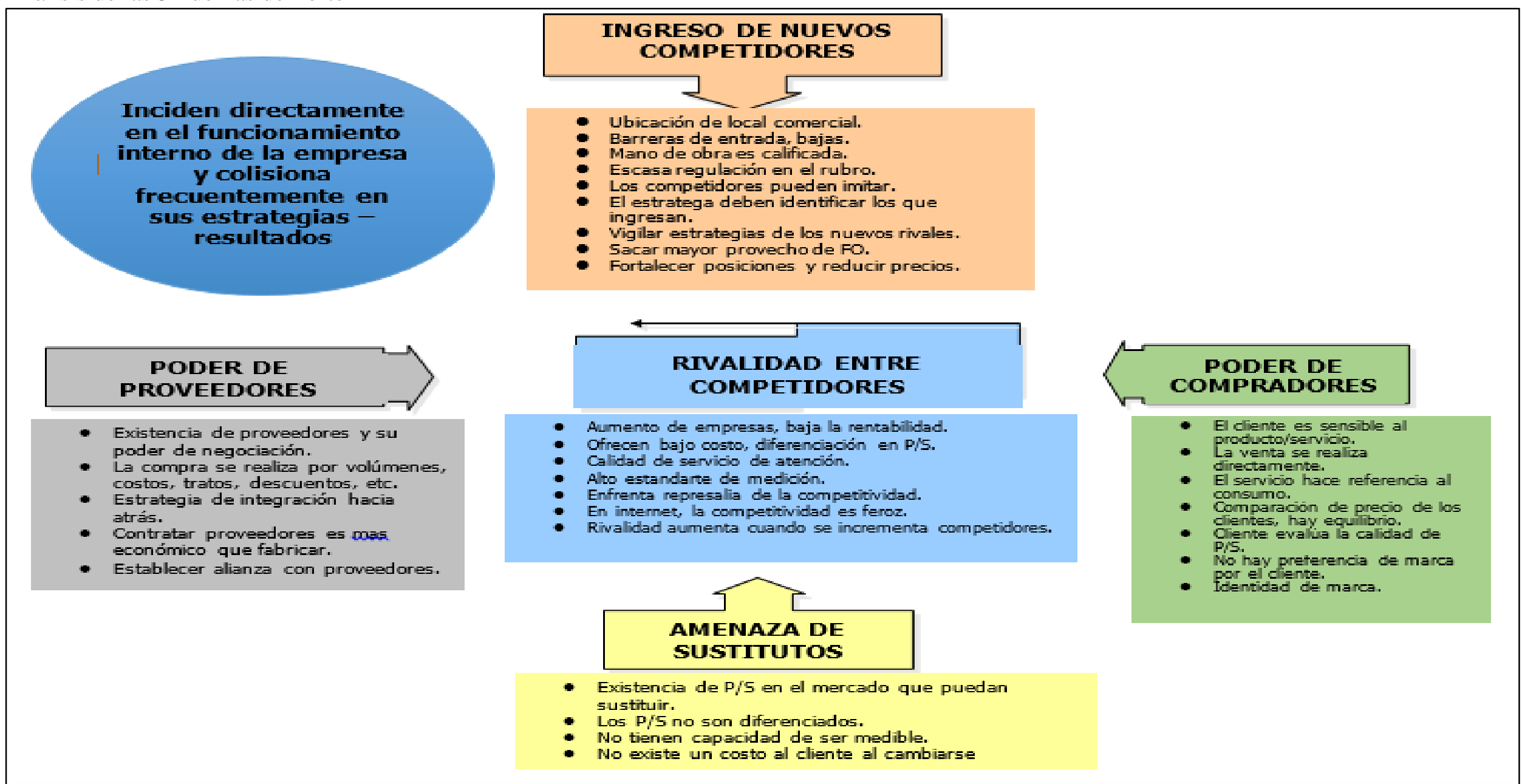

FUENTE: Elaboración propia 


\subsubsection{Evaluación de Factores Externos.}

Un principio básico de un Plan de Negocios es que la organización requiere plantear estrategias para aprovechar las oportunidades externas y evitar o reducir el riesgo

Para desarrollar la Evaluación de Factores Externos (EFE) se ha propuesto las oportunidades y amenazas que podían presentantes, el peso relativo o valor de cada una de las oportunidades y amenazas, así como la calificación para cada una de ellas es de acuerdo a mi criterio personal como ejemplo, asignando los valores de acuerdo al conocimiento que se tiene del sector.

Cuadro $\mathrm{N}^{\mathrm{o}} 2.2$.

Evaluación de Factores Externos - EFE

\begin{tabular}{|l|l|l|l|}
\hline Factor crítico de éxito & Peso Relativo & Calificación & $\begin{array}{l}\text { Calificación } \\
\text { Ponderada }\end{array}$ \\
\hline OPORTUNIDADES & 0.15 & 4 & 0.6 \\
\hline Crecimiento de la actividad de Restaurantes & 3 & 0.45 \\
\hline $\begin{array}{l}\text { Crecimiento y coyuntura económico favorable } \\
\text { en el centro financiero de San Isidro. }\end{array}$ & 0.15 & 3 & 0.3 \\
\hline $\begin{array}{l}\text { Búsqueda de una alimentación saludable. } \\
\text { nutricional. }\end{array}$ & 0.1 & 3 & 0.6 \\
\hline AMENAZAS & 0.2 & 2 & 0.1 \\
\hline Diversidad de productos sustitutos. & 0.05 & 2 & 0.4 \\
\hline $\begin{array}{l}\text { Pocas barreras de entradas hacia nuevos } \\
\text { competidores }\end{array}$ & 0.2 & 2 & 0.1 \\
\hline $\begin{array}{l}\text { Poco acceso a proveedores que venden insumos } \\
\text { tendencia orgánica. }\end{array}$ & 0.05 & 1 & 0.1 \\
\hline Disminución del poder adquisitivo en el Perú. & 0.1 & 1 & $\mathbf{2 . 6 5}$ \\
\hline
\end{tabular}

FUENTE: Elaboración propia. 
Analizando la matriz EFE, obtuvimos una calificación de 2.65 superando el promedio mínimo de 2.5 esperado que necesitábamos llegar lo que significaría que puede responder de manera excelente a los cambios en la industria, que es a lo que deberíamos.

\subsection{Análisis del Mercado.}

El análisis del mercado es uno de los puntos más importantes de todo el plan de negocios porque nos va a permitir obtener la información necesaria sobre las características del mercado, el tamaño de este, además de analizar las relaciones existentes entre la oferta y la demanda del servicio. Nos permitirá obtener información sobre la percepción de nuestra propuesta, para el mercado potencial, dentro de la zona definida, así como la intención de compra, lo que nos ayudará a dimensionar el mercado y formular la estrategia del negocio para la ejecución del plan.

\subsection{1 Área del Estudio.}

Según INEI, San Isidro es uno de los 43 distritos de la provincia de Lima, con una superficie total de $9.78 \mathrm{~km} 2$, una población estimada según su municipio, de 54,206 habitantes al 2015, encontrando sedes importantes como consulados, embajadas, organismos internacionales, organismo público, asociaciones educativas, religiosas, establecimientos financieros, comerciales, entre otros, siendo el distrito que reúne las condiciones para ejecutar nuestro plan de negocios.

Este distrito, se encuentra dividido en 5 sectores, distribuidos, según la información que se muestra en el siguiente cuadro: 
Cuadro No 2.3:

División Geográfica del distrito de San Isidro

\begin{tabular}{|c|l|}
\hline SECTOR & \multicolumn{1}{|c|}{ LIMITES } \\
\hline $\begin{array}{c}\text { SECTOR } \\
1\end{array}$ & $\begin{array}{l}\text { Delimitado por la Av. Santo Toribio - calle Las Palmeras, la Av. Aurelio } \\
\text { Miro Quesada - Av. Alberto del Campo, Av. Juan de Aliaga y } \\
\text { los limites distritales con Jesús Maria, Lince y Magdalena del Mar. }\end{array}$ \\
\hline $\begin{array}{c}\text { SECTOR } \\
\mathbf{2}\end{array}$ & $\begin{array}{l}\text { Delimitado por la Av. Juan de Aliaga, Av. Alberto del Campo, Av. } \\
\text { Aurelio Miro Quesada, la Av. Camino Real, la Av. Francisco Tudela y } \\
\text { Varela, la Av. Angamos Oeste, la Av. Francisco Alayza y Paz Soldán, } \\
\text { el limite distrital con Miraflores, el Océano Pacifico y el limite distrital } \\
\text { con Magdalena del Mar. }\end{array}$ \\
\hline $\begin{array}{c}\text { SECTOR } \\
\mathbf{3}\end{array}$ & $\begin{array}{l}\text { Cavenecia, calle José del Llano Zapata, calle Alfredo Salazar, Av. } \\
\text { Francisco Tudela y Varela, la Av. Camino Real, la Av. Aurelio Miro } \\
\text { Quesada, Av. Santo Toribio, calle Las Palmeras y el limite distrital con } \\
\text { Lince y Miraflores. }\end{array}$ \\
\hline SECTOR & $\begin{array}{l}\text { Delimitado entre la Av. República de Panamá, Av. Andrés Aramburu, } \\
\text { Av. Arequipa y limite con el Distrito de Lince. }\end{array}$ \\
\hline $\mathbf{S E C T O R}$ & $\begin{array}{l}\text { Delimitado entre la Av. República de Panamá, Av. Javier Prado, } \\
\text { Av. Guardia Civil, Av. José Gálvez Barrenechea y el limite distrital con } \\
\text { Surquillo. }\end{array}$ \\
\hline
\end{tabular}

FUENTE: Plan de Seguridad Ciudadana - Municipalidad de San Isidro.

En el informe emitido por la Municipalidad de San Isidro (Plan Local de Seguridad Ciudadana de San Isidro 2016), este distrito, por encontrarse en una ubicación estratégica dentro del área Central de Lima Metropolitana y por la localización y desarrollo de las actividades empresariales, concentra una atractiva población flotante, que según Garrocho (2011), se refiere a la población que no vive en la ciudad pero la usa; esta asciende a 755,717 habitantes, según el estudio realizado por Arellano Marketing, para la municipalidad de San Isidro en el año 2015.

Es pertinente mencionar que para el presente proyecto, la ubicación del local estará entre la cuadra 3 de la avenida Luis Felipe Villareal 
y la cuadra 5 de la avenida Juan De Arona. Esta ubicación, pertenece a la zona 4, del distrito de San Isidro. (Véase Imagen 2.6)

Imagen $\mathrm{N}^{\mathrm{o}} 2$ 6:

Ubicación Geográfica del local

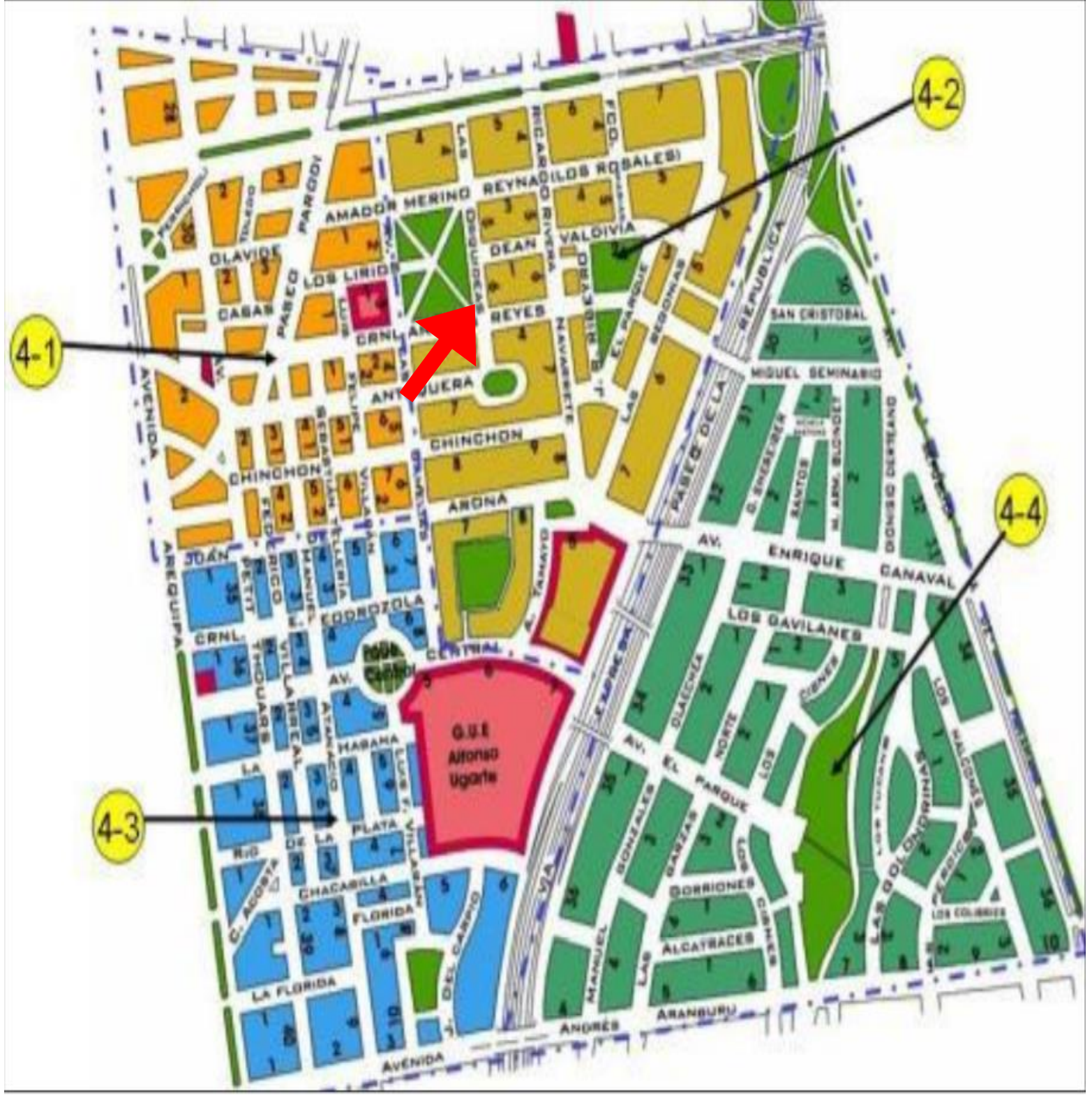

Fuente: Municipalidad de San Isidro.

Según el Plan de Seguridad ciudadana de San Isidro, la zona 4 se caracteriza por: 
Delimita por la Av. República de Panamá, Av. Andrés Aramburú, Av. Arequipa y el distrito de Lince. Está conformado por 4 Sub Sectores

Se asienta el Centro Financiero y empresarial, más importante del país.

Cuenta con gran cantidad de Instituciones Públicas y Privadas.

Se ubica el centro comercial Las Begonias (Tottus, Ripley, Saga, Metro)

Se encuentra el The Westin, Liam Hotel Libertador con el Centro de Convenciones, más importante del país

Se ubica la Vía más importante de Lima, la Av. Paseo de la República y la Vía Expresa, que divide el Sector y el distrito en dos. Por ser ruta metropolitana, se ha visto incrementado el tránsito vehicular y peatonal.

Esta información sigue validando el atractivo comercial para este proyecto.

\subsubsection{Perfil del Consumidor.}

El perfil de nuestro consumidor, es decir nuestro mercado potencial, es el siguiente: hombres y mujeres, ejecutivos, de 26 a 55 años de edad, que trabajen en la zona 4 del distrito de San Isidro, y pertenezcan a hogares de NSE A y B.

Para dimensionar este mercado potencial, se debe en primer lugar hacer el cálculo de la población flotante, considerando la ubicación 
del local, por tanto es conveniente obtener la proporción de población flotante, en cada zona de San Isidro. En la zona 1, se tiene al 15\%, en zona 2 al $6 \%$, en zona 3 al 23\%, en zona 4 al $40 \%$ y en zona 5 al 16\%. Plan Local de seguridad ciudadana -San Isidro.2016.

Imagen $\mathrm{N}^{\circ} 27$ :

Población Flotante San Isidro por Sector

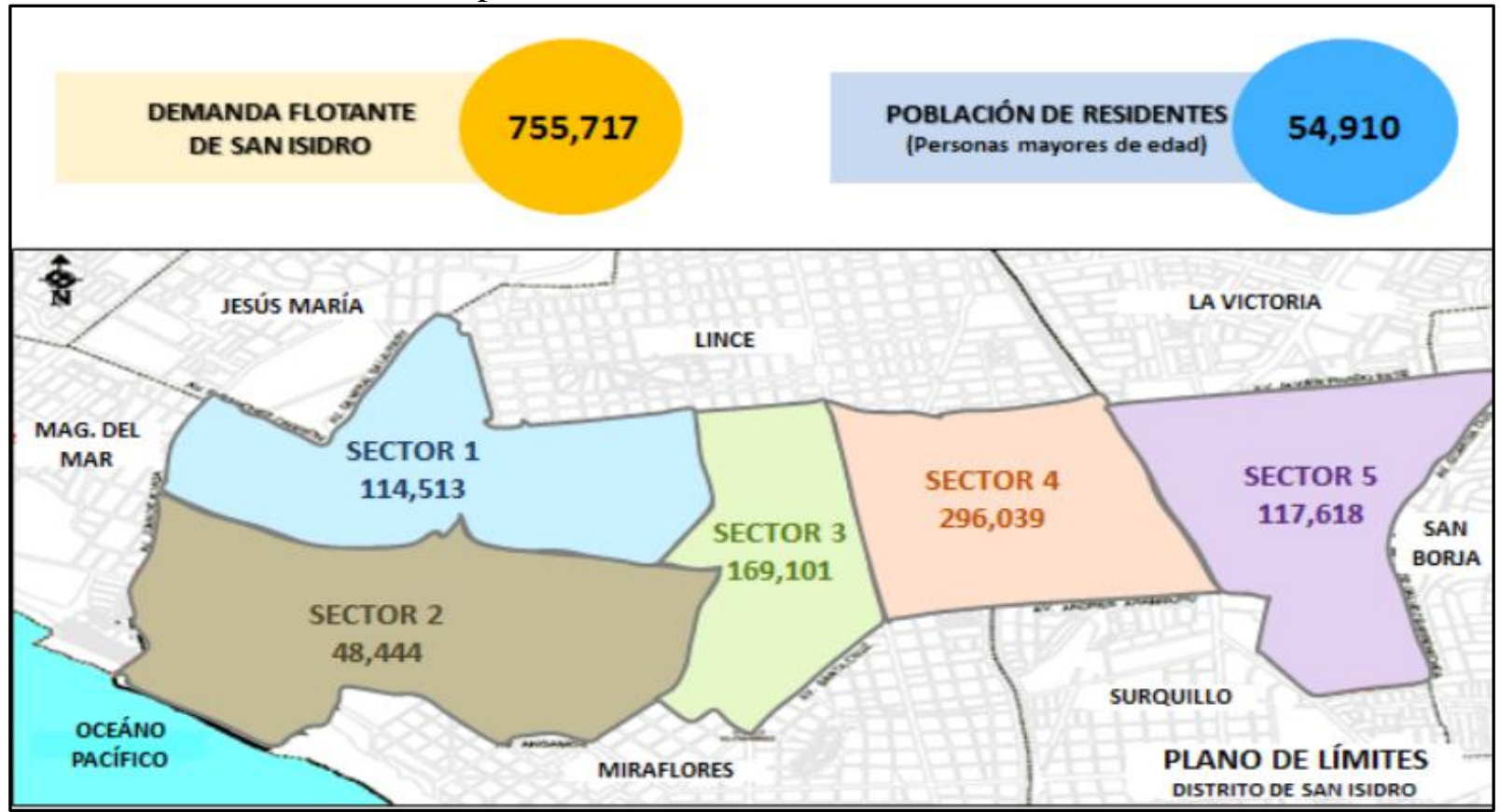

Fuente: Compendio Estadístico 2016-Municipalidad de San Isidro.

Imagen $\mathrm{N}^{\circ} 2$ 8:

Perfil de la Población Flotante San Isidro

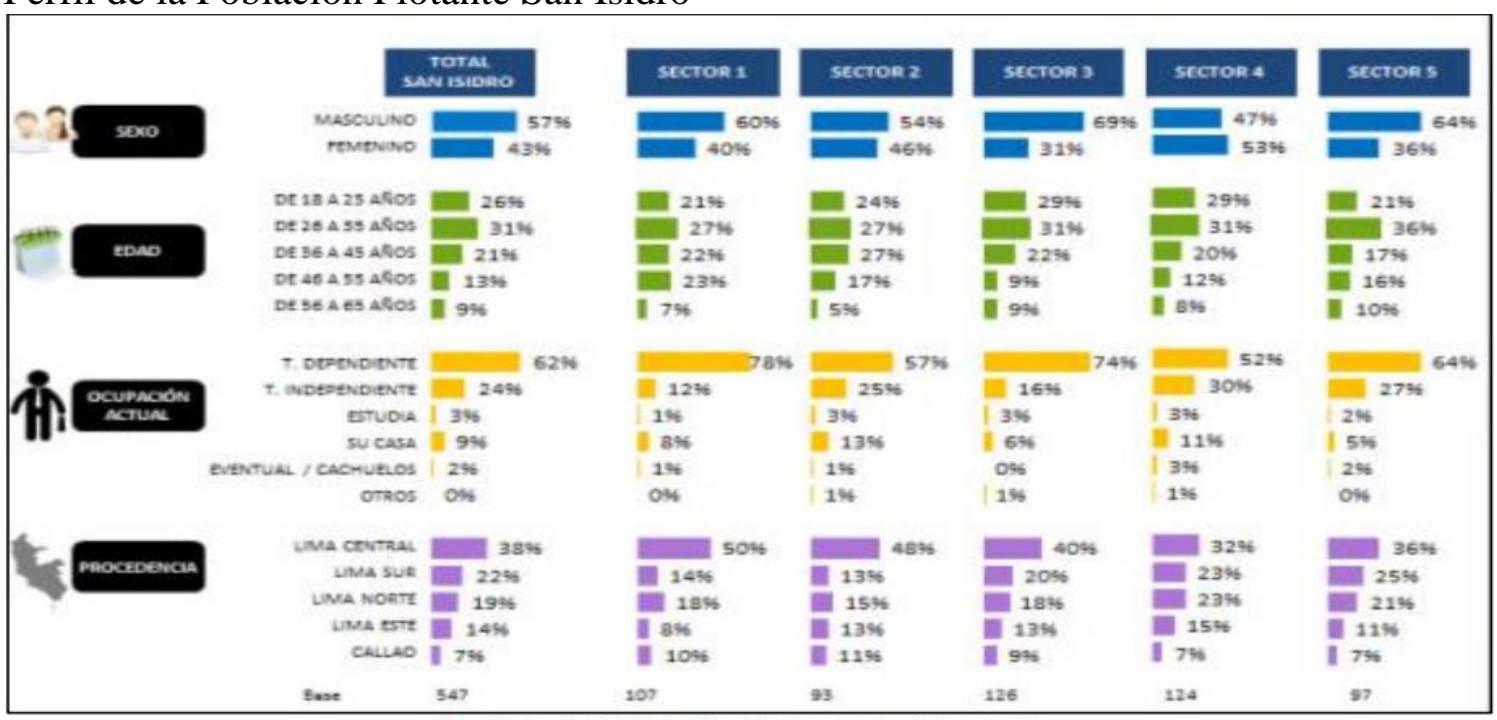

Perfil de la Población Flotante de San isidro

Fuente: Estudio realizado por Arellano Marketing para la MSI - Jun 2015 
Considerando que los ejecutivos son trabajadores dependientes dentro de una empresa, el 52\% de población flotante dentro de la zona 4, tienen esta característica. Plan Local de seguridad ciudadana -San Isidro. 2016.

La cantidad de población flotante que tiene entre 26 a 55 años, dentro de la zona 4 del distrito es de $63 \%$ (de 26 a 35 años, $31 \%$; de 35 a 45 años, de 20\%; de 46 a 55 años, 12\%).

La cantidad de personas en Lima Metropolitana, distribuidas según nivel socioeconómico, corresponde al $4.4 \%$ para el NSE A y $24.5 \%$ para el NSE B. ( APEIM - NSE 2017).

Con la data presentada, se ha definido la fórmula que estimará nuestro mercado potencial:

Imagen $\mathrm{N}^{\circ} 2$ 9:

Fórmula que estimará nuestro mercado potencial

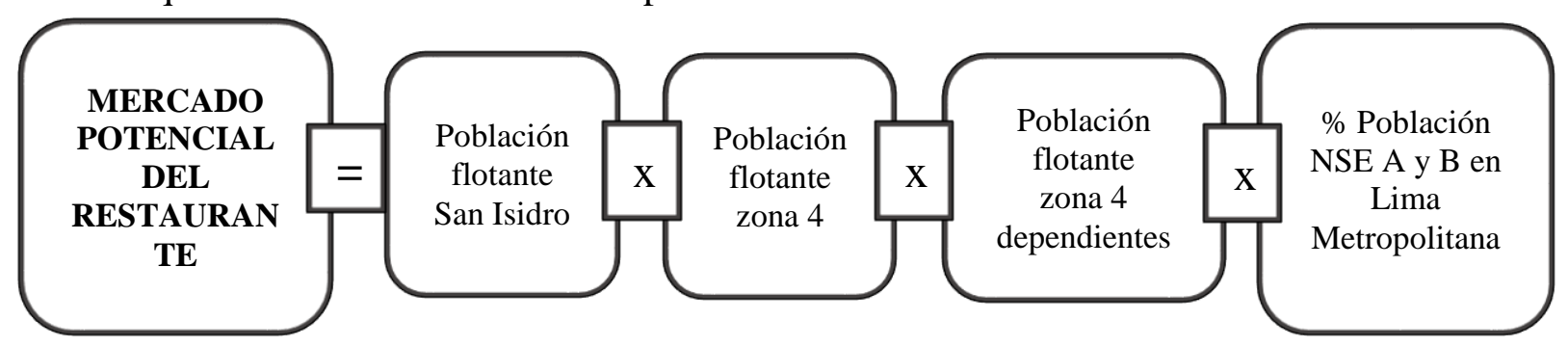

Mercado potencial $=755717 \times 40 \% \times 52 \% \times 63 \% \times 28.9 \%=28,620$

\section{Determinación del tamaño de la muestra.}

El tipo de muestreo empleado en el presente proyecto, obedece a un muestreo probabilístico. Con un tamaño de población infinita, aplicando la siguiente fórmula: 
Fórmula:

Definición:

$$
n=\frac{Z^{2} \cdot \mathrm{N} \cdot \mathrm{P} \cdot \mathrm{Q}}{E^{2}(\mathrm{~N}-1)+Z^{2} \cdot \mathrm{P} \cdot \mathrm{Q}}
$$

$\mathrm{n}=$ Tamaño de la muestra

$\mathrm{Z}=$ Margen de Seguridad (95\%)

$\mathrm{N}=$ Número de universo o población total a investigarse

$\mathrm{P}=$ Probabilidad pertinente del hecho que se investiga (0.5)

$\mathrm{Q}=$ Probabilidad no pertinente frente al hecho a investigar (0.5)

$\mathrm{E} 2=$ Margen de error $(4.9 \%)$

\section{Dónde:}

$\mathrm{Z}=1.96$ (ya que la seguridad es del 95\%)

$\mathrm{P}=0.5$

$\mathrm{Q}=0.5$

$\mathrm{N}=755,717$

$\mathrm{E}=4.9 \%$

$n=400$

\section{Investigación de Mercado.}

\section{Selección de la Muestra.}

Para el cálculo del tamaño de la muestra se procede a utilizar el método probabilístico aleatorio simple, tomando como universo el total de población flotante en el distrito del San Isidro.

\section{Problema de Investigación:}

¿Conocer el nivel de aceptación del mercado objetivo de una nueva propuesta de negocio en el rubro restaurante para atender a los hombres y mujeres de 26 a 55 años que trabajan en el sector 4 del distrito de San Isidro? 


\section{Objetivos de la investigación:}

Esta investigación abordará los siguientes objetivos en base al mercado potencial:

- Conocer los hábitos de compra y consumo de alimentos de la población objetivo en restaurantes del sector 4 del distrito de San Isidro.

- Cuantificar la demanda para el proyecto del restaurante con insumos naturales y orgánico.

\section{Diseño de la investigación:}

En un primer momento, se realizó una investigación exploratoria y luego una segunda etapa de investigación concluyente, que se detallan a continuación:

\section{Fase Exploratoria:}

Se realizó la búsqueda de la información a través de las fuentes secundarias como material impreso, materiales digitales de las páginas web de la municipalidad de San Isidro, Ministerio de Trabajo entre otros y publicaciones al momento de realizar el estudio.

\section{Fase Concluyente y Descriptiva:}

En esta fase se procedió a cuantificar la información, siguiendo una metodología de investigación cuantitativa. Se empleó la técnica de encuesta cara a cara, para aplicar el instrumento de investigación, el cual es un cuestionario de preguntas cerradas y escalas de medición de actitudes, elaborado con el fin de cubrir cada uno de los objetivos de investigación propuestos. La encuesta se realizó con 
interceptación de los entrevistados en las cercanías de la dirección planeada para el proyecto.

\section{Muestreo:}

Se empleó un muestreo probabilístico aleatorio simple, donde se seleccionó a la muestra al azar, extrayendo 1 contando cada 2 personas que transitaban para abordarlos y así sucesivamente, y aplicarles las preguntas filtro para continuar con el desarrollo de la encuesta.

El trabajo de campo se realizó entre los días 01 al 04 de abril del 2019. 


\subsection{Resultados de la investigación:}

La investigación a nivel cuantitativo, dio los siguientes resultados:

Sobre los hábitos de consumo de alimentos

Respecto al tipo de comida que consume la población flotante que transita en el sector 4 del distrito de San Isidro, el 66\% refiere que consume comida criolla de manera destacada frente a otros tipos de comidas (VER GRAFICO N${ }^{\circ}$ ).

Gráfico $\mathrm{N}^{\mathrm{o}}$ 2. 1:

Tipo de comida que come la población flotante del sector IV de San Isidro

GRAFICO N¹: Tipo de comida que come el consumidor flotante del Sector 4 de San Isidro

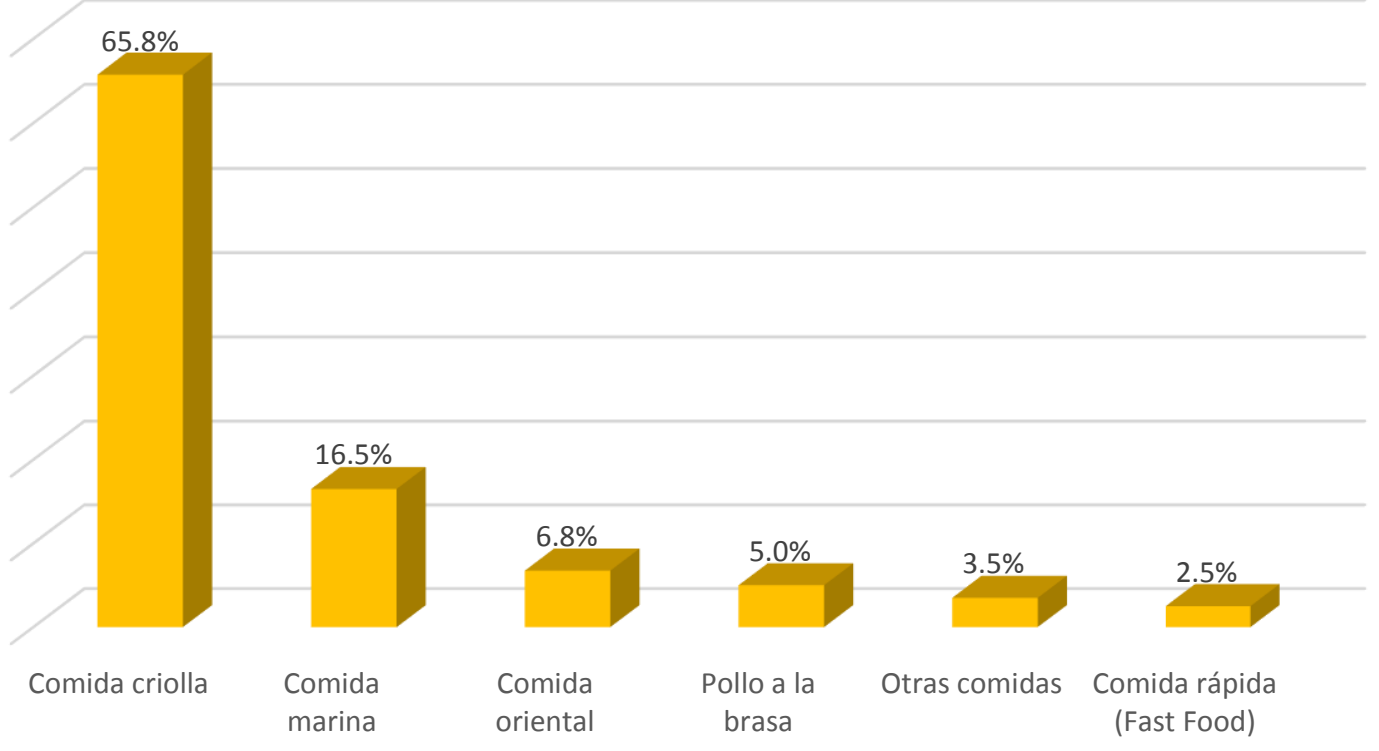

Fuente. Elaboración propia

Base: 400 encuestas 
El 55.8\% de la población encuestada refiere que gasta menos de 15 soles, seguido de un $38 \%$ que gasta entre 15 y 25 soles. En promedio el gasto resultó de $\mathrm{S} / 17.89$ soles (VER GRAFICO N²)

Gráfico $\mathrm{N}^{\mathrm{o}}$ 2. 2:

Disponibilidad de pago

\section{GRAFICO N ${ }^{\circ}$ : Cantidad de dinero que gasta en un almuerzo en los restaurantes de San Isidro}

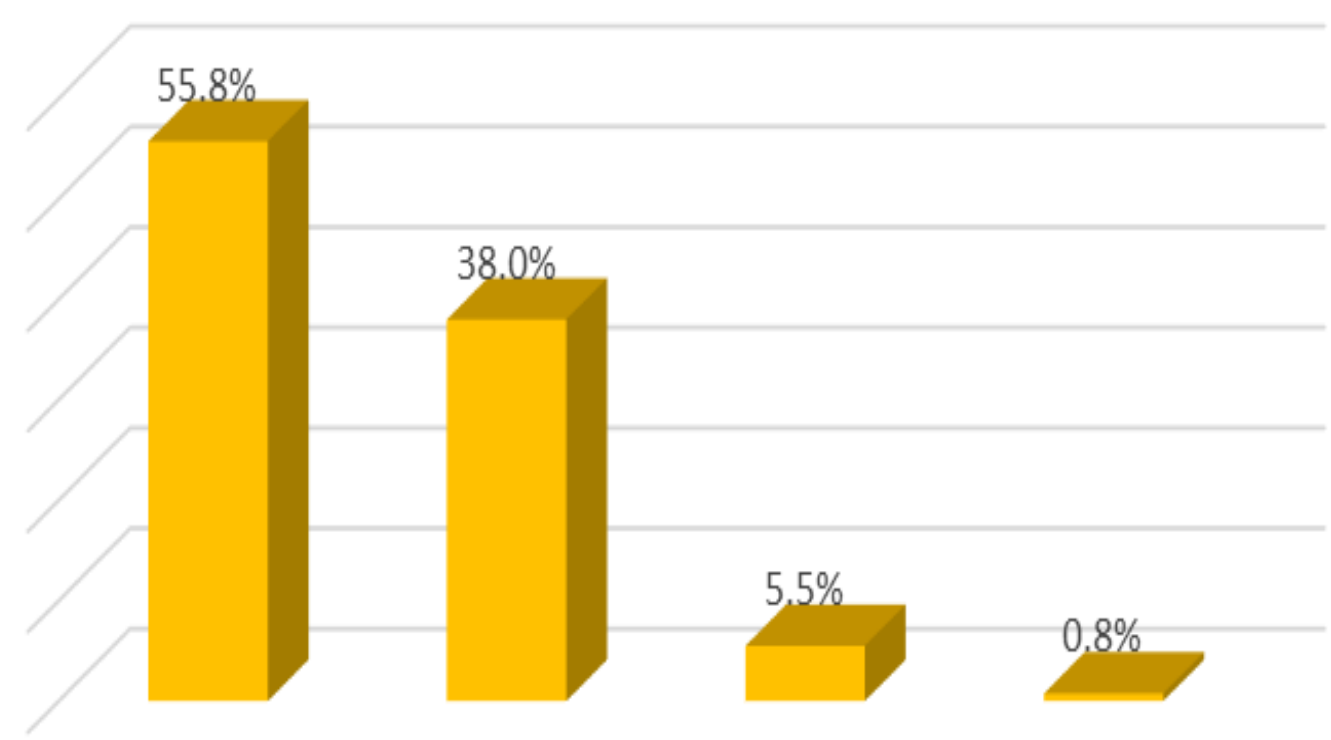
Menos de 15 De 15 a 25 soles De 26 a 35 soles Más de 36 soles soles

Fuente. Elaboración propia

Base: 400 encuestas 
Respecto a la frecuencia con que almuerzan en San Isidro, el $40 \%$ refiere que lo hace todos los días, sobre todo el NSE A, mientras que el NSE B refiere en un $26 \%$ que lo hace de tres a cuatro veces por semana.

Gráfico $\mathrm{N}^{\circ}$ 2. 3:

Tipo de comida que come la población flotante del sector IV de San Isidro

GRAFICO N³: Frecuencia con que suele almorzar en el sector 4 de San Isidro

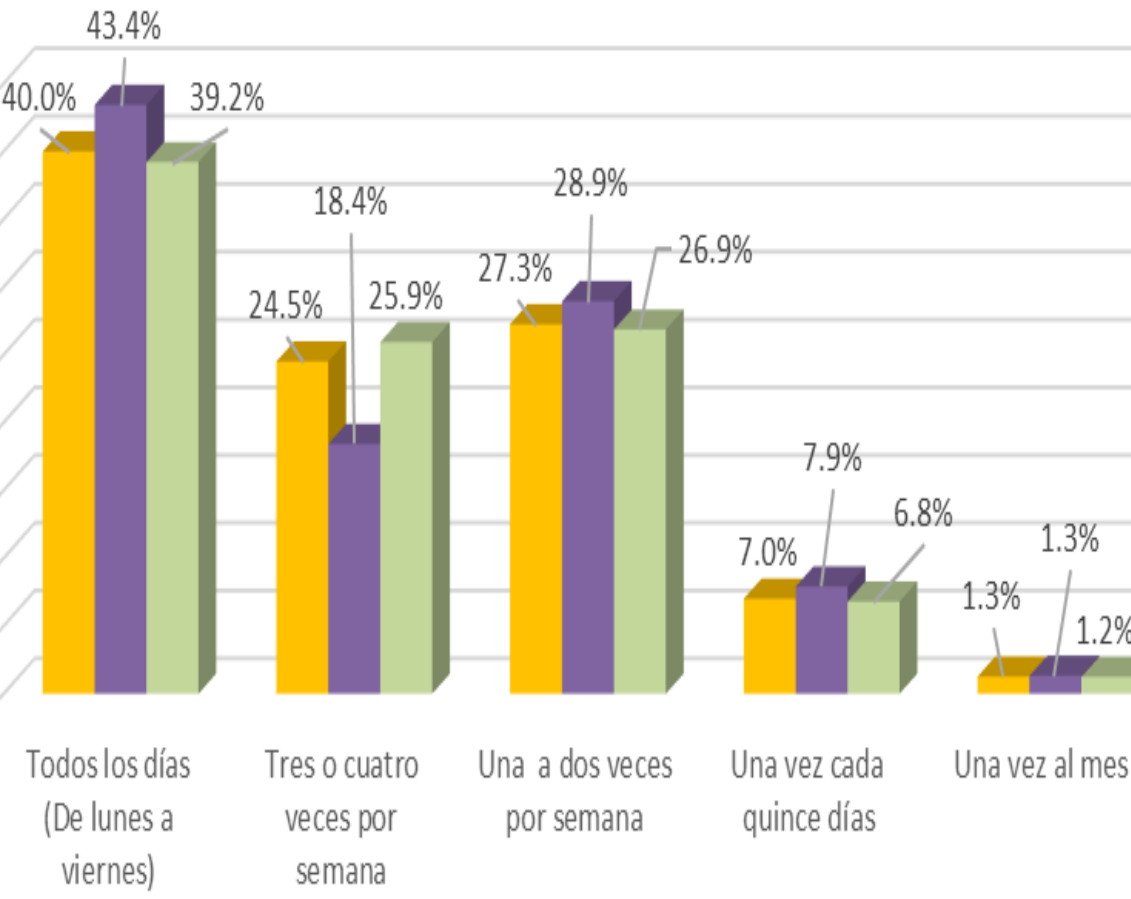

Fuente. Elaboración propia

Base: 400 encuestas 


\subsection{Sobre la Evaluación del concepto de negocio}

En esta segunda parte de la evaluación de presentó el concepto de negocio descrito de la siguiente manera:

ORGÁNICOS”, ESTOS SON PRODUCTOS AGRÍCOLAS O AGROINDUSTRIALES, QUE SE PRODUCEN BAJO UN CONJUNTO DE PROCEDIMIENTOS DENOMINADOS "ECOLÓGICOS", ESTOS MÉTODOS EVITAN EL USO DE PRODUCTOS SINTÉTICOS, COMO PESTICIDAS, HERBICIDAS Y FERTILIZANTES ARTIFICIALES.

AL NO USAR PESTICIDAS SE CONTRIBUYE CON EL CUIDADO DEL MEDIO AMBIENTE.

LAS PLANTAS, HORTALIZAS, ABSORVEN MAYORES MINERALES Y VITAMINAS.

INCLUSO LOS ANIMALES CRIADOS BAJO ESTE SISTEMA ORGÁNICO, SE CRÍAN EN UN ESTADO DE SEMI LIBERTAD, Y ALIMENTACIÓN NATURAL.

AHORA, LE COMENTAMOS SOBRE EL PROYECTO, DEL NEGOCIO PARA EL CUAL LE PEDIREMOS SU OPINIÓN. SE BASA EN LA CREACIÓN DE UN RESTAURANTE QUE ELABORE ALMUERZOS VARIADOS, BÁSICAMENTE DE COMIDA CRIOLLA, HACIENDO USO DE INSUMOS SALUDABLES Y ORGÁNICOS, Y DEBIDAMENTE MONITOREADOS POR UN NUTRICIONISTA.

EL RESTAURANTE ESTARÁ UBICADO EN EL DISTRITO DE SAN ISIDRO Y ATENDERÁ DESAYUNOS, ALMUERZOS, LONCHES Y CENAS, EN UN HORARIO DE 11 A 5 PM. 
A partir de ello, los consumidores flotantes del sector 4 de San Isidro revelaron un TOP TO BOX (algo interesante y muy interesante) de $95.5 \%$ ante la nueva propuesta.

Gráfico $\mathrm{N}^{\circ}$ 2. 4:

Interés frente a la nueva propuesta de negocio

GRAFICO N${ }^{\circ}$ : Interes que mostraron frente a la nueva propuesta de negocio del nuevo restaurante

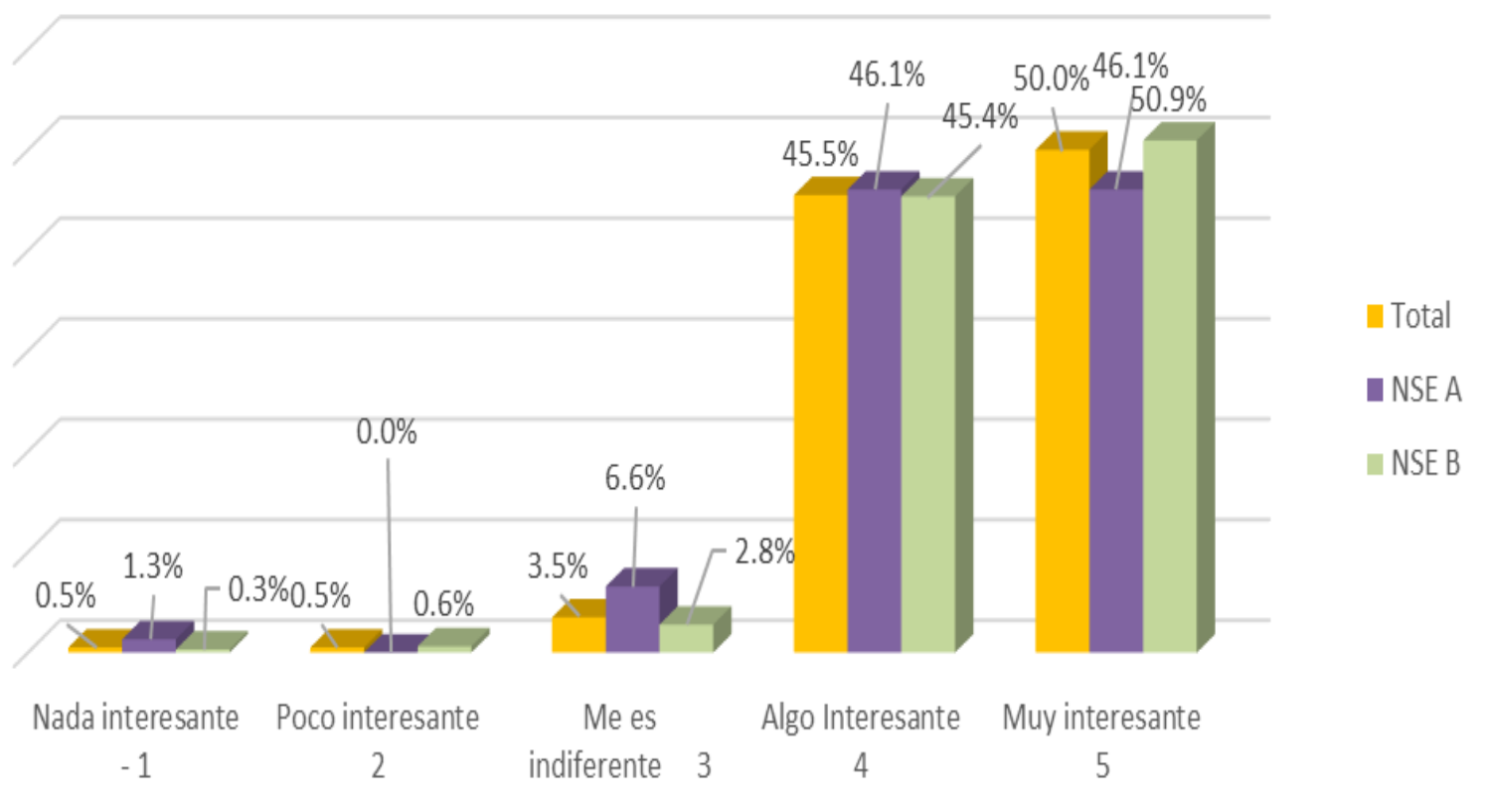

Fuente. Elaboración propia

Base: 400 encuestas 
En cuanto a las variables diferenciales que ofrece este concepto, resaltó de manera significativa los atributos de ubicación (67\%), la posibilidad de reservas online (63.8\%), el uso de insumos orgánicos $(64 \%)$ y la certificación de una nutricionista $(68 \%)$.

Gráfico $\mathrm{N}^{\mathrm{0}}$ 2. 5:

Nivel de agrado de atributos

\section{GRAFICO N5: Nivel de agrado de los atributos diferenciales del concepto}

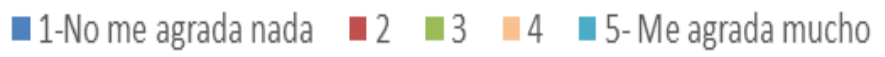

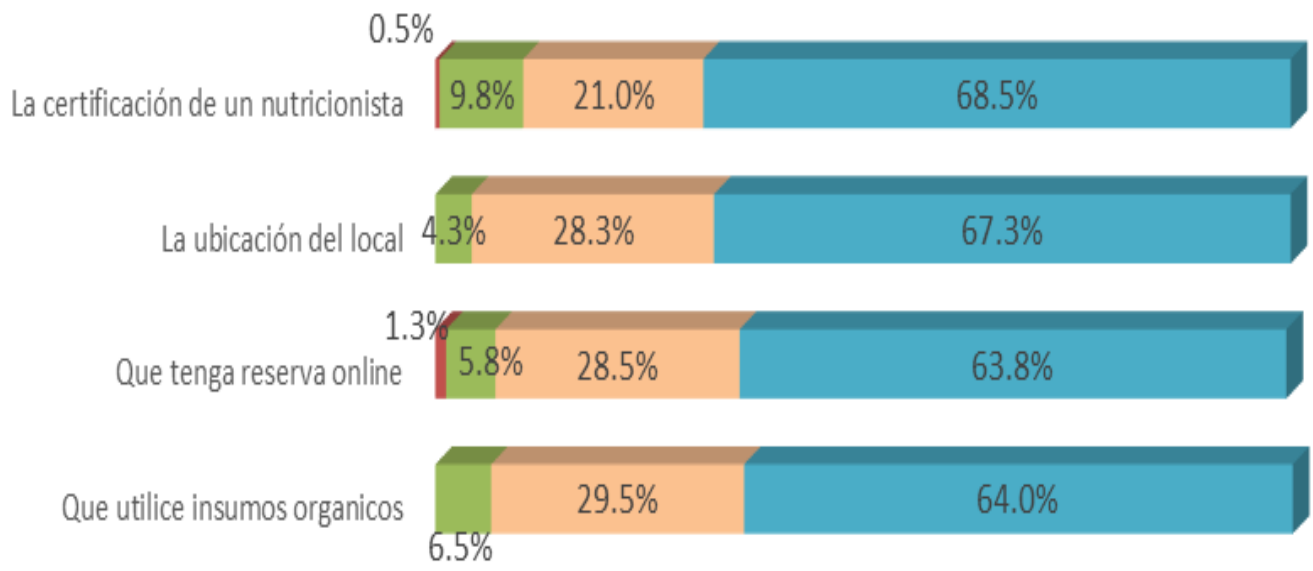

Fuente. Elaboración propia

Base: 400 encuestas 


\begin{abstract}
Respecto a la intención de consumo, el TTB (probablemente si/ definitivamente sí) revela un $88.8 \%$ de intención. De las respuestas vertidas, el $62 \%$ dijo que probablemente sí consumiría, sobre todo el NSE B (63.6\%) (VER GRAFICO Nº)
\end{abstract}

Gráfico No 2. 6:

Intención de consumo según NSE

GRAFICO N6: Intención de consumir en el nuevo restaurante propuesto

- Total NSEA $\quad$ NSEB

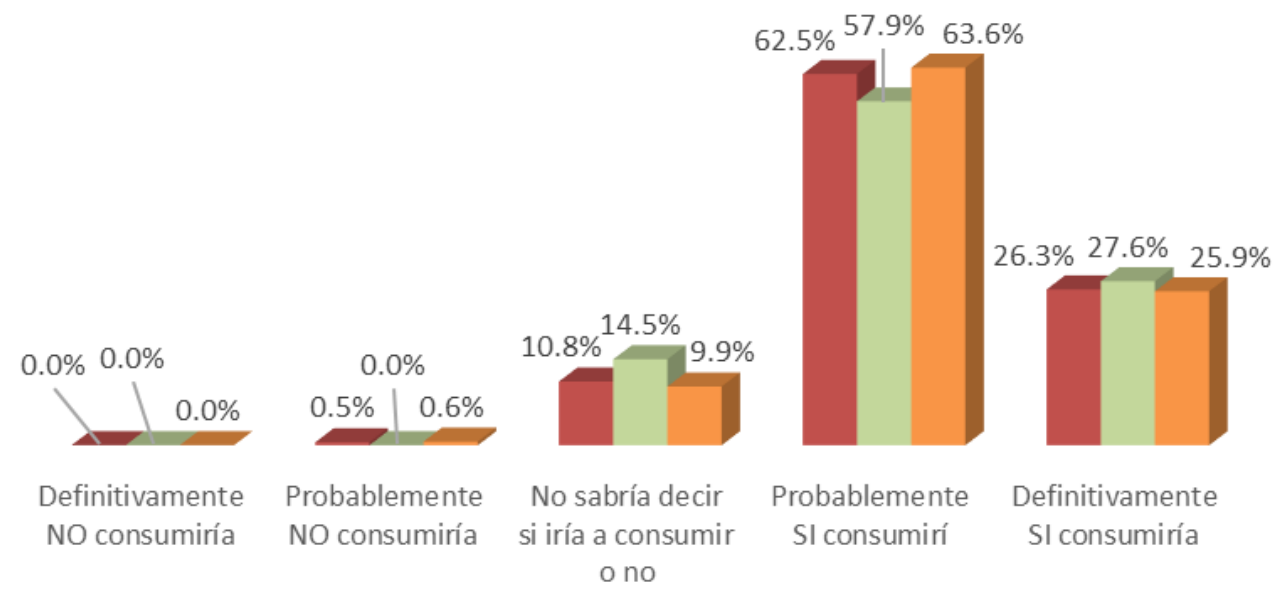

Fuente. Elaboración propia

Base: 400 encuestas 
Cuando se mostraron 3 opciones de almuerzo, la mayoría mostró interés por la opción 2 que incluye entrada, plato de fondo y refresco. (VER GRAFICO N${ }^{\circ}$ )

Gráfico $\mathrm{N}^{\circ}$ 2.7:

Evaluación según las opciones de almuerzo

\section{GRAFICO 7: Evaluación de las opciones de combinación de almuerzos}

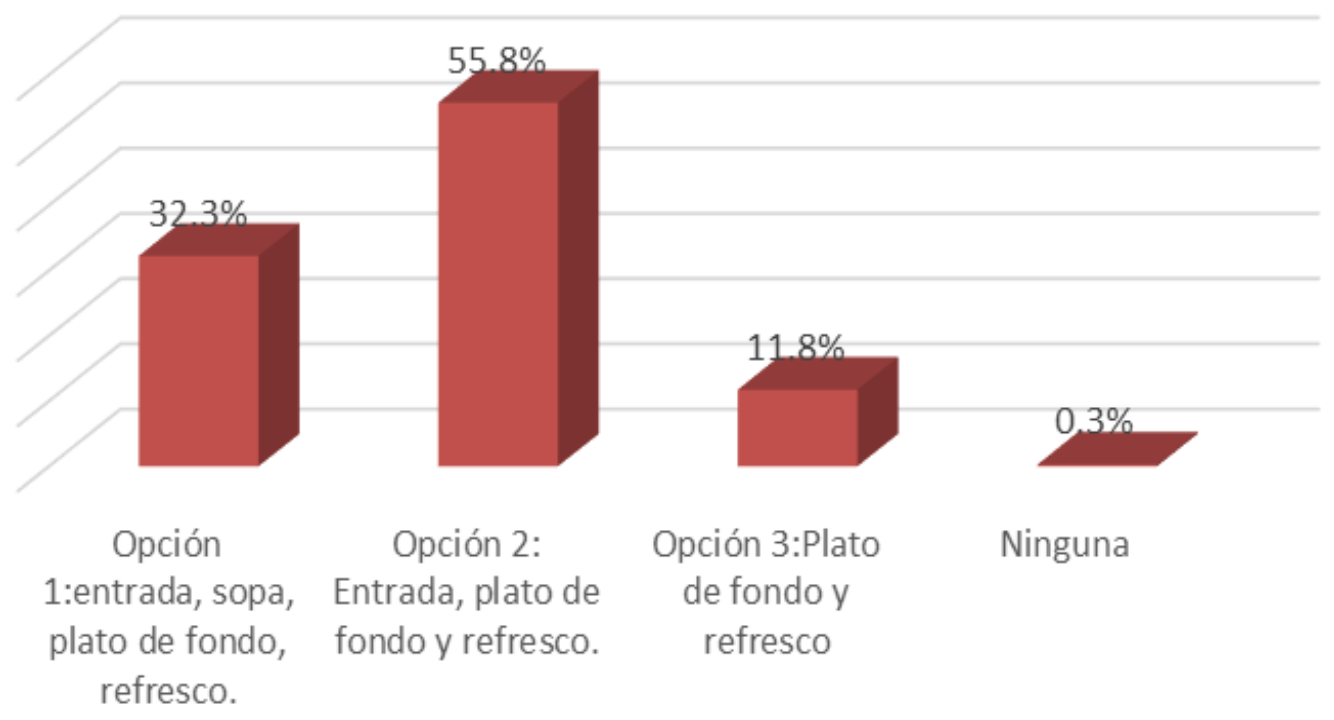

Fuente. Elaboración propia

Base: 400 encuestas 
Y el monto promedio que están dispuestos a pagar por su menú es de 13 soles, con un $47 \%$ que está dispuesto a pagar entre 15 y 19.99 soles (VER GRAFICO $\mathrm{N}^{\circ}$ 9), incluso el grupo que manifestó que probablemente/definitivamente acudiría a consumir en ese restaurante (VER GRÁFICO Nº 8) . Y el 100\% refirió que no pagarían más de 25 soles.

Gráfico $\mathrm{N}^{\circ}$ 2. 8:

Disponibilidad de pago

GRAFICO N8: Monto dispuesto a pagar la población flotante que Definitivamente/probablemente compraria (TTB)

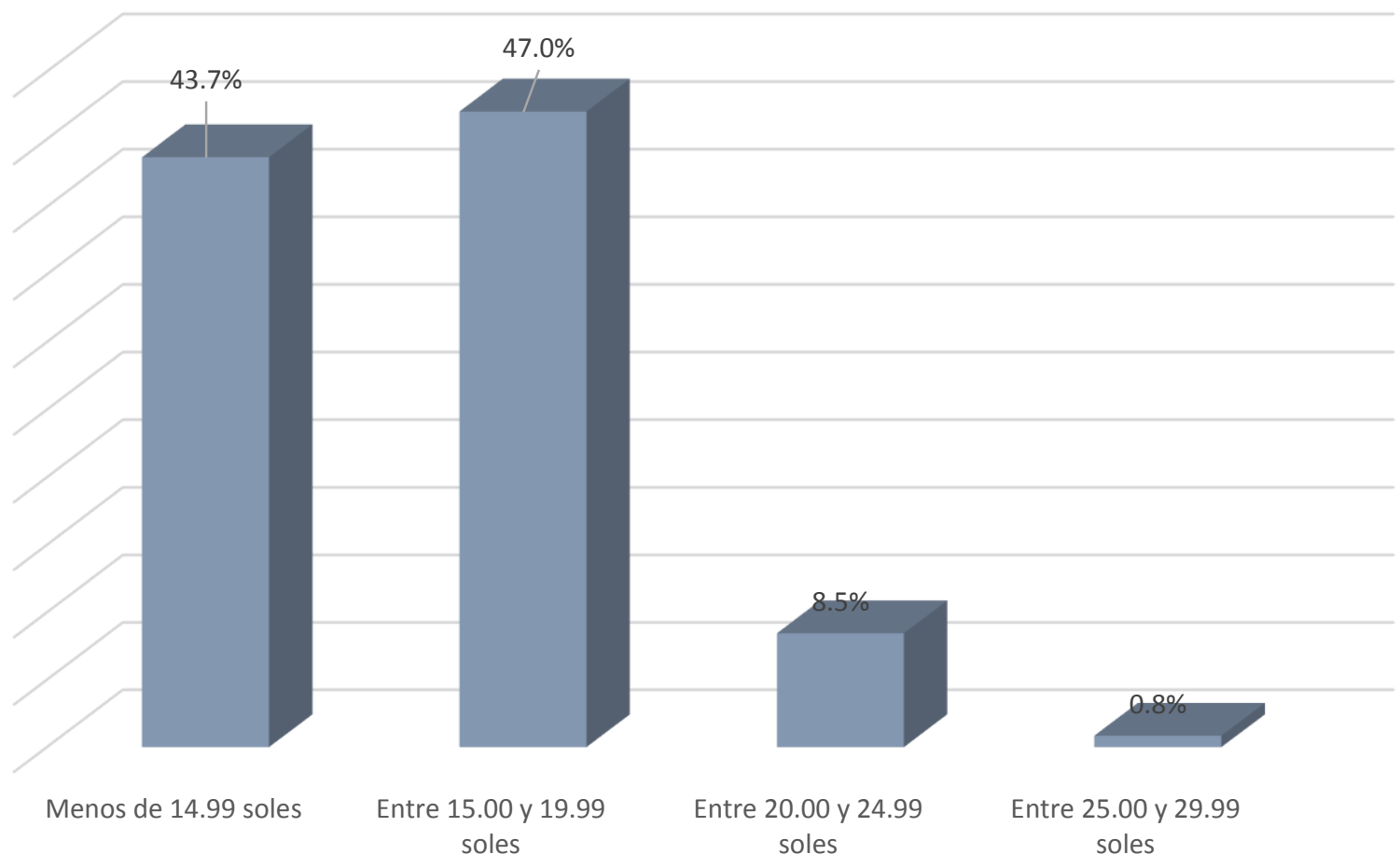

Fuente. Elaboración propia

Base: 400 encuestas 
Con relación a la frecuencia con que comprarían el almuerzo en el restaurante propuesto, el $29 \%$ refirió que lo haría 3 veces a la semana. (VER GRAFICO $\mathrm{N}^{\circ} 9$ ).

Gráfico $\mathrm{N}^{\circ}$ 2. 9:

Frecuencia de compra.

GRAFICO N9: Intención de pago de acuerdo al tipo de opción elegida

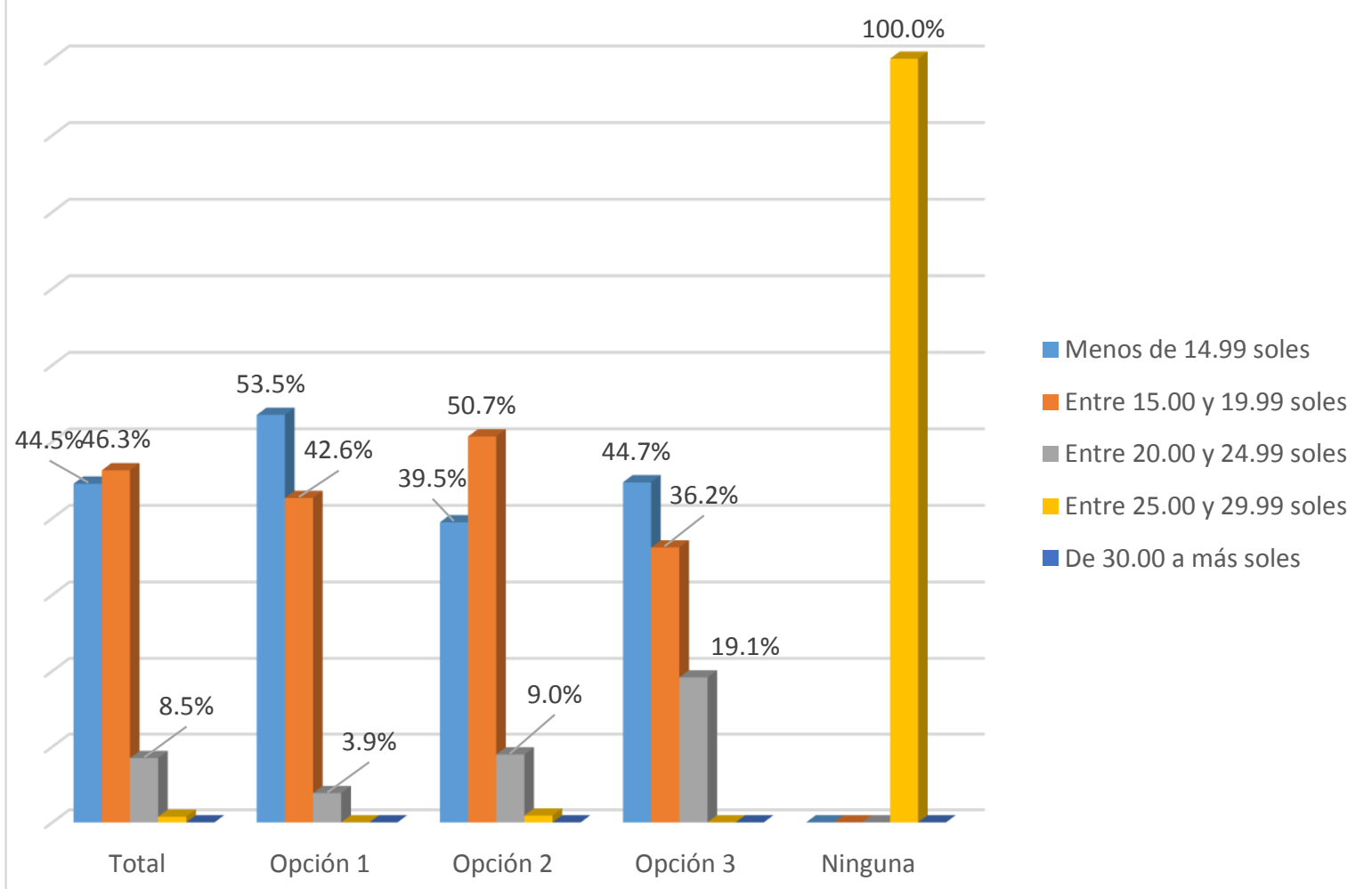

Fuente. Elaboración propia

Base: 400 encuestas 


\section{Y finalmente les gustaría informarse por las redes sociales. (VER GRAFICO N 10$)$.}

Gráfico $\mathrm{N}^{\mathrm{o}}$ 2. 10:

Medios de información

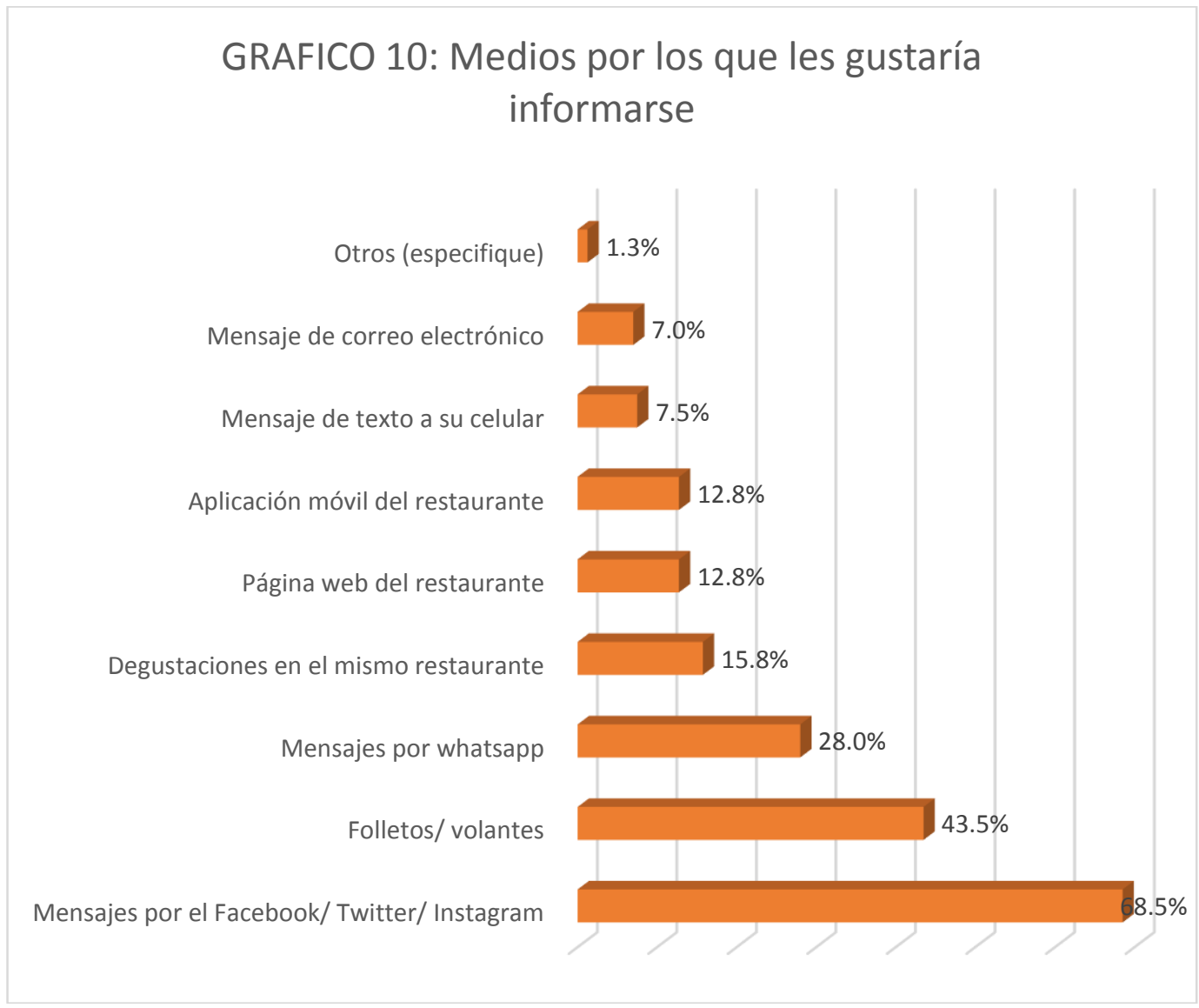

Fuente. Elaboración propia

Base: 400 encuestas 


\subsubsection{Diseño del Instrumento.}

Se diseñó como instrumento, un cuestionario (Ver anexo Nro1), cuyo objetivo principal fue conocer la opinión, expectativa y valoración que tiene el potencial cliente sobre la idea del servicio de restaurante con insumos saludables y orgánica, para ello se plantearon objetivos específicos que permitieron conocer lo siguiente:

Hábitos de consumo de alimentos a la hora de almuerzo motivación de compra (lugares donde frecuentemente hacen sus pedidos, composición del menú que consumen y preferencia de platos),

- Percepción de la atención de lugares donde frecuentemente consumen su almuerzo durante la semana.

- Percepción del producto presentado.

- Percepción del precio del producto.

- Medios que usan para conocer las promociones ofertas de comidas.

\subsection{Análisis de la Demanda.}

Haciendo uso de los resultados de la investigación de mercados, se procede a mostrar la cuantificación de la demanda para el restaurante.

\subsubsection{Cuantificación del Mercado.}

El mercado estudiado, abarca a la población flotante del distrito de San Isidro, considerando a los trabajadores dependientes del sector 
4 de dicho distrito, como ejecutivos de las empresas de la zona en estudio. Bajo esta consideración, el rango de edad, y el nivel socio económico del entrevistado, se realizan las siguientes estimaciones de la demanda:

\section{$\checkmark$ Mercado Potencial}

Según Moyano (2015), el mercado potencial es el total de personas del segmento que elegimos, y que posiblemente, consumirían nuestro producto o servicio.

Para realizar el cálculo del mercado potencial, se ha partido del total de la población flotante en el distrito de San Isidro que asciende a 755717 habitantes, considerándose luego, solo a la población flotante de la zona 4 (40\%), ya que se ha considerado la ubicación que tendrá el restaurante y esta pertenece a dicha zona. El porcentaje de trabajadores dependientes dentro de esa zona asciende al $52 \%$ y en la zona se ha identificado que el $63 \%$ de dicha población tiene entre 26 a 55 años.

Finalmente, se ha tomado el dato de la distribución de personas según el nivel socio económico al que pertenecen, los habitantes de Lima Metropolitana (APEIM 2017), considerando solo al $24.5 \%$ que representa a la población de NSE A y B.

Al acotar toda la población flotante de San Isidro con estas variables, el mercado potencial formado por los Ejecutivos de 26 a 55 años que laboran en la zona 4 de San Isidro y pertenecen a hogares de NSE A y B, de Lima Metropolitana, asciende a las 28620 personas. 
Cuadro No 2.4:

Determinación del Mercado Potencial

\begin{tabular}{|c|c|}
\hline \multicolumn{2}{|c|}{ DETERMINACIÓN DEL MERCADO POTENCIAL } \\
\hline Población Flotante San Isidro & 755,717 \\
\hline Población Flotante Zona 4 & $40 \%$ \\
\hline Pob. Flotante Zona 4 dependientes & $52 \%$ \\
\hline Pob. Flotante Zona 4 de 26 a 55 años & $63 \%$ \\
\hline \% Población NSE A Lima Metropolitana & $4.40 \%$ \\
\hline \% Población NSE B Lima Metropolitana & $24.50 \%$ \\
\hline Merc & 28,620 \\
\hline
\end{tabular}

Fuente. Elaboración propia

\section{$\checkmark$ Mercado Disponible}

Continuando con las definiciones de Moyano (2015), el mercado disponible, es una parte del mercado potencial y está formada por el conjunto de consumidores que están interesados en el nuevo producto o les llama la atención. Y este dato se obtiene al medir con una escala de nivel de interés, la percepción del mercado potencial, hacia la propuesta del restaurante.

Según el estudio sobre Salud y Etiquetado de Kantar Worldpanel (KWP), cada vez, los peruanos son más conscientes de lo que consumen. Es así como el 54\% de hogares peruanos se considera "saludable" o "muy saludable".

Tomando esta información el mercado potencial de 28620 ejecutivos se reduce al $54 \%$, población que responde a aquellos que se consideran saludables o muy saludables, obteniéndose un mercado disponible de 15455 ejecutivos. 


\section{$\checkmark$ Mercado Efectivo}

Es una parte del mercado disponible y está formado por el conjunto de consumidores que además de la necesidad específica, tienen la intención de comprar el bien o servicio que ofrece el nuevo negocio.

Para realizar el cálculo del Mercado Efectivo se tomó la información que proporciona la siguiente pregunta:

De acuerdo al concepto que le acabo de leer, y haciendo uso de las alternativas de respuesta que le muestro en la siguiente escala, cuan interesante o no, le parece esta idea a usted?

Para esta operación se utilizó únicamente la respuesta más positiva 'muy interesante' que fue marcada por el $50 \%$ de participantes.

Cuadro $\mathrm{N}^{\mathrm{o}} 2.5$ :

Interés frente a la nueva idea del negocio

\begin{tabular}{|c|c|c|c|c|}
\hline \multicolumn{5}{|c|}{ P4.-¿Cuán interesante o no, le parece esta idea a usted? } \\
\hline Nada interesante & $\begin{array}{c}\text { Poco } \\
\text { interesante }\end{array}$ & $\begin{array}{c}\text { Me es } \\
\text { indiferente }\end{array}$ & $\begin{array}{c}\text { Algo } \\
\text { Interesante }\end{array}$ & $\begin{array}{c}\text { Muy } \\
\text { interesante }\end{array}$ \\
\hline $0.5 \%$ & $0.5 \%$ & $3.5 \%$ & $\mathbf{4 5 . 5 \%}$ & $\mathbf{5 0 \%}$ \\
\hline
\end{tabular}

Base: 400 encuestados

Fuente propia

Es así como el mercado efectivo de 15,455 ejecutivos se reduce al $50 \%$ que responde a aquellos que el concepto les parece muy interesante, obteniéndose un mercado efectivo 7,728 ejecutivos.

\section{$\checkmark$ Mercado Objetivo}

Es una parte del mercado efectivo que la empresa espera atender, es decir la parte del mercado efectivo que se fija como meta a ser alcanzada por el negocio. 
Por no contar con datos históricos se utilizó la pregunta sobre intención de consumir los productos del restaurant:

Cuadro $\mathrm{N}^{\mathrm{o}}$ 6:

Intención de consumo frente a la nueva propuesta de negocio.

\begin{tabular}{|c|c|c|c|c|c|}
\hline \multicolumn{6}{|c|}{$\begin{array}{l}\text { P6.- Haciendo uso de la siguiente escala de respuestas y pensando en el RESTAURANTE DE ALMUERZOS } \\
\text { CON INSUMOS NATURALES Y ORGÁNICOS, en general cuál de estas respuestas que le voy a leer, } \\
\text { representa mejor su intención de consumir o no, los almuerzos de este restaurante? }\end{array}$} \\
\hline Opciones & $\begin{array}{l}\text { Definitivamente } \\
\text { NO consumiría }\end{array}$ & $\begin{array}{l}\text { Probablemente } \\
\text { NO consumiría }\end{array}$ & $\begin{array}{c}\text { No sabría decir si lo } \\
\text { consumiría o no }\end{array}$ & $\begin{array}{c}\text { Probablemente SI } \\
\text { lo consumiría }\end{array}$ & $\begin{array}{c}\text { Definitivamente SI } \\
\text { consumiría }\end{array}$ \\
\hline RPTA & $0 \%$ & $0.50 \%$ & $10.80 \%$ & $62.50 \%$ & $26.30 \%$ \\
\hline MC DANIELS & $0 \%$ & $10 \%$ & $17.50 \%$ & $35 \%$ & $70 \%$ \\
\hline RESULTADO & $0 \%$ & $0.05 \%$ & $1.90 \%$ & $21.90 \%$ & $18.40 \%$ \\
\hline
\end{tabular}

Fuente propia

A las respuestas proporcionadas se le aplica la teoría de Mc Daniels para obtener una estimación razonable y conservadora. Luego de aplicarla el total de consumidores o mercado objetivo seria $42.25 \%$ del mercado efectivo. Aplicando esta cifra al mercado efectivo, el mercado objetivo está formado por 3,265 personas.

De esta manera se ha desarrollado la evolución del mercado potencial hasta el mercado objetivo, tomando como principal factor de crecimiento el PBI en un 3\% por año, esto nos ha permitido determinar una evolución de la cuota de penetración de mercado por periodo, según las opciones ofrecidas como se muestra en el siguiente cuadro:

Cuadro $\mathrm{N}^{\mathrm{o}} 7$ :

Proyección mercado objetivo

\begin{tabular}{|c|c|c|c|c|}
\hline \multirow{2}{*}{ AÑNO } & \multirow{2}{*}{$\begin{array}{l}\text { Mercado } \\
\text { Potencial }\end{array}$} & Mercado & Mercado & Mercado \\
\cline { 3 - 5 } & & Disponible & Efectivo & Objetivo \\
\cline { 3 - 5 } & $\mathbf{5 4 \%}$ & $\mathbf{5 0 \%}$ & $\mathbf{4 2 . 2 5 \%}$ \\
\hline Año 1 & 28,620 & 15,455 & 7,727 & 3,265 \\
\hline Año 2 & 29,479 & 15,918 & 7,959 & 3,363 \\
\hline Año 3 & 30,363 & 16,396 & 8,198 & 3,464 \\
\hline Año 4 & 31,274 & 16,888 & 8,444 & 3,568 \\
\hline Año 5 & 32,212 & 17,395 & 8,697 & 3,675 \\
\hline
\end{tabular}

Fuente propia 
Año $=365$ días

Vacaciones $=30$ días

Feriados en el año $=12$ días

Horario de verano $=13$ días

Total días no laborables $=55$, equivale a 8 semanas

La demanda anual debe proyectarse a 44 semanas efectivas al año

\subsection{Análisis de la Competencia.}

\subsubsection{Identificación de los Competidores.}

El segmento de alimentación saludable está en proceso crecimiento en el mercado, razón por la que se ha realizado un levantamiento de información en la zona con la realización de visitas al sector 4 y los alrededores al potencial lugar donde se instalaría el restaurante proyectado. Para ello se ha utilizado la metodología de observación y registro geográfico, según se adjunta la IMAGEN №2.10.

Mapeo y registro geográfico de restaurantes

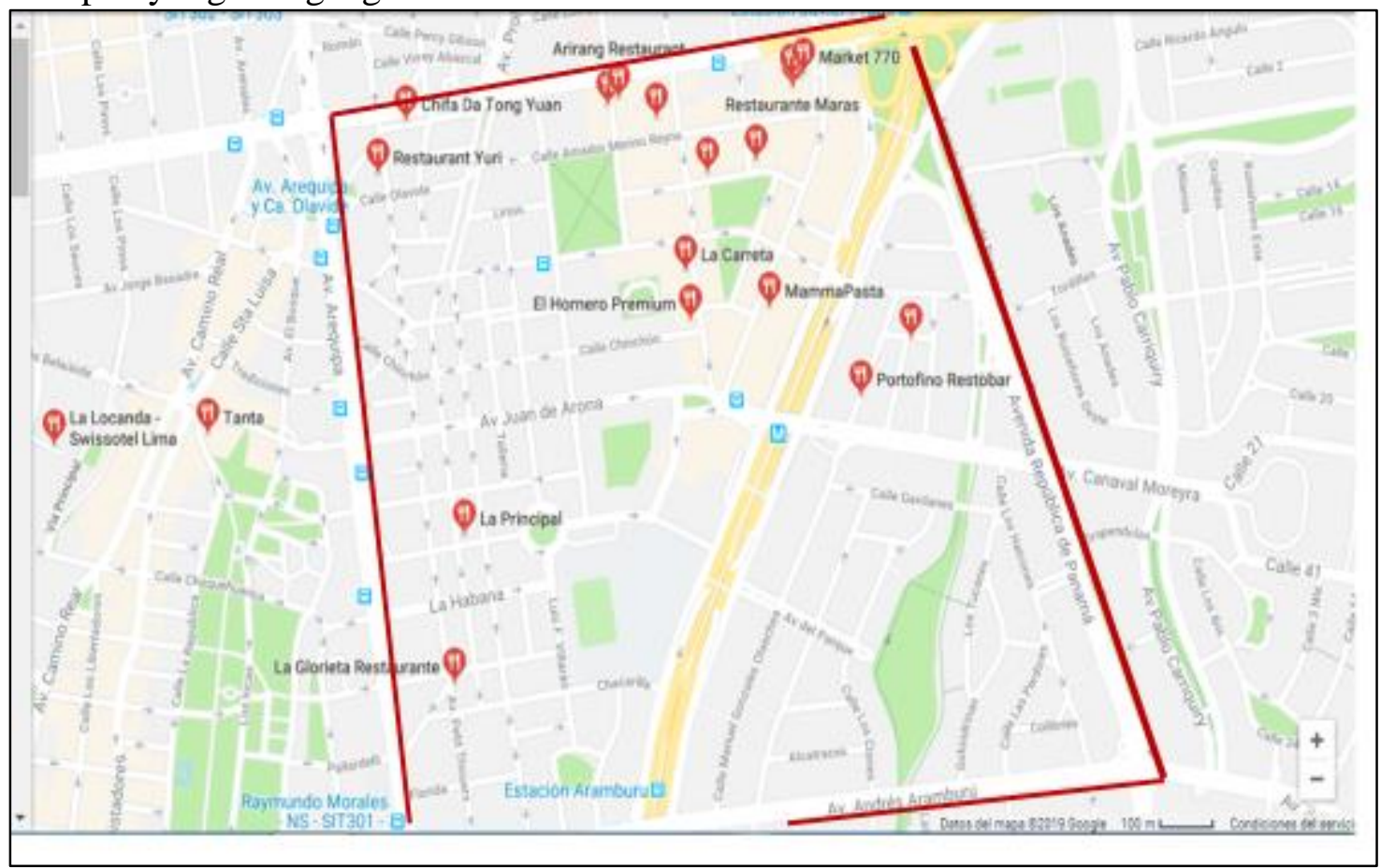

Fuente propia 
Así se identificaron los principales restaurantes dentro del sector 4:

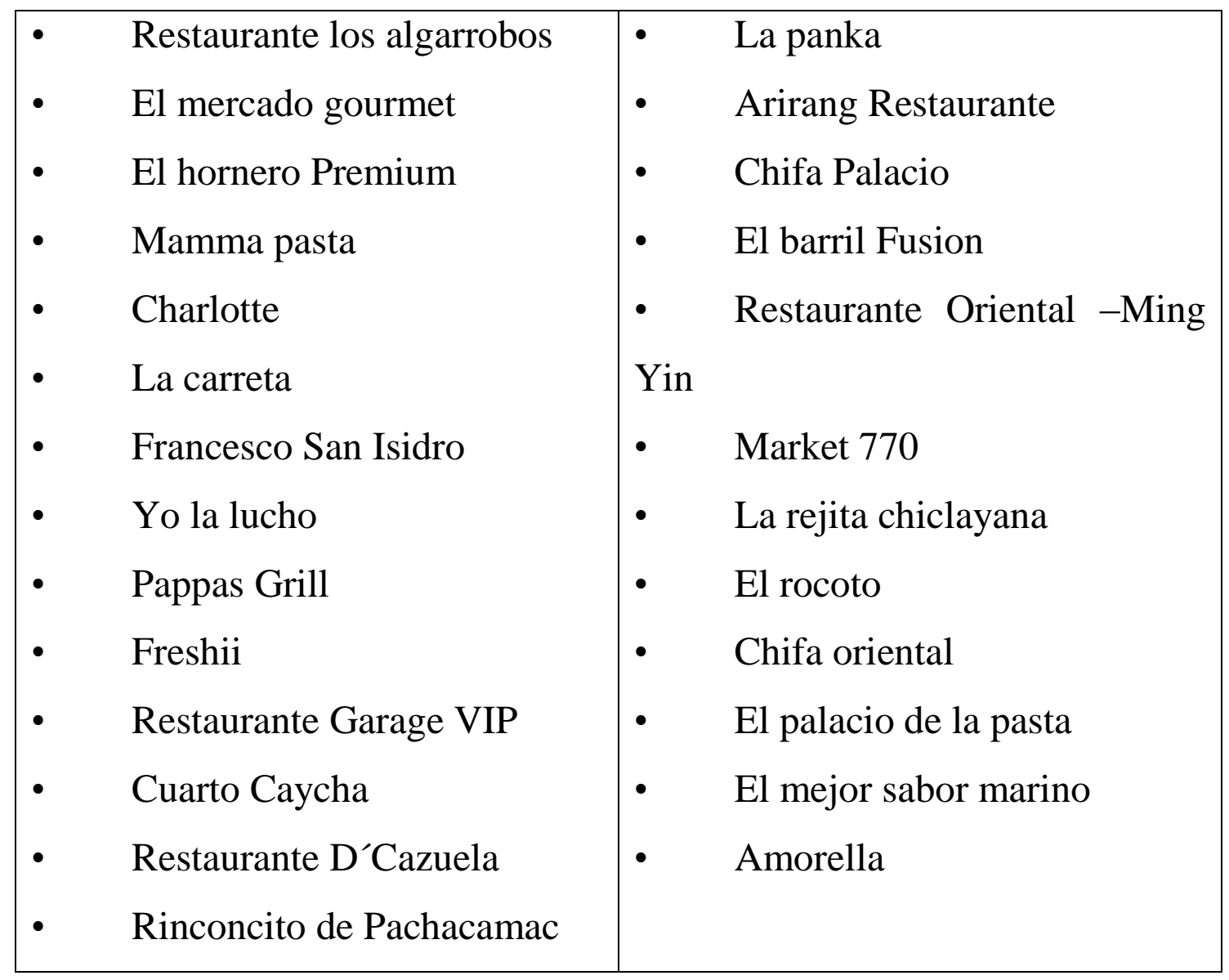

Los competidores en el ámbito de restaurantes que ofrecen una alimentación con insumos saludables y orgánicos registrados como tales dentro de su oferta culinaria resultaron escasos. Por ello, se ha identificado a los que se asemejan a la propuesta de negocio, resaltando Green is Bether y Qumara (VER CUADRO N².8) 
Cuadro No 2.8:

Restaurantes asemejan a la nueva propuesta de negocio

\begin{tabular}{|c|c|c|}
\hline NOMBRE DE LA EMPRESA & QUMARA & $\begin{array}{c}\text { SALADBAR GREEN IS } \\
\text { BETTER }\end{array}$ \\
\hline UBICACIÓN & Av. Andrés Reyes 437, San Isidro & $\begin{array}{l}\text { Calle Dean Valdivia } 243 \text { - San } \\
\text { Isidro. }\end{array}$ \\
\hline CARACTERISTICAS & opciones saludables & $\begin{array}{l}\text { Ofrecen comida fast food bajo el } \\
\text { concepto de ser saludable. }\end{array}$ \\
\hline PRODUCTOS & $\begin{array}{l}\text { bowl, smoothies, panqueques de } \\
\text { avena, ensaladas, sándwich, } \\
\text { wraps, y bowls de arroz, quinua o } \\
\text { fideos integrales }\end{array}$ & $\begin{array}{l}\text { Ensaladas, aliños, platos } \\
\text { calientes, Green express, } \\
\text { acompañamientos, cremas, } \\
\text { jugos. }\end{array}$ \\
\hline HORARIO DE ATENCIÓN & $\begin{array}{l}\text { De lunes a viernes de 07:30am a } \\
20: 00, \text { y sábados 07:30am a } \\
14: 30\end{array}$ & $\begin{array}{l}\text { Lunes a sábado 8:00 am a } \\
\text { 17:00 pm. }\end{array}$ \\
\hline PRECIO & Desde $S / 7.00$ hasta $S / 30.00$ & Desde $S / 7.00$ hasta $S / 22.00$ \\
\hline INFORMACIÓN & Ingredientes saludables & $\begin{array}{l}\text { Ingredientes Frescos, opciones } \\
\text { saludables, atención } \\
\text { personalizada. }\end{array}$ \\
\hline
\end{tabular}

Y como competencia indirecta, se ha considerado sobre todo por el servicio que ofrece, considerando mesas con manteles y mozos principalmente.

- Malabar Restaurante

- Maras Restaurante

- Aguaymanto

Se está considerando el análisis de los siguientes restaurantes por la cercanía a nuestra propuesta de negocio como sigue: 
Cuadro No 2.9:

Competencia indirecta por la cercanía

\begin{tabular}{|c|c|c|c|}
\hline $\begin{array}{l}\text { NOMBRE DE LA } \\
\text { EMPRESA }\end{array}$ & $\begin{array}{c}\text { MALABAR } \\
\text { RESTAURANT }\end{array}$ & MARAS & AGUYMANTO \\
\hline UBICACIÓN & Camino Real 101 San Isidro. & $\begin{array}{l}\text { Esquina las Begonias con } \\
\text { Amador Merino Isidro }\end{array}$ & $\begin{array}{l}\text { Calle Los Libertadores } \\
490 \text { San Isidro }\end{array}$ \\
\hline ARACTERISTICAS & $\begin{array}{l}\text { Malabar ofrece comida } \\
\text { espontánea, sabrosa, } \\
\text { saludable, artesanal. }\end{array}$ & $\begin{array}{l}\text { Ofrecen cocina peruana } \\
\text { moderna con sabores típicos y } \\
\text { nuevas sensaciones de } \\
\text { experiencia gastronómica. }\end{array}$ & $\begin{array}{l}\text { Sirve desayuno, almuerzo, } \\
\text { cena, café y bebidas }\end{array}$ \\
\hline PROD & $\begin{array}{l}\text { Corvina al horno, merluza, } \\
\text { tallarines, cuy, pato, cabrito, } \\
\text { remolachas orgánicas, } \\
\text { espárragos orgánicos, } \\
\text { ensalada de quinua crujiente. }\end{array}$ & $\begin{array}{l}\text { Asado de tiras, ceviche, atún y } \\
\text { chicharrón de tapioca, } \\
\text { adobado, postres, helados entre } \\
\text { otros. }\end{array}$ & $\begin{array}{l}\text { Menús } \\
\text { S/38.00 } \\
\text { (Incluido impuestos y } \\
\text { servicios) } \\
\text { Entrada - Plato de Fondo } \\
\text { - Postre - Bebida del día } \\
\end{array}$ \\
\hline $\begin{array}{l}\text { HORARIO DE } \\
\text { ATENCIÓN }\end{array}$ & $\begin{array}{l}\text { Lunes a viernes de } 12: 30 \text { a } \\
\text { 15:30 /19:00 a 23:00 sábado } \\
\text { de 12:30 a 15:30 / 19:00 a } \\
\text { 23:00 }\end{array}$ & $\begin{array}{l}\text { Lunes a viernes de } 12: 00 \text { a } \\
\text { 16:00 /19:00 a 00:00 sábado de } \\
\text { 19:00 a 00:00 }\end{array}$ & $\begin{array}{l}\text { De lunes a viernes 12:30 } \\
\text { p.m. a 3:30 p.m. /07:00 a } \\
\text { 11:00 sábado y Domingo } \\
\text { de 12:30 a 15:00 / 19:00 a } \\
\text { 23:00 }\end{array}$ \\
\hline PRECIO & Desde $S / 34.00$ a $S / 89.00$ & Desde $S / 35.00$ a $S / 200.00$ & $\mathrm{~S} / 38.00$ \\
\hline INFORMACIÓN & $\begin{array}{l}\text { Cocinamos, con cariño de } \\
\text { hogar, lo que nos nace y lo } \\
\text { que la naturaleza peruana nos } \\
\text { ofrece. }\end{array}$ & $\begin{array}{l}\text { Experiencia única en calidad y } \\
\text { sabor. Selección de insumos } \\
\text { más saludables y frescos. }\end{array}$ & $\begin{array}{l}\text { Descubra nuevas } \\
\text { sensaciones con nuestra } \\
\text { gastronomía. }\end{array}$ \\
\hline
\end{tabular}

Fuente: Elaboración propia.

\subsubsection{Participación de Mercado.}

Como se indicó anteriormente, la participación de mercado se obtuvo en base a la información adquirida mediante la técnica de observación en varios turnos de atención en distintos días a la semana, en los locales de los restaurantes indicados en el Gráfico $N^{0}$ 2.11, para elaborar nuestro cuadro se necesitó conocer la rotación de personas por mesas, capacidad del local, gasto promedio de atención, horario de atención, entre otros, determinando de esta manera el cálculo de ventas promedio, porcentaje de participación de cada uno de nuestros competidores. 
Cuadro $\mathrm{N}^{\mathrm{o}} 2.10$ :

Participación de Mercado

\begin{tabular}{|l|r|r|r|r|r|r|r|r|r|r|r|}
\hline Restaurante & Mesas & Sillas & Capacidad & $\begin{array}{c}\text { Total dias } \\
\text { al año }\end{array}$ & $\begin{array}{c}\text { Capacidad } \\
\text { al año }\end{array}$ & $\begin{array}{c}\text { \% de } \\
\text { atencion }\end{array}$ & $\begin{array}{c}\text { Total } \\
\text { atencion al }\end{array}$ & $\begin{array}{c}\text { Gasto } \\
\text { Promedio }\end{array}$ & $\begin{array}{c}\text { Rotacion de } \\
\text { sillas }\end{array}$ & $\begin{array}{c}\text { Ventas al año } \\
\text { en S/. }\end{array}$ & \% \\
\hline Quinoa & 20 & 65 & 65 & 245 & 15,925 & $50 \%$ & 7,963 & 30.00 & 14 & $3,344,250.00$ & $14.23 \%$ \\
\hline Malabar & 38 & 130 & 130 & 300 & 39,000 & $32 \%$ & 12,480 & 56.00 & 10 & $6,988,800.00$ & $29.74 \%$ \\
\hline Maras & 40 & 140 & 135 & 300 & 40,500 & $34 \%$ & 13,770 & 65.00 & 9 & $8,055,450.00$ & $34.28 \%$ \\
\hline Aguaymanto & 30 & 78 & 75 & 320 & 24,000 & $22 \%$ & 5,280 & 45.00 & 10 & $2,376,000.00$ & $10.11 \%$ \\
\hline La Locanda & 28 & 70 & 65 & 320 & 20,800 & $20 \%$ & 4,160 & 38.00 & 9 & $1,422,720.00$ & $6.05 \%$ \\
\hline Green is better & 12 & 30 & 30 & 320 & 9,600 & $65 \%$ & 6,240 & 15.00 & 14 & $1,310,400.00$ & $5.58 \%$ \\
\hline
\end{tabular}

Fuente. Elaboración propia

Gráfico No 2 11:

Distribución de Ventas de la competencia

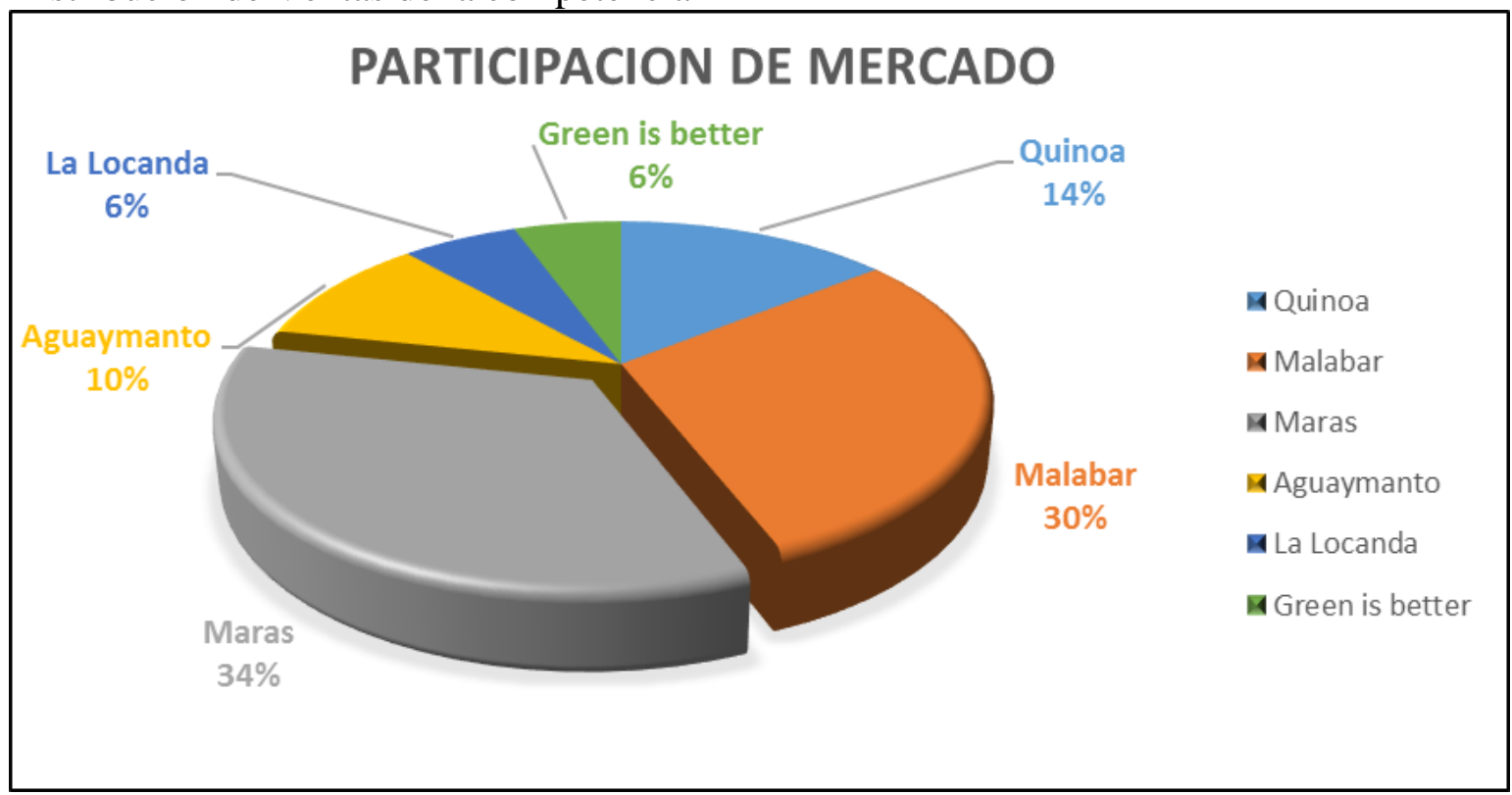

Fuente: Elaboración Propia

\subsection{Análisis de la Cadena de Valor.}

A través de esta herramienta estratégica vamos a analizar las actividades de la empresa, identificando sus principales ventajas competitivas que nos va a permitir competir dentro de nuestro segmento (Imagen 2.13). 
Michael E. Porter (2008, pág. 51), en su trabajo Ventaja Competitiva cita que "La ventaja competitiva no puede ser comprendida viendo a una empresa como un todo. Radica en las muchas actividades discretas que desempeña una empresa en el diseño, producción, mercadotecnia, entrega y apoyo de sus productos. Cada una de estas actividades puede contribuir a la posición de costo relativo de las empresas y crear una base para la diferenciación". Así mismo, presenta a la cadena de valor como herramienta sistemática que permite examinar todas las actividades que una empresa desempeña y cómo estas interactúan, este análisis permite identificar y analizar las fuentes de la ventaja competitiva.

Para el presente plan de negocios analizaremos cada componente de la cadena de valor que permitirá generar una ventaja competitiva.

\subsubsection{Actividades Primarias}

Logística Interna

En esta actividad se deberá tener presente:

- La compra de insumos perecibles y no perecibles deberán ser de calidad y frescos teniendo cuidado en la fecha de caducidad y la calidad sanitaria.

- Tener cuidado en el transporte y manipulación que minimiza daños de los insumos.

- Contar con adecuado almacenamiento, asegurando la conservación de los insumos.

- Control de los inventarios por muy sobre todo en la fecha de caducidad. 
Operaciones

- Control en todos los procesos: preparación, presentación, y limpieza puntos clave de diferenciación.

Logística externa

- El trato cordial al momento de efectuar la venta directa o telefónica en a la información de las reservas e información de los platos y promociones del día.

- Cumplir con el tiempo de entrega.

Mercadotecnia y Ventas

- Producir material publicitario y entregar información de menús diarios a través de correos a clientes potenciales.

- Promover la recomendación de amigos y conocidos de clientes.

- Informar a través del portal web y redes sociales los menús diarios.

- Promover las relaciones personales con el público objetivo, identificando el gusto de cada cliente.

Servicio:

- Atención de un nutricionista para personalizar la alimentación de los clientes.

- Contar con información del cliente que permita fidelizarlo.

- Efectuar encuestas de calificación del producto y servicio, para medir la satisfacción del producto.0 


\subsubsection{Actividades y Perfil del Personal para el Negocio.}

Infraestructura de la empresa

Las actividades de infraestructura comprenden la dirección del negocio, planificación, finanzas, contabilidad, control de costes, la gestión de la calidad y los temas legales y fiscales.

Administración de Recursos Humanos

- Entrenamiento del personal en proceso de compra, transporte, manipulación, almacenamiento y control de inventarios.

- Contar con políticas para la retención del personal.

- Capacitación constante en temas de atención al cliente.

- Contar con programas de incentivos para los empleados.

- Capacitación constante en temas de atención de objeciones.

Desarrollo Tecnológico

- Aplicación de tecnologías para la conservación de alimentos.

- Sistemas de control de abastecimiento de insumos.

- Contar con un sistema que permite tomar pedidos y permita optimizar tiempos.

- Contar con un Portal web para pc's y teléfonos móviles. 
- Tener sistemas de información que permite interactuar con el cliente.

Abastecimiento:

- Cuidar que en el transporte de insumos se minimicen las pérdidas y daños.

- Los insumos deberán ser de la más alta calidad, frescura y precios adecuados.

Estas actividades permitirán construir las siguientes ventajas competitivas:

- Diferenciar nuestro producto entregando menús sanos, nutritivos, variados, con altos estándares de calidad y las mejores condiciones de higiene. Elaborados con la asistencia de nutricionistas, de acuerdo con las necesidades de cada cliente.

- Otro factor diferenciador es la rapidez, puntualidad en el servicio. 
Imagen $\mathrm{N}^{\mathrm{o}} 2$ 11:

Análisis de la Cadena de Valor

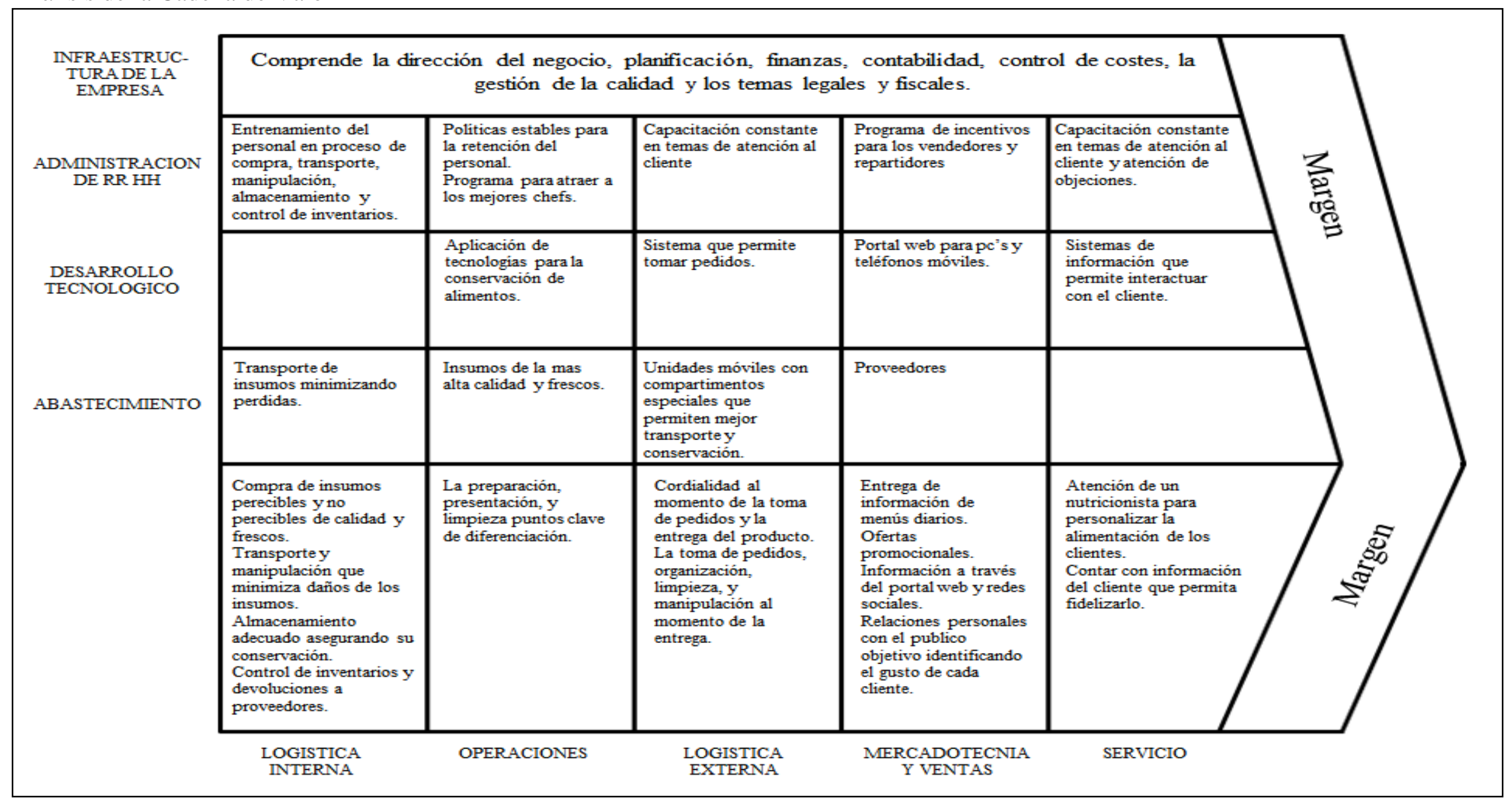

Fuente: Elaboración propia. 


\section{CAPÍTULO III}

\section{PLAN DE MARKETING Y VENTAS}

Con la finalidad de lograr los objetivos comerciales de nuestra empresa vamos a utilizar la estrategia funcional formada por las estrategias de marketing mix o también llamada las 4Ps del marketing, son las variables imprescindibles con las que cuenta una empresa para conseguir sus objetivos comerciales. Estas cuatro variables (producto, precio, distribución y promoción), pero si hablamos de una empresa del sector servicios debemos pasar de 4 a 7 p's, este nuevo marketing mix contiene tres elementos adicionales (Personas, Procesos y Evidencia Física), desarrolladas en los siguientes puntos:

\subsection{Estrategia de Producto.}

Nuestra estrategia de producto está dirigida al ejecutivo del Centro Financiero de San Isidro, cuya finalidad es brindar un servicio de alimentación con insumos saludables y orgánicos, todo ello bajo la supervisión de un especialista en nutrición; la información nutricional de los alimentos que el cliente consuma se encontrara disponible en el aplicativo o página web en la dirección electrónica proporcionado por la empresa al momento de recibir las ordenes de servicio del cliente.

Se ofrecerá una combinación de sabores entre hortalizas, carnes, vegetales, cereales y legumbres, asegurándonos de obtener los suficientes nutrientes, minerales, vitaminas, carbohidratos, fibras y grasas, todos los insumos mantendrán la calidad de ser saludables y tendencia orgánica. Se brindará un ambiente cálido, natural y 
cómodo, con una atención personalizada enfocada al cliente, así como la tecnología sofisticada orientada al cliente al momento de tomar los pedidos con el objetivo de mejorar la experiencia, así como el tiempo de espera del servicio para la entrega de los alimentos.

Para determinar nuestro Market share la empresa luego de haber identificado el mercado objetivo, llevara a cabo la estrategia de penetración de mercado, teniendo en cuenta la importancia de llegar al cliente enfocándose en entrar al mercado con precios por debajo de la competencia que se asemejan a nuestro servicio, ventas personales consistentes en formar alianzas con las empresas con la finalidad de ofrecer una alimentación saludable a sus empleados, así como promociones y publicidades agresivas con la finalidad de persuadir a los clientes potenciales y los de la competencia con la finalidad que puedan visitar nuestro restaurante e iniciar una nueva alternativa de alimentación con insumos saludables y orgánicos.

\section{La empresa va a desarrollar las siguientes acciones:}

\section{Calidad en el servicio:}

El negocio estará enfocado al servicio del cliente, buscar la fidelización de ellos con la finalidad de ser recomendados a sus amigos y familias.

$\underline{\text { Recompensas novedosas: }}$

Incentiva con un premio la lealtad de nuestros comensales con programas interactivos y dinámicas en línea, que permite a los negocios decidir qué recompensas tradicionales o innovadoras vamos 
a ofrecer a los clientes. El otro plus es brindar al cliente a localizar el negocio (en un mapa), conocer qué tipo de recompensas tienes y vincularse directamente con los que ya forman parte de nuestra comunidad.

\section{Diferenciación del concepto:}

El concepto de la alimentación estará diseñado enfocado al uso de insumos saludables y orgánicos, garantizado por un nutricionista que vigilará todo el proceso productivo, así como la información nutricional de los alimentos ofrecidos.

\section{Delimitación del Publico:}

Nuestro público objetivo son personas que valoren la alimentación saludable y estén dispuestos a pagar por ello y que rechacen el formato fast food.

\section{$\underline{\text { Beneficios del Producto }}$}

- El cliente podrá realizar la reserva de su mesa vía internet, teléfono, aplicativos móviles y redes sociales de la empresa.

- Se le ofrecerá la alternativa de reservar la mesa por un determinado tiempo y hacer los pedidos previos al momento de llegar al restaurant.

- Todos los platos ofrecidos al cliente se le brindara una información nutricional detallada mediante un acceso a su aplicativo móvil, correo o cartilla informativa. 
- Todos los alimentos se preparan siguiendo los más altos estándares de calidad, preparados al momento, con insumos frescos de buena calidad y la supervisión del especialista en nutrición en todo el proceso de elaboración de los alimentos.

- Los proveedores de los insumos como las hortalizas, frutas, cereales, tubérculos, granos serán de calidad y certificados para la venta de insumos y alimentos orgánicos en el Perú (Libre de todo tipo de pesticidas, insecticidas o sustancias químicas que alteren la naturaleza de los insumos), contando con un directorio certificado de proveedores.

\section{Presentación del Producto}

La presentación de nuestra cartilla de alimentos consistirá en principales productos diferenciándose para nuestro mercado objetivo que son los ejecutivos del centro financiero de San Isidro de mandos o cargos sénior, executivo y manager, asignándole a cada uno una propuesta de cartilla como sigue:

- Platos de Entrada: Sopas o ensaladas

- Plato de Fondo

- Bebida.

Elaborado con insumos saludables y tendencia orgánica, manteniendo los estándares de calidad, se le brindara la cartilla de información nutricional, acceso al aplicativo de la red o correo electrónico. 


\section{$\underline{\text { La Marca }}$}

Nuestra marca LIKE HOME - Restaurant, tiene la finalidad de brindar al cliente la sensación y el momento de estar en el hogar, sentir que la alimentación que consume, el servicio que recibe y toda su estancia en ese momento lo haga sentir cómodo, saludable y cuidado de manera íntegra como en casa.

Imagen $\mathrm{N}^{\circ} 31$ :

Marca del producto

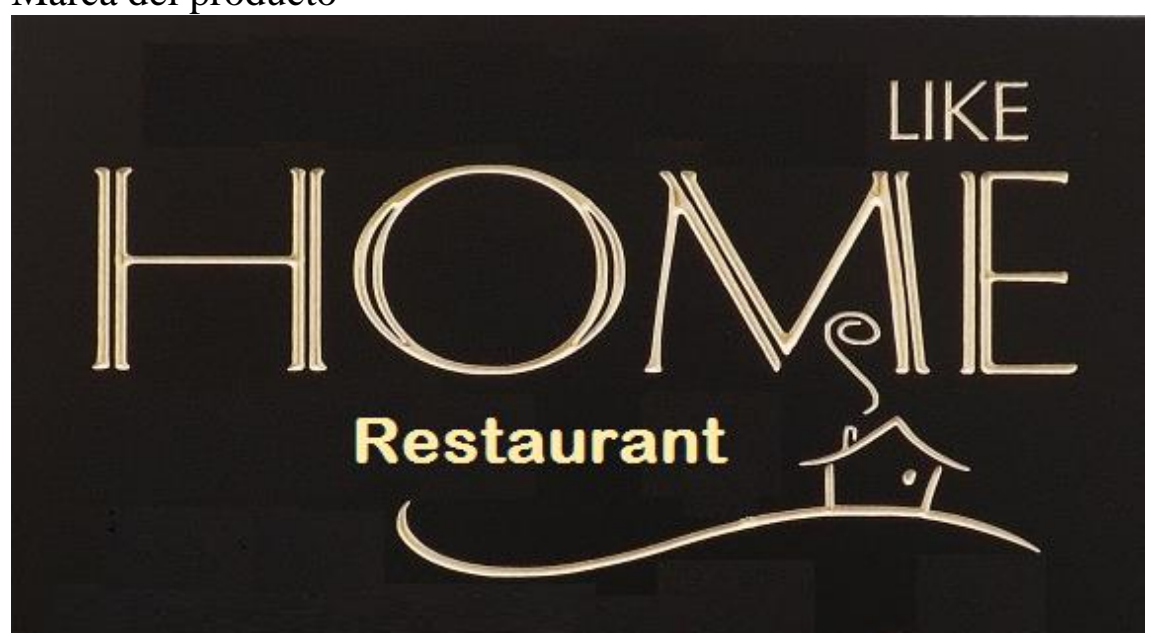

Fuente: Elaboración Propia.

- El nombre de nuestra marca es "Like Home - Restaurant".

- El Logotipo de la marca es la casa con la chimenea la casa.

- La Imagen de la marca es la curva de una pradera y la casa con la chimenea humeante.

- Nuestro eslogan será “...Al servicio del cliente”

\subsection{Estrategia de Plaza}

Según Lidia Arbaiza, 2015, Como elaborar un Plan de Negocios -

"Para definir la estrategia de plaza, de distribución o de lugar se 
evaluará cada una de las posibilidades de colocación considerando las características del producto y el nivel de exposición requerido, el perfil de los clientes y distribuidores y los recursos económicos de la empresa. En este sentido el giro del nuestro negocio es un restaurante, la distribución del producto final se llevará a cabo en un local comercial fijo y de forma inmediata para cada uno de nuestros clientes.

Nuestra empresa de Servicios "LIKE HOME - Restaurante, tiene como objetivo principal ofrecer una alimentación con insumos saludables y tendencia orgánica a los ejecutivos del Centro Financiero Empresarial, en una ubicación fija, por ello se ha definido la ubicación en el distrito de San Isidro.

Cuadro $\mathrm{N}^{\circ} 3$ 1:

Información del distrito de San Isidro

\begin{tabular}{l|l|}
\hline \multicolumn{2}{c}{ INFORMACIÓN GENERAL DE SAN ISIDRO } \\
\hline Extensión & $9.78 \mathrm{Km} 2$ ó 978.47 Hectáreas; / 805 Manzanas \\
\hline Población según Censo 2007 & 58,056 habitantes (25,184 hombres y 32,872 mujeres \\
\hline Densidad & 5,936 habitantes/Km2 \\
\hline Norma de creación & Decreto Ley No 7113 \\
\hline Fecha de creación & 24 de abril de 1931 \\
\hline Altura (m.s.n.m) & 109 metros (Base: Parque el Olivar) \\
\hline Límites del distrito & $\begin{array}{l}\text { Oeste: Magdalena del Mar y el Océano Pacífico } \\
\text { Norte: Jesús María, Lince y La Victoria } \\
\text { Este: San Borja } \\
\text { Sur: Miraflores y Surquillo }\end{array}$ \\
\hline Zonificación por Juntas Vecinales & 5 sectores urbanos; 24 subsectores \\
\hline
\end{tabular}

FUENTE: Elaboración propia. 
Imagen $\mathrm{N}^{\mathrm{o}} 3$ 2:

Panorama de local - Restaurant en San Isidro Centro Financiero Empresarial

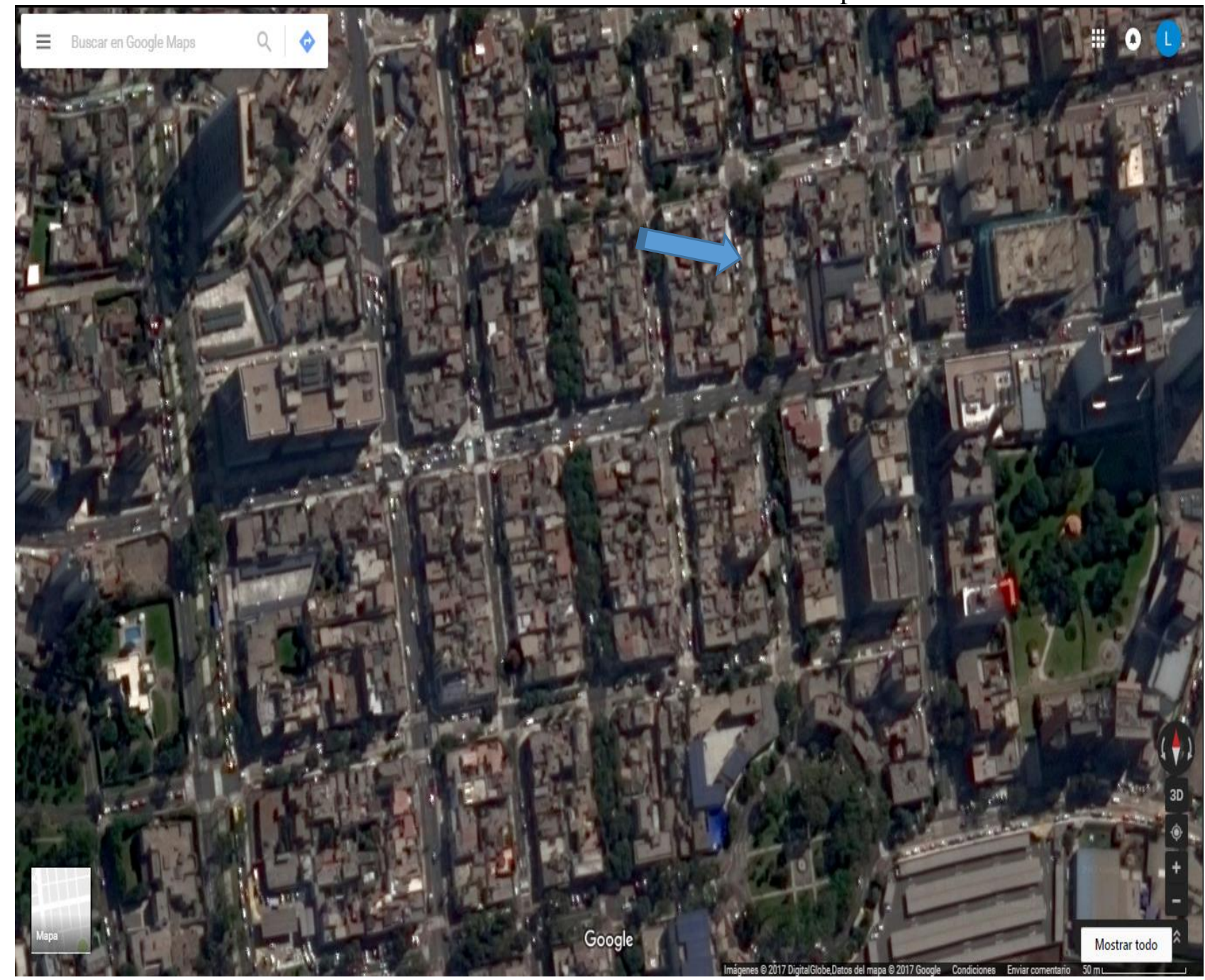

Fuente: Elaboración propia

\subsubsection{Determinación de la capacitad operativa.}

Para poder asegurar la atención de la demanda proyectada en donde nos proponemos atender en promedio 100 personas diarias, se ha considerado tomar como base dos indicadores, el primero es la capacidad de aforo del local y el segundo es las afluencia de clientes que puede tener el negocio siendo nuestro referente el mercado objetivo proyectado en nuestro plan de negocios, tanto en horas de mayor o menor afluencia, para ello se ha tomado como referencia la cantidad de mesas y sillas que tiene el negocio. 
Cuadro No 3 2:

Determinación de la capacidad operativa

\begin{tabular}{|c|c|c|c|}
\hline $\mathbf{N}^{\circ}$ MESAS & MODELO & MEDIDAS & PERSONAS \\
\hline 12 & Mesa 2 personas & $90 \mathrm{~cm} \mathrm{x} 90 \mathrm{~cm}$. & 24 \\
\hline 14 & Mesa 4 personas & $1.10 \mathrm{~cm} \times 1.110 \mathrm{~cm}$. & 56 \\
\hline \multicolumn{3}{|c|}{ CAPACIDAD DE PERSONAS EN SIMULTANEO } & $\overline{80}$ \\
\hline \multicolumn{3}{|c|}{ HORARIO DE ATENCIÓN } & HORAS \\
\hline \multicolumn{2}{|c|}{ Lunes a Viernes } & 11:00 am hasta 19:00 pm & 8 \\
\hline \multicolumn{2}{|l|}{ Sábado } & 12:00 pm hasta 17:00 pm & 5 \\
\hline \multicolumn{3}{|c|}{ HORA PUNTA DE MAYOR AFLUENCIA DE CLIENTES } & HORAS \\
\hline \multicolumn{2}{|r|}{ 01:00 pm a 15:00 } & & 2 \\
\hline \multicolumn{4}{|c|}{ HORA DE MENOR AFLUENCIA DE CLIENTES } \\
\hline \multirow[t]{3}{*}{ Hora : } & 12:00 am hasta 01 & & 1 \\
\hline & 15:00 pm hasta 19 & & $\underline{4}$ \\
\hline & TOTAL & & $\overline{5}$ \\
\hline \multicolumn{4}{|c|}{ CAPACIDAD MAXIMA DE ATENCIÓN POR DIA } \\
\hline \multicolumn{3}{|c|}{ MAYOR AFLUENCIA de personas por día } & 160 \\
\hline \multicolumn{3}{|c|}{ MENOR AFLUENCIA de personas por día } & $\underline{400}$ \\
\hline \multicolumn{3}{|c|}{ TOTAL } & $\overline{560}$ \\
\hline \multicolumn{3}{|c|}{ FACTOR DE AJUSTE } & PERSONAS \\
\hline \multicolumn{3}{|c|}{ El factor de ajuste se va a dar al $20 \%$ debido a que } & 112 \\
\hline \multicolumn{4}{|c|}{ en una mesa de 2 o de 4 se ubique solo una persona. } \\
\hline \multicolumn{4}{|c|}{ CAPACIDAD MAXIMA INSTALADA PARA ATENDER DURANTE EL AÑOS } \\
\hline \multicolumn{4}{|c|}{ Promedio de atencion duante los 25 dias del mes en } \\
\hline \multicolumn{4}{|c|}{ un periodo de 12 meses del año. } \\
\hline Personas & Días & Meses & Personas \\
\hline 112 & 25 & 12 & 33,600 \\
\hline
\end{tabular}

Fuente: Elaboración propia.

\subsection{Estrategia de Precio.}

Según Fred R. David, 2008, en su libro Conceptos de Administración Estratégica, indica que son cinco grupos de interés en un negocio afectan las decisiones sobre la fijación de precios: consumidores, gobierno, proveedores, distribuidores y competidores, en nuestro caso para la fijación de precio afectara la decisión de los proveedores por ser el grupo que nos proporcionan los producto e insumos de calidad a diferencia de nuestros competidores, por ello utilizaremos la estrategia de penetración de mercado, donde se comenzara con un precio por debajo de la competencia directa de mercado con la finalidad de ganar volumen de ventas. 
Una vez que se cuente con una base de clientes leales, se incrementara los precios introduciendo nuevos productos con nuevas opciones y presentaciones, manteniendo los estándares de calidad de los insumos.

Durante la fase de introducción al mercado, se ofrecerá durante los 3 primeros meses $20 \%$ de descuento sobre el precio de lista y los siguientes 3 meses $10 \%$ de descuento sobre el precio de lista.

Para realizar el cobro de los servicios de alimentación vamos a contar con los POS de visa, MasterCard y American Express y débito que brindan seguridad y tranquilidad a los clientes que no dispongan el efectivo al momento del pago.

De manera referencial para determinar el precio de nuestro producto es tener conocimiento de los precios de nuestra competencia que se muestra a continuación.

Cuadro No 3 3:

Cuadro comparativo de precios promedio de Menú

\begin{tabular}{llcc}
\multicolumn{1}{c}{ EMPRESA } & \multicolumn{1}{c}{ TIPO DE } & \multicolumn{2}{c}{ Precio promedio en Nuevos soles } \\
& & & MENÚ \\
\cline { 3 - 4 } & & A la carta & 25.00 \\
\hline QUINOA RESTAURANT & A la carta & 20.00 & 75.00 \\
\hline LA BALANZA & A la carta & 35.00 & 40.00 \\
\hline MARAS RESTAURANT & Menú & 38.00 & 200.00 \\
\hline AGUAYMANTO & A la carta & 29.00 & 38.00 \\
\hline LA LOCANDA & A la carta & 7.00 & 22.00 \\
\hline GREEN IS BETTER & &
\end{tabular}

Fuente: Elaboración Propia

\subsection{Promoción.}

Como estrategia de promoción se implantará algunas ofertas como:

- Al ser conscientes que a las personas les encanta subir fotos de todo tipo a las redes sociales, se va a crear un aplicativo propio de la 
empresa para que lo hagan, para ello vamos a realizar algo simple dándoles un premio y/o beneficio, cada foto que suban tendrá una serie de puntos que se podrá canjear con los productos que ofrece LIKE HOME - Restaurant.

- Generación de la cuenta Vip a través del portal web el cliente se encontrará informado de la acumulación de puntos que le permitirá obtener algunos beneficios extras como, descuentos en sus pedidos, y regalos suvenires de oficina. El registro de los puntos acumulados se realizará en el sistema al momento de cancelar el consumo, se generará una cuenta del cliente y cargara automáticamente sus puntos por los consumos realizados, enviando a su correo personal ingresado los puntos que ha acumulado.

\subsection{Publicidad}

Es importante plantear los siguientes objetivos para desarrollar estrategias de publicidad:

- Lograr que nuestro público objetivo tenga conocimiento de nuestro negocio.

- Después de haber logrado el objetivo anterior, es importante que a la gente le agrade el producto que ofrecemos, y lograr su fidelización.

Las estrategias aplicadas para conseguir los objetivos planteados son:

- Tarjetas de visita: estas tarjetas servirán para presentarnos a los clientes cuando se efectúen la visita personalizada mostrará 
información mínima como nombre del contacto, teléfono fijo y móvil, página web y correo electrónico.

- Coordinar con las empresas del Centro Financiero, convenios de alimentación a través de promociones y beneficios para el personal de la empresa.

- Entrega de folletos: En los que se especifique la carta semanal de los productos que ofrecemos, de la misma forma mostrará información mínima como nombre del contacto, teléfono fijo y móvil, página web y correo electrónico.

- Página Web y Aplicativos Smart Phone: En la que los clientes podrán encontrar de forma detallada los servicios que ofrecemos, las promociones y la carta con sus correspondientes precios.

- Crear cuentas en redes sociales: Tales como Facebook y Twitter, vamos a darnos a conocer mediante este sistema creando eventos en los que se invite a un gran número de personas y se les informe de las promociones y servicios que ofrecemos.

- La estrategia de marketing en redes sociales, por ser abiertas, masivas y directas se va a determinar qué tipo de seguidores o fans tenemos y dividirlos o segmentarlos de acuerdo a algunos parámetros específicos relacionados con nuestras necesidades y sobre todo con las de nuestro público objetivo.

Para ello se contará con un especialista en marketing digital quien desarrollará las características y necesidades comunes de nuestras redes sociales como: Edad, sexo, ubicación geográfica, estudios, nivel 
socioeconómico, intereses, hábitos, hobbies, lugares de trabajo, estado civil, ocupación, ingresos, entre otros. Acciones y canales para nuestro restaurant en las redes sociales.

\section{FACEBOOK 33\%}

- Fotos de los platos.

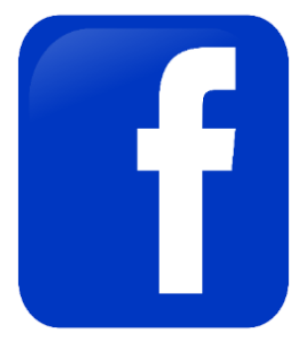

- Fotos de las instalaciones.

- Promociones y concursos

- Publicar entre 1- 4 al día

- Geolocalizar la Audiencia

- Horario de publicaciones cerca de las comidas.

- Anécdotas del Restaurant.

\section{Instagram $33 \%$}

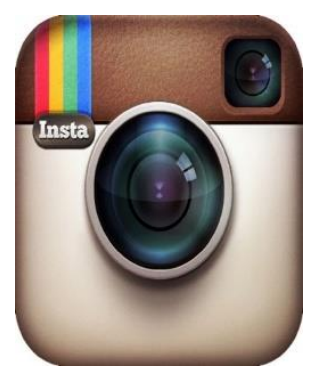

- Fotos comidas e instalaciones.

- Fotos cocina y personal.

- Utilizará los Hashtags para tendencias, localización, promociones o temas.

- Concursos de fotografías.

\section{$\underline{\text { Twitter 34\% }}$}

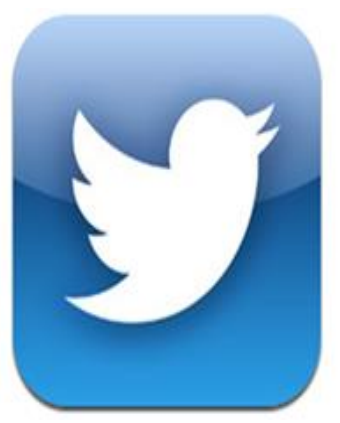

- Fotos y link de los platos del día.

- Descuentos para grupos.

- Disponibilidad de mesas y horario.

- Utilizar los hashtags.

- Publicaciones entre 5 y 10 veces al día.

- Geolocalizar la audiencia. 
- Horario de publicaciones cerca de las comidas.

\subsection{Personas}

Esta variable es la base fundamental de nuestro plan de marketing ya que construye la relación directa en la cual interactuamos con nuestros clientes, teniendo como objetivos buscar la retención y fidelización del cliente, percibiendo una experiencia extraordinaria desde el momento en que ingresa a nuestro local, con la finalidad de posicionar nuestro de servicios de "Estar al servicios del cliente", para ello se va a seguir una procedimiento de Atención al Cliente por nuestros colaboradores ya que son ellos los que van a estar en contacto directo con ellos, como:

- Saludos al momento de ingreso y salida de los clientes

- $\quad$ Speech de recepción de llamadas.

- $\quad$ Procedimientos de toma de los pedidos.

- $\quad$ Speech de respuestas en diversas situaciones.

- Manejo de calificaciones de atención al cliente.

Para la debida aplicación de los procedimientos se realizará mensualmente una capacitación al personal y los incentivos a los que se desarrollaron y destacaron en sus actividades.

\subsection{Procesos.}

Nuestro plan de negocios para el restaurant va a desarrollar procesos sistematizados que van a ser controlados por la parte administrativa, de acuerdo a los procedimientos y flujogramas desarrollados en el punto 4.3. Procesos Productivos, con la finalidad de buscar 
homogenizar los procesos que conllevan la atención de los clientes desde su ingreso hasta su salida del restaurante, cuyo objetivo final es evita la migración de los clientes.

Una de las principales acciones de esta estrategia es el desarrollo del seguimiento post venta y automatización, buscando la retención del cliente y el posicionamiento en la mente del consumidor.

\subsection{Evidencia Física}

El objetivo de nuestro negocio va a estar centrado en posicionarnos en la mente del nuestro consumidor, generando fidelización y retención del cliente para ello nuestro colaborador marcaran a través de estrategias de posicionamiento del producto como:

Parafraseo de la Marca

Speech de Alimentación Saludable de nuestros alimentos.

Speech de Insumos Saludables y orgánicos.

Información Nutricional de nuestros especialistas.

Nuestros Manteles y servilletas llevaran el logo de la empresa, así como los uniformes de los mozos, recepcionistas y cajeros.

Se reforzarán las promociones informadas en nuestra estrategia de productos.

\subsection{Proyección de Ventas.}

\subsubsection{Proyección de ventas propuestas}

La proyección de ventas se ha desarrollado teniendo como referencia la evolución del mercado objetivo por años según el cuadro $\mathrm{N}^{\mathrm{o}} 2.7$, según el sondeo de frecuencia se considera un consumo semanal de 
$24.5 \%$ acuden a un restaurante entre 2 y 3 veces a la semana, (cuadro

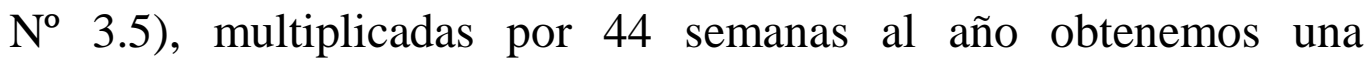
proyección de ventas por año, en resumen, se va a obtener la cantidad de platos de entrada, platos de fondo y refresco como se muestra en el cuadro $\mathrm{N}^{\circ} 3.6$ del cuadro.

Cuadro $\mathrm{N}^{\circ} 3$ 4:

Determinación de la proyección de ventas

\begin{tabular}{|c|c|c|c|c|c|c|c|c|c|}
\hline \multirow{3}{*}{ AÑ̃ } & \multirow{3}{*}{$\begin{array}{l}\text { Mercado } \\
\text { Potencial }\end{array}$} & Mercado & Mercado & Mercado & \multirow{3}{*}{$\begin{array}{c}\text { Frecuencia } \\
\text { de } \\
\text { almuerzo }\end{array}$} & \multirow{3}{*}{$\begin{array}{c}\text { Semanas } \\
\text { efectivas } \\
\text { al año }\end{array}$} & \multirow{3}{*}{$\begin{array}{c}\text { Proyección } \\
\text { ventas } \\
\text { anuales } \\
\text { cant. }\end{array}$} & \multirow{3}{*}{ Precio } & \multirow{3}{*}{$\begin{array}{l}\text { Proyección de } \\
\text { ventas en soles } \\
\text { anuales }\end{array}$} \\
\hline & & Disponible & Efectivo & Objetivo & & & & & \\
\hline & & $54 \%$ & $50 \%$ & $42.25 \%$ & & & & & \\
\hline Año 1 & 28,620 & 15,455 & 7,727 & 3,265 & $24.50 \%$ & 44 & 35,197 & $\mathrm{~S} / 25.00$ & $\mathrm{~S} / 879,917.50$ \\
\hline Año 2 & 29,479 & 15,918 & 7,959 & 3,363 & $24.50 \%$ & 44 & 36,253 & S/ 26.00 & S/ 942,581.64 \\
\hline Año 3 & 30,363 & 16,396 & 8,198 & 3,464 & $24.50 \%$ & 44 & 37,342 & S/ 28.00 & S/ 1,045,573.76 \\
\hline Año 4 & 31,274 & 16,888 & 8,444 & 3,568 & $24.50 \%$ & 44 & 38,463 & S/ 29.00 & S/ $1,115,428.16$ \\
\hline Año 5 & 32,212 & 17,395 & 8,697 & 3,675 & $24.50 \%$ & 44 & 39,617 & S/ 30.00 & S/ $1,188,495.00$ \\
\hline
\end{tabular}

Tomando como base los datos analizados, se ha considerado tomar como proyección de ventas el $24.5 \%$ de nuestro mercado objetivo y considera anualmente 44 semanas efectivas obteniendo una proyección anual de 35,197 menús al precio de S/ 25.00 soles, de acuerdo a la investigación de nuestro estudio de mercado; obteniendo una proyección de ventas anuales de S/ 879,917.50 soles. Las ventas para los siguientes años se va a considerar los mismos supuestos, aplicándole un porcentaje de crecimiento del 3\% anual - Referencia crecimiento PBI.

\section{Cuadro No 35 :}

Proyección de venta propuesta por platos

\begin{tabular}{l|c|c|c|c|c|}
\hline \multicolumn{1}{c}{ PROPUESTA } & Año 1 & Año 2 & Año 3 & Año 4 & Año 5 \\
\hline Platos de Fondo & 35,197 & 36,253 & 37,342 & 38,740 & 39,617 \\
Entrada & 35,197 & 36,253 & 37,342 & 38,740 & 39,617 \\
Bebidas & 35,197 & 36,253 & 37,342 & 38,740 & 39,617 \\
PRODUCCIÓN ANUAL & & & & \\
PROMEDIO & $\mathbf{3 5 , 1 9 7}$ & $\mathbf{3 6 , 2 5 3}$ & $\mathbf{3 7 , 3 4 2}$ & $\mathbf{3 8 , 7 4 0}$ & $\mathbf{3 9 , 6 1 7}$ \\
\hline
\end{tabular}

FUENTE: Elaboración propia. 
Cuadro No 3 6:

Resumen de la proyección de venta propuesta en soles

\begin{tabular}{l|c|c|c|c|c|}
\hline $\begin{array}{l}\text { PRESUPUESTO } \\
\text { DE VENTAS }\end{array}$ & AÑO 1 & AÑO 2 & AÑO 3 & AÑO 4 & AÑO 5 \\
\hline Ventas Sin IGV & $\mathrm{S} / .721,532.35$ & $\mathrm{~S} / .772,916.94$ & $\mathrm{~S} / .857,370.48$ & $\mathrm{~S} / .914,651.09$ & $\mathrm{~S} / .974,565.90$ \\
IgV & $\mathrm{S} / .158,385.15$ & $\mathrm{~S} / .169,664.70$ & $\mathrm{~S} / .188,203.28$ & $\mathrm{~S} / .200,777.07$ & $\mathrm{~S} / .213,929.10$ \\
\hline $\begin{array}{l}\text { Ventas con IGV } \\
\text { Anuales }\end{array}$ & $\mathrm{S} / . \mathbf{8 7 9 , 9 1 7 . 5 0}$ & $\mathrm{S} / . \mathbf{9 4 2 , 5 8 1 . 6 4}$ & $\mathrm{S} / \mathbf{1 , 0 4 5 , 5 7 3 . 7 6}$ & $\mathrm{S} / . \mathbf{1 , 1 1 5 , 4 2 8 . 1 6}$ & $\mathrm{S} / . \mathbf{1 , 1 8 8 , 4 9 5 . 0 0}$ \\
\hline
\end{tabular}

FUENTE: Elaboración propia. 


\section{CAPítulo IV}

\section{PLAN DE OPERACIONES}

\subsection{Ubicación geográfica.}

El local se encuentra en una zona estratégica, de alta afluencia de clientes, ubicado en una esquina entre la cuadra 3 de la -avenida Luis Felipe Villarán y la cuadra 5 de la avenida Juan de Arona (Sector 4), en el distrito de San Isidro, con un área de $260 \mathrm{~m}^{2}$, a tres cuadras de los edificios de Telefónica del Perú, Pacifico Seguros y Banco de Crédito.

Figura $\mathrm{N}^{\mathrm{o}} 41$ :

Ubicación geográfica por sector según el distrito

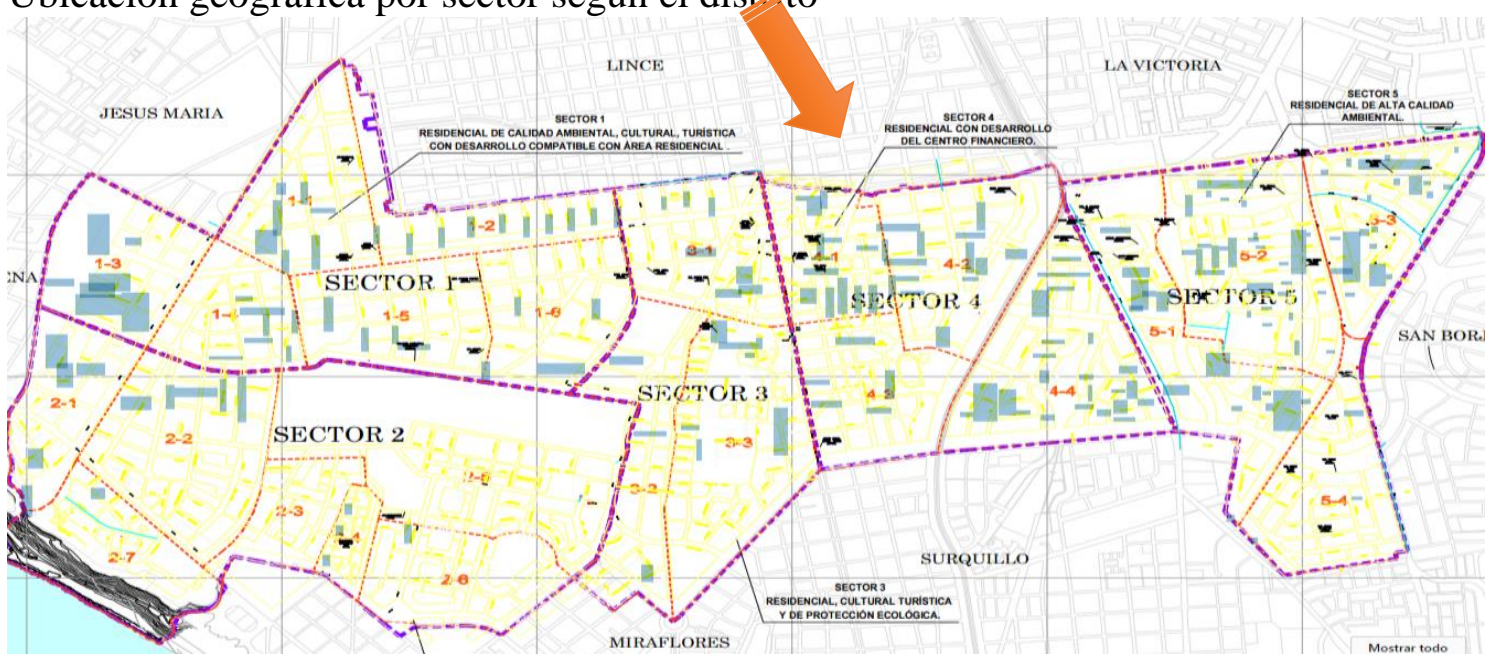

FUENTE: Elaboración propia.

En la siguiente figura se puede ver que el sector 4 se encuentra dividido en tres subsectores (4-1, 4-2 y 4-3), ubicándose nuestro negocio en el 4-1. 
Figura $\mathrm{N}^{\circ} 42$ :

Divisiones del sector según el distrito de San Isidro

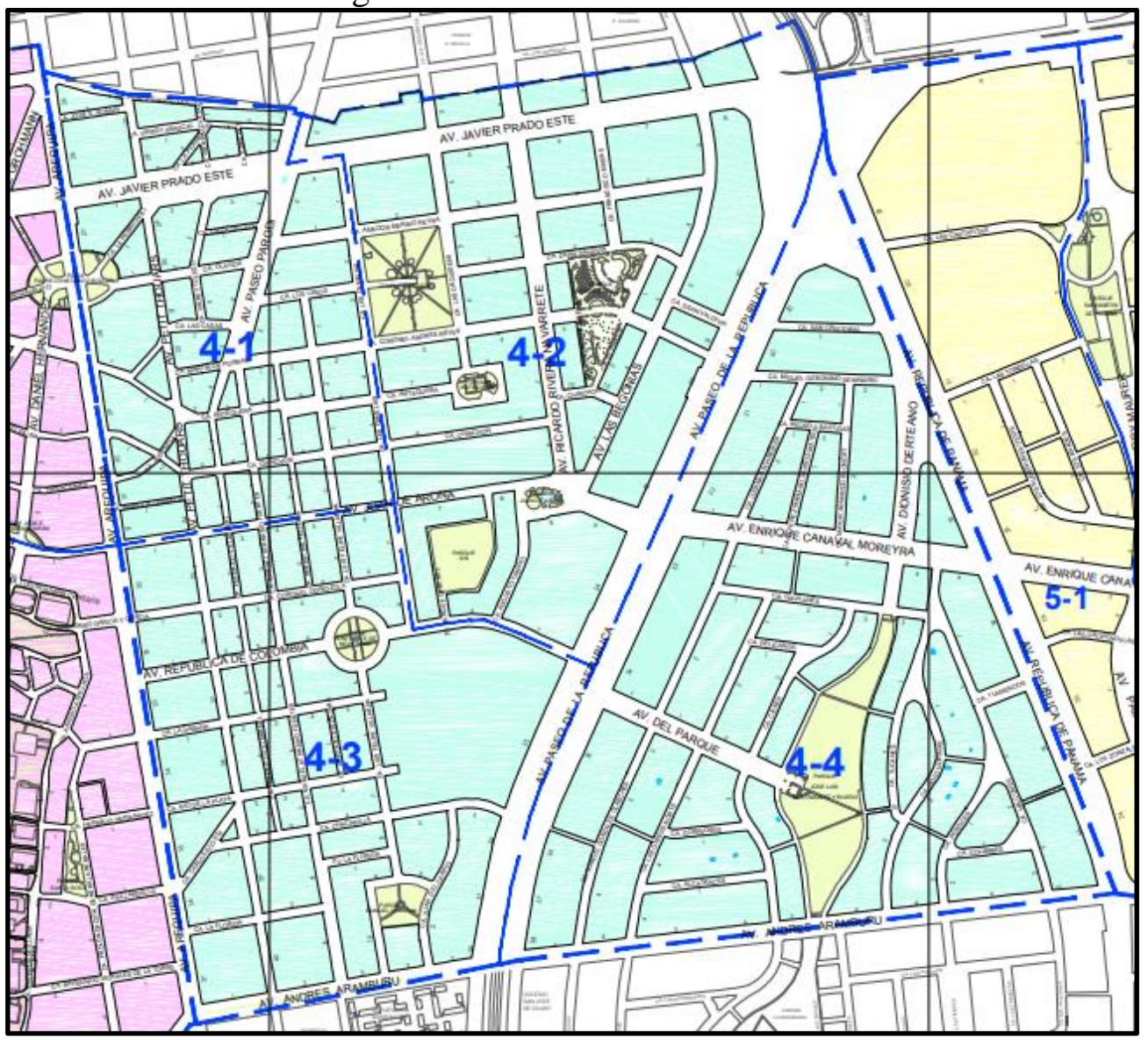

FUENTE: Elaboración propia.

Para poder elegir la mejor opción de ubicación geográfica se han tomado como referencias variables que nos brindaran la información necesaria que determino la localización final.

\section{- Afluencia:}

Referido al alto transito afluencia de personas o cliente que circulan en un perímetro de la zona de influencia comercial.

\section{- Estacionamiento:}

Nuestros clientes potenciales se ubican en el NSE A, y B, una de las características es el uso de sus vehículos particulares para movilizarse, 
siendo indispensable la consideración de un estacionamiento para la elección final al momento de elegir.

\section{- Tamaño y capacidad del local:}

Siendo uno de nuestros objetivos brindar una experiencia agradable a los clientes, se ha considerado mantener un tamaño adecuado desde la entrada hasta la última mesa.

La capacidad de personas que en simultáneo será de 64 distribuidos de la siguiente manera:

14 mesas, cada mesa tendrá capacidad para 4 personas.

10 mesas, cada mesa tendrá capacidad para 2 personas.

2 sillones, cada sillón tendrá capacidad para 2 personas.

Se está considerando que la permanencia del cliente en el restaurant será de una hora aproximadamente y las horas punta de alta afluencia se encontrará entre las 12:00 pm y las 15:00 pm.

\section{- Horario de Atención:}

El horario de atención al público durante el día será de lunes a viernes de 10:00 am a 19:00 pm. Este horario se determinó de acuerdo a los resultados de la investigación de mercado como las encuestas y considerando que en el entorno comercial del mismo rubro se maneja el mismo horario de cierre.

\section{- Seguridad:}

El local brindara una seguridad completa tanto interna como externa. A nivel interno se contará con las medidas necesarias ante cualquier 
tipo de desastres naturales y otros. A nivel externo se contará con un personal de seguridad que se ubicará en las afueras del local.

\section{- Acceso a Proveedores:}

Para la atención de los proveedores se tendrá un horario definido de 6:00 am hasta las 10:00 am y de 16:00 pm hasta las 18:00 pm un lugar determinado solo proveedores ubicado en la parte posterior del local sin interferir ni obstaculizar cualquier proceso de atención al cliente y del personal de servicio.

\section{- Costo de Alquiler:}

El costo del alquiler es de S/. 11,000 mensuales, siendo un precio promedio de mercado que se bienes manejando con los demás bienes inmuebles aledaños.

Figura $\mathrm{N}^{\circ} 43$ :

Ubicación del local comercial - Restaurant

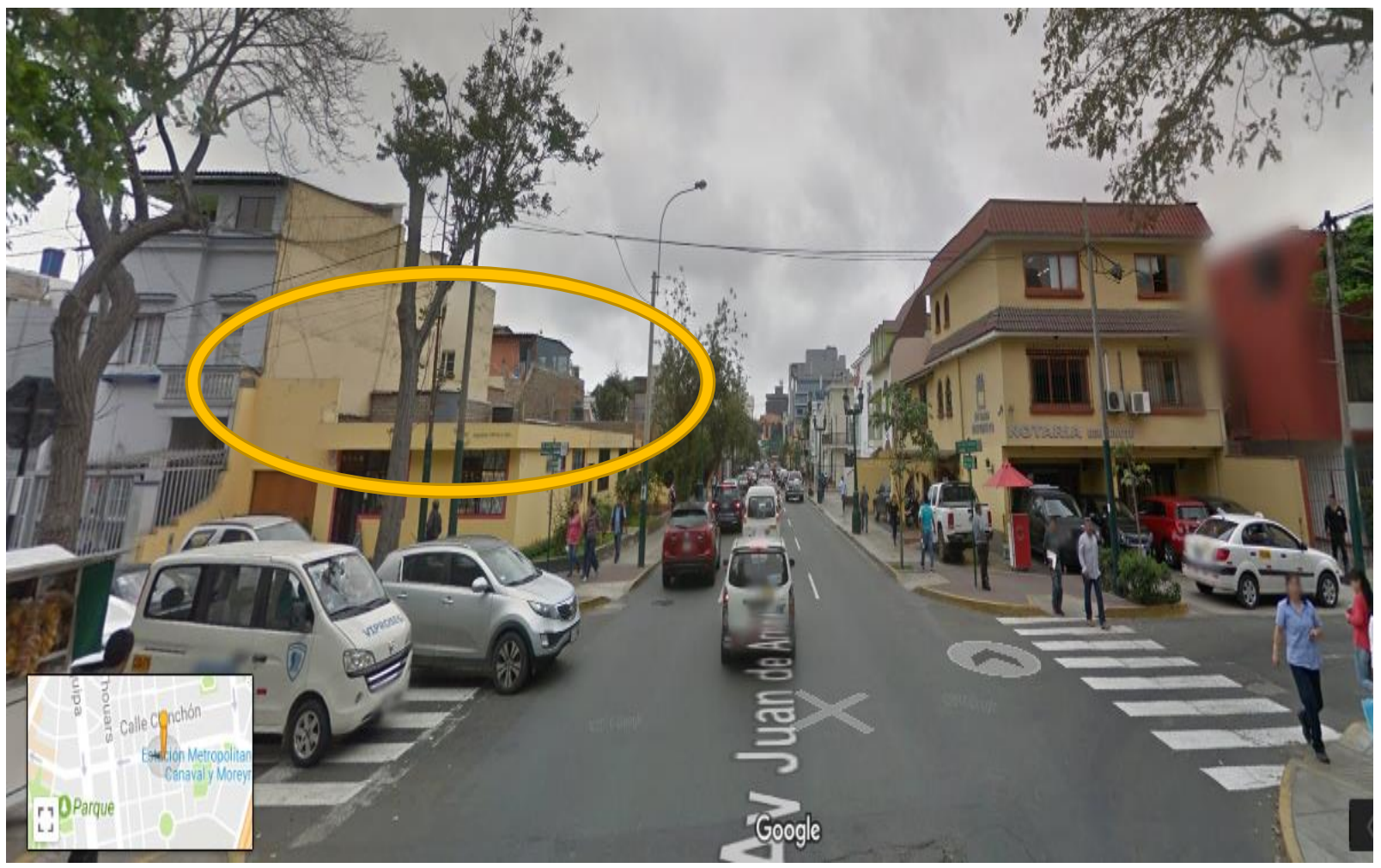

Fuente: Elaboración propia 


\subsection{Infraestructura.}

\subsubsection{Diseño y composición de interiores.}

Para la infraestructura del restaurant se está considerando una construcción que permita tener una rápida y correcta secuencia de operaciones entre los mozos y la cocina para la elaboración de los pedidos. La distribución de los ambientes como el área de recepción, el salón comedor, la cocina, el almacén, los servicios higiénicos, debe evitar la contaminación de los alimentos, donde dentro de cada ambiente no debe haber objetos ajenos al mismo.

El objetivo de este análisis es asegurar la higiene de los equipos, de las instalaciones, de las materias primas, insumos entre otros, con la finalidad de facilitar las labores del personal para poder lograr un trabajo eficaz y eficiente con la optimización de los recurso y prevención de accidentes en el trabajo.

\section{- Pisos.}

Los pisos deben ser lisos e impermeables a la humedad y su acabado deberá tener uniones y hendiduras que no permitan la acumulación de suciedad, polvo o tierra. Además, deben contar con sumideros y rejillas, para facilitar su higienización.

\section{- Paredes.}

Las paredes deberán ser lisas y con acabado de superficie continua e impermeable de color claro y fáciles de limpiar y desinfectar. 


\section{- Techos.}

Los techos deben ser lisos sin grietas, de color claro e impermeable para impedir la condensación, así evitar el desarrollo de bacterias y hongos.

\section{- Ventanas.}

Las ventanas deben tener vidrio en buen estado y estar provistas de mallas contra insectos, roedores y aves.

\section{- Puertas.}

Las puertas deben ser lisas, fáciles de limpiar y desinfectar. Contará con un sistema de cierre automático que impida la manipulación de perilla y/o manija. La distancia entre el piso y la puerta no debe exceder de $1 \mathrm{~cm}$.

\section{- Iluminación.}

La iluminación será fundamental en todo el local para los clientes y el personal que labora, ayudara a un mejor rendimiento de este durante la ejecución de las operaciones de preparación, de los alimentos. También garantiza la correcta limpieza de las instalaciones, para comprobar la calidad y el buen estado de los alimentos, y evitar accidentes por contrastes luminosos.

\section{- Ventilación.}

Se contará con un sistema de ventilación que ayudara a eliminar el vapor, el humo y las gotas de aceite para prevenir condensaciones, 
olores, manchas y formación de altas temperaturas y humedades en el local, así como para controlar la entrada de aire fresco, para asegurar la buena distribución del aire limpio y evitar las corrientes de aire contaminado, que pueden llegar a ser causa de incomodidad para el personal. La ventilación será mecánica para asegurar el movimiento del aire y la evacuación de impurezas.

Para ellos se utilizará extractores de aire (como campanas) que estarán situadas sobre los aparatos de cocción y deben sobresalir 15 cm. más allá de la zona de cocción, y la zona de entrada del vapor debe tener un filtro de grasa. La entrada de aire será distribuida por un ventilador central y un sistema de conductos que desembocan en las zonas escogidas de trabajo.

\subsubsection{Disposición de áreas.}

\section{Áreas de Producción.}

El área de producción se va a encontrar definido como el lugar donde se elaboran los alimentos y bebidas solicitado por los clientes, la cual va a estar conformado por:

\section{- La cocina}

Es el área donde se elaboran y procesan los alimentos y se e encuentra ubicada cerca a los salones con la finalidad de dar facilidad en la entrega de los pedidos y cerca al almacén para facilitar el acceso a los insumos y materias primas.

La cocina se encuentra separada en dos secciones según las funciones específicas de los cocineros y sus ayudantes, como son: 
Cocina alimentos fríos: Lugar donde se preparan las entradas, ensaladas, todo tipo de alimentos que no necesiten ser cocinados.

Cocina alimentos calientes: Lugar donde se preparan los alimentos que necesitan ser cocinados a altas temperaturas.

\section{- Almacén}

Es el área de almacén siempre se encontrará ubicado cerca de la cocina, dependiendo de las características de los insumos o materias primas se encontrará clasifica en tres áreas como son:

Almacén de fríos: Lugar donde se almacena los productos perecibles y alimentos que necesiten refrigeración para mantener la calidad de su contenido.

Almacén general: Lugar donde se guarda todas las materias primas que no necesiten refrigeración, son clasificados de acuerdo a su fecha de vencimiento y tipo de producto.

Lavado y limpieza: Primera etapa del ingreso de los insumos y materia prima para su almacenamiento. Se encontrará con el equipo adecuado para el lavado y desinfección.

\section{- Área de Atención y Servicio.}

Esta área se encuentra definido por tres zonas importantes cuya finalidad va a ser el servicio al cliente consistente en:

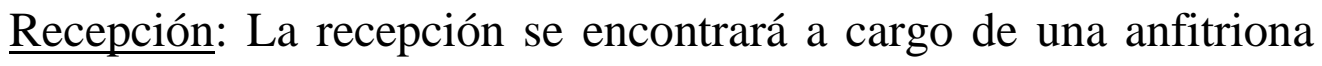
quien estará ubicada en la puerta de ingreso del restaurante. 
Salón de atención: Es el área donde se ubica a los clientes para su respectiva atención, estará asignado a los clientes que asistan al restaurante de una a dos personas.

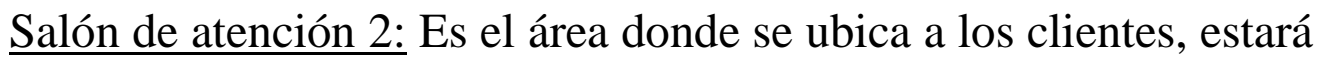
asignado a los clientes que asistan en grupos de 3 a más personas.

\section{- Instalaciones Sanitarias.}

El establecimiento contara con servicios sanitarios diferenciados para hombres y mujeres. El baño de damas contará con dos lavatorios y dos inodoros uno destinado a los discapacitados, el baño para caballeros estará compuesto por un lavatorio, un urinario y un inodoro acondicionado para discapacitados la cual se encontrarán debidamente señalizados, en buen estado de conservación e higiene, equipados con material fácil de limpiar y desinfectar.

\section{- Vigilancia y seguridad.}

La seguridad del local será muy importante, se contará con un personal durante todo el tiempo que se encuentre funcionando, además se realizará una instalación de 6 cámaras de video vigilancia, dos cámaras externas y tres cámaras dentro del local, monitoreadas por el área administrativa.

\subsubsection{Capacidad instalada de atención a los clientes.}

La determinación de la capacidad máxima instalada para atender a los clientes en nuestro local se ha desarrollado en base a la infraestructura y cantidad de muebles máximos a ser colocados en el área. 
En el siguiente cuadro vamos a determinar cuánto es el promedio de atención a clientes de acuerdo a nuestra infraestructura y capacidad instalada teniendo como base la cantidad de mesas y área del local comercial.

Cuadro $\mathrm{N}^{\circ} 41$ :

Determinación de la capacidad de aforo de clientes

\begin{tabular}{|c|c|c|c|c|c|}
\hline \multicolumn{6}{|l|}{$\begin{array}{l}\text { COMPARACIÓN DE SOLO AMBIEN } \\
\text { PRINCIPALES AMBIENTES DE } \\
\text { RESTAURANTE } \\
\text { NORMA: RNE A.070 COMERCIO ART. }\end{array}$} \\
\hline \multicolumn{5}{|c|}{ AMBIENTES POSIBLES } & \multirow{7}{*}{\begin{tabular}{|l} 
considerar la \\
mayor cantidad \\
\\
\\
zona de juegos \\
son usados por \\
los mismos \\
usuarios \\
SIN PERSONAL \\
QUE \\
PERMANECE \\
TRABAJAN EN
\end{tabular}} \\
\hline PISO - AMBIENTES Y OTROS & M2/UND & INDICE & CANT. & PARCIAL & \\
\hline $\begin{array}{l}\text { COMEDOR por } \mathrm{m} 2 \\
\text { POR MOBILIARIOS } \\
\text { COCINA (por m2 } \\
\text { o por cantidad de trabajador) } \\
\text { PERS. SERVICIOS, MOZOS } \\
\text { CAJA }\end{array}$ & $\begin{array}{c}130 \\
0 \\
40 \\
0 \\
4 \\
2\end{array}$ & $\begin{array}{c}\text { 1.5M2/PERS } \\
1 \text { SILLA/PERS } \\
10.0 \mathrm{M} 2 / \text { PERS } \\
1 \text { TRABJ/PERS } \\
1 \text { TRABJ/PERS } \\
1 \text { TRABJ/PERS }\end{array}$ & $\begin{array}{c}87 \\
0 \\
4 \\
0 \\
4 \\
2\end{array}$ & 97 & \\
\hline $\begin{array}{l}\text { BARRA CON BANCAS } \\
\text { BARMAN } \\
\text { ZONA P/CONSUMO EXTERNO } \\
\text { EXPENDIDOR DE COMIDA }\end{array}$ & $\begin{array}{l}0 \\
0\end{array}$ & $\begin{array}{l}1 \text { BANCA/PERS } \\
\text { 1TRABJ/PERS } \\
1 \text { 1TRABJ/PERS }\end{array}$ & $\begin{array}{l}0 \\
0 \\
0\end{array}$ & \multirow[b]{2}{*}{4} & \\
\hline $\begin{array}{l}\text { ZONA DE RECREO - SALA DE ESPERA } \\
\text { OFICINA } \\
\text { DEPÓSITOS-ALMACENES }\end{array}$ & $\begin{array}{c}0 \\
20\end{array}$ & $\begin{array}{l}4 \mathrm{M} 2 / \mathrm{PERS} \\
9.5 \mathrm{M} 2 / \mathrm{PERS} \\
40 \mathrm{M} 2 / \mathrm{PERS} \\
\end{array}$ & $\begin{array}{l}3 \\
0 \\
1\end{array}$ & & \\
\hline & & & AFORO & 100 & \\
\hline \multicolumn{5}{|c|}{$\begin{array}{l}\text { NOTA 1: REALIZADO POR PISO O NIVEL } \\
\text { NOTA 2: CONSIDERAR AFORO EN CASO DE AMBIENTES QUE SE ATIENDE A EXTERNOS QUE NO TRABAJAN EN } \\
\text { LA EDIFICACIÓN } \\
\text { NOTA 3: PARA MOBILIARIO SE DEBE CUMPLIR CON LOS ANCHOS PARA CIRCULACIÓN }(1 \\
\text { CRUJIA, 2 CRUJIAS) } \\
\text { NOTA 4: CONSIDERAR VISITANTE A OFICINA SOLO SI NO ES UN TRABAJADOR DE } \\
\text { LA EDIFICACIÓN } \\
\text { NOTA 5: REDONDEAR LAS CANTIDADES } \\
\text { AL ENTERO MAYOR } \\
\text { ASUARIOS, } \quad \text { AFORO CERO CUANDO ES UTILIZADO POR LOS MISMOS } \\
\text { USUARIOS } \\
\text { NOTA 7: CONSIDERAR EL MÁXIMO AFORO PARA EL AFORO TOTAL } \\
\text { PERMITIDO }\end{array}$} & \\
\hline
\end{tabular}

FUENTE: Elaboración Propia. 
Figura $N^{\circ} 4$ :

Distribución del Restaurant

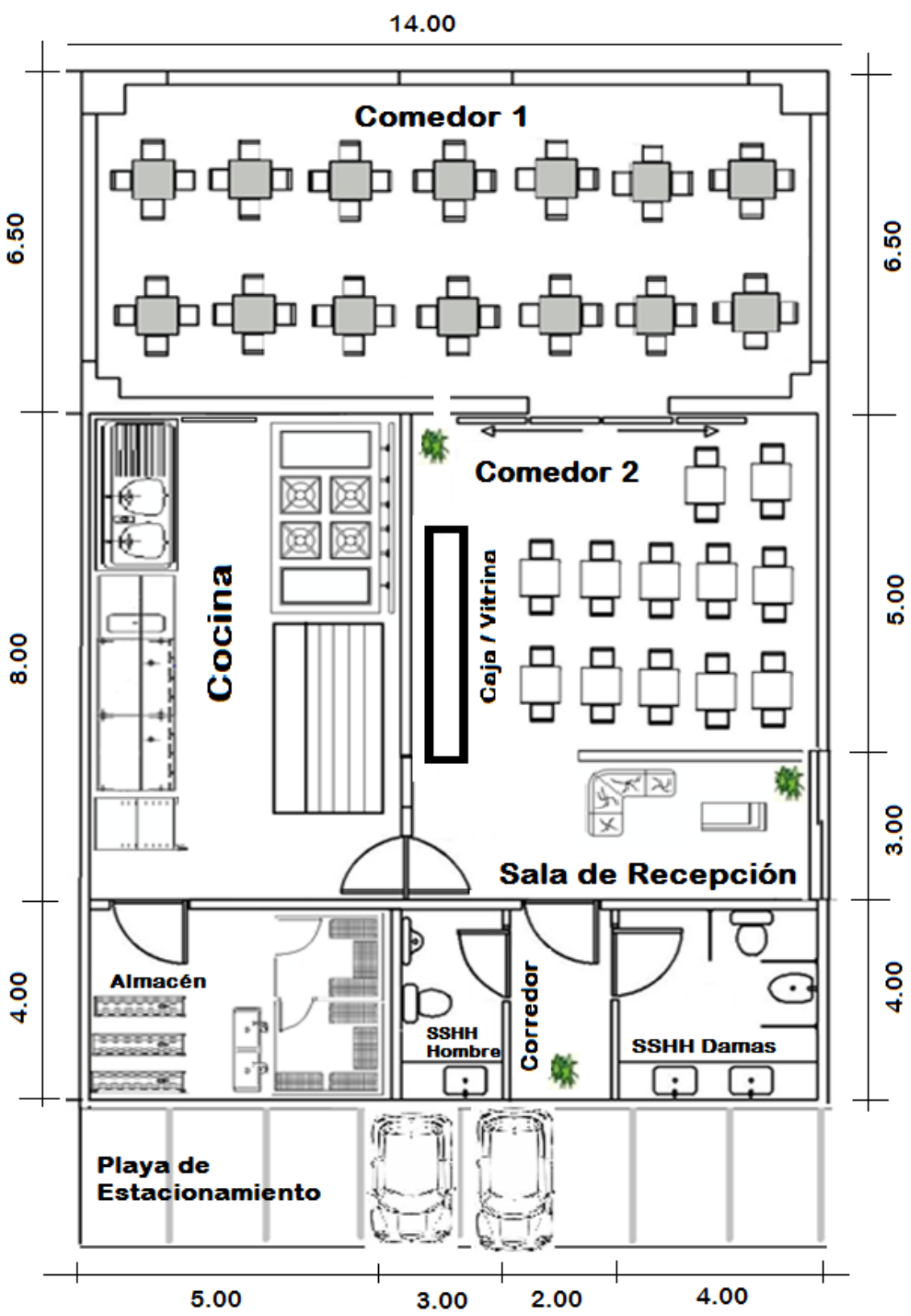

Elaboración Propia

\subsection{Proceso Productivo.}

Para iniciar el proceso productivo, es necesario seguir las siguientes etapas y diagramas de flujos correspondientes.

\subsubsection{Proceso de compras de insumos y materias primas.}

Todo proceso se encontrará implementado bajo un sistema de control de inventarios, la cual permitirá el control adecuado del 
almacén, el ingreso de los insumos y materias primas será registrado al momento, así como las salidas diarias de ello.

El administrador junto al chef, planifican la compra de materia prima e insumos de acuerdo al informe diario de los saldos de almacén, así poder atender a los pedidos del día.

Las compras de los insumos y materias primas se van a realizar a proveedores que hayan demostrado la calidad y frescura de sus productos, buenos precios y tiempo de entrega.

En el caso de proveedores de insumos tendencia orgánica se manejará una lista de proveedores certificados permitiendo el manejo adecuado del control de calidad de los insumos,

Figura $\mathrm{N}^{\circ} 4$ :

Flujograma de atención a proveedores

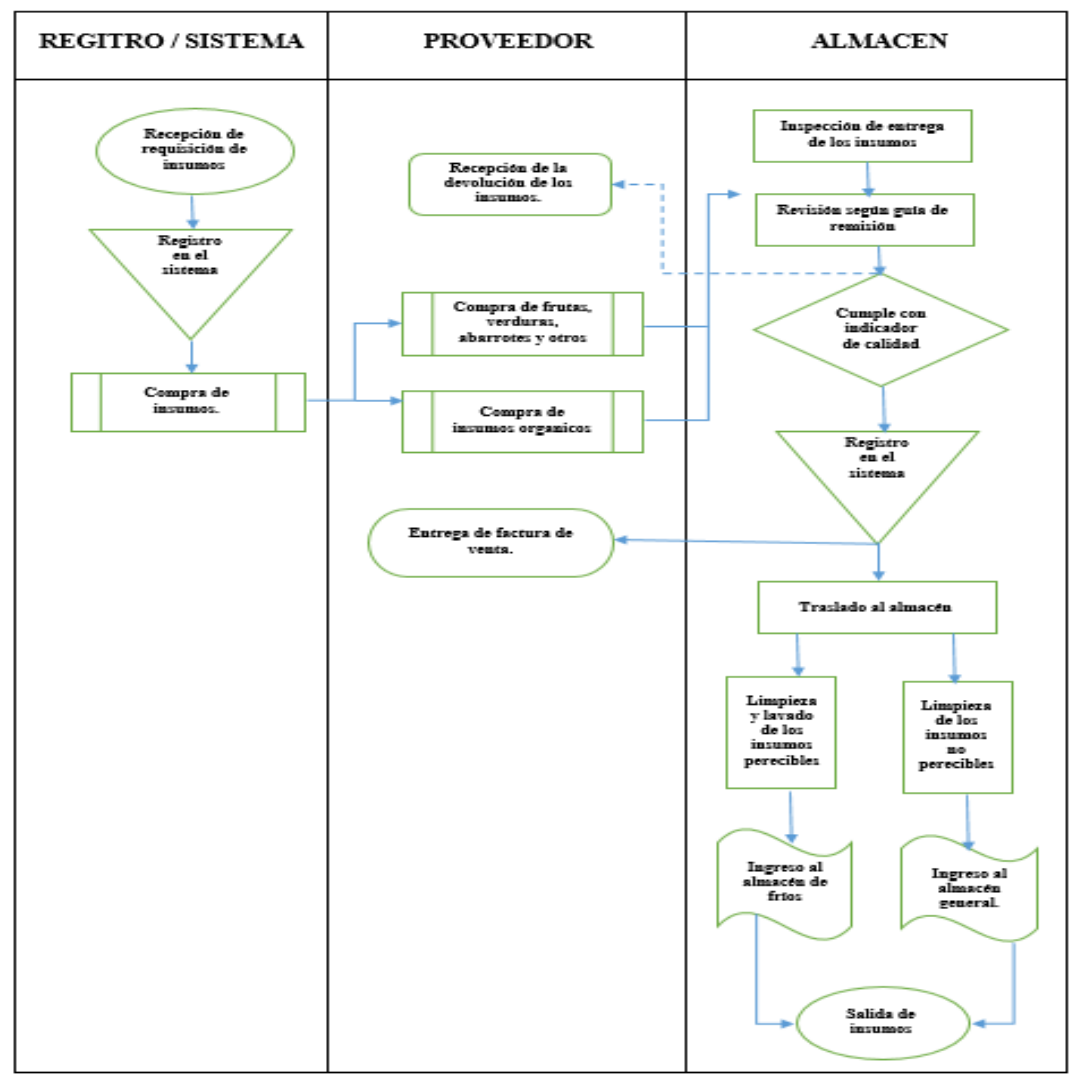

Elaboración: Propia. 
En el caso de los demás insumos y materias primas (Frutas y Verduras) se realizará compras inter diarias hacia los mercados mayoristas.

Cuando exista alguna compra de producto o pedido de última hora, la compra se efectuará en el supermercado más cercano, para ello se dispondrá un fondo de caja chica.

Las verduras, hortalizas, etc., se almacenarán en equipos de refrigeración para ello se guardarán en bolsas plásticas especiales para ser sellados al vacío. Generalmente serán adquiridos para uso del día.

Las carnes tendrán similar tratamiento y serán dispuestas en porciones para facilitar la preparación.

Los abarrotes se comprarán semanalmente y se guardarán en un almacén.

El horario de recepción a proveedores de los insumos y materia prima se efectuará a partir de las 7:00 am hasta las 10:00 am. Todos los insumos, abarrotes y materias primas pasaran por un proceso de limpieza previa.

\subsubsection{Proceso de Producción de Alimentos.}

La jornada diaria del proceso de producción de los alimentos se realizará en el área de la cocina, antes de la preparación de los alimentos se realizará una limpieza previa, para luego proceder a organizar cada puesto de trabajo y repartición de funciones como la 
preparación previa de los platillos que resulten más elaborados, para de esta manera ahorrar el tiempo en su preparación.

Una vez que el pedido ha sido registrado a través de dispositivo IPad por los meseros, automáticamente se genera una alerta en el sistema indicando el pedido realizado por la mesa, se procede a elevar las indicaciones para su preparación, una vez lista se envía una alerta al dispositivo IPad del mesero indicando que el pedido se encuentra terminado. El mesero se acerca inmediatamente al área de entrega y lleva el pedido al cliente para su consumo. 
Figura $N^{\circ} 46$ :

Diagrama de Flujo del área de la cocina

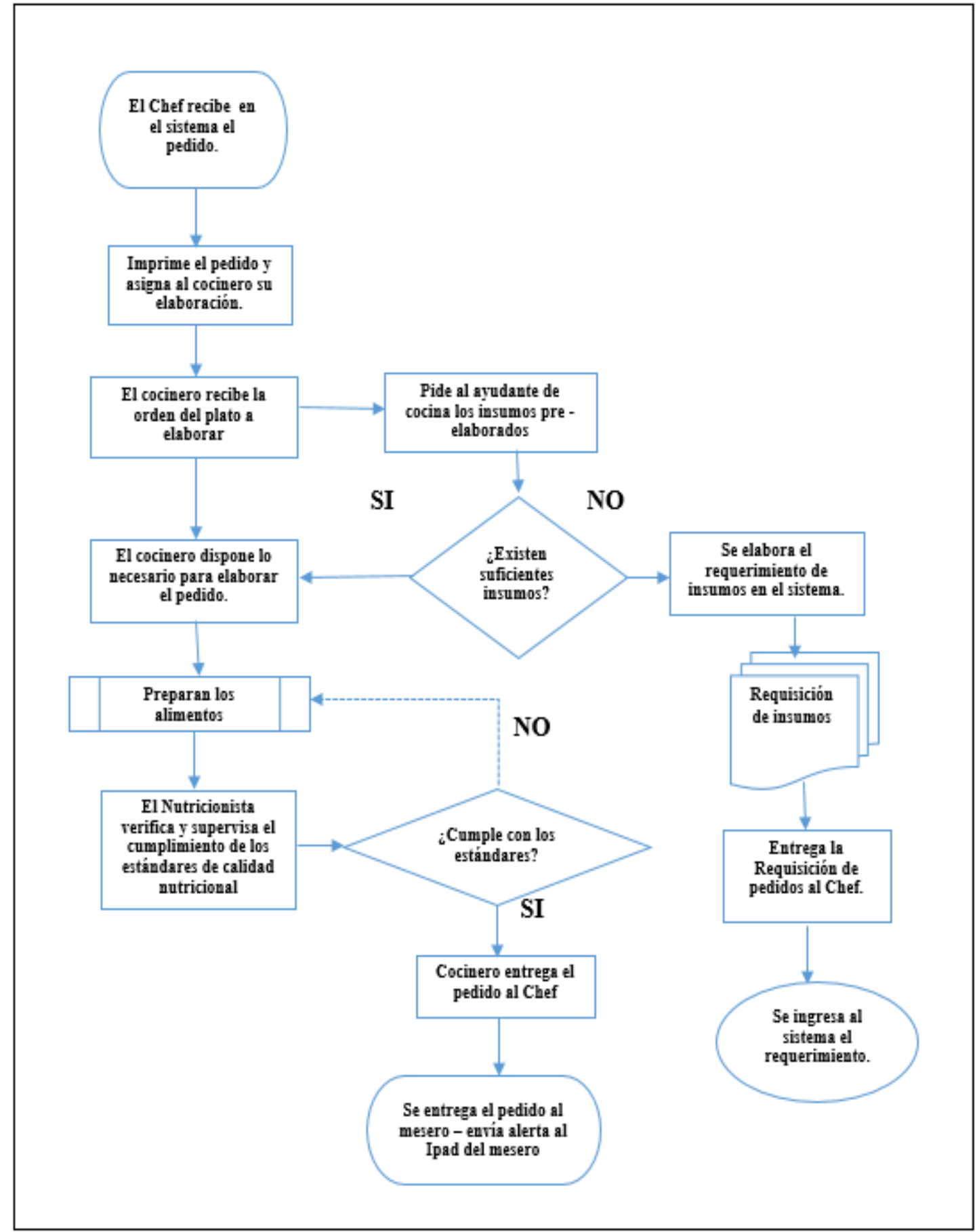

FUENTE: Elaboración Propia. 
Figura $N^{\circ} 47$ :

Diagrama de Flujo de Atención al Cliente

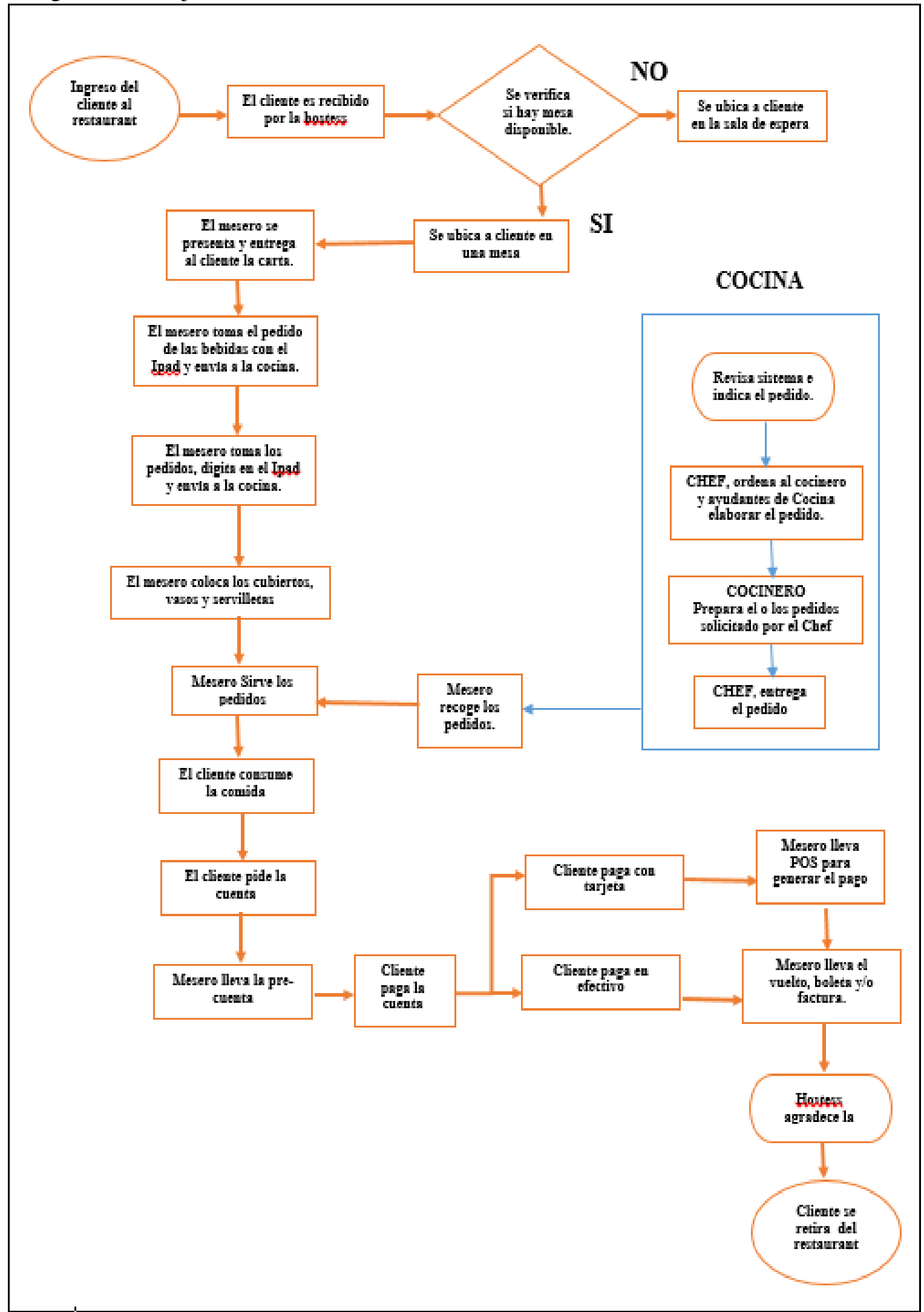

FUENTE: Elaboración propia. 


\subsubsection{Proveedores.}

Nuestra política con los proveedores dentro de la forma de entrega y pago de mercaderías e insumos recibidos es de la fecha de recepción de los productos se procederá con el sello de verificación y el pago se concretará a 30 días calendarios. Los días de recepción son únicamente los lunes, miércoles y viernes en los horarios de 6:00 am hasta las 10:00 am y de 16:00 pm hasta las 18:00 pm. Coordinados previamente con el área de almacén.

Siendo uno de nuestros principales características diferenciadas en el mercado la de ofrecer una alternativa de alimentación con insumos saludables y tendencia orgánica, la selección de proveedores dentro de nuestro directorio se ha realizado manteniendo criterios de precios, garantía de la calidad de los productos, referencias de su trayectoria empresarial, referencias de instituciones públicas ligadas al rubro de los insumos, así como certificaciones que garantizan a los insumos tendencia orgánica emitidas por la instituciones correspondientes como SENASA, Autoridad Nacional encargada de la fiscalización de la producción orgánica nacional.

A continuación, se presentan el directorio de proveedores con las cuales va a trabajar el restaurant.

Cuadro $\mathrm{N}^{\circ} 42$ :

Listado de proveedores de insumos orgánicos

\section{PROVEEDORES DE INSUMOS ECOLOGICOS}

ASOCIACIÓN DE PRODUCTORES ECOLÓGICOS VALLE DE

SANTA CRUZ

Contacto: Edgardo Cáceres

Productos: Cítricos,

BIO AGRICULTURA CASA BLANCA

Contacto: Carmen Felipe-Morales / Ulises Moreno

Productos: Lúcuma y sus derivados 
BIO ANDEN

Contacto: Efraín Valdivia

Productos: Banano, manzana

BIORGANIKA SAC

Contacto: Jack García-Barandiarán

Productos: Banano

CHACRA SANA

Contacto: Andrés Castro Koechlin

Productos: Banano, Uva de mesa y sus derivados

COLCA SA

Contacto: Rodolfo Muñante

Productos: Palta

\section{GRUPO ECOLÓGICA PERÚ}

Contacto: Laureano Casas Ticliayauri

Productos: Durazno, mango, aguaymanto, lúcuma, manzana, uva, palta, fresa, limón, granadilla

Productos: Coliflor, col, choclo, cebolla, tomate, pepinillo, alcachofa, pimiento, zanahoria, lechuga, espinaca

\section{INMOLAG}

Contacto: José Vico

Productos: Aceitunas y sus derivados

\section{INSTITUTO HUAYUNA}

Contacto: José Luis Bazo

Productos: Hortalizas

\section{LUZ ALFA EIRL}

Contacto: Héctor Jiménez

Productos: Hortalizas

\section{PERUVIAN NATURE S\&S SAC}

Contacto: Damián Silva

Productos: Ají y sus derivados

\section{AGROINDUSTRIAS FLORIS SAC}

Contacto: Rosa Ucañá

Productos: Lechuga, yuca, zanahoria, cebolla, ajos, alfalfa, espinaca y sus derivados

ASOCIACIÓN DE PRODUCTORES ECOLÓGICOS DE LA CUENCA DEL RÍO TURÍN MONTICIELO

Contacto: Elizabeth Hidalgo

Productos: Arveja, cebolla, habas, tomate, tubérculos, choclo

FUNDO SAMACA

Contacto: Magnolia Espinar

Productos: Arveja, papa, zapallo 
Contacto: María Teresa Uranga

Productos: Acelga, albahaca, berros, zanahoria, lechuga, perejil, culantro,

apio, espinaca, nabo, cebolla, rabanito, poro

GRANOS ORGÁNICOS NACIONALES SA - GRONSA

Contacto: Magdalena Diez Canseco

Productos: Ajonjolí, kiwicha, quinua y sus derivados

\section{GRANJA ECOLÓGICA EL PARAÍSO}

Contacto: Pedro Vargas Ortega

Productos: Huevos, carne de cabrito, codorniz, conejo cuy, gallina, pato, pavo, pollo, derivados lácteos

FUENTE: Elaboración Propia.

\subsubsection{Ambiente Físico y Presentación del Restaurant.}

Decoración: El local contara con una decoración moderna enfocada a un estilo mediterráneo, basada en la premisa de la iluminación natural, fundamental para lograr un ambiente alegre, cálido, que transmita sensaciones relacionadas con las vacaciones y el tiempo libre, donde predominen los colores blancos, ocre, aguamarina y el verde oliva. En general premie una decoración sin complicaciones y con referencia a la naturaleza.

Música: La música es un elemento de mucha importancia para nuestro sector, clave para influir en la experiencia de los comensales de manera positiva desde su ingreso, estadía y salida del local. El tipo de música seleccionada se encontrará como las clásicas fusionadas con electrónicas al estilo bossa nova.

Uniformes: Todo el personal contara con uniformes de acuerdo al área que le corresponde desarrollar sus actividades debiendo estar siempre limpias y bien planchadas, se contara con un uniforme de estilo elegante, con botones del cuello y mangas, cinturón, el 
calzado debe encontrarse bien lustrados, para las damas usara un tacón de goma. El vestuario buscará vender la marca del restaurant contando para ello el logo de nuestra marca en el uniforme, siendo esta una herramienta importante para posicionar nuestra marca con el cliente y a la vez será muy cómoda para el desarrollo de las actividades del personal.

Decoración: El local contara con una decoración moderna enfocada a un estilo mediterráneo, basada en la premisa de la iluminación natural, fundamental para lograr un ambiente alegre, cálido, que transmita sensaciones relacionadas con las vacaciones y el tiempo libre, donde predominen los colores blancos, ocre, aguamarina y el verde oliva. En general premie una decoración sin complicaciones y con referencia a la naturaleza.

Música: La música es un elemento de mucha importancia para nuestro sector, clave para influir en la experiencia de los comensales de manera positiva desde su ingreso, estadía y salida del local. El tipo de música seleccionada se encontrará como las clásicas fusionadas con electrónicas al estilo bossa nova.

Uniformes: Todo el personal contara con uniformes de acuerdo al área que le corresponde desarrollar sus actividades debiendo estar siempre limpias y bien planchadas, se contara con un uniforme de estilo elegante, con botones del cuello y mangas, cinturón, el calzado debe encontrarse bien lustrados, para las damas usara un tacón de goma. El vestuario buscará vender la marca del restaurant contando para ello el logo de nuestra marca en el uniforme, siendo esta una herramienta importante para posicionar nuestra marca con 
el cliente y a la vez será muy cómoda para el desarrollo de las actividades del personal.

\subsection{Regulaciones de Licencias y Políticas}

\subsubsection{Constitución de la empresa.}

El restaurant operara bajo la personería jurídica como Sociedad Anónima Cerrada de acuerdo a la Ley General de Sociedades, estará conformada por dos socios donde cada uno realizara una aportación de capital de S/139,103 el valor de cada acción estará valorada en S/69.55, iniciando las actividades con un total de 2000 acciones.

$\begin{array}{ll}\text { Razón Social: } & \text { Like Home Restaurant SAC } \\ \text { Marca: } & \text { Like Home } \\ \text { RUC: } & 20000000000 . \\ \text { Dirección: } & \text { Juan de Arona 542 - San Isidro. } \\ \text { Teléfono: } & 400-0000 \\ \text { Correo Electrónico: } & \text { Reservas@ Likehome.restaurant.com } \\ \text { Página Web: } & \text { www.likehomerestaurant.com.pe }\end{array}$

El proceso para la constitución de una empresa jurídica involucra la ejecución de los siguientes pasos:

\section{1) Elaboración de la minuta de constitución.}

En este documento se detalla el tipo de modalidad empresarial la cual se ha decidido constituir, los datos de los socios/accionistas de la misma, los estatutos (los que plantean 
las pautas direccionales, así como sanciones, responsabilidades, cargos direccionales, etc.).

\section{Requisitos:}

- La reserva del nombre en la Sunarp.

- Búsqueda de los índices

Se puede verificar si ya existe el nombre que planea colocar a su empresa en el directorio nacional de personas jurídicas de la SUNARP . Derecho de trámite S/.4.00.

- Solicitar la Reserva del Nombre de la persona jurídica a constituir, luego de solicitar la inscripción del nombre de la empresa, debo esperar aproximadamente un día para que me entreguen la reserva de nombre. Esto significa que el índice de denominación se bloquea por treinta (30) días naturales y nadie puede tomar dentro de ese plazo tal nombre. También puedo realizar esta reserva en línea a través de la página WEB de la SUNARP, aquí ingresa toda la información e imprime el formulario con el cual se acerca a la SUNARP y cancela 18.00 Nuevos Soles.

- Documentos Personales.

- Descripción de la Actividad Económica.

- Capital de la Empresa.

\section{2) Escritura Pública.}

Requisitos para que el notario pueda elevar la escritura pública: 
- Minuta de constitución de la empresa/acto constitutivo (Incluyendo una copia simple).

- Pago de los derechos notariales

- Si el trámite se realiza de manera particular, el monto a pagar será la tarifa establecida por el Notario.

\section{3) Inscripción en los Registros Públicos.}

Una vez que obtenga mi escritura pública de constitución, el notario o el titular o los socios tendrán que realizar la inscripción de la empresa en la Oficina Registral competente en el Registro de Personas Jurídicas de la SUNARP. El pago por derechos registrales es de $1.08 \%$ UIT por derechos de calificación y 3/1000 del capital por derechos de inscripción.

\section{4) Tramitar el Registro Único de Contribuyente (Ruc).}

Para tramitar el Registro Único de Contribuyente se realiza en las oficinas de la SUNAT, donde se va a elegir el régimen tributario y solicitar autorización para la impresión de comprobante de pago.

\section{5) Inscribir a los Trabajadores en EsSalud.}

Se registra a la empresa mediante el programa de declaración telemática - PDT, o el formulario $\mathrm{N}^{\circ}$ 402. La afiliación de los trabajadores se realiza a través del Programa de Declaración Telemática - PDT Formulario Virtual $\mathrm{N}^{\circ} 601$ Planilla Electrónica. 


\section{6) Solicitar Permiso, autorización o registro especial.}

Se solicitará permiso y/o registros al Ministerio de Comercio Exterior y Turismo - MINCETUR y a la Dirección General de Salud Ambiental - DIGESA, según el rubro de servicios de restaurante, donde permitan certificar que se cumpla con las normas de salud y pueda operar el negocio garantizando sobre todo no poner en riesgo la salud humana.

\section{7) Obtener la Autorización del Libro de Planillas}

Se deberá registrar las planillas de pago de los trabajadores. Las planillas de pago son un registro contable que brindan elementos que permiten demostrar, de manera transparente, ante la autoridad competente, la relación laboral del trabajador con la empresa, su remuneración y los demás beneficios que se le pagan

\section{8) Legalizar los libros contables.}

La legalización es la constancia, puesta por un notario, en la primera hoja útil del libro contable. Si uso registros por medio computarizado, esta constancia debe estar en la primera hoja suelta

\section{9) Tramitar la licencia municipal.}

El trámite de Licencia Municipal de Funcionamiento se realiza en la Municipalidad de San Isidro, el trámite de la licencia toma como máximo quince (15) días hábiles, sujeto a silencio administrativo positivo. 


\subsection{Costos de producción.}

Para determinar los costos de producción del restaurante se ha tomado en cuenta tres importantes grupos que son lo siguiente:

- Mano de Obra

- Materia Prima o Insumos

- Gastos Administrativos

- Gastos de Ventas

- Gastos Operacionales.

\section{1) Mano de Obra.}

En este grupo se va a encontrar 2 categorías bien definidas como son:

- Mano de Obra Directa: Conformada por todas las personas que se encuentran directamente vinculadas al proceso productivo de los alimentos como son; el chef, el cocinero principal, el ayudante de cocina, y el nutricionista.

- Mano de Obra Indirecta: Conformado por los costos de mano de obra generada por los meseros, anfitriona, vigilante, caja y limpieza del restaurante, los gastos administrativos, son los costos generado por el área administrativa como son el gerente general, el jefe del área de ventas y marketing y el jefe del área de contabilidad y finanzas. 


\section{2) Materia Prima.}

Uno de los factores fundamentales en un buen restaurante es la calidad de la materia prima por ello se va a considerar no abaratar los costos a todos los insumos que van a usarse al momento de elaborar los alimentos, como son los insumos naturales y orgánicos suministrados por nuestros principales proveedores. 
Cuadro $N^{\circ} 43$ :

Costos de Producción - Mano de Obra

\begin{tabular}{|l|c|r|r|r|r|r|r|r|r|}
\hline \multicolumn{1}{|c|}{ TOTAL MANO DE OBRA } & Cantidad & Sueldo & Mensual & $\begin{array}{c}\text { Periodo } \\
\text { Meses }\end{array}$ & Sub total & $\begin{array}{c}\text { Gratificación } \\
\text { anual }\end{array}$ & CTS & Essalud & TOTAL \\
\hline Mano de Obra Directa & 4 & $5,550.00$ & $5,550.00$ & 12 & $66,600.00$ & $11,100.00$ & $6,475.00$ & $5,994.00$ & $90,169.00$ \\
\hline Mano de Obra Indirecta & 8 & $11,950.00$ & $13,850.00$ & 12 & $166,200.00$ & $27,700.00$ & $14,258.33$ & $14,958.00$ & $223,116.33$ \\
\hline TOTAL & & $\mathbf{1 7 , 5 0 0 . 0 0}$ & $\mathbf{1 9 , 4 0 0 . 0 0}$ & $\mathbf{1 2}$ & $\mathbf{2 3 2 , 8 0 0 . 0 0}$ & $\mathbf{3 8 , 8 0 0 . 0 0}$ & $\mathbf{2 0 , 7 3 3 . 3 3}$ & $\mathbf{2 0 , 9 5 2 . 0 0}$ & $\mathbf{3 1 3 , 2 8 5 . 3 3}$ \\
\hline
\end{tabular}

\begin{tabular}{|l|l|c|r|r|r|r|r|r|r|r|}
\hline \multicolumn{1}{|c|}{ Personal } & MANO DE OBRA DIRECTA & Cantidad & \multicolumn{1}{c|}{ Sueldo } & Mensual & $\begin{array}{c}\text { Periodo } \\
\text { Meses }\end{array}$ & \multicolumn{1}{c|}{ Sub total } & $\begin{array}{c}\text { Gratificación } \\
\text { anual }\end{array}$ & \multicolumn{1}{c|}{ CTS } & \multicolumn{1}{c|}{ Essalud } & \multicolumn{1}{c|}{ TOTAL } \\
\hline Chef & Mano de Obra Directa & 1 & $2,000.00$ & $2,000.00$ & 12 & $24,000.00$ & $4,000.00$ & $2,333.33$ & $2,160.00$ & $32,493.33$ \\
\hline Cocinero & Mano de Obra Directa & 1 & $1,500.00$ & $1,500.00$ & 12 & $18,000.00$ & $3,000.00$ & $1,750.00$ & $1,620.00$ & $24,370.00$ \\
\hline Ayudante de cocina & Mano de Obra Directa & 1 & 850.00 & 850.00 & 12 & $10,200.00$ & $1,700.00$ & 991.67 & 918.00 & $13,809.67$ \\
\hline Nutricionista & Mano de Obra Directa & 1 & $1,200.00$ & $1,200.00$ & 12 & $14,400.00$ & $2,400.00$ & $1,400.00$ & $1,296.00$ & $19,496.00$ \\
\hline & TOTAL & $\mathbf{4}$ & & $\mathbf{5 , 5 5 0 . 0 0}$ & $\mathbf{1 2}$ & $\mathbf{6 6 , 6 0 0 . 0 0}$ & $\mathbf{1 1 , 1 0 0 . 0 0}$ & $\mathbf{6 , 4 7 5 . 0 0}$ & $\mathbf{5 , 9 9 4 . 0 0}$ & $\mathbf{9 0 , 1 6 9 . 0 0}$ \\
\cline { 2 - 9 }
\end{tabular}

\begin{tabular}{|c|c|c|c|c|c|c|c|c|c|c|}
\hline Personal & $\begin{array}{l}\text { MANO DE OBRA } \\
\text { INDIRECTA }\end{array}$ & Cantidad & Sueldo & Mensual & $\begin{array}{l}\text { Periodo } \\
\text { Meses }\end{array}$ & Sub total & $\begin{array}{c}\text { Gratificación } \\
\text { anual }\end{array}$ & CTS & Essalud & TOTAL \\
\hline Mesero & Mano de Obra Indirecta & 3 & 950.00 & $2,850.00$ & 12 & $34,200.00$ & $5,700.00$ & $1,425.00$ & $3,078.00$ & $44,403.00$ \\
\hline Anfitriona & Mano de Obra Indirecta & 1 & 800.00 & 800.00 & 12 & $9,600.00$ & $1,600.00$ & 933.33 & 864.00 & $12,997.33$ \\
\hline Vigilante & Mano de Obra Indirecta & 1 & 950.00 & 950.00 & 12 & $11,400.00$ & $1,900.00$ & $1,108.33$ & $1,026.00$ & $15,434.33$ \\
\hline Caja & Mano de Obra Indirecta & 1 & 900.00 & 900.00 & 12 & $10,800.00$ & $1,800.00$ & $1,050.00$ & 972.00 & $14,622.00$ \\
\hline Limpieza & Mano de Obra Indirecta & 1 & 850.00 & 850.00 & 12 & $10,200.00$ & $1,700.00$ & 991.67 & 918.00 & $13,809.67$ \\
\hline Gerente General & Administrativo & 1 & $3,500.00$ & $3,500.00$ & 12 & $42,000.00$ & $7,000.00$ & $4,083.33$ & $3,780.00$ & $56,863.33$ \\
\hline Ventas y Logistica & Administrativo & 1 & $2,000.00$ & $2,000.00$ & 12 & $24,000.00$ & $4,000.00$ & $2,333.33$ & $2,160.00$ & $32,493.33$ \\
\hline $\begin{array}{l}\text { Contabilidad y } \\
\text { finanzas }\end{array}$ & Administrativo & 1 & $2,000.00$ & $2,000.00$ & 12 & $24,000.00$ & $4,000.00$ & 2,333.33 & $2,160.00$ & $32,493.33$ \\
\hline & TOTAL & 10 & & $13,850.00$ & 12 & $166,200.00$ & $27,700.00$ & $14,258.33$ & $14,958.00$ & $223,116.33$ \\
\hline
\end{tabular}

FUENTE: Elaboración Propia 
Cuadro $\mathrm{N}^{\circ} 4$ 4:

Presupuesto de Materia Prima

\begin{tabular}{l|c|c|c|c|c|}
\hline $\begin{array}{l}\text { PRESUPUESTO DE } \\
\text { MATERIA PRIMA }\end{array}$ & AÑO 1 & AÑO 2 & AÑO 3 & AÑO 4 & AÑO 5 \\
\hline $\begin{array}{l}\text { Materia Prima - sin IGV } \\
\text { IGV }\end{array}$ & S/. 176,339.62 & S/. $181,632.51$ & S/. 187,087.43 & S/. 194,091.97 & S/. 198,483.34 \\
\hline $\begin{array}{l}\text { Materia Prima - Insumos } \\
\text { con IGV }\end{array}$ & S/. $/ .215,048.870 .55$ & S/.41,067.97 & S/. 42,605.55 & S/. 43,569.51 \\
\hline
\end{tabular}

Fuente: Elaboración propia.

\section{a. Gastos de Operacionales}

Dentro de fabricación vamos a encontrar todos los gastos que se van a realizar para poner a funcionar el negocio, dentro de este rubro se va a clasificar a los costos que van a estar directamente vinculado con la fabricación como son los gastos de producción, suministros diversos, y todos los gastos que se generen en el proceso productivo.

\section{b. Gastos Administrativos:}

En los Gastos Administrativos se considerado todos aquellos que intervienen directamente con la administración gerencial del negocio, en este caso se toma los gastos del personal administrativo del restaurante y otros como los alquileres, pago de arbitrios, servicios básicos (Agua, Luz, Teléfono).

\section{c. Gastos de Venta:}

En este punto se ha considerado los gastos asociados a la gestión comercial como descuentos, promociones, publicidad, aquellos directamente relacionados a las ventas. 


\begin{tabular}{|c|c|c|c|c|c|c|}
\hline $\begin{array}{c}\text { GASTOS } \\
\text { ADMINISTRATIVOS }\end{array}$ & PROVEEDOR & CANTIDAD & $\begin{array}{l}\text { COSTO } \\
\text { UNT. }\end{array}$ & $\begin{array}{c}\text { COSTO } \\
\text { ANUAL } \\
\text { CON IGV }\end{array}$ & $\begin{array}{l}\text { COSTO } \\
\text { TOTAL }\end{array}$ & \\
\hline $\begin{array}{l}\text { Alquiler Local } \\
\text { Comercial }\end{array}$ & $1 \mathrm{mes}$ & 1 & $11,000.00$ & $132,000.00$ & $132,000.00$ & \\
\hline Arbitrios Municipales & Municpalidad & 1 & 120.00 & $1,440.00$ & $1,440.00$ & \\
\hline Energía Eléctrica & $1 \mathrm{mes}$ & 1 & 300.00 & $3,600.00$ & $3,600.00$ & \\
\hline Agua & $1 \mathrm{mes}$ & 1 & 120.00 & $1,440.00$ & $1,440.00$ & \\
\hline \multirow[t]{2}{*}{$\begin{array}{l}\text { Teléfono + Internet + } \\
\text { cable }\end{array}$} & $1 \mathrm{mes}$ & 1 & 400.00 & $4,800.00$ & $4,800.00$ & \\
\hline & & & & $143,280.00$ & $143,280.00$ & \\
\hline $\begin{array}{c}\text { GASTOS } \\
\text { ADMINISTRATIVOS }\end{array}$ & PROVEEDOR & CANTIDAD & $\begin{array}{r}\text { COSTO } \\
\text { UNT. }\end{array}$ & $\begin{array}{l}\text { COSTO } \\
\text { CON IGV }\end{array}$ & $\begin{array}{l}\text { COSTO } \\
\text { SIN IGV }\end{array}$ & IGV \\
\hline Archivador & Tai Loy & 15 & 5.10 & 76.50 & 64.83 & 11.67 \\
\hline Clips caja x 500 & Tai Loy & 5 & 1.27 & 6.35 & 5.38 & 0.97 \\
\hline Papel Bond x 1000 & Tai Loy & 10 & 20.00 & 200.00 & 169.49 & 30.51 \\
\hline $\begin{array}{l}\text { Sobre Manila paq. } 20 \\
\text { und. }\end{array}$ & Tai Loy & 5 & 3.75 & 18.75 & 15.89 & 2.86 \\
\hline Cinta Adhesiva & Tai Loy & 10 & 1.69 & 16.90 & 14.32 & 2.58 \\
\hline Algodón & Farmaindustria & 10 & 2.70 & 27.00 & 22.88 & 4.12 \\
\hline Gasa & Farmaindustria & 5 & 1.00 & 5.00 & 4.24 & 0.76 \\
\hline Alcohol & Farmaindustria & 5 & 7.00 & 35.00 & 29.66 & 5.34 \\
\hline Bolígrafo & Tai Loy & 50 & 0.60 & 30.00 & 25.42 & 4.58 \\
\hline Corrector & Tai Loy & 20 & 1.88 & 37.60 & 31.86 & 5.74 \\
\hline Grapas & Tai Loy & 5 & 1.41 & 7.05 & 5.97 & 1.08 \\
\hline Block cuadriculado & Tai Loy & 5 & 2.20 & 11.00 & 9.32 & 1.68 \\
\hline Resaltador & Tai Loy & 5 & 1.30 & 6.50 & 5.51 & 0.99 \\
\hline Cartucho Tinta Negra & Tai Loy & 4 & 35.00 & 140.00 & 118.64 & 21.36 \\
\hline Cartucho Tinta Color & Tai Loy & 4 & 60.00 & 240.00 & 203.39 & 36.61 \\
\hline Borrador & Tai Loy & 5 & 2.00 & 10.00 & 8.47 & 1.53 \\
\hline Chaqueta de cocina & AROCA & 3 & 40.00 & 120.00 & 101.69 & 18.31 \\
\hline Delantal de cocina & AROCA & 3 & 30.00 & 90.00 & 76.27 & 13.73 \\
\hline $\begin{array}{l}\text { Pantalon tipo buzo } \\
\text { cocina }\end{array}$ & AROCA & 3 & 40.00 & 120.00 & 101.69 & 18.31 \\
\hline Gorro cocinero pirata & AROCA & 3 & 30.00 & 90.00 & 76.27 & 13.73 \\
\hline Camisa negra & AROCA & 3 & 40.00 & 120.00 & 101.69 & 18.31 \\
\hline Pantalon a rayas negro & AROCA & 3 & 40.00 & 120.00 & 101.69 & 18.31 \\
\hline $\begin{array}{l}\text { Gorro de cocineros tipo } \\
\text { togas }\end{array}$ & AROCA & 1 & 40.00 & 40.00 & 33.90 & 6.10 \\
\hline & & & & 700.00 & 593.22 & 106.78 \\
\hline
\end{tabular}

FUENTE: Elaboración propia. 
Cuadro $\mathrm{N}^{\circ} 45$ :

Gastos de Venta

\begin{tabular}{|c|c|c|c|c|c|c|c|}
\hline GASTOS DE VENTA & PROVEEDOR & CANTIDAD & COSTOUNT. & $\begin{array}{l}\text { COSTO TOTAL } \\
\text { MENSUAL }\end{array}$ & $\begin{array}{l}\text { COSTO } \\
\text { ANUAL } \\
\text { CON IGV }\end{array}$ & $\begin{array}{c}\text { COSTO SIN } \\
\text { IGV }\end{array}$ & IGV \\
\hline POS & VISA & 1 & 150.00 & 150.00 & $1,800.00$ & $1,525.42$ & 274.58 \\
\hline Publicidad & IMPRERU S.C.R.L & 1 & $2,000.00$ & $2,000.00$ & $24,000.00$ & $20,338.98$ & $3,661.02$ \\
\hline Volantes millar & IMPRERU S.C.R.L & 1 & 150.00 & 150.00 & $1,800.00$ & $1,525.42$ & 274.58 \\
\hline Evento inaugural & IMPRERU S.C.R.L & 1 & $2,000.00$ & $2,000.00$ & $2,000.00$ & $1,694.92$ & 305.08 \\
\hline Invitaciones & IMPRERU S.C.R.L & 1 & 50.00 & 50.00 & 600.00 & 508.47 & 91.53 \\
\hline $\begin{array}{l}\text { Promocion de acumulacion de } \\
\text { puntos }\end{array}$ & & 5 & 50.00 & 250.00 & $3,000.00$ & $2,542.37$ & 457.63 \\
\hline Campaña regalo merchandising & & 15 & 30.00 & 450.00 & $5,400.00$ & $4,576.27$ & 823.73 \\
\hline TOTAL & & & & $5,050.00$ & $38,600.00$ & $32,711.86$ & $5,888.14$ \\
\hline
\end{tabular}

Fuente: Elaboración propia

Cuadro $\mathrm{N}^{\circ} 4$ 6:

Gastos de Útiles de Limpieza

\begin{tabular}{|c|c|c|c|c|c|c|c|}
\hline UTILES DE LIMPIEZA Y OTROS & PROVEEDOR & CANTIDAD & PRECIO UNT. & $\begin{array}{c}\text { COSTO CON } \\
\text { IGV } \\
\text { mensual } \\
\end{array}$ & $\begin{array}{c}\text { COSTO } \\
\text { CON IGV } \\
\text { anual } \\
\end{array}$ & $\begin{array}{c}\text { COSTO } \\
\text { ANUAL SIN } \\
\text { IGV }\end{array}$ & IGV \\
\hline Guantes descartables paq 100 & SODIMAC & 10 & 8.00 & 80.00 & 960.00 & 813.56 & 146.44 \\
\hline Papel Film 18" x $1400 \mathrm{mts}$ & SODIMAC & 5 & 12.00 & 60.00 & 720.00 & 610.17 & 109.83 \\
\hline Papel aluminio SF HD(7.62m X 45.7c & SODIMAC & 10 & 8.00 & 80.00 & 960.00 & 813.56 & 146.44 \\
\hline Lavavajillas pasta $\times 1 \mathrm{~kg}$. & MAKRO & 10 & 10.00 & 100.00 & $1,200.00$ & $1,016.95$ & 183.05 \\
\hline Paño absorbente 3M & MAKRO & 10 & 5.00 & 50.00 & 600.00 & 508.47 & 91.53 \\
\hline Esponja Verde x 15 und & MAKRO & 10 & 13.70 & 137.00 & $1,644.00$ & $1,393.22$ & 250.78 \\
\hline Esponja Gris x 15 und. & MAKRO & 5 & 22.00 & 110.00 & $1,320.00$ & $1,118.64$ & 201.36 \\
\hline Removedores de grasa & MAKRO & 7 & 8.90 & 62.30 & 747.60 & 633.56 & 114.04 \\
\hline Recarga de extintor & SERVINDUSTRIA & 5 & 30.00 & 150.00 & 150.00 & 127.12 & 22.88 \\
\hline Bolsa Basura grande & MAKRO & 2 & 45.00 & 90.00 & $1,080.00$ & 915.25 & 164.75 \\
\hline Escoba & MAKRO & 5 & 9.00 & 45.00 & 540.00 & 457.63 & 82.37 \\
\hline Desinfectante & MAKRO & 5 & 8.95 & 44.75 & 537.00 & 455.08 & 81.92 \\
\hline Jabón Espuma & MAKRO & 5 & 21.27 & 106.35 & $1,276.20$ & $1,081.53$ & 194.67 \\
\hline Papel higienico elite & MAKRO & 2 & 19.90 & 39.80 & 477.60 & 404.75 & 72.85 \\
\hline Kimberly papel toalla Scott & MAKRO & 4 & 32.40 & 129.60 & $1,555.20$ & $1,317.97$ & 237.23 \\
\hline Isopo de Inodoro & MAKRO & 5 & 7.50 & 37.50 & 450.00 & 381.36 & 68.64 \\
\hline Gas de 45 kilos & SOLGAS & 2 & 130.00 & 260.00 & $3,120.00$ & $2,644.07$ & 475.93 \\
\hline Acido Muriático & MAKRO & 5 & 4.07 & 20.35 & 244.20 & 206.95 & 37.25 \\
\hline \multirow[t]{2}{*}{ desatorador de inodoro } & MAKRO & 1 & 4.50 & 4.50 & 54.00 & 45.76 & 8.24 \\
\hline & & & & $1,607.15$ & $17,635.80$ & $14,945.59$ & $2,690.21$ \\
\hline
\end{tabular}

FUENTE: Elaboración propia. 
Cuadro $N^{\circ} 47$ :

Gastos de Inversión

\begin{tabular}{|c|c|c|c|c|c|c|}
\hline GASTOS INVERSION & PROVEEDOR & CANT. & $\begin{array}{l}\text { COSTO } \\
\text { UNT. }\end{array}$ & $\begin{array}{c}\text { COSTOSIN } \\
\text { IGV }\end{array}$ & IGV & $\begin{array}{l}\text { COSTO } \\
\text { CONIGV }\end{array}$ \\
\hline Alquiler Local Comercial MES & 2 mes garantia & 2 & $11,000.00$ & $22,000.00$ & 0.00 & $22,000.00$ \\
\hline $\begin{array}{l}\text { Certificado de búsqueda mercantil, } \\
\text { Solicitud de resenva de razón social }\end{array}$ & SUNARP & 1 & 4.00 & 3.39 & 0.61 & 4.00 \\
\hline Reserva de nombre & SUNARP & 1 & 18.00 & 15.25 & 2.75 & 18.00 \\
\hline Elaboración de la minuta & NOTARIA MEDINA RAGGIO & 1 & 510.00 & 432.20 & 77.80 & 510.00 \\
\hline Elevación a escritura pública de minuta & NOTARIA MEDINA RAGGIO & 1 & 45.00 & 38.14 & 6.86 & 45.00 \\
\hline $\begin{array}{l}\text { Derechos de calificacion 3/1000 del valor } \\
\text { de capital }\end{array}$ & SUNARP & 1 & 43.74 & 37.07 & 6.67 & 43.74 \\
\hline Derechos de inscripcion & SUNARP & 1 & 8.64 & 7.32 & 1.32 & 8.64 \\
\hline Inscripción del RUC & SUNAT & 1 & 0.00 & 0.00 & 0.00 & 0.00 \\
\hline Legalización de libros contables & NOTARIA MEDINA RAGGIO & 1 & 250.00 & 211.86 & 38.14 & 250.00 \\
\hline Legalización de libros societarios & NOTARIA MEDINA RAGGIO & 1 & 100.00 & 84.75 & 15.25 & 100.00 \\
\hline Autorizacion de Planillas de pago & NOTARIA MEDINA RAGGIO & 1 & 35.00 & 29.66 & 5.34 & 35.00 \\
\hline Búsqueda de antecedentes foneticos & SUNARP & 1 & 110.51 & 93.65 & 16.86 & 110.51 \\
\hline Busqueda de antecedentes figurativos & SUNARP & 1 & 130.82 & 110.86 & 19.96 & 130.82 \\
\hline Registro de marca & SUNARP & 1 & 533.30 & 451.95 & 81.35 & 533.30 \\
\hline Publicacion diario El Peruano & EL PERUANO & 1 & 50.00 & 42.37 & 7.63 & 50.00 \\
\hline Registro sanitario & MUNICIPALIDAD & 1 & 30.00 & 25.42 & 4.58 & 30.00 \\
\hline \begin{tabular}{|l|} 
Licencia Municipal \\
\end{tabular} & MUNICIPALIDAD & 1 & 150.00 & 127.12 & 22.88 & 150.00 \\
\hline Permisos municipales para remodelacion & MUNICIPALIDAD & 1 & 290.30 & 246.02 & 44.28 & 290.30 \\
\hline Certificado de defensa civil & MUNICIPALIDAD & 1 & 85.68 & 72.61 & 13.07 & 85.68 \\
\hline Certificado de seguridad en defensa civil & MUNICIPALIDAD & 1 & 223.00 & 188.98 & 34.02 & 223.00 \\
\hline Registro sanitario & DIGESA & 1 & 70.00 & 59.32 & 10.68 & 70.00 \\
\hline Antivirus & WORLD OFFICE Perú & 1 & 120.00 & 101.69 & 18.31 & 120.00 \\
\hline Portal web & WORLD OFFICE Perú & 1 & $2,000.00$ & $1,694.92$ & 305.08 & $2,000.00$ \\
\hline Cambio de pisos & MARCOLE PERU ARQUITES & 2 & $1,500.00$ & $2,542.37$ & 457.63 & $3,000.00$ \\
\hline Cambio de ventanas & MARCOLE PERU ARQUITES & 2 & $1,500.00$ & $2,542.37$ & 457.63 & $3,000.00$ \\
\hline Iluminación del local & MARCOLE PERU ARQUITES & 4 & 300.00 & $1,016.95$ & 183.05 & $1,200.00$ \\
\hline Pintado de paredes & MARCOLE PERU ARQUITES & 1 & $1,500.00$ & $1,271.19$ & 228.81 & $1,500.00$ \\
\hline Acabados & MARCOLE PERU ARQUITES & 1 & $2,000.00$ & $1,694.92$ & 305.08 & $2,000.00$ \\
\hline \begin{tabular}{|l|} 
Instalaciones electricas \\
\end{tabular} & MARCOLE PERU ARQUITE & 10 & 100.00 & 847.46 & 152.54 & $1,000.00$ \\
\hline Decoración del ambiente. & MARCOLE PERU ARQUITE & 1 & $3,500.00$ & $2,966.10$ & 533.90 & $3,500.00$ \\
\hline & TOTAL & & & $38,955.92$ & $3,052.07$ & $42,007.99$ \\
\hline
\end{tabular}

FUENTE: Elaboración propia. 
Cuadro $\mathrm{N}^{\circ} 4$ 8:

Suministros y Menajes

\begin{tabular}{|c|c|c|c|c|c|c|}
\hline SUMINISTROS Y MENAJES & PROVEEDOR & CANT. & $\begin{array}{l}\text { PRECIO } \\
\text { UNT. }\end{array}$ & $\begin{array}{c}\text { COSTO SIN } \\
\text { IGV }\end{array}$ & IGV & \begin{tabular}{|c|} 
COSTO CON \\
IGV \\
\end{tabular} \\
\hline Platos color blanco tendido & FURUKAWA & 100 & 8.00 & 677.97 & 122.03 & 800.00 \\
\hline Platos color blanco hondos & FURUKAWA & 100 & 8.00 & 677.97 & 122.03 & 800.00 \\
\hline Set de Cubiertos & MAGEFESA & 100 & 7.00 & 593.22 & 106.78 & 700.00 \\
\hline Vasos altos de vidrio & KROOSNO & 100 & 7.00 & 593.22 & 106.78 & 700.00 \\
\hline Platos de entrada color blanco & FURUKAWA & 100 & 4.80 & 406.78 & 73.22 & 480.00 \\
\hline Taza y plato redondo blanco & FURUKAWA & 100 & 5.00 & 423.73 & 76.27 & 500.00 \\
\hline Batidor de acero inoxidable & FURUKAWA & 2 & 30.00 & 50.85 & 9.15 & 60.00 \\
\hline $\begin{array}{l}\text { Colador base de acero } \\
\text { inoxidable. }\end{array}$ & FURUKAWA & 1 & 41.00 & 34.75 & 6.25 & 41.00 \\
\hline Cuchara acero set de 6 und. & FURUKAWA & 1 & 55.00 & 46.61 & 8.39 & 55.00 \\
\hline Cucharon de acero inoxidable & OXO & 1 & 42.00 & 35.59 & 6.41 & 42.00 \\
\hline Dispensador multiusos plastico. & FOXRUN & 2 & 8.00 & 13.56 & 2.44 & 16.00 \\
\hline Espatula de silicona & FURUKAWA & 2 & 24.00 & 40.68 & 7.32 & 48.00 \\
\hline Espumadera & FURUKAWA & 2 & 42.00 & 71.19 & 12.81 & 84.00 \\
\hline Exprimidor de limon & FURUKAWA & 1 & 25.00 & 21.19 & 3.81 & 25.00 \\
\hline Mazo para carnes & OXO & 1 & 63.00 & 53.39 & 9.61 & 63.00 \\
\hline Mortero de granito blanco & FURUKAWA & 1 & 80.00 & 67.80 & 12.20 & 80.00 \\
\hline Pinza de acero inoxidable & FURUKAWA & 1 & 30.00 & 25.42 & 4.58 & 30.00 \\
\hline Prensador de ajos & FURUKAWA & 1 & 30.00 & 25.42 & 4.58 & 30.00 \\
\hline Rallador & OXO & 1 & 35.00 & 29.66 & 5.34 & 35.00 \\
\hline Soplete profesional de cocina & FURUKAWA & 1 & 100.00 & 84.75 & 15.25 & 100.00 \\
\hline Taza medidora 4T & OXO & 1 & 43.00 & 36.44 & 6.56 & 43.00 \\
\hline Servilletas de mesa & FURUKAWA & 100 & 7.00 & 593.22 & 106.78 & 700.00 \\
\hline Mantel de mesa & FURUKAWA & 100 & 38.00 & $3,220.34$ & 579.66 & $3,800.00$ \\
\hline Salero de mesa & FURUKAWA & 25 & 2.00 & 42.37 & 7.63 & 50.00 \\
\hline Pimientero de mesa & FURUKAWA & 25 & 2.00 & 42.37 & 7.63 & 50.00 \\
\hline Bloque de cuchillos X10 und. & BODUM & 2 & 120.00 & 203.39 & 36.61 & 240.00 \\
\hline Tablas de cortar polipropileno & OXO & 5 & 100.00 & 423.73 & 76.27 & 500.00 \\
\hline Sarten wok & ILKO & 3 & 120.00 & 305.08 & 54.92 & 360.00 \\
\hline Fuentes en acero & ILKO & 12 & 50.00 & 508.47 & 91.53 & 600.00 \\
\hline Bowls & ILKO & 2 & 100.00 & 169.49 & 30.51 & 200.00 \\
\hline Tachos de basura & HOME CENTE & 6 & 35.00 & 177.97 & 32.03 & 210.00 \\
\hline Espejos & FURUKAWA & 4 & 150.00 & 508.47 & 91.53 & 600.00 \\
\hline Contenedor de basura c/tapa & HOME CENTE & 1 & 75.00 & 63.56 & 11.44 & 75.00 \\
\hline Recogedor de residuos & HOME CENTE & 2 & 3.05 & 5.17 & 0.93 & 6.10 \\
\hline Dispensador de papel toalla & HOME CENTE & 3 & 50.00 & 127.12 & 22.88 & 150.00 \\
\hline Dispensador de papel higienico & HOME CENTE & 3 & 45.00 & 114.41 & 20.59 & 135.00 \\
\hline Dispensador de jabon & HOME CENTE & 4 & 40.00 & 135.59 & 24.41 & 160.00 \\
\hline Balon de gas grande & SOLGAS & 2 & 134.50 & 227.97 & 41.03 & 269.00 \\
\hline Extintor & SERVINDUST & 2 & 100.00 & 169.49 & 30.51 & 200.00 \\
\hline \multicolumn{4}{|c|}{ TOTAL } & $11,048.39$ & $1,988.71$ & $13,037.10$ \\
\hline
\end{tabular}

FUENTE: Elaboración propia. 


\section{CAPÍTULO V}

\section{PLAN DE RECURSOS HUMANOS}

Para el desarrollo del siguiente capítulo se ha considerado la estructura de una empresa constituida como sociedad anónima cerrada, giro de restaurante conformada por dos accionistas.

\subsection{Organización Funcional.}

La cultura organizacional de Like Home Restaurant estará fundamentada en principios de éticas, políticas y valores de mucha importancia que permitirán el éxito de la empresa.

\section{1) Valores}

Vocación de servicio: Nuestra inclinación profesional estará orienta a satisfacer las necesidades del cliente durante su estadía en el restaurant.

Espíritu de superación: Demostrar constante lucha y afán de asumir nuevos retos y responsabilidades sin temor a los obstáculos que se presenten.

Transparencia: Actitud de demostrar sinceridad siempre guiados por solidos principios profesionales

Medio Ambiente: Preservar el medio ambiente es responsabilidad de todos y sobre todo el de nuestra empresa.

\section{2) Principios}

Calidad: Nuestros productos y servicios ofrecidos serán de primera calidad, manteniendo la pulcritud y limpieza en todo momento. 
Servicio: El cliente es lo más importante por ende nuestro objetivo es conseguir 100\% de satisfacción en todo momento.

Identidad: Este principio se fundamenta en que todos trabajamos para un solo objetivo alineados hacia el éxito de la empresa.

\subsection{Organigrama.}

El principal órgano de dirección de la empresa va a estar encabezado por el Gerente General de la empresa quien dirige, controla y toma las decisiones en coordinación con la junta de accionistas y tres órganos de línea que son los Departamentos de Producción, Departamento de Ventas y Marketing y el Departamento de contabilidad y Finanzas.

La descripción de los puestos se da de acuerdo al siguiente organigrama.

Figura $\mathrm{N}^{\circ} 5$ 1:

Organigrama de la empresa

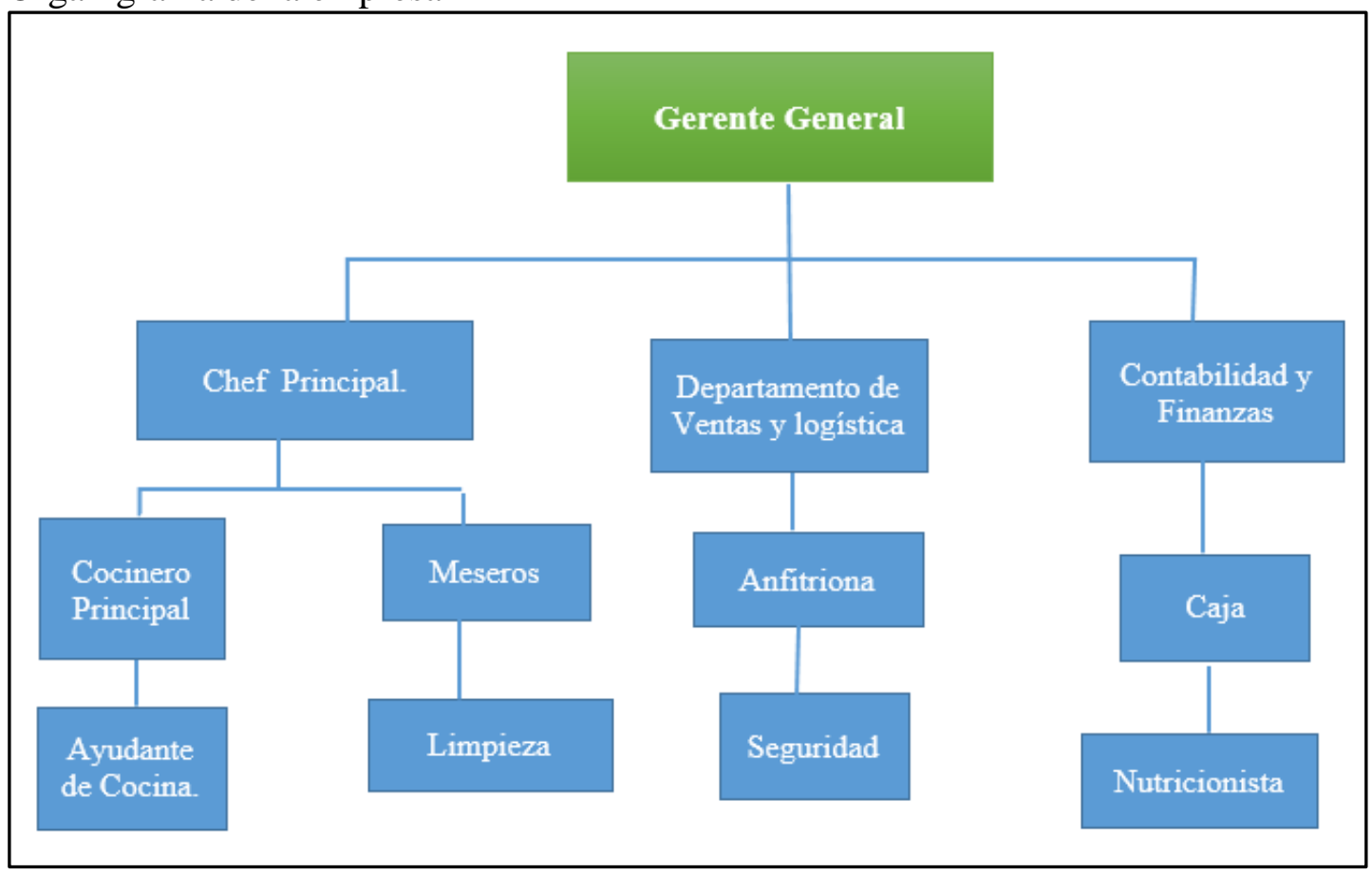

Fuente: Elaboración Propia. 


\section{1) Gerente General.}

Función Básica: Dirigir, controlar, planificar y desarrollar actividades que aseguren la rentabilidad y buen funcionamiento de la empresa.

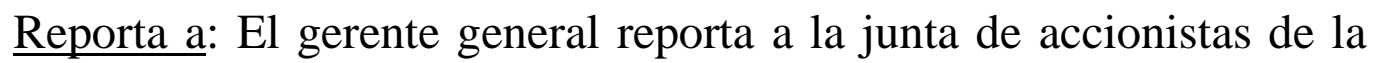
empresa.

Actividades Específicas: Planear y desarrollar metas a mediano y largo plazo junto con los objetivos anuales y entregarlas a los jefes de cada área para su desarrollo y cumplimiento.

○ Evaluar periódicamente el desempeño y cumplimiento de objetivos de cada una de las áreas de la empresa.

- Administrar y organizar la empresa de forma óptima, para que se cumplan todas las metas que se han establecido.

- Representar a la organización frente a los clientes, proveedores y demás importantes colaboradores de la empresa.

○ Identificar arreas de oportunidad dentro y fuera de la empresa.

Perfil del Puesto: Licenciado en Administración de Empresas, capacidad para planear y dirigir de manera independiente sus actividades y toma de decisiones, conocimientos de contabilidad y finanzas, capacidad de negociación, mínimo 5 años de experiencia en el puesto, conocimiento de inglés intermedio.

\section{a. Jefe de Ventas y Logística.}

Función básica: Responsable máximo del área comercial, ventas y compras diarias, tiene la función de brindar proyecciones mensuales, desarrollar estrategias de negocios de promociones y ventas. 
Reporta a: Administrador.

\section{Actividades Específicas:}

- Coordinar e informar al área administrativa el movimiento de ventas e inventario diario.

○ Explicar al cliente los platillos del menú.

- Coordinar con los proveedores las cotizaciones de insumos.

- Elaborar planes de mercadeo y promociones de ventas, así como buscar alianzas y convenios corporativos.

○ Emitir boletas o facturas según conveniencia del cliente.

- Coordinar con el área de contabilidad y finanzas sobre las facturas de compra y ventas.

- Llevar el control de caja.

Perfil del Puesto: Joven de ambos sexos, entre 25 a 30 años, Egresado o Licenciado en Administración de empresas o carreras afines, con experienciade manejo de caja y puestos similares, predisposición a trabajar bajo presión, característica principal honradez, atento en el trato al público y con capacidad de manejo de equipos.

\section{b. Jefe de Contabilidad y Finanzas.}

Función Básica: Llevar la contabilidad y finanzas de la empresa, así como estar a cargo del pago del personal, proveedores.

Reporta a: Jefe de Administración.

\section{$\underline{\text { Actividades Específicas }}$}

- Coordinar con jefe de administración los requerimientos de caja chica para cubrir las necesidades de dineros. 
- Supervisar que los pagos se efectúen en las fechas indicadas.

- Suministra la información contable tributaria a las autoridades correspondientes.

- Verifica los comprobantes de ingreso y ordenes de pagos.

○ Elabora informes contables mensuales, trimestrales de la empresa.

\section{Perfil del Puesto:}

Licenciado en Contabilidad y Finanzas, mínimo 5 años de experiencia, conocimiento de las Normas Internacionales de Contabilidad, Capacidad de análisis y síntesis de la información.

\section{c. Chef Principal}

Función básica: Responsable máximo del servicio del área de cocina del restaurant.

Reporta a: Jefe de Producción.

Actividades Específicas:

- Controlar los horarios y trabajo del personal de cocina.

- Controlar la calidad de los insumos y productos.

- Verificar el buen funcionamiento de las maquinarias y equipos.

- Dar la conformidad de las compras de los insumos, así como al ingreso a almacén.

- Realizar trabajo en equipo en el restaurant, así como diálogos de reconocimiento y sugerencias de mejoras. 
- Supervisar la elaboración de los platos fríos y calientes controlando su temperatura y decoración.

\section{Perfil del Puesto:}

Edad de 35 a 50 años, sexo masculino, nivel educativo profesional en Gastronomía, Hotelería y/o Turismo, Administración de Empresas. Experiencia mínima 3 años en el puesto, conocimiento de inglés intermedio.

\section{d. Cocinero Principal.}

Función básica: preparación de los menús y la supervisión de la preparación de los mismos.

Reporta a: Jefe de Producción.

\section{Actividades Específicas:}

○ Planificación de la carta semanal.

○ Elaboración de menús en general.

○ Cumplir con las normas de sanidad e higiene.

- Contabilizar las entradas y salidas de inventario por producto.

- Ver las requisiciones de compra para su área.

- Mantener un adecuado ambiente de trabajo.

- Supervisar al personal a cargo.

Perfil del Puesto: Ambos sexos, entre 28 y 35 años, con estudios de cocina. Experiencia mínima de tres años en puesto similar. Tolerante 
a trabajos bajo presión con capacidad de coordinar con el personal a cargo. Creativo en la preparación y presentación de menús.

\section{e. Ayudante de cocina}

Función básica: apoyo en la preparación de menús.

$\underline{\text { Reporta a: }}$ Cocinero Principal.

Actividad específica:

○ Elaboración de menús en general.

- Presentación de los mismos.

○ Cumplir con las normas de sanidad e higiene.

- Cuidar que el lugar de trabajo cuente con las temperaturas apropiadas, en cada uno de los procesos de producción.

- Informar al maestro cocinero los stocks mínimos de la materia prima e insumos.

Perfil del Puesto: Ambos sexos, entre 25 a 30 años, con estudios de cocina, tolerante al trabajo bajo presión. Creativo en la preparación de alimentos y eficiente manejo de recursos.

\section{f. Personal de limpieza}

Función básica: responsable de limpieza del local.

Reporta a: Jefe de Producción.

Actividades Específicas 
- Encargado del requerimiento de materiales necesarios para llevar a cabo sus funciones.

- Encargado de recibir las materias primas y los insumos y ser almacenados en coordinación con el Maestro cocinero.

○ Encargado de la limpieza del local.

Perfil del Puesto: Joven de sexo masculino, entre 20 y 25 años, con estudios secundarios completos, experiencia mínima de un año en puesto similar.

\section{g. Cobrador - Pagador (Caja).}

Función básica: Toma de pedidos y cobrar la cuenta.

$\underline{\text { Reporta a: }}$ Jefe de Contabilidad y Finanzas

Actividades Específicas:

- Tratar amablemente a los clientes.

- Explicar al cliente los platillos del menú.

○ Entablar relaciones de largo plazo con el cliente.

- Recuperar clientes que hayan dejado de consumir.

○ Generar nuevos clientes.

- Informar al Administrador de las recomendaciones, gustos y preferencias de los clientes.

Perfil del Puesto: Joven de ambos sexos, entre 25 y 30 años, con estudios técnicos en administración o carreras técnicas afines, experiencia mínima de un año en puesto similar. Predisposición a 
trabajar bajo presión, característica principal honradez, atento en el trato al público. Deberá contar con licencia de conducir moto.

\section{h. Anfitriona.}

Función Básica: Representa la imagen de bienvenida que brinda al cliente al momento de su ingreso al restaurant.

\section{$\underline{\text { Actividades Específicas }}$}

- Recibir a los clientes, verificar sus reservas de mesas y ubicarlos en su sitio correspondiente.

- Mantener contacto directo con los mozos para la rápida atención de los clientes.

- Comunicar al Chef la llegada de los proveedores.

- Informar a los clientes de cómo funciona el proceso de atención.

\section{Perfil del Puesto:}

Personal femenino, con conocimientos de computación y sistemas informáticos, egresada o estudiante universitaria, instituto superior técnico de la especialidad de Administración Hotelera.

\section{i. Meseros.}

Función Básica: La tarea principal de este puesto es atender al cliente, representando la principal imagen del restaurant debido al contacto directo con el cliente.

\section{Actividades Específicas}

- Atender al cliente asignado y dar solución a todos los problemas que tenga relacionados al servicio y/o alimentos del restaurant. 
- Mantener las mesas limpias y con sus respectivos cubiertos, manteniendo los estándares de calidad.

○ Demostrar buena disposición y un trato amable hacia los clientes.

\section{Perfil del Puesto:}

Personal con estudios universitarios concluidos o carreras técnicas en administración hotelera o afines, contar con experiencia en restaurantes,

\section{j. Seguridad}

Función Básica: Encargado de cuidar la seguridad del restaurant, así como preservar el orden interno y externo en el local.

Actividades Específicas

- Vigilar el local para mantenerlo seguro.

- Revisar constantemente las cámaras de seguridad ubicados en los diversos puntos del local.

- Cuidar los bienes y equipos del restaurant, así como estar vigilante con las pertenencias de los clientes.

- Realizar informes diarios de ocurrencias ocurridas durante el día.

Perfil del Puesto:

Secundaria completa, mayor de 18 años, con más de 1 año de experiencia en funciones similares, contar con arma propia y licencia para portar armas

\section{k. Nutricionista}

Función básica: Brindar información nutricional a clientes.

Reporta a: Administrador

Actividades específicas:

- Tratar amablemente a los clientes.

- Explicar al cliente su mejor menú de acuerdo a sus necesidades. 
- Registrar el menú de cada cliente.

Perfil del Puesto: Ambos sexos, entre 25 a 30 años, Egresado o Licenciado en Nutrición y atento en el trato al público.

\subsection{Política de Contratación.}

\subsubsection{Legislación Laboral.}

Según el Régimen Laboral Especial este se aplica a todos los trabajadores sujetos al régimen laboral de la actividad privada, que presten servicios en las Micro y Pequeñas Empresas, así como a sus conductores y empleadores.

\section{a. Jornada de trabajo}

- Se deberá considerar la jornada máxima legal 8 horas diarias de 48 horas semanales.

- La jornada nocturna, es el tiempo trabajado entre las 10:00 pm a las 06:00 a.m., la remuneración tendrá una sobretasa del $35 \%$ y no podrá ser menor del sueldo mínimo vigente.

- El horario de refrigerio no debe ser menor de 45 minutos y coincidirá en lo posible con los horarios habituales de desayuno almuerzo cena, no forma parte de la jornada de trabajo y es establecido por el empleador.

- Las horas extra de trabajo deberán ser remuneradas al mismo tiempo en pago del suelo y su monto debe ser registrado en el libro de planillas en un rubro separado. Las dos primeras horas extras se pagan un recargo del $25 \%$, en función del valor de por hora de la remuneración, y 35\% para las horas restantes.

- Se debe contar con un registro permanente de control de asistencia en el que los trabajadores consignarán personalmente el tiempo de labores, este registro deberá 
contener como mínimo: el nombre, denominación o razón social del empleador; número RUC del empleador; nombre y DNI del trabajador; fecha, hora y minutos del ingreso y salida de la jornada de trabajo; y las horas y minutos de permanencia fuera de la jornada de trabajo.

\section{b. Compensación por tiempo de servicio}

- El derecho nace desde el cumplimiento del primer mes de iniciado del vínculo laboral.

- Los trabajadores deberán cumplir cuando menos en promedio una jordana mínima de 4 horas diarias.

- Este beneficio se calcula semestralmente al final de los periodos de abril y octubre de cada año, deberá ser depositado en cualquiera de las empresas del sistema financiero dentro de los primeros 15 días de los meses siguientes

- Los depósitos que se incurrió sus intereses son intangibles inembargables salvo por alimentos y hasta un monto máximo del $50 \%$.

- El monto máximo posible de la CTS que podrá retirar el trabajador no podrá exceder en su conjunto del $50 \%$ del total computado desde el inicio de los depósitos.

- El derecho a la Compensación por Tiempo de Servicios (CTS) equivalente a 15 días de remuneración por año de servicio con tope de 90 días de remuneración.

\section{c. Gratificaciones legales}

- Todo trabajador del régimen laboral especial tiene derecho a percibir 2 gratificaciones al año (Fiestas Patrias y Navidad) en razón del 50\% de la remuneración. 
- Las gratificaciones se computan de manera semestral en los periodos de enero a julio y julio a diciembre y serán pagadas en la primera quincena de los meses de julio y diciembre.

- La gratificación se pagará de manera proporcional a los meses calendario completo que haya laborado el trabajador de no haberse cumplido el semestre.

- La gratificación trunca es aquella que le corresponde percibir a un trabajador que no tiene vínculo laboral vigente, forma parte de la liquidación de beneficios sociales.

\section{d. Vacaciones}

- Consiste en otorgar Descanso Vacacional de 15 días calendario, el derecho a vacaciones será otorgado a todo trabajador que cumplas cuando menos 4 horas de jornada de trabajo diario.

- El goce de vacaciones es otorgado a quienes hayan cumplido un año calendario de servicios.

- Las vacaciones son otorgadas en el período anual siguiente a aquel que alcanzó el goce esta será fijada por acuerdo entre trabajador y el empleador en base a las necesidades de la empresa y los intereses propios de lo contrario el empleador decidirá uso de su facultad de directriz.

- El disfrute del descanso vacacional debe ser ininterrumpido sin embargo el trabajador podrá solicitar sus accionamientos no pudiendo otorgarse descanso en periodos inferiores a 7 días naturales.

\subsection{Política Salarial}

Dentro de nuestro Plan de Recursos Humanos se está considerando contar con un total de 16 colaboradores distribuidos en todas las áreas, 
así como su respectivo nivel remunerativo donde el monto más bajo está considerando por $\mathrm{S} / .850 .00$ y el monto de remuneración más alta de S/. 5,500.0, considerada al cargo gerencial, generando un total de remuneración al mes de S/31,200.00, sin considerar los beneficios sociales del trabajador que está obligado a pagar el empleador, detallados en el siguiente cuadro:

Cuadro $\mathrm{N}^{\circ} 5$ 1:

Esquema de Remuneración del personal

\begin{tabular}{|l|c|l|r|}
\hline \multicolumn{1}{|c|}{ CARGO } & CANTIDAD & \multicolumn{1}{c|}{ TIPO DE } \\
CONTRATO & \multicolumn{1}{c|}{$\begin{array}{r}\text { SUELDO } \\
\text { MENSUAL }\end{array}$} \\
\hline Chef & 1 & Plazo determinado & $2,000.00$ \\
\hline Cocinero principal & 1 & Plazo determinado & $1,500.00$ \\
\hline Ayudante de cocina & 1 & Plazo determinado & 850.00 \\
\hline Nutricionista & 1 & Plazo determinado & $1,200.00$ \\
\hline Mesero & 3 & Plazo determinado & 950.00 \\
\hline Anfitriona & 1 & Plazo determinado & 800.00 \\
\hline Vigilante & 1 & Plazo determinado & 950.00 \\
\hline Caja & 1 & Plazo determinado & 900.00 \\
\hline Limpieza & 1 & Plazo determinado & 850.00 \\
\hline Gerente General & 1 & Plazo determinado & $3,500.00$ \\
\hline Ventas y Logistica & 1 & Plazo determinado & $2,000.00$ \\
\hline Contabilidad y finanzas & 1 & Plazo determinado & $2,000.00$ \\
\hline TOTAL & $\mathbf{1 4}$ & Plazo determinado & $\mathbf{1 7 , 5 0 0 . 0 0}$ \\
\hline
\end{tabular}

Elaboración Propia

Contar con una política salarial compatible con el mercado es esencial para que la empresa retenga a sus talentos y se mantenga competitiva en el mercado, por ello se va a tener en cuenta los siguientes tramos:

\subsubsection{Admisión.}

Para la admisión de los trabajadores son requisitos indispensables para su incorporación:

- Ser mayor de edad.

- Gozar de buena salud y tener aptitud física.

- Carecer de antecedentes penales, judiciales o policiales.

- Contar con el carnet de sanidad vigente. 
- Cumplir con los requisitos mínimos establecidos para el desempeño en el puesto que se necesite cubrir.

Todo nuevo trabajador recibir orientación sobre los objetivos, organización y funcionamiento de la empresa, así como de las labores que le corresponden desarrollar en su puesto de trabajo. Todo trabajador recibir un documento de identificación proporcionado por la empresa, debiendo portarla en lugar visible durante su permanencia en el Centro de Trabajo.

\subsubsection{Derechos, obligaciones y prohibiciones del trabajador.}

Dentro de los derechos y obligaciones del trabajador y el empleador se va a considerar lo siguiente:

- A percibir una remuneración acorde a las funciones que desempeñe.

- A ser evaluado periódicamente sobre su rendimiento laboral y ser considerado para ocupar cargos de mayor jerarquía, de ser el caso.

- Al descanso anual de treinta (30) días de vacaciones remuneradas, conforme a las normas legales vigentes.

- Al descanso semanal remunerado.

- Hacer uso de licencias por causas justificadas o motivos particulares.

- A la capacitación, actualización y perfeccionamiento laboral permanente.

- A la Compensación por Tiempo de Servicios.

- A un trato cortes y de respeto por parte de sus superiores. 
- A recurrir a las instancias pertinentes para solicitar orientación o plantear reclamos respecto a cualquier decisión que, conforme a su criterio, lo perjudique.

- Guardar un comportamiento acorde con las normas de cortesía y buen trato hacia sus superiores, compañeros de labores, clientes y público en general.

- Dar cumplimiento a las órdenes, directivas e instrucciones que por razones de trabajo sean impartidas por sus jefes o superiores jerárquicos. Cumplir y observar adecuadamente las normas y disposiciones internas de la empresa, las que rigen sus funciones y especialmente las que tienen directa relación con la labor desempeñada.

- Cumplir puntualmente con el horario de trabajo y de refrigerio que se tiene establecido.

- Reintegrar el valor de los bienes que estando bajo su responsabilidad se perdieran o deterioraren por descuido, omisión o negligencia, debidamente comprobada.

- Proporcionar oportunamente la documentación y/o información que se solicite para su respectivo legajo personal.

- Someterse a exámenes médicos físicos y/o mentales en los términos, condiciones y periodicidad que se determine.

- Cumplir con las disposiciones internas en materia de seguridad e higiene ocupacional que se tiene implantado.

- Conservar en buen estado los equipos de oficina, útiles y demás bienes.

- Permitir la revisión de sus efectos personales o paquetes cada vez que le sea exigido, al ingresar o salir del Centro de Trabajo. 
- Atender con prontitud y cortesía a los clientes de la Institución y en general al público que acuda a la misma.

- Asistir a las sesiones a las que se les convoque con fines de instrucción, entrenamiento, desarrollo o capacitación.

- No cometer actos que afecten la tranquilidad de los trabajadores con comportamientos de connotación sexual. 


\section{CAPÍtULO Vi}

\section{PLAN FINANCIERO}

Luego de recoger la información desarrollada y cuantificada - en unidades monetarias, en este capítulo se desarrollarán todos los aspectos financieros para evaluar la rentabilidad del plan de negocios.

La planificación financiera exige la elaboración de proyecciones de ingresos y egresos, basadas en las estrategias para la puesta en marcha del Plan de Negocio y finalmente la elaboración de Estados Financieros Proyectados: Flujo de Caja, Estados de Ganancias y Pérdidas, Balances, Balances y análisis de Sensibilidad.

\subsection{Inversiones}

\subsubsection{Inversiones en Activo Fijo.}

La inversión en activo fijo Corresponde al conjunto de bienes que son necesarios para el equipamiento e implementación de la cocina mediante la cual nos va a permitir desarrollar las principales actividades que son la producción de los alimentos.

Estos Equipos se compran una sola vez para un periodo fijo determinado, en nuestro caso se estima una vida de 5 años, correspondiendo una depreciación anual del $20 \%$.

En el siguiente cuadro (Cuadro 6.1) se detalla la relación de maquinarias, muebles y equipo que se van a adquirir, incluye la información de proveedores, precio sin IGV y precio con IGV, luego se detalla su correspondiente depreciación anual. 
Dentro de los activos tangibles se invierte en muebles y equipos por un monto de S/.24,279.66, en maquinaria para la cocina por un monto de $\mathrm{S} / 24,724.58$. 


\section{Cuadro $\mathrm{N}^{\circ} 61$ :}

Relación de Activo Fijo - Maquinarias

\begin{tabular}{|c|c|c|c|c|c|c|c|}
\hline MAQUINARIA & DESCRIPCION & PROVEEDOR & CANT. & $\begin{array}{l}\text { PRECIO } \\
\text { UNT. }\end{array}$ & $\begin{array}{l}\text { COSTO SIN } \\
\text { IGV }\end{array}$ & IGV & $\begin{array}{l}\text { PRECIO } \\
\text { TOTAL }\end{array}$ \\
\hline Camara Frigorifica & Puerta de camara en acero inoxidable. & TONINO & 1 & $6,500.00$ & $5,508.47$ & 991.53 & $6,500.00$ \\
\hline Cocina Industrial & $\begin{array}{l}4 \text { parrilas de fierro fundido, planchas de acero } \\
\text { inoxidable. }\end{array}$ & HARMAN'S & 1 & $2,800.00$ & $2,372.88$ & 427.12 & $2,800.00$ \\
\hline $\begin{array}{l}\text { Mesa de trabajo con } \\
\text { cajones }\end{array}$ & $\begin{array}{l}2 \text { puertas, } 4 \text { repisas, incluye } 9 \text { bandejas de } 1 / 3 \\
(30.5 \times 15.3 \times 15.3)\end{array}$ & MUNDO HOGAR & 1 & $1,800.00$ & $1,525.42$ & 274.58 & $1,800.00$ \\
\hline Licuadora Industrial & $\begin{array}{l}\text { De aluminio pulido, Alimentación: 110/220V, } \\
\text { Potencia: } 0.33 \mathrm{CV} \text {. }\end{array}$ & METROLOGICA & 1 & $1,000.00$ & 847.46 & 152.54 & $1,000.00$ \\
\hline Horno microondas & $\begin{array}{l}\text { Potencia: } 1000 \text { Watts, Uso: Medio, Capacidad. } 1.2 \\
\text { pies cúbicos, Niveles de potencia: } 5 \text {, Control: } \\
\text { Digital, Programable } 100 \text { memorias. }\end{array}$ & ACP & 1 & $1,500.00$ & $1,271.19$ & 228.81 & $1,500.00$ \\
\hline $\begin{array}{l}\text { Campana estractora de } \\
\text { Grasa Industriales }\end{array}$ & $\begin{array}{l}\text { Fabricado en acero inoxidable, con vigas } t \\
\text { refuerzos. }\end{array}$ & HARMAN'S & 1 & $1,800.00$ & $1,525.42$ & 274.58 & $1,800.00$ \\
\hline $\begin{array}{l}\text { Lavaderos Industriales } \\
\text { de } 2 \text { pozas }\end{array}$ & $\begin{array}{l}\text { Tablero superior y poza de } 1 / 16(1.5 \mathrm{~mm}) \text { con } \\
\text { bordes sanitarios y respaldar de } 20 \mathrm{~cm} \text {. }\end{array}$ & HARMAN'S & 1 & $1,500.00$ & $1,271.19$ & 228.81 & $1,500.00$ \\
\hline Estante de Rejillas & $\begin{array}{l}\text { Farbicado en barras de acero, set de } 4 \text { rejillas } \\
\text { ventiladas. }\end{array}$ & FRIONOX & 4 & 350.00 & $1,186.44$ & 213.56 & $1,400.00$ \\
\hline $\begin{array}{l}\text { Estanteria para camara } \\
\text { frigorifica }\end{array}$ & Estructura metálica pulida para mejorar la limpieza. & FRIONOX & 4 & 400.00 & $1,355.93$ & 244.07 & $1,600.00$ \\
\hline $\begin{array}{l}\text { Mesa refrigerada de } 3 \\
\text { puertas }\end{array}$ & $\begin{array}{l}\text { Exterior en acero inox AISI 304, respaldo en chapa } \\
\text { galvanizada. Interior en acero inox AISI } 304 \text {. }\end{array}$ & HARMAN'S & 1 & $2,400.00$ & $2,033.90$ & 366.10 & $2,400.00$ \\
\hline $\begin{array}{l}\text { hervidoras de acero } \\
\text { inoxidable }\end{array}$ & $\begin{array}{l}\text { Estanque Acero inoxidable 316L, de } 120 \text { a } 180 \\
\text { litros. }\end{array}$ & TROTTER & 1 & 650.00 & 550.85 & 99.15 & 650.00 \\
\hline Horno industrial a gas & $\begin{array}{l}\text { Fabricado con planchas de Acero Inoxidable, con } \\
\text { aislamiento de fibra de vidrio por sus } 5 \text { lados. }\end{array}$ & HARMAN'S & 1 & $1,800.00$ & $1,525.42$ & 274.58 & $1,800.00$ \\
\hline Batidora electrica & Fabricado en acero inoxidable & KITCHENAID & 1 & $1,200.00$ & $1,016.95$ & 183.05 & $1,200.00$ \\
\hline Balanza & Mecanica de Plataforma Plana. & WESTON & 1 & 200.00 & 169.49 & 30.51 & 200.00 \\
\hline $\begin{array}{l}\text { Cortador de papas } \\
\text { profesional }\end{array}$ & De material inoxidable. & WESTON & 1 & 350.00 & 296.61 & 53.39 & 350.00 \\
\hline Extractor de jugos & Sistema Electrico & TRIBEST & 1 & 450.00 & 381.36 & 68.64 & 450.00 \\
\hline $\begin{array}{l}\text { Prensa para hacer } \\
\text { hamburguesa }\end{array}$ & Prensador de carne & WESTON & 1 & 116.00 & 98.31 & 17.69 & 116.00 \\
\hline Juego 3 de bol multiusos & De material inoxidable. & OXO & 1 & 200.00 & 169.49 & 30.51 & 200.00 \\
\hline Ollas acero inoxidable & De material inoxidable. & CUISINART & 10 & 150.00 & $1,271.19$ & 228.81 & $1,500.00$ \\
\hline Olla alta de acero & De material inoxidable. & TRAMONTINA & 1 & 409.00 & 346.61 & 62.39 & 409.00 \\
\hline & & & & & $24,724.58$ & $4,450.42$ & $29,175.00$ \\
\hline
\end{tabular}

FUENTE: Elaboración propia. 
Cuadro $\mathrm{N}^{\circ} 62$ :

Relación de Activo Fijo - Muebles y Equipos

\begin{tabular}{|c|c|c|c|c|c|c|}
\hline MUEBLES Y EQUIPOS & PROVEEDOR & CANT. & PRECIO UNT. & $\begin{array}{l}\text { COSTO } \\
\text { SIN IGV }\end{array}$ & IGV & $\begin{array}{l}\text { COSTO CON } \\
\text { IGV }\end{array}$ \\
\hline Computadoras personales & HIRAOKA & 3 & 900.00 & $2,288.14$ & 411.86 & $2,700.00$ \\
\hline Ipads & HIRAOKA & 6 & $1,000.00$ & $5,084.75$ & 915.25 & $6,000.00$ \\
\hline Impresora ticketera & HIRAOKA & 1 & 300.00 & 254.24 & 45.76 & 300.00 \\
\hline Impresora multifuncional & HIRAOKA & 2 & 300.00 & 508.47 & 91.53 & 600.00 \\
\hline $\begin{array}{l}\text { Mesas de madera } 1.10 \mathrm{~cm} \mathrm{x} \\
1.10 \mathrm{~cm} \\
\end{array}$ & MUEBLES CONTINENTAL & 14 & 250.00 & $2,966.10$ & 533.90 & $3,500.00$ \\
\hline $\begin{array}{l}\text { Mesas de madera } 90 \mathrm{~cm} x \\
90 \mathrm{~cm}\end{array}$ & MUEBLES CONTINENTAL & 12 & 220.00 & $2,237.29$ & 402.71 & $2,640.00$ \\
\hline $\begin{array}{lll}\text { Sillas de madera asiento } \\
\text { forro perla }\end{array}$ & MUEBLES CONTINENTAL & 90 & 95.00 & $7,245.76$ & $1,304.24$ & $8,550.00$ \\
\hline Escritorio melamine & MUEBLES CONTINENTAL & 2 & 200.00 & 338.98 & 61.02 & 400.00 \\
\hline Computadoras personales & HIRAOKA & 1 & $1,000.00$ & 847.46 & 152.54 & $1,000.00$ \\
\hline \begin{tabular}{|l} 
Estantes para archivadores \\
\end{tabular} & MUEBLES CONTINENTAL & 3 & 120.00 & 305.08 & 54.92 & 360.00 \\
\hline Estantes para guardar ropas & MUEBLES CONTINENTAL & 2 & 200.00 & 338.98 & 61.02 & 400.00 \\
\hline Televisor pantalla plana & HIRAOKA & 2 & 800.00 & $1,355.93$ & 244.07 & $1,600.00$ \\
\hline Telefonos & HIRAOKA & 3 & 200.00 & 508.47 & 91.53 & 600.00 \\
\hline & & & & $24,279.66$ & $4,370.34$ & $28,650.00$ \\
\hline
\end{tabular}

FUENTE: Elaboración propia

Cuadro $\mathrm{N}^{\circ} 63$ :

Depreciación de Activo Fijo Maquinaria y Equipos

\begin{tabular}{|c|c|c|c|}
\hline \multicolumn{4}{|c|}{ Depreciación Anual 5 años (Activos Fijos - Maquinarias) } \\
\hline Año & Activo Inicial & Depreciación Año & Activo Final \\
\hline 1 & $24,724.58$ & $4,944.92$ & $19,779.66$ \\
\hline 2 & $19,779.66$ & $4,944.92$ & $14,834.75$ \\
\hline 3 & $14,834.75$ & $4,944.92$ & $9,889.83$ \\
\hline 4 & $9,889.83$ & $4,944.92$ & $4,944.92$ \\
\hline 5 & 4,944.92 & $4,944.92$ & 0.00 \\
\hline \multicolumn{4}{|c|}{ Depreciación Anual 5 años (otros activos) } \\
\hline Año & Activo Inicial & Depreciación Año & Activo Final \\
\hline 1 & $24,279.66$ & $4,855.93$ & $19,423.73$ \\
\hline 2 & $19,423.73$ & $4,855.93$ & $14,567.80$ \\
\hline 3 & $14,567.80$ & $4,855.93$ & $9,711.86$ \\
\hline 4 & $9,711.86$ & $4,855.93$ & $4,855.93$ \\
\hline 5 & $4,855.93$ & $4,855.93$ & 0.00 \\
\hline \multicolumn{4}{|c|}{$\begin{array}{l}\text { Total Inversiones Activo Fijo (In. } \\
\text { Maq. Eq.) (Neto) }\end{array}$} \\
\hline & Monto S/ & Depreciación S/ & \\
\hline & $49,004.24$ & $9,800.85$ & \\
\hline & $39,203.39$ & $9,800.85$ & \\
\hline & $29,402.54$ & $9,800.85$ & \\
\hline & $19,601.69$ & $9,800.85$ & \\
\hline & $9,800.85$ & $9,800.85$ & \\
\hline
\end{tabular}

FUENTE: Elaboración propia 
Cuadro $\mathrm{N}^{\circ} 64$ :

Amortización Intangibles

Amortización Anual 10 años (Intangibles)

\begin{tabular}{l|l|l|l|} 
Año & Activo Inicial & Depreciación Año & Activo Final \\
\hline
\end{tabular}

\begin{tabular}{cccc}
1 & $42,007.99$ & $4,200.80$ & $37,807.19$ \\
\hline 2 & $37,807.19$ & $4,200.80$ & $33,606.39$ \\
\hline 3 & $33,606.39$ & $4,200.80$ & $29,405.59$ \\
\hline 4 & $29,405.59$ & $4,200.80$ & $25,204.79$ \\
\hline 5 & $25,204.79$ & $4,200.80$ & $21,004.00$ \\
\hline 6 & $21,004.00$ & $4,200.80$ & $16,803.20$ \\
\hline 7 & $16,803.20$ & $4,200.80$ & $12,602.40$ \\
\hline 8 & $12,602.40$ & $4,200.80$ & $8,401.60$ \\
\hline 9 & $8,401.60$ & $4,200.80$ & $4,200.80$ \\
\hline 10 & $4,200.80$ & $4,200.80$ & 0.00 \\
\hline
\end{tabular}

FUENTE: Elaboración propia

\subsubsection{Inversión de Capital de Trabajo.}

Según Nassir Sapag Chain (2011), el capital de trabajo es la inversión necesaria para financiar el periodo de operación entre la ocurrencia de los ingresos y los egresos.

Para determinar el capital de trabajo necesario del negocio se ha calculado en función al método déficit acumulado, consistente en determinar la inversión del capital de trabajo necesario para financiar los costos de operación desde que se inician los desembolsos hasta que se logren recuperar.

Este método nos permite determinar el máximo déficit acumulado de manera mensual que se produce entre las ocurrencias de los egresos con los ingresos. Los resultados nos permiten determinar el capital de trabajo necesario de este plan de negocios consistente en S/ 51,239 soles, reflejado en el siguiente cuadro. 
Cuadro $\mathrm{N}^{\circ} 65$ :

Método del máximo Déficit Acumulado

\begin{tabular}{|c|c|c|c|c|c|c|c|c|c|c|c|c|}
\hline & \multicolumn{12}{|c|}{ Año 1} \\
\hline Detalle & Ene & Feb & Mar & $\mathrm{Abr}$ & May & Jun & Jul & Ago & Sep & Oct & Nov & Dic \\
\hline \multirow[t]{2}{*}{ Ingresos por Ventas } & 35,197 & 43,996 & 52,795 & 52,795 & 61,594 & 70,393 & 79,193 & 79,193 & 87,992 & 87,992 & 105,590 & 123,188 \\
\hline & $4 \%$ & $5 \%$ & $6 \%$ & $6 \%$ & $7 \%$ & $8 \%$ & $9 \%$ & $9 \%$ & $10 \%$ & $10 \%$ & $12 \%$ & $14 \%$ \\
\hline Egresos & 50,670 & 52,820 & 54,971 & 54,971 & 57,121 & 59,272 & 61,422 & 61,422 & 63,573 & 63,573 & 67,874 & 72,175 \\
\hline Materia prima e insumos & 8,602 & 10,752 & 12,903 & 12,903 & 15,053 & 17,204 & 19,354 & 19,354 & 21,505 & 21,505 & 25,806 & 30,107 \\
\hline Mano de obra directa & 7,514 & 7,514 & 7,514 & 7,514 & 7,514 & 7,514 & 7,514 & 7,514 & 7,514 & 7,514 & 7,514 & 7,514 \\
\hline Mano de obra indirecta & 18,593 & 18,593 & 18,593 & 18,593 & 18,593 & 18,593 & 18,593 & 18,593 & 18,593 & 18,593 & 18,593 & 18,593 \\
\hline Gastos Administrativos & 11,989 & 11,989 & 11,989 & 11,989 & 11,989 & 11,989 & 11,989 & 11,989 & 11,989 & 11,989 & 11,989 & 11,989 \\
\hline Gastos de Ventas & 2,726 & 2,726 & 2,726 & 2,726 & 2,726 & 2,726 & 2,726 & 2,726 & 2,726 & 2,726 & 2,726 & 2,726 \\
\hline Gastos de Operativos & 1,245 & 1,245 & 1,245 & 1,245 & 1,245 & 1,245 & 1,245 & 1,245 & 1,245 & 1,245 & 1,245 & 1,245 \\
\hline Deficit & $-15,473$ & $-8,825$ & $-2,176$ & $-2,176$ & 4,473 & 11,122 & 17,770 & 17,770 & 24,419 & 24,419 & 37,716 & 51,014 \\
\hline Déficit acumulado mensual & $-15,473$ & $-24,298$ & $-26,474$ & $-28,649$ & $-24,177$ & $-13,055$ & 4,715 & 22,485 & 46,904 & 71,323 & 109,039 & 160,053 \\
\hline
\end{tabular}

\begin{tabular}{l|r|rrrrrr}
\hline Detalle & Año 0 & Año 1 & Año 2 & Año 3 & Año 4 & Año 5 \\
\hline Crecimiento de Ingresos & & & $3 \%$ & $3 \%$ & $3 \%$ & $3 \%$ \\
\hline
\end{tabular}

Requerimiento de Capital de Trabajo

Variación de capital de trabajo

$\begin{array}{lllll}-28,649 & -29,509 & -30,394 & -31,306 & -32,245\end{array}$

Inversión en Capital de trabajo

$\begin{array}{llll}-859 & -885 & -912 & -939 \\ -885 & -912 & -939 & \end{array}$

Recuperación capital de trabajo

FUENTE: Elaboración propia. 


\subsubsection{Inversiones en activos Intangibles}

La inversión en activos intangibles asciende a un monto de S/. 38,955.92, dentro de los cuales se encuentra los pagos de constitución de empresa, pago de registros, publicaciones, permisos entre otros y gastos por remodelación, cambio de pisos, ventanas, pintados entre otros.

Cuadro $\mathrm{N}^{\circ} 6$ 6:

Activos Intangibles - Gastos de Inversión

\begin{tabular}{|c|c|c|c|c|c|c|}
\hline GASTOS INVERSIÓN & PROVEEDOR & CANT. & $\begin{array}{l}\text { COSTO } \\
\text { UNT. }\end{array}$ & $\begin{array}{l}\text { COSTO } \\
\text { SIN IGV }\end{array}$ & IGV & $\begin{array}{l}\text { COSTO } \\
\text { CON IGV }\end{array}$ \\
\hline Alquiler Local Comercial MES & 2 mes garantía & 2 & $11,000.00$ & $22,000.00$ & 0.00 & $22,000.00$ \\
\hline $\begin{array}{l}\text { Certificado de búsqueda mercantil, } \\
\text { Solicitud de reserva de razón social }\end{array}$ & SUNARP & 1 & 4.00 & 3.39 & 0.61 & 4.00 \\
\hline Reserva de nombre & SUNARP & 1 & 18.00 & 15.25 & 2.75 & 18.00 \\
\hline Elaboración de la minuta & $\begin{array}{l}\text { NOTARIA MEDINA } \\
\text { RAGGIO }\end{array}$ & 1 & 510.00 & 432.20 & 77.80 & 510.00 \\
\hline Elevación a escritura pública de minuta & $\begin{array}{l}\text { NOTARIA MEDINA } \\
\text { RAGGIO }\end{array}$ & 1 & 45.00 & 38.14 & 6.86 & 45.00 \\
\hline $\begin{array}{l}\text { Derechos de calificación 3/1000 del valor } \\
\text { de capital }\end{array}$ & SUNARP & 1 & 43.74 & 37.07 & 6.67 & 43.74 \\
\hline Derechos de inscripción & SUNARP & 1 & 8.64 & 7.32 & 1.32 & 8.64 \\
\hline Inscripción del RUC & SUNAT & 1 & 0.00 & 0.00 & 0.00 & 0.00 \\
\hline Legalización de libros contables & $\begin{array}{l}\text { NOTARIA MEDINA } \\
\text { RAGGIO }\end{array}$ & 1 & 250.00 & 211.86 & 38.14 & 250.00 \\
\hline Legalización de libros societarios & $\begin{array}{l}\text { NOTARIA MEDINA } \\
\text { RAGGIO }\end{array}$ & 1 & 100.00 & 84.75 & 15.25 & 100.00 \\
\hline Autorización de Planillas de pago & $\begin{array}{l}\text { NOTARIA MEDINA } \\
\text { RAGGIO }\end{array}$ & 1 & 35.00 & 29.66 & 5.34 & 35.00 \\
\hline Búsqueda de antecedentes fonéticos & SUNARP & 1 & 110.51 & 93.65 & 16.86 & 110.51 \\
\hline Búsqueda de antecedentes figurativos & SUNARP & 1 & 130.82 & 110.86 & 19.96 & 130.82 \\
\hline Registro de marca & SUNARP & 1 & 533.30 & 451.95 & 81.35 & 533.30 \\
\hline Publicación diario El Peruano & EL PERUANO & 1 & 50.00 & 42.37 & 7.63 & 50.00 \\
\hline Registro sanitario & MUNICIPALIDAD & 1 & 30.00 & 25.42 & 4.58 & 30.00 \\
\hline Licencia Municipal & MUNICIPALIDAD & 1 & 150.00 & 127.12 & 22.88 & 150.00 \\
\hline Permisos municipales para remodelación & MUNICIPALIDAD & 1 & 290.30 & 246.02 & 44.28 & 290.30 \\
\hline Certificado de defensa civil & MUNICIPALIDAD & 1 & 85.68 & 72.61 & 13.07 & 85.68 \\
\hline Certificado de seguridad en defensa civil & MUNICIPALIDAD & 1 & 223.00 & 188.98 & 34.02 & 223.00 \\
\hline Registro sanitario & DIGESA & 1 & 70.00 & 59.32 & 10.68 & 70.00 \\
\hline Antivirus & WORLD OFFICE Perú & 1 & 120.00 & 101.69 & 18.31 & 120.00 \\
\hline Portal web & WORLD OFFICE Perú & 1 & $2,000.00$ & $1,694.92$ & 305.08 & $2,000.00$ \\
\hline Cambio de pisos & $\begin{array}{l}\text { MARCOLE PERU } \\
\text { ARQUITECTOS } \\
\end{array}$ & 2 & $1,500.00$ & $2,542.37$ & 457.63 & $3,000.00$ \\
\hline Cambio de ventanas & \begin{tabular}{|l|} 
MARCOLE PERU \\
ARQUITECTOS \\
\end{tabular} & 2 & $1,500.00$ & $2,542.37$ & 457.63 & $3,000.00$ \\
\hline lluminación del local & \begin{tabular}{|l|} 
MARCOLE PERU \\
ARQUITECTOS \\
\end{tabular} & 4 & 300.00 & $1,016.95$ & 183.05 & $1,200.00$ \\
\hline Pintado de paredes & $\begin{array}{l}\text { MARCOLE PERU } \\
\text { ARQUITECTOS }\end{array}$ & 1 & $1,500.00$ & $1,271.19$ & 228.81 & $1,500.00$ \\
\hline Acabados & $\begin{array}{l}\text { MARCOLE PERU } \\
\text { ARQUITECTOS } \\
\end{array}$ & 1 & $2,000.00$ & $1,694.92$ & 305.08 & $2,000.00$ \\
\hline Instalaciones electricas & $\begin{array}{l}\text { MARCOLE PERU } \\
\text { ARQUITECTOS }\end{array}$ & 10 & 100.00 & 847.46 & 152.54 & $1,000.00$ \\
\hline Decoración del ambiente. & $\begin{array}{l}\text { MARCOLE PERU } \\
\text { ARQUITECTOS } \\
\end{array}$ & 1 & $3,500.00$ & $2,966.10$ & 533.90 & $3,500.00$ \\
\hline & TOTAL & & & $38,955.92$ & $3,052.07$ & $42,007.99$ \\
\hline
\end{tabular}

FUENTE: Elaboración propia. 


\subsection{Financiamiento.}

Para desarrollar el Plan de Negocios se ha determinado dos fuentes de financiamiento, la inversión de capital propio y capital financiado por una entidad bancaria o financiera como se indica en el siguiente cuadro:

Cuadro $\mathrm{N}^{\circ} 67$ :

Programación del financiamiento

\begin{tabular}{|l|c|r|r|}
\hline \multirow{2}{*}{\multicolumn{1}{|c|}{ INVERSIÓN }} & TOTAL & PROPIO & \multicolumn{1}{c|}{ FINANCIADO } \\
\cline { 2 - 4 } & $100 \%$ & $60 \%$ & $40 \%$ \\
\hline Activo Fijo Tangible & 49,004 & 29,403 & 19,602 \\
\hline Activo Fijo Intangible & 38,956 & 23,374 & 15,582 \\
\hline Inversión en KW & 28,649 & 17,190 & 11,460 \\
\hline Total inversión & 116,610 & 69,966 & 46,644 \\
\hline
\end{tabular}

FUENTE: Elaboración propia.

Como emprendedores de un nuevo negocio al buscar un apalancamiento financiero se presentan dificultades para acceder a ello, siendo no muy accesible o fácil de obtener por los requisitos y exigencia que solicitan las entidades financieras y bancarias, debido a que todas las entidades bancarias y financieras buscan que el cliente cuente con un historial crediticio, un negocio que tenga como mínimo un año de existencia y una garantía que puede ser hipotecaria para proceder con el préstamo de capital de trabajo.

Una de las mejores alternativas presentadas entre todas las instituciones bancarias y financieras ha sido la elección del Scotiabank debido a que no hubo limitaciones al monto que estábamos solicitando, la tasa es bastante baja con respecto a las demás ofertas, se presentó un aval solidario con la finalidad de contar con el plazo del crédito de 5 años, que permitió la aceptación de nuestro préstamo bancario.

Este tipo de financiamiento está dirigido a pequeñas y medianas empresas denominadas como Banca Negocios: 


\section{Producto:}

\section{Capital de Trabajo}

\section{General}

Financiamiento a corto plazo para adquisición de inventarios, cuentas por cobrar, materia prima y/o cualquier otra necesidad de capital de trabajo mediante líneas rotativas o créditos decrecientes.

\section{Características:}

- $\quad$ Líneas Rotativas

- Disponibilidad aprobada con retiros parciales o totales.

\section{Ventajas}

- Disponibilidad inmediata de efectivo, cuando lo requieras

- Se pagan intereses únicamente por el monto desembolsado

- $\quad$ Pago de capital al finalizar el plazo de cada desembolso

- $\quad$ Plazo de desembolsos hasta 360 días

- $\quad$ Los abonos realizados generan disponibilidad

- Garantía:

Hasta $\$ 30,000$ sin garantía hipotecaria

Mayor a $\$ 30,000$ con garantía hipotecaria

Créditos decrecientes

Un solo desembolso al momento de la formalización

\section{Ventajas}

- Hasta 4 años plazo (Se envía a comité de créditos para ampliar el plazo a 5 años)

- $\quad$ Pago de capital e intereses mensuales

\section{Garantía:}

- Hasta $\$ 30,000$ sin garantía hipotecaria, pero si exigen la presencia de un garante solidario para la firma del contrato.

- $\quad$ Mayor a \$30,000 con garantía hipotecaria 
Cuadro $\mathrm{N}^{\circ} 68$ :

Cronograma de pagos de Capital de Trabajo.

\begin{tabular}{|c|c|c|c|c|c|}
\hline \multicolumn{6}{|c|}{ CUADRODE } \\
\hline Periodo & saldo & Intereses & Amortizacion & Cuota & Escudo Fiscal \\
\hline $\mathbf{O}$ & 46,644 & & & & \\
\hline 1 & 46,186 & 779 & 458 & 1,237 & 230 \\
\hline 2 & 45,721 & 772 & 465 & 1,237 & 228 \\
\hline 3 & 45,248 & 764 & 473 & 1,237 & 225 \\
\hline 4 & 44,767 & 756 & 481 & 1,237 & 223 \\
\hline 5 & 44,277 & 748 & 489 & 1,237 & 221 \\
\hline 6 & 43,780 & 740 & 497 & 1,237 & 218 \\
\hline 7 & 43,275 & 732 & 506 & 1,237 & 216 \\
\hline 8 & 42,761 & 723 & 514 & 1,237 & 213 \\
\hline 9 & 42,238 & 714 & 523 & 1,237 & 211 \\
\hline 10 & 41,707 & 706 & 531 & 1,237 & 208 \\
\hline 11 & 41,166 & 697 & 540 & 1,237 & 206 \\
\hline 12 & 40,617 & 688 & 549 & 1,237 & 203 \\
\hline 13 & 40,059 & 679 & 558 & 1,237 & 200 \\
\hline 14 & 39,491 & 669 & 568 & 1,237 & 197 \\
\hline 15 & 38,914 & 660 & 577 & 1,237 & 195 \\
\hline 16 & 38,327 & 650 & 587 & 1,237 & 192 \\
\hline 17 & 37,730 & 640 & 597 & 1,237 & 189 \\
\hline 18 & 37,124 & 630 & 607 & 1,237 & 186 \\
\hline 19 & 36,507 & 620 & 617 & 1,237 & 183 \\
\hline 20 & 35,880 & 610 & 627 & 1,237 & 180 \\
\hline 21 & 35,242 & 600 & 638 & 1,237 & 177 \\
\hline 22 & 34,594 & 589 & 648 & 1,237 & 174 \\
\hline 23 & 33,935 & 578 & 659 & 1,237 & 171 \\
\hline 24 & 33,265 & 567 & 670 & 1,237 & 167 \\
\hline 25 & 32,583 & 556 & 681 & 1,237 & 164 \\
\hline 26 & 31,891 & 544 & 693 & 1,237 & 161 \\
\hline 27 & 31,186 & 533 & 704 & 1,237 & 157 \\
\hline 28 & 30,470 & 521 & 716 & 1,237 & 154 \\
\hline 29 & 29,743 & 509 & 728 & 1,237 & 150 \\
\hline 30 & 29,002 & 497 & 740 & 1,237 & 147 \\
\hline 31 & 28,250 & 485 & 752 & 1,237 & 143 \\
\hline 32 & 27,485 & 472 & 765 & 1,237 & 139 \\
\hline 33 & 26,707 & 459 & 778 & 1,237 & 135 \\
\hline 34 & 25,916 & 446 & 791 & 1,237 & 132 \\
\hline 35 & 25,112 & 433 & 804 & 1,237 & 128 \\
\hline 36 & 24,295 & 420 & 817 & 1,237 & 124 \\
\hline 37 & 23,463 & 406 & 831 & 1,237 & 120 \\
\hline 38 & 22,618 & 392 & 845 & 1,237 & 116 \\
\hline 39 & 21,759 & 378 & 859 & 1,237 & 111 \\
\hline 40 & 20,886 & 364 & 874 & 1,237 & 107 \\
\hline 41 & 19,998 & 349 & 888 & 1,237 & 103 \\
\hline 42 & 19,095 & 334 & 903 & 1,237 & 99 \\
\hline 43 & 18,177 & 319 & 918 & 1,237 & 94 \\
\hline 44 & 17,243 & 304 & 933 & 1,237 & 90 \\
\hline 45 & 16,294 & 288 & 949 & 1,237 & 85 \\
\hline 46 & 15,329 & 272 & 965 & 1,237 & 80 \\
\hline 47 & 14,348 & 256 & 981 & 1,237 & 76 \\
\hline 48 & 13,351 & 240 & 997 & 1,237 & 71 \\
\hline 49 & 12,337 & 223 & 1,014 & 1,237 & 66 \\
\hline 50 & 11,306 & 206 & 1,031 & 1,237 & 61 \\
\hline 51 & 10,258 & 189 & 1,048 & 1,237 & 56 \\
\hline 52 & 9,192 & 171 & 1,066 & 1,237 & 51 \\
\hline 53 & 8,109 & 154 & 1,084 & 1,237 & 45 \\
\hline 54 & 7,007 & 135 & 1,102 & 1,237 & 40 \\
\hline 55 & 5,887 & 117 & 1,120 & 1,237 & 35 \\
\hline 56 & 4,748 & 98 & 1,139 & 1,237 & 29 \\
\hline 57 & 3,591 & 79 & 1,158 & 1,237 & 23 \\
\hline 58 & 2,414 & 60 & 1,177 & 1,237 & 18 \\
\hline 59 & 1,217 & 40 & 1,197 & 1,237 & 12 \\
\hline 60 & 0 & 20 & 1,217 & 1,237 & 6 \\
\hline TOTAL & & 25,267 & 45,248 & 70,514 & \\
\hline
\end{tabular}

FUENTE: Elaboración propia. 
Cuadro $\mathrm{N}^{\circ} 69$ :

Propuesta de Financiamiento de Capital de Trabajo

\begin{tabular}{lr}
\hline PRÉSTAMO BANCARIO & 46,644 \\
\hline TEA & $22.00 \%$ \\
\hline TEM & $1.67 \%$ \\
\hline CUOTA MENSUAL & 1,237 \\
\hline PLAZO & 60 \\
\hline
\end{tabular}

FUENTE: Elaboración propia.

Cuadro $N^{\circ} 610$ :

Propuesta entidades Bancarias

\begin{tabular}{|c|c|c|c|c|c|c|c|c|}
\hline BANCO & PRODUCTO & $\begin{array}{l}\text { MONTO A } \\
\text { FINANCIAR }\end{array}$ & $\begin{array}{l}\text { VALOR } \\
\text { CUOTA }\end{array}$ & $\begin{array}{c}\text { TEA } \\
\text { ANUAL }\end{array}$ & $\begin{array}{c}\text { TEA } \\
\text { MENSUAL }\end{array}$ & PLAZO & MONEDA & GARANTIA \\
\hline \multirow{2}{*}{ BBVA Continental } & CAPITAL DE & & & & & & & \\
\hline & TRABAJO & $55,641.00$ & $1,449.53$ & $21.00 \%$ & $1.60 \%$ & 60 Meses & SOLES & $\mathrm{SI}$ \\
\hline In & CAPITAL DE & & & & & & & \\
\hline & TRABAJO & $55,641.00$ & $1,553.34$ & $25.00 \%$ & $1.88 \%$ & 60 Meses & SOLES & NO \\
\hline & $\begin{array}{l}\text { GARANTIA } \\
\text { HIPOTECARIA }\end{array}$ & $55,641.00$ & $1,514.49$ & $23.50 \%$ & $1.77 \%$ & 60 Meses & SOLES & SI \\
\hline Scotiabank & $\begin{array}{l}\text { CAPITAL DE } \\
\text { TRABAJO }\end{array}$ & $55,641.00$ & $1,476.00$ & $22.00 \%$ & $1.67 \%$ & 60 Meses & SOLES & NO \\
\hline
\end{tabular}

FUENTE: Elaboración propia.

\subsubsection{Costo de Oportunidad.}

Se define como lo que tienes que sacrificar al tomar una decisión en lugar de otra.

Para determinar el costo de oportunidad del plan de negocios se calculó el COK en base a los siguientes datos: tasa libre de riesgo, la cual hace referencia al rendimiento de los bonos del tesoro americano (se consideró el promedio de los últimos 10 años, información extraída de la página web de Damodaran), el rendimiento, Dow Jones promedio, calculado por el método del CAPM..

Los componentes para el cálculo son los siguientes: 
Cuadro $\mathrm{N}^{\circ} 6$ 11:

Indicadores y datos financieros

\begin{tabular}{|c|c|c|}
\hline \multicolumn{2}{|l|}{ DATOS } & TASA \\
\hline Bonos del Tesoro Americano & $\mathrm{Rf}$ & $2.52 \%$ \\
\hline Rendimiento Dow Jones & $\mathrm{Rm}$ & $12.57 \%$ \\
\hline Riego País Standard \& Poor's & $\mathrm{Rp}$ & $1.01 \%$ \\
\hline Beta desapalancada & $\beta d$ & 0.68 \\
\hline Riesgo Proyecto & & $4.00 \%$ \\
\hline Inflación Estados Unidos & & $2.96 \%$ \\
\hline Año 2010 & $1.50 \%$ & 1.0150 \\
\hline Año 2011 & $2.96 \%$ & 1.0296 \\
\hline Año 2012 & $1.74 \%$ & 1.0174 \\
\hline Año 2013 & $1.50 \%$ & 1.0150 \\
\hline Año 2014 & $0.76 \%$ & 1.0076 \\
\hline Año 2015 & $0.73 \%$ & 1.0073 \\
\hline Año 2016 & $2.07 \%$ & 1.0207 \\
\hline Año 2017 & $2.11 \%$ & 1.0211 \\
\hline Año 2018 & $1.91 \%$ & $\underline{1.0191}$ \\
\hline \multicolumn{2}{|c|}{ Promedio } & 1.16338253 \\
\hline Inflación Perú & & $1.70 \%$ \\
\hline Año 2010 & $2.08 \%$ & 1.0208 \\
\hline Año 2011 & $4.74 \%$ & 1.0474 \\
\hline Año 2012 & $2.65 \%$ & 1.0265 \\
\hline Año 2013 & $2.86 \%$ & 1.0286 \\
\hline Año 2014 & $3.22 \%$ & 1.0322 \\
\hline Año 2015 & $4.40 \%$ & 1.0440 \\
\hline Año 2016 & $3.23 \%$ & 1.0323 \\
\hline Año 2017 & $1.30 \%$ & 1.0136 \\
\hline Año 2018 & $2.19 \%$ & $\underline{1.0219}$ \\
\hline \multicolumn{2}{|c|}{ Promedio } & 1.30078041 \\
\hline \% Deuda Perú & & $22.00 \%$ \\
\hline Impuesto a la Renta & & $29.50 \%$ \\
\hline
\end{tabular}

Fuente: DAMODARAN [en línea]. Lima: Bonos tesoro americano, 2019. [citado 25 abril 2019 Microsoft HTML.

Disponible en]..http://people.stern.nyu.edu/adamodar/New Home Page/home.htm

Fuente: BANCO CENTRAL DE RESERVA DEL PERÚ. Reporte de Inflación. [en línea].

Lima: BCRP, 2018. [citado 25 abril 2019]. Adobe Acrobat. Disponible en:

http://www.bcrp.gob.pe/docs/Publicaciones/Reporte-Inflacion/2018/diciembre/reporte-de-inflacion-diciembre-

2018.pdf

Fuente: Inflacion.eu Inflación Histórica EEUU [en línea]. Lima: Inflación IPC, 2019. [citado 25 abril 2019 Microsoft HTML. Disponible en].https://es.inflation.eu/tasas-de-inflacion/estados-unidos/inflacion-historica/ipc-inflacionestados-unidos.aspx

Fuente: Rendimiento Dow Jones [en línea]. Lima: S\&P, 2019. [citado 25 abril 2019 Microsoft HTML. Disponible en]. https://espanol.spindices.com/indices/equity/dow-jones-industrial-average 


\section{Determinación del COK:}

Para poder determinar el COK del plan de negocios se calculó teniendo en cuenta lo siguiente:

a. Para ello se obtiene la beta apalancada

$$
\begin{aligned}
& \beta_{\mathrm{d}}=\beta_{\mathrm{a}}[(1+(1-t)(D / P)] \\
& \beta_{\mathrm{a}}=0.9996
\end{aligned}
$$

b. Cok Usa nominal

\section{$C O K_{E E U U}=R f+\beta_{a}(R m-R f)$}

$\begin{array}{lll}\text { COK } & =2.52 \%+0.9996 *(12.57 \%-2.52 \%) \\ \text { COK } & =12.57 \% \text { nominal }\end{array}$

c. Cok Perú nominal

COK peru nominal $_{\text {a }}=$ COK eEUu nom inal + Riesgo Pais + Riesgo Proyecto

COK Peru nominal $=12.57 \%+1.01 \%+4 \%$

COK $_{\text {PERU NOMINAL }}=17.580 \%$ 
d. Cok Perú Real

COK ${ }_{\text {PERU REAL }}=$ Inflación Relativa PERU/EEUU + COK Peru Nominal

Inflacion Relativa $=\quad 1.24 \%$

$$
\text { COK } \text { PERU REAL }=1.24 \%+17.58 \%
$$

COK ${ }_{\text {PERU Real }}=18.82 \%$

e. Ajuste por Inflación.

\begin{tabular}{|l}
$\begin{array}{c}\text { AJUSTE DE } \\
\text { INFLACION }\end{array}$ \\
INOK EEUU - INFLACION EEUU \\
$1+$ INFLACION EEUU
\end{tabular}

\begin{tabular}{l}
$\begin{array}{l}\text { AJUSTE DE } \\
\text { INFLACION }\end{array}=9.33 \%$ \\
\hline
\end{tabular}

La tasa real Perú es de $18.82 \%$ (Costo de Oportunidad), encontrándose en una categoría apropiada, considerando que es un plan de negocios nuevo.

\subsubsection{Costo Promedio del Capital.}

Es el costo promedio ponderado del capital (CPPC) obtenido por aportes de los accionistas y de los recursos obtenidos vía endeudamiento, más conocido como WACC, se va a calcular para utilizar como tasa de descuento de los flujos económicos, proporcionándonos un beneficio de evaluación a nuestro plan de negocios. 
La propuesta de nuestro plan de negocios es la aportación de capital $60 \%$ del accionista y el $40 \%$ se obtendrá por un préstamo bancario.

\subsubsection{Determinación del WACC.-}

Para el cálculo del WACC, se está considerando el COK apalancado, calculado en el punto 6.2.1, el costo de la deuda es la tasa de interés del préstamo bancario, pero se está considerando una TEA real, el indicador de capital y endeudamiento se ha establecido en base a la capacidad de aporte de los socios inversionistas, además se está considerando el $29.5 \%$ de impuesto a la renta.

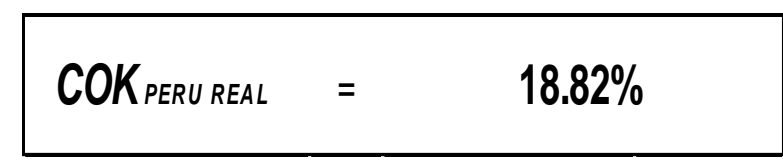

$$
\text { TEA real }=\frac{1+22 \%}{1+2.96 \%}-1
$$

TEA real $=18.49$

$\begin{aligned} \text { WACC } & =18.82 \% \times 60 \%+\text { TEA } \times(1-29.5 \%) \times 40 \% \\ \text { WACC } & =16.51 \%\end{aligned}$

Como se puede apreciar, el WACC, calculado para este plan de negocios es de $16.51 \%$. 


\subsection{Presupuesto Base.}

\subsubsection{Presupuesto de Ventas.}

El presupuesto de ventas se está proyectado para cinco años tomando como referencia los clientes potenciales determinados en nuestro sondeo de estudio de mercado.

El incremento que se está tomando para la proyección de los 5 años es con la tendencia de un crecimiento anual de $3 \%$ similar a la tendencia del crecimiento de nuestro PBI.

Cuadro $\mathrm{N}^{\circ} 6$ 12:

Proyección de Ventas

\begin{tabular}{|c|c|c|c|c|c|c|c|c|c|}
\hline \multirow{3}{*}{ AÑO } & \multirow{3}{*}{$\begin{array}{l}\text { Mercado } \\
\text { Potencial }\end{array}$} & Mercado & Mercado & Mercado & \multirow{3}{*}{$\begin{array}{c}\begin{array}{c}\text { Frecuencia } \\
\text { de } \\
\text { almuerzo }\end{array} \\
\text { almuent }\end{array}$} & \multirow{3}{*}{$\begin{array}{l}\text { Semanas } \\
\text { efectivas al } \\
\text { año }\end{array}$} & \multirow{3}{*}{$\begin{array}{l}\text { Proyección } \\
\text { ventas } \\
\text { anuales } \\
\text { cant. }\end{array}$} & \multirow{3}{*}{ Precio } & \multirow{3}{*}{$\begin{array}{l}\text { Proyección de } \\
\text { ventas en soles } \\
\text { anuales }\end{array}$} \\
\hline & & Disponible & Efectivo & Objetivo & & & & & \\
\hline & & $54 \%$ & $50 \%$ & $42.25 \%$ & & & & & \\
\hline Año 1 & 28,620 & 15,455 & 7,727 & 3,265 & $24.50 \%$ & 44 & 35,197 & S/ 25.00 & S/ 879,917.50 \\
\hline Año 2 & 29,479 & 15,918 & 7,959 & 3,363 & $24.50 \%$ & 44 & 36,253 & S/ 26.00 & S/ 942,581.64 \\
\hline Año 3 & 30,363 & 16,396 & 8,198 & 3,464 & $24.50 \%$ & 44 & 37,342 & S/ 28.00 & $\mathrm{~S} / 1,045,573.76$ \\
\hline Año 4 & 31,274 & 16,888 & 8,444 & 3,568 & $24.50 \%$ & 44 & 38,463 & S/ 29.00 & $\mathrm{~S} / 1,115,428.16$ \\
\hline Año 5 & 32,212 & 17,395 & 8,697 & 3,675 & $24.50 \%$ & 44 & 39,617 & S/ 30.00 & S/ 1,188,495.00 \\
\hline
\end{tabular}

Luego de determinar la proyección de la cantidad tickets de menús a vender, además para fijar el precio del menú propuesto se ha tomado como referencia el resultado del estudio de mercado a la pregunta ¿ Cuánto suele gastar aproximadamente en un almuerzo - menú ejecutivo, al acudir a estos restaurantes cercanos a su centro de labores?, tomando como resultado a la propuesta el precio de S/25.00 soles, por estar en un punto medio al gasto promedio de nuestro público objetivo.

\subsubsection{Presupuesto de Compras.}

Para determinar nuestra proyección de compras se ha tomado como referencia el presupuesto de venta con la cantidad de menús, 
que los ejecutivos estarían dispuestos a consumir, según el cuadro $\mathrm{N}^{\circ} 6$.

La proyección de crecimiento se ha considerado el crecimiento del $3 \%$ anual del PBI, directamente relacionado al crecimiento de nuestro mercado objetivo.

En el anexo $\mathrm{N}^{\circ} 2$ se está detallando el costo de los insumos que se requiere para elaborar cada menú por plato y propuesta de la carta, manteniendo la propuesta que la mayoría de nuestro mercado objetivo le interesa la presentación de plato de entrada, plato de fondo y refresco.

Se ha elaborado un resumen y proyección de compras a 5 años, totalizados por cada año, la información es en soles, como se puede apreciar los precios icluye el IGV, llegando al quinto año con una proyección de compra de S/242,052.85.

Cuadro $\mathrm{N}^{\circ} 613$ :

Costos de producción-Materia Prima

\begin{tabular}{|c|c|c|c|c|c|c|c|c|}
\hline PRESUPUESTO DE MATERIA PRIM & & AÑO 1 & $\overline{\text { AÑO2 }}$ & & AÑO 3 & & $\overline{A N ̃ O} 4$ & AÑO 5 \\
\hline Materia Prima - sin IGV & $S /$. & $176,339.62$ & S/. $181,632.51$ & S/ & $187,087.43$ & $\overline{S /}$ & $194,091.97$ & $\begin{array}{ll}S / . & 198,483.34\end{array}$ \\
\hline IGV & & $38,708.70$ & S/. $\quad 39,870.55$ & S/ & $41,067.97$ & S/ & $42,605.55$ & $43,569.51$ \\
\hline Materia Prima - Insumos con IGV & $S /$. & $215,048.32$ & S/. 221,503.06 & $\bar{S} /$ & $228,155.40$ & $\mathrm{Sl}$ & $236,697.53$ & S/. $242,052.85$ \\
\hline
\end{tabular}


Cuadro Nº 614 :

Determinación de los costos de producción por plato

\begin{tabular}{|c|c|c|c|c|c|c|c|c|c|c|c|c|}
\hline PROPUESTA & PLATOS & $\%$ PARTIC & UND. & \multicolumn{2}{|c|}{ costo } & \multicolumn{2}{|c|}{ AÑO 1} & \multicolumn{2}{|c|}{ AÑO 2} & \multirow{2}{*}{$\frac{\text { AÑO } 3}{\text { S/. } 21,957.05}$} & \multirow{2}{*}{$\begin{array}{c}\text { AÑO } 4 \\
\text { S/. } 22,779.12\end{array}$} & \multirow{2}{*}{$\begin{array}{c}\text { AÑO } 5 \\
\text { S/. } 23,294.50\end{array}$} \\
\hline \multirow{15}{*}{$\begin{array}{l}\text { Platos de } \\
\text { Fondo }\end{array}$} & Gordon bleu & $15 \%$ & Plato & $\mathrm{S} /$. & 3.92 & $\mathrm{~S} /$. & $20,695.66$ & $\mathrm{~S} /$. & $21,316.85$ & & & \\
\hline & Asado de res con pure & $9 \%$ & Plato & $\mathrm{S} /$. & 3.90 & $\mathrm{~S} /$. & $12,354.04$ & $\mathrm{~S} /$. & $12,724.85$ & S/. $13,107.01$ & S/. $13,597.74$ & S/. $13,905.39$ \\
\hline & Medallon de Pavita al horno & $8 \%$ & Plato & $\mathrm{S} /$. & 3.52 & $\mathrm{~S} /$. & $9,911.39$ & $\mathrm{~S} /$. & $10,208.88$ & S/. $10,515.48$ & S/. $10,909.18$ & S/. $11,156.01$ \\
\hline & Lasaña de verduras & $7 \%$ & Plato & $\mathrm{S} /$. & 3.36 & $\mathrm{~S} /$. & $8,278.26$ & $\mathrm{~S} /$. & $8,526.74$ & S/. $8,782.82$ & S/. $9,111.65$ & S/. $9,317.80$ \\
\hline & Filete de pollo a la parrilla con papa & $10 \%$ & Plato & $\mathrm{S} /$. & 3.03 & $\mathrm{~S} /$. & $10,664.60$ & $\mathrm{~S} /$. & $10,984.70$ & S/. $11,314.60$ & S/. $11,738.22$ & S/. $12,003.80$ \\
\hline & Filete de pollo al vapor con papas & $12 \%$ & Plato & $\mathrm{S} /$. & 3.08 & $\mathrm{~S} /$. & $13,008.70$ & $\mathrm{~S} /$. & $13,399.16$ & S/. $13,801.57$ & S/. $14,318.30$ & S/. $14,642.26$ \\
\hline & Filete de carne con papa horno & $5 \%$ & Plato & $\mathrm{S} /$. & 3.88 & $\mathrm{~S} /$. & $6,828.16$ & $\mathrm{~S} /$. & $7,033.11$ & S/. $7,244.33$ & $\mathrm{~S} / . \quad 7,515.56$ & $\mathrm{~S} / . \quad 7,685.60$ \\
\hline & Filete de carne con verdura & $3 \%$ & Plato & $\mathrm{S} /$. & 3.96 & $\mathrm{~S} /$. & $4,181.37$ & $\mathrm{~S} /$. & $4,306.87$ & S/. $\quad 4,436.22$ & S/. $\quad 4,602.31$ & S/. $4,706.44$ \\
\hline & Tallarines al pesto & $7 \%$ & Plato & $\mathrm{S} /$. & 3.36 & $\mathrm{~S} /$. & $8,278.26$ & $\mathrm{~S} /$. & $8,526.74$ & S/. $\quad 8,782.82$ & S/. $\quad 9,111.65$ & S/. $\quad 9,317.80$ \\
\hline & Hamburguesa casera & $4 \%$ & Plato & $\mathrm{S} /$. & 3.66 & $\mathrm{~S} /$. & $5,152.80$ & $\mathrm{~S} /$. & $5,307.46$ & S/. $\quad 5,466.86$ & S/. $\quad 5,671.54$ & S/. $\quad 5,799.86$ \\
\hline & Lomo Saltado & $6 \%$ & Plato & $\mathrm{S} /$. & 3.80 & $\mathrm{~S} /$. & $8,024.85$ & $\mathrm{~S} /$. & $8,265.72$ & S/. $8,513.96$ & S/. $\quad 8,832.72$ & S/. $9,032.56$ \\
\hline & Pescado a la parrilla con papa & $5 \%$ & Plato & $\mathrm{S} /$. & 3.66 & $\mathrm{~S} /$. & $6,441.00$ & $\mathrm{~S} /$. & $6,634.32$ & S/. $\quad 6,833.57$ & S/. $7,089.42$ & S/. $7,249.82$ \\
\hline & Pescado al vapor con vegetales & $3 \%$ & Plato & $\mathrm{S} /$. & 3.98 & $\mathrm{~S} /$. & $4,202.49$ & $\mathrm{~S} /$. & $4,328.62$ & S/. $4,458.63$ & S/. $4,625.56$ & S/. $4,730.21$ \\
\hline & Pastel de quinua & $4 \%$ & Plato & $\mathrm{S} /$. & 3.90 & $\mathrm{~S} /$. & $5,490.69$ & $\mathrm{~S} /$. & $5,655.49$ & S/. $\quad 5,825.34$ & S/. $\quad 6,043.44$ & S/. $\quad 6,180.17$ \\
\hline & Guiso de Zapallo Italiano & $2 \%$ & Plato & $\mathrm{S} /$. & 3.78 & $\mathrm{~S} /$. & $2,660.87$ & $\mathrm{~S} /$. & $2,740.74$ & S/. $2,823.05$ & S/. $2,928.74$ & S/. $2,995.01$ \\
\hline & Ensalada Capresse & $28 \%$ & Plato & $\mathrm{S} /$. & 1.84 & $\mathrm{~S} /$. & $18,133.34$ & $\mathrm{~S} /$. & $18,677.62$ & S/. $19,238.56$ & S/. $19,958.85$ & S/. 20,410.42 \\
\hline & Ensalada Cesar & $14 \%$ & Plato & $\mathrm{S} /$. & 2.09 & $\mathrm{~S} /$. & $10,298.55$ & $\mathrm{~S} /$. & $10,607.67$ & S/. $10,926.25$ & S/. $11,335.32$ & S/. $11,591.79$ \\
\hline & Provolone a la plancha & $25 \%$ & Plato & $\mathrm{S} /$. & 1.82 & $\mathrm{~S} /$. & $16,014.50$ & $\mathrm{~S} /$. & $16,495.18$ & S/. $16,990.57$ & S/. $17,626.70$ & S/. 18,025.51 \\
\hline Entrada & Portobello a la parrilla & $8 \%$ & Plato & $\mathrm{S} /$. & 2.01 & $\mathrm{~S} /$. & $5,659.63$ & $\mathrm{~S} /$. & $5,829.50$ & S/. $\quad 6,004.58$ & S/. $\quad 6,229.39$ & S/. $\quad 6,370.33$ \\
\hline & Ensalada de Choclo de la casa & $10 \%$ & Plato & $\mathrm{S} /$. & 2.14 & $\mathrm{~S} /$. & $7,532.09$ & $\mathrm{~S} /$. & $7,758.17$ & S/. $7,991.17$ & S/. $\quad 8,290.36$ & S/. $8,477.93$ \\
\hline & Verduras a la parrilla & $10 \%$ & Plato & $\mathrm{S} /$. & 1.49 & $\mathrm{~S} /$. & $5,244.31$ & $\mathrm{~S} /$. & $5,401.72$ & S/. $\quad 5,563.95$ & S/. $\quad 5,772.26$ & S/. $\quad 5,902.86$ \\
\hline & Ceviche de champiñones & $5 \%$ & Plato & $\mathrm{S} /$. & 2.07 & $\mathrm{~S} /$. & $3,642.86$ & $\mathrm{~S} /$. & $3,752.20$ & S/. $\quad 3,864.89$ & S/. $\quad 4,009.59$ & S/. $\quad 4,100.31$ \\
\hline & Refrescos Frutas & $35 \%$ & Vaso & $\mathrm{S} /$. & 0.80 & $\mathrm{~S} /$. & $9,855.08$ & $\mathrm{~S} /$. & $10,150.88$ & S/. $10,455.74$ & S/. $10,847.20$ & S/. 11,092.62 \\
\hline Rohid & Bebidas calientes & $25 \%$ & Taza & $\mathrm{S} /$. & 0.50 & $\mathrm{~S} /$. & $4,399.59$ & $\mathrm{~S} /$. & $4,531.64$ & S/. $\quad 4,667.74$ & S/. $\quad 4,842.50$ & S/. $4,952.06$ \\
\hline Bebidas & Agua & $25 \%$ & Vaso & $\mathrm{S} /$. & 0.50 & $\mathrm{~S} /$. & $4,399.59$ & $\mathrm{~S} /$. & $4,531.64$ & S/. $4,667.74$ & S/. $\quad 4,842.50$ & S/. $4,952.06$ \\
\hline & Café americano/ expreso & $15 \%$ & Taza & $\mathrm{S} /$. & 0.70 & $\mathrm{~S} /$. & $3,695.65$ & $\mathrm{~S} /$. & $3,806.58$ & S/. $\quad 3,920.90$ & S/. $\quad 4,067.70$ & S/. $4,159.73$ \\
\hline
\end{tabular}

Fuente: Elaboración propia 


\subsection{Estados Financieros Proyectados.}

Para elaborar las proyecciones de los Estados Financieros, proyectados del Plan de Negocios con la finalidad de evaluar la rentabilidad del negocio.

\subsubsection{Estado de Pérdidas y Ganancias}

El Estado de Ganancias y Pérdidas es un Estado Financiero que muestra ordenada y detalladamente la forma de cómo se obtuvo el resultado del ejercicio durante un periodo determinado.

El Estado de Ganancias y Pérdidas (EGP) muestra al proyecto rentable en términos generales con una solidez clara desde el primer año de ejecución.

El estado de ganancias y pérdidas del proyecto, muestra en todos los años un resultado positivo el primer año con un margen del $2 \%$ equivalente a una utilidad neta de $\mathrm{S} / .17,689.95$ al 5to año, con el $13 \%$ equivalente $\mathrm{S} / .129,812.26$ tal como se puede apreciar:

Para la elaboración de los Estados de Ganancias y Pérdidas del año 1 al año 5 (proyectado) tiene las siguientes premisas: 
Cuadro $\mathrm{N}^{\circ} 615$ :

Estados de Ganancias y Pérdidas

\begin{tabular}{|c|c|c|c|c|c|}
\hline \multicolumn{6}{|c|}{ ESTADO DE GANACIAS Y PERDIDAS } \\
\hline Periodo & Año 1 & Año 2 & Año 3 & Año 4 & Año 5 \\
\hline VENTAS & $721,532.35$ & $772,916.94$ & $857,370.48$ & $914,651.09$ & $974,565.90$ \\
\hline COSTO DE VENTAS & $489,624.95$ & $504,316.40$ & $519,451.84$ & $536,427.31$ & $551,088.74$ \\
\hline Materia prima & $176,339.62$ & $181,632.51$ & $187,087.43$ & $194,091.97$ & $198,483.34$ \\
\hline Mano de Obra directa & $90,169.00$ & $92,874.07$ & $95,660.29$ & $98,530.10$ & $101,486.00$ \\
\hline Mano de Obra Indirecta & $223,116.33$ & $229,809.82$ & $236,704.12$ & $243,805.24$ & $251,119.40$ \\
\hline UTILIDAD BRUTA & $231,907.40$ & $268,600.54$ & $337,918.65$ & $378,223.78$ & $423,477.16$ \\
\hline \multicolumn{6}{|l|}{ GASTOS DE OPERACIÓN } \\
\hline Gastos Administrativos & $143,980.00$ & $148,299.40$ & $152,748.38$ & $157,330.83$ & $162,050.76$ \\
\hline Gastos de Venta & $38,600.00$ & $39,758.00$ & $40,950.74$ & $42,179.26$ & $43,444.64$ \\
\hline Gastos Operativos & $17,635.80$ & $18,164.87$ & $18,709.82$ & $19,271.11$ & $19,849.25$ \\
\hline Depreciación & $9,800.85$ & $9,800.85$ & $9,800.85$ & $9,800.85$ & $9,800.85$ \\
\hline Amortización & $4,200.80$ & $4,200.80$ & $4,200.80$ & $4,200.80$ & $4,200.80$ \\
\hline TOTAL GASTOS DE OPERACIÓN & $214,217.45$ & $220,223.92$ & $226,410.59$ & $232,782.86$ & $239,346.29$ \\
\hline UTILIDAD ANTES DE IMPUESTOS & $17,689.95$ & $48,376.62$ & $111,508.06$ & $145,440.92$ & $184,130.86$ \\
\hline (-) Impuesto a la Renta $29.5 \%$ & & $14,271.10$ & $32,894.88$ & $42,905.07$ & $54,318.60$ \\
\hline UTILIDAD NETA & $17,689.95$ & $34,105.52$ & $78,613.18$ & $102,535.85$ & $129,812.26$ \\
\hline Margen Neto & $2 \%$ & $4 \%$ & $9 \%$ & $11 \%$ & $13 \%$ \\
\hline
\end{tabular}

Fuente: Elaboración propia.

La siguiente información corresponde a la proyección del Estado de Ganancias y Pérdidas para el plan de negocios correspondiente a un periodo de 5 años, en la cual se detallan todos los ingresos, egresos, y utilidades o perdidas que genera.

En ella se van a identificar los costos y gastos que dieron origen al ingreso o pérdida del mismo. Por tanto, debe ser aplicado perfectamente al principio del periodo contable para que la información que presente sea útil y confiable para la toma de decisiones.

\subsubsection{Flujo de Caja}

En este punto se ha elaborado el flujo de caja proyectado, indicando los detalles de los ingresos y egresos de dinero que se va a tener durante un periodo, en este caso se ha proyectado para 
los 5 años, en este caso va estar compuesto por: el Flujo de Caja Operativo, Flujo de Caja Económico, Flujo de Caja Financiero.

En el siguiente cuadro se puede apreciar los ingresos y egresos a lo largo de los 5 años.

Cuadro $\mathrm{N}^{\circ} 6$ 16:

Flujo de Caja Operativa Proyectado

\begin{tabular}{|c|c|c|c|c|c|c|}
\hline \multicolumn{7}{|c|}{$\begin{array}{r}\text { ESTRUCTURA DEL FLUJO DE CAJA } \\
\text { RESTAURANTE "LIKE HOME" }\end{array}$} \\
\hline & AÑO 0 & AÑO 1 & AÑO2 & AÑO 3 & AÑO 4 & AÑO 5 \\
\hline Ingreso por Ventas & & 721,532 & 772,917 & 857,370 & 914,651 & 974,566 \\
\hline \multicolumn{7}{|l|}{ Menos: } \\
\hline Materia prima & & 176,340 & 181,633 & 187,087 & 194,092 & 198,483 \\
\hline Mano de Obra directa & & 90,169 & 92,874 & 95,660 & 98,530 & 101,486 \\
\hline Mano de Obra Indirecta & & 223,116 & 229,810 & 236,704 & 243,805 & 251,119 \\
\hline UTILIDAD BRUTA & & 231,907 & 268,601 & 337,919 & 378,224 & 423,477 \\
\hline \multicolumn{7}{|l|}{ Menos: } \\
\hline Gastos Utiles y enseres & & 17,636 & 18,165 & 18,710 & 19,271 & 19,849 \\
\hline Gastos Administrativos & & 143,980 & 148,299 & 152,748 & 157,331 & 162,051 \\
\hline Gastos de Venta & & 38,600 & 39,758 & 40,951 & 42,179 & 43,445 \\
\hline Depreciación & & 9,801 & 9,801 & 9,801 & 9,801 & 9,801 \\
\hline Amortización & & 4,201 & 4,201 & 4,201 & 4,201 & 4,201 \\
\hline UTILIDAD OPERATIVA & & 17,690 & 48,377 & 111,508 & 145,441 & 184,131 \\
\hline \multicolumn{7}{|l|}{ Menos: } \\
\hline Impuesto a la Renta (29.5\%) & & 0 & 14,271 & 32,895 & 42,905 & 54,319 \\
\hline UTILIDAD NETA & & 17,690 & 34,106 & 78,613 & 102,536 & 129,812 \\
\hline \multicolumn{7}{|l|}{ Mas } \\
\hline Depreciacion & & 9,801 & 9,801 & 9,801 & 9,801 & 9,801 \\
\hline Amortizacion & & 4,201 & 4,201 & 4,201 & 4,201 & 4,201 \\
\hline FLUJO DE CAJA OPERATIVA & & 31,692 & 48,107 & 92,615 & 116,537 & 143,814 \\
\hline \multicolumn{7}{|l|}{ Mas } \\
\hline Inversion Fija Tangible & $-49,004$ & & & & & 24,502 \\
\hline Inversion Fija Intangible & $-38,956$ & & & & & \\
\hline Capital de Trabajo & $-28,649$ & -859 & -885 & -912 & -939 & 32,245 \\
\hline FLUJO DE CAJA ECONOMICO & $-116,610$ & 30,832 & 47,222 & 91,703 & 115,598 & 200,561 \\
\hline \multicolumn{7}{|l|}{ Más: } \\
\hline Prestamo & 46,644 & & & & & \\
\hline Cuota & & $-14,845$ & $-14,845$ & $-14,845$ & $-14,845$ & $-14,845$ \\
\hline Escudo Fiscal & & 2,601 & 2,210 & 1,733 & 1,151 & 441 \\
\hline FLUJO DE CAJA FINANCIERO & $-69,966$ & 18,588 & 34,587 & 78,591 & 101,904 & 186,157 \\
\hline
\end{tabular}

FUENTE: Elaboración Propia. 


\section{Evaluación de la rentabilidad.}

Para realizar la evaluación de la rentabilidad del Plan de Negocios se ha usado dos herramientas de evaluación financiera como el Valor Actual Neto (VAN) y la Tasa Interna de Retorno (TIR). El análisis de ambas herramientas nos dara la idea si el proyecto puede ser rentable o no en base a las condiciones planteadas.

\section{Valor Actual Neto - VAN}

El VAN es un indicador financiero que mide los flujos de los futuros ingresos y egresos que tendrá nuestro Plan de Negocios, para determinar si el proyecto es viable. Mediante este procedimiento vamos a calcular el valor presente de los flujos de caja futuros originados por la inversión.

Para nuestro Plan de Negocios se ha obtenido un VAN económico y financiero mayor a cero, inclusive nuestro VAN financiero es mayor que el económico, indicándonos que es conveniente financiar el Plan de Negocios con terceros.

Cuadro $\mathrm{N}^{\circ} 6$ 17:

Valor Actual Neto - VANE/VANF

\begin{tabular}{|l|r|}
\hline \multicolumn{2}{|c|}{ EVALUACION FINANCIERA } \\
\hline VANE & $204,214.66$ \\
\hline VANF & $189,096.00$ \\
\hline
\end{tabular}

FUENTE: Elaboración Propia.

El Valor Actual Neto Financiero, permite calcular el valor presente de un determinado número de flujos de caja financieros. El valor actual neto financiero resulta $\mathrm{S} / 189,096.00$ lo cual es mayor a cero, por tanto, según el criterio de la VANF es rentable para el accionista por tanto le es conviene invertir en el plan de negocios. 


\section{Tasa Interna de Retorno - TIR}

Es una herramienta Financiera denominada Tasa Interna de Retorno (TIR) es la tasa que iguala el Valor Actual Neto a cero, introduce el valor del dinero en el tiempo permitiendo evaluar el plan de negocios en función a una única tasa de rendimiento por todo el periodo de evaluación.

De este modo decimos que si la TIR $>0$ o igual a cero con respecto al Kprop, decimos que el negocio es factible o rentable para los inversionistas. Pero, por otro lado

Cuadro $\mathrm{N}^{\circ} 618$ :

Tasa interna de retorno Económico - TIRE

\begin{tabular}{|l|l|}
\hline \multicolumn{2}{|c|}{ EVALUACION ECONOMICA } \\
\hline WACC & $16.51 \%$ \\
\hline TIRE & $51.00 \%$ \\
\hline
\end{tabular}

FUENTE: Elaboración Propia.

La tasa interna de retorno económico (TIRE) ha dado como resultado un $51.00 \%$, lo cual demuestra según evaluación de la TIRE, es viable dado que supera los costos del capital ponderado (WACC) que es el $16.51 \%$ por tanto conviene realizar el plan de negocios.

Cuadro $N^{\circ} 6$ 19:

Tasa interna de retorno financiera- TIRF

\begin{tabular}{|l|l|}
\hline \multicolumn{2}{|c|}{ EVALUACION FINANCIERA } \\
\hline COK & $18.82 \%$ \\
\hline TIRF & $65.00 \%$ \\
\hline
\end{tabular}

FUENTE: Elaboración Propia.

La TIR resulta $65 \%$ lo cual es una tasa mayor al $18.82 \%$, que es el costo de oportunidad del inversionista de invertir en otro proyecto 
de similar riego, por ende es factible para los socios accionistas, invertir en el plan de negocios.

\section{Valor Actual de la empresa en Periodo Continuo.}

Para determinar los flujos después del 5to año se ha tomado como datos los flujo de caja proyectado de 5 años. En la proyección se tienen en cuenta las políticas definidas para el futuro de la empresa dentro de las cuales están: los ingresos por ventas, el costo de ventas, los gastos operativos, la tasa de impuesto a la renta, la depreciación de los activos, las inversiones en activos fijos y el incremento del capital de trabajo.

Luego de obtener los flujos netos libres de caja para cada año, se traen a valor presente con el costo de capital promedio ponderado. De esta manera se calcula el Valor Actual del Periodo Explícito (VAPE) de la empresa:

Como se puede apreciar el valor de la empresa con estos supuestos seria de S/1,071,084.34, a manera de resumen se presentan el siguiente cuadro de cálculos:

$$
\mathrm{VAN}=-\mathrm{I}^{\circ}+\sum \frac{\mathrm{FNE}}{(1+\mathrm{i})^{\mathrm{n}}}
$$

FNE Flujo Neto de Efectivo

G Tasa de crecimiento

VAN $=-$ I0 $\frac{\mathrm{F} 1}{(1+\mathrm{COK})^{1}}+\frac{\mathrm{F} 2}{(1+\mathrm{COK})^{2}}+\frac{\mathrm{F} 3}{(1+\mathrm{COK})^{3}}+\frac{\mathrm{F} 4}{(1+\mathrm{COK})^{4}}+\frac{\mathrm{F} 5}{(1+\mathrm{COK})^{5}}+\frac{\frac{\mathrm{F} 6}{(\mathrm{COK}-\mathrm{G})}}{(1+\mathrm{COK})^{6}}$ 
Cuadro $\mathrm{N}^{\circ} 6$ 20:

Valor Actual de la empresa en Periodo Continuo

\begin{tabular}{|c|c|c|c|}
\hline Año & Flujo de Caja & Facto de ajuste & Valor Actual \\
\hline 0 & $-69,965.78$ & & $-69,965.78$ \\
\hline 1 & $18,588.43$ & 1.133 & $16,408.52$ \\
\hline 2 & $34,587.08$ & 1.283 & $26,950.53$ \\
\hline 3 & $78,591.01$ & 1.454 & $54,057.14$ \\
\hline 4 & $101,904.16$ & 1.647 & $61,872.66$ \\
\hline 5 & $186,156.87$ & 1.866 & $99,772.93$ \\
\hline VAPE & & & $189,096.00$ \\
\hline 6 & $1,864,242.85$ & 2.114 & $881,988.34$ \\
\hline VAPC & & & $881,988.34$ \\
\hline \multicolumn{3}{|c|}{ VE } & $1,071,084.34$ \\
\hline
\end{tabular}

Fuente: Elaboración Propia

Cuadro $N^{\circ} 621$ :

Determinación del Punto de Equilibrio

\begin{tabular}{|l|l|}
\hline DETERMINACION DEL PUNTO DE EQUILIBRIO \\
PUNTO DEEQUILIBRIO & $\frac{\text { Costos Fijos }}{1-\frac{\text { Costos Variables }}{\text { Importe de las Ventas }}}$ \\
PUNTO DEEQUILIBRIO & $\frac{330,921.13}{1-\frac{214,939.62}{721,532.35}}=$ \\
PUNTO DEEQUILIBRIO & $\mathbf{4 7 1 , 3 2 5 . 9 6}$ \\
\hline
\end{tabular}

FUENTE: Elaboración propia. 


\section{CAPÍTULO VII}

\section{CONCLUSIONES Y RECOMENDACIONES}

\subsection{Conclusiones}

1. Para el 2019, el "Consumo Saludable, el Estilo de vida -saludable" será una tendencia que seguirá influenciando el consumo, y por ende se generara una demanda insatisfecha son la base para el desarrollo del plan de negocios.

2. El plan de Negocios se concluye que es viable su ejecución ya que tiene un VANE S/. 204,214.66 (mayor a cero) y la TIRE de 51\% siendo mayor al WACC de $16.51 \%$.

3. El Plan de negocios se ha elaborado con una proyección de crecimiento de nuestro mercado objetivo del $3 \%$ anual.

4. 3. A partir del 4to año estaríamos generando un $11 \%$ de margen neto según nuestra proyección lo indica que existe tendencia de la población peruana a consumir comida saludable y tendencia orgánica, frente a la oferta de comida rápida que es alto en calorías y grasas.

5. 4. El nicho de mercado elegido por el plan de negocios, es muy exigente dentro de las cualidades exigidas para elegir un menú utilizando los aplicativos y redes sociales que en la actualidad son los medios de comunicación más utilizados por la población objetivo.

6. 5. El plan de negocios demuestra que menú con insumos saludables y tendencia orgánica puede lograr el liderazgo 
brindando nuevas alternativas de alimentación, en el mediano plazo.

\subsection{Recomendaciones.}

Este modelo de negocio es fácil de imitar, la única forma de contrarrestar esta debilidad es innovando constantemente. Se recomienda tener en cuenta las siguientes indicaciones:

- Implementar continuamente nuevos servicios y productos a través de estrategias, de acuerdo a las necesidades del mercado, como son aplicativos móviles y diversas modalidades pago (billetera electrónica, tarjeta de crédito y débito).

- Como mercado de menú saludable es nuevo, se necesita desarrollar en los usuarios el hábito de compra de comida por medios digitales. Para esto es necesario trabajar fuertemente en desarrollar campañas publicitarias que ayuden a comprender los beneficios del servicio y la seguridad del mismo.

- Registrar en Indecopi la marca LIKE HOME RESTAURANT, con el objetivo a futuro de ofrecerlo como franquicia a inversionistas nacionales y extranjeros.

- Verificar constantemente que nuestro local cuente con la capacidad instalada suficiente (producción, infraestructura y capacidad instalada) para atender el aumento de clientes. Asimismo, es muy importante asegurar que todo el proceso de venta cumpla con los estándares de calidad en su servicio. 
- Se recomienda desarrollar normas y procedimientos de calidad y atención al cliente, así como tener minucioso cuidado en la estandarización de recetas y proceso de producción.

- Se ha determinado que inicialmente el mercado objetivo del servicio se centre primordialmente en el distrito de San Isidro por ser considerado uno los de mayor concentración de movimiento empresarial y financiero, Por lo tanto, se recomienda establecer el centro del negocio en el radio de cobertura para facilitar la llegada de los clientes.

- Durante el desarrollo del negocio y previo a la apertura, se debe levantar todas las incidencias que pudieran generarse para su posterior análisis y evaluaciones preventivas. 


\section{ANEXOS}

\section{ANEXO 1. CARACTERÍSTICAS Y PROPUESTAS.}

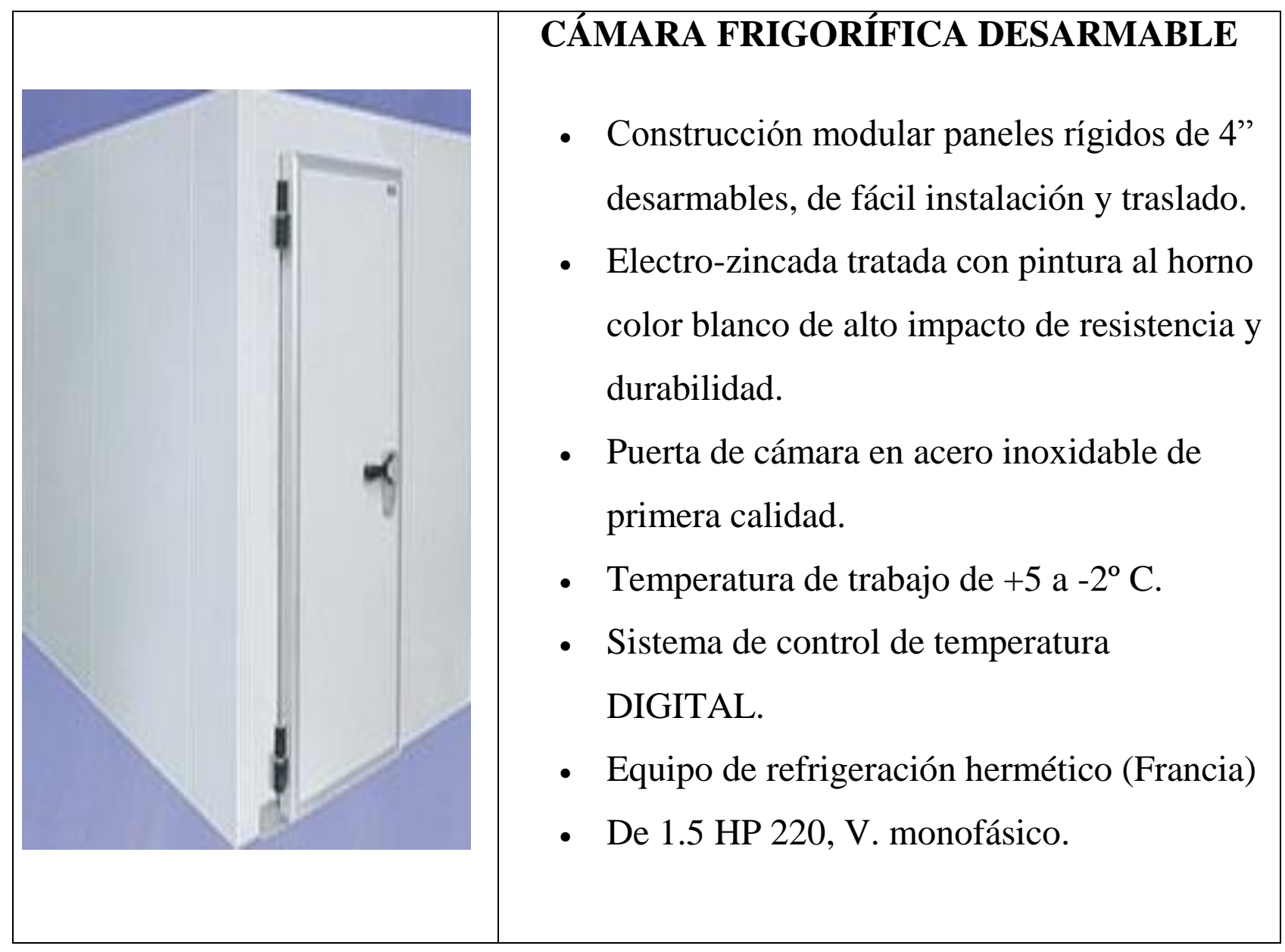



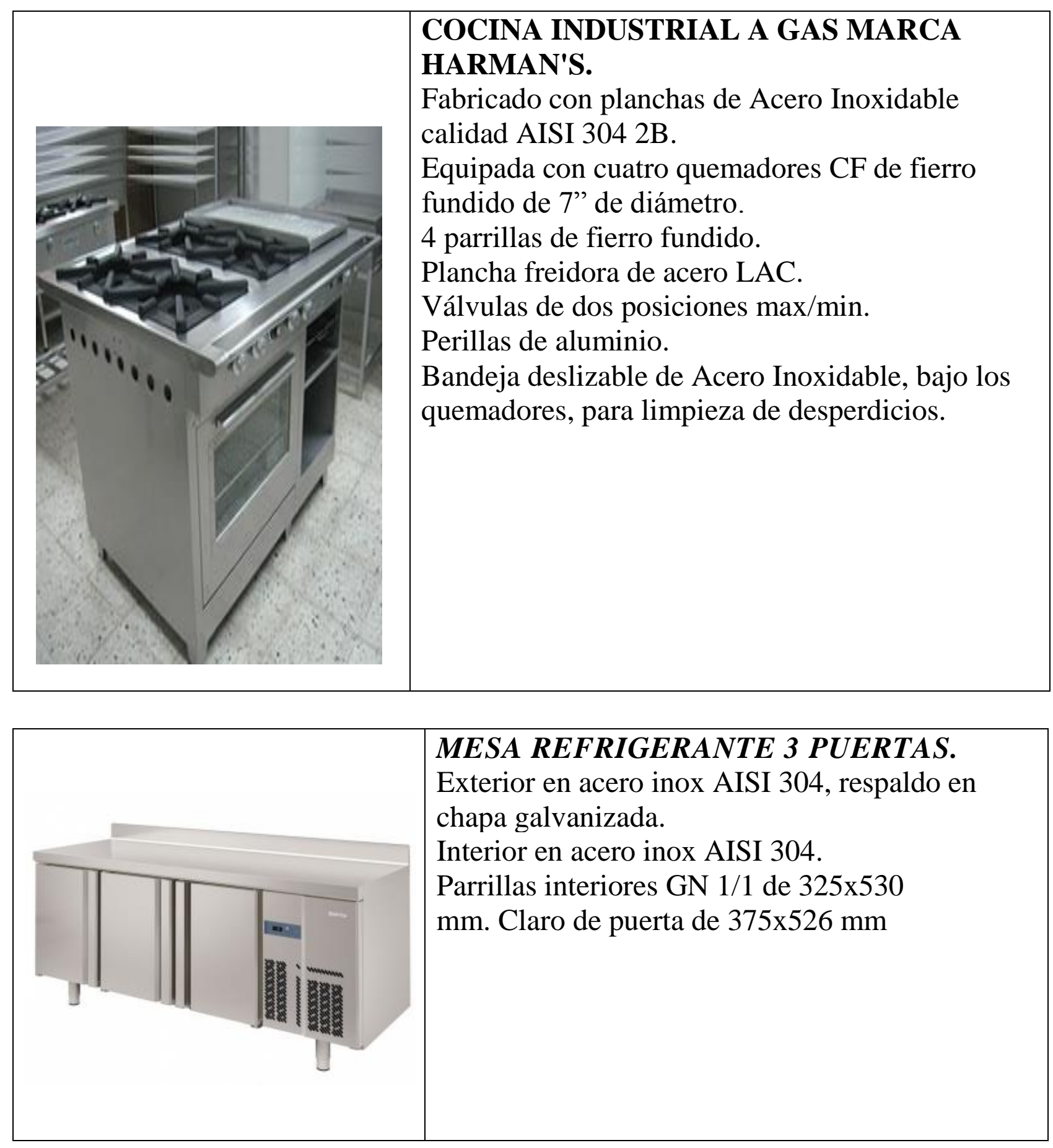


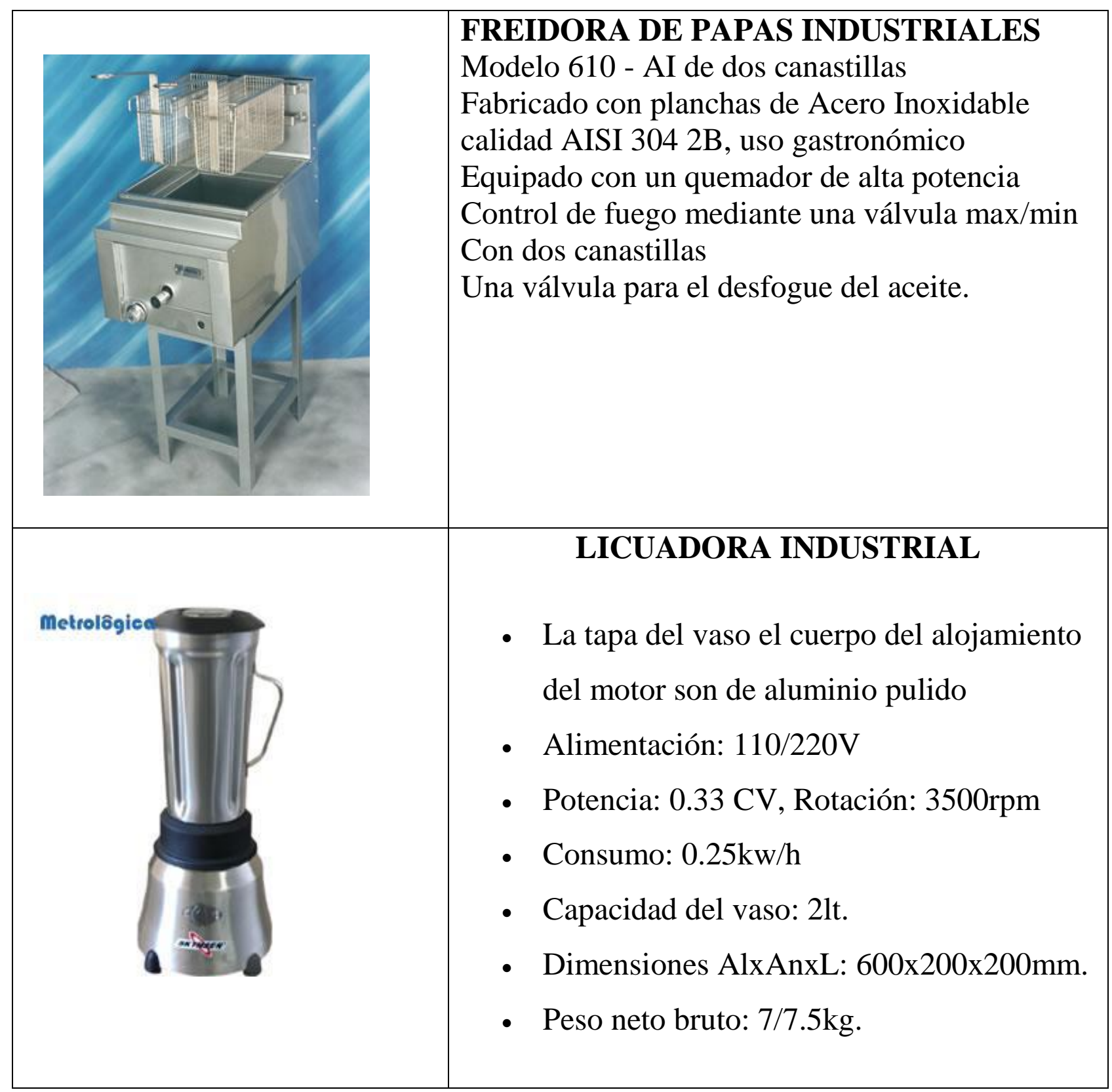




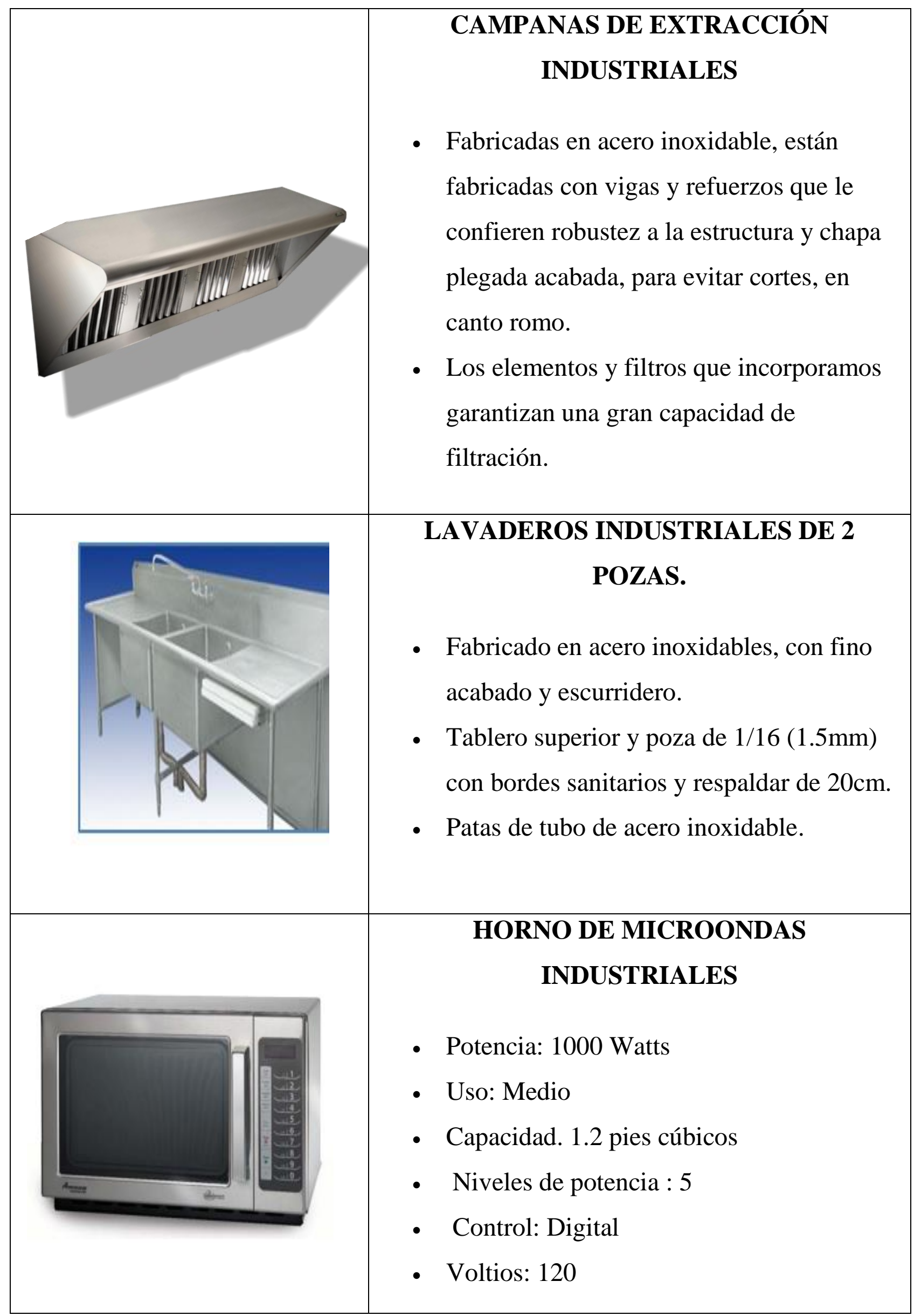




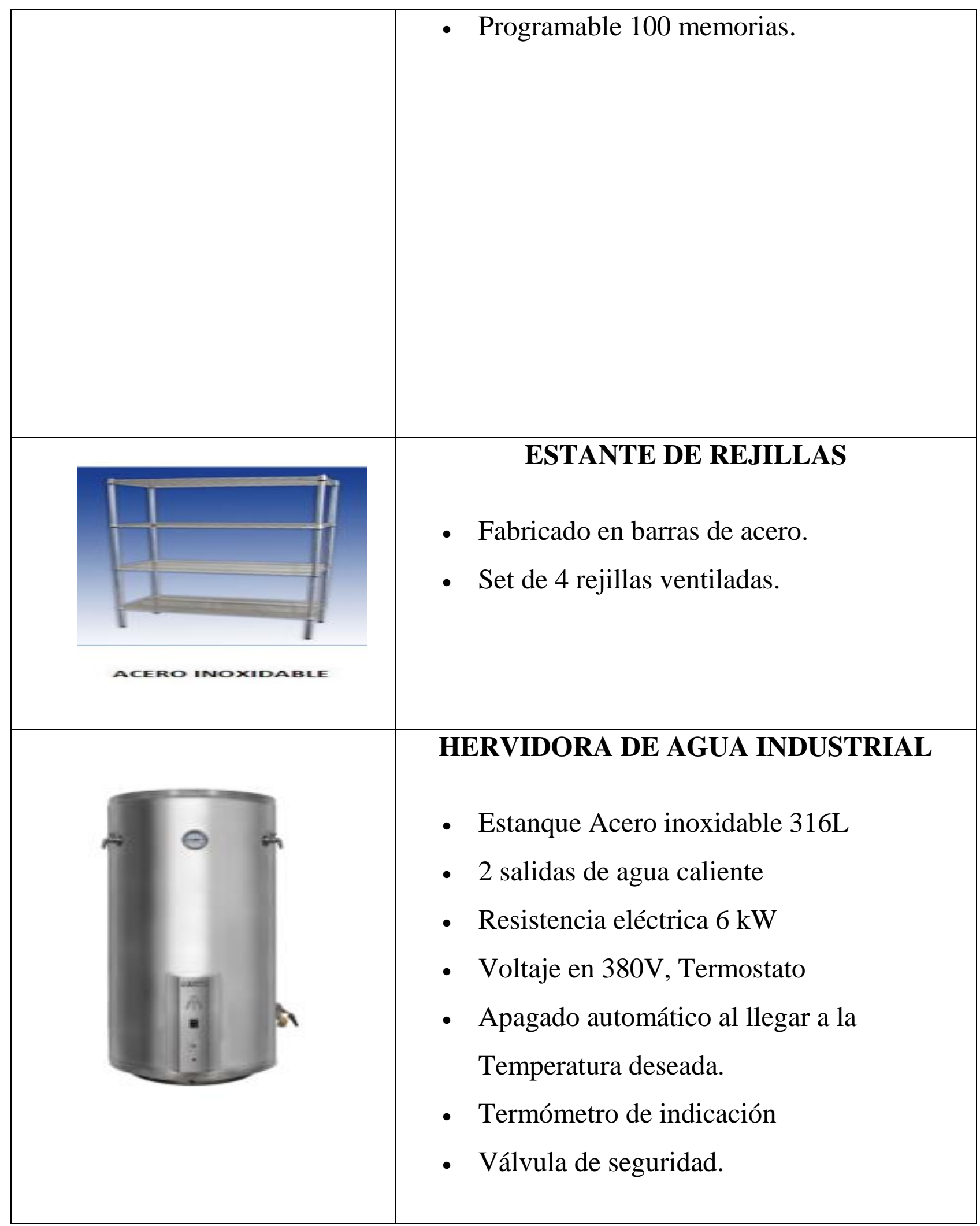




\section{ANEXO 2. COSTOS UNITARIOS POR PLATO DE MENÚ.}

\begin{tabular}{|c|c|c|c|}
\hline OPCION & \multicolumn{3}{|c|}{1} \\
\hline Nombre del plato & \multicolumn{3}{|c|}{ GORDON BLEU } \\
\hline Precio estimado & \multicolumn{2}{|c|}{$S / . \quad 25.00$} & \\
\hline Costo Total & $\mathrm{S} /$ & 6.26 & \\
\hline Margen neto & $\mathrm{S} /$ & 18.74 & \\
\hline \multicolumn{4}{|c|}{ ENTRADA - Ensalada Capresse } \\
\hline Producto & Cantidad & Costo $x$ un & Costo total \\
\hline Queso & 0.1 & 12.00 & $\mathrm{~S} / . \quad 1.20$ \\
\hline Tomate & 0.1 & 3.00 & $\mathrm{~S} / . \quad 0.30$ \\
\hline Berengena & 0.2 & 1.00 & $\mathrm{~S} / . \quad 0.20$ \\
\hline Albahaca & 0.1 & 0.50 & S/. $\quad 0.05$ \\
\hline Aceite de Oliva & 0.005 & 8.00 & S/. $\quad 0.04$ \\
\hline sal & 0.003 & 1.50 & $\mathrm{~S} / . \quad 0.00$ \\
\hline Pimienta & 0.008 & 6.00 & S/. 0.05 \\
\hline \multicolumn{3}{|l|}{ TOTAL } & S/. 1.84 \\
\hline \multicolumn{4}{|c|}{ PLATO DE FONDO - Gordon Bleu } \\
\hline Producto & $\begin{array}{l}\text { Cantidad } \\
\text { gm }\end{array}$ & $\begin{array}{l}\text { Costo } \\
\mathrm{Kg} / \mathrm{Lt}\end{array}$ & Costo total \\
\hline Pollo & 250 & 7.00 & S/. 1.75 \\
\hline Queso & 40 & 12.00 & $S / . \quad 0.48$ \\
\hline Jamon Ingles & 50 & 12.00 & $S / . \quad 0.60$ \\
\hline Arroz & 150 & 3.50 & S/. $\quad 0.53$ \\
\hline Harina & 30 & 3.00 & S/. $\quad 0.09$ \\
\hline Zanahoria & 50 & 2.00 & $\mathrm{~S} / . \quad 0.10$ \\
\hline Vainita & 50 & 2.00 & S/. $\quad 0.10$ \\
\hline Leche & 50 & 3.50 & $\mathrm{~S} / . \quad 0.18$ \\
\hline Mantequilla & 5 & 6.00 & $\mathrm{~S} / . \quad 0.03$ \\
\hline Ajos & 8 & 8.00 & S/. $\quad 0.06$ \\
\hline Sal & 5 & 1.50 & S/. $\quad 0.01$ \\
\hline \multicolumn{3}{|l|}{ TOTAL } & S/. 3.92 \\
\hline \multicolumn{4}{|l|}{ REFRESCO } \\
\hline \multicolumn{3}{|l|}{ Producto } & Costo total \\
\hline Te de naramja & & & $S / . \quad 0.30$ \\
\hline Azucar & & & S/. $\quad 0.10$ \\
\hline Agua & & & $\mathrm{S} / . \quad 0.10$ \\
\hline TOTAL & & & $\mathrm{S} / . \quad 0.50$ \\
\hline
\end{tabular}

OPCION 2

Nombre del plato MEDALLON PAVO AL HC

$\begin{array}{lll}\text { Precio estimado S/. } & 25.00\end{array}$ Costo Total $\quad \mathrm{S} / . \quad 6.14$ Margen neto 18.86

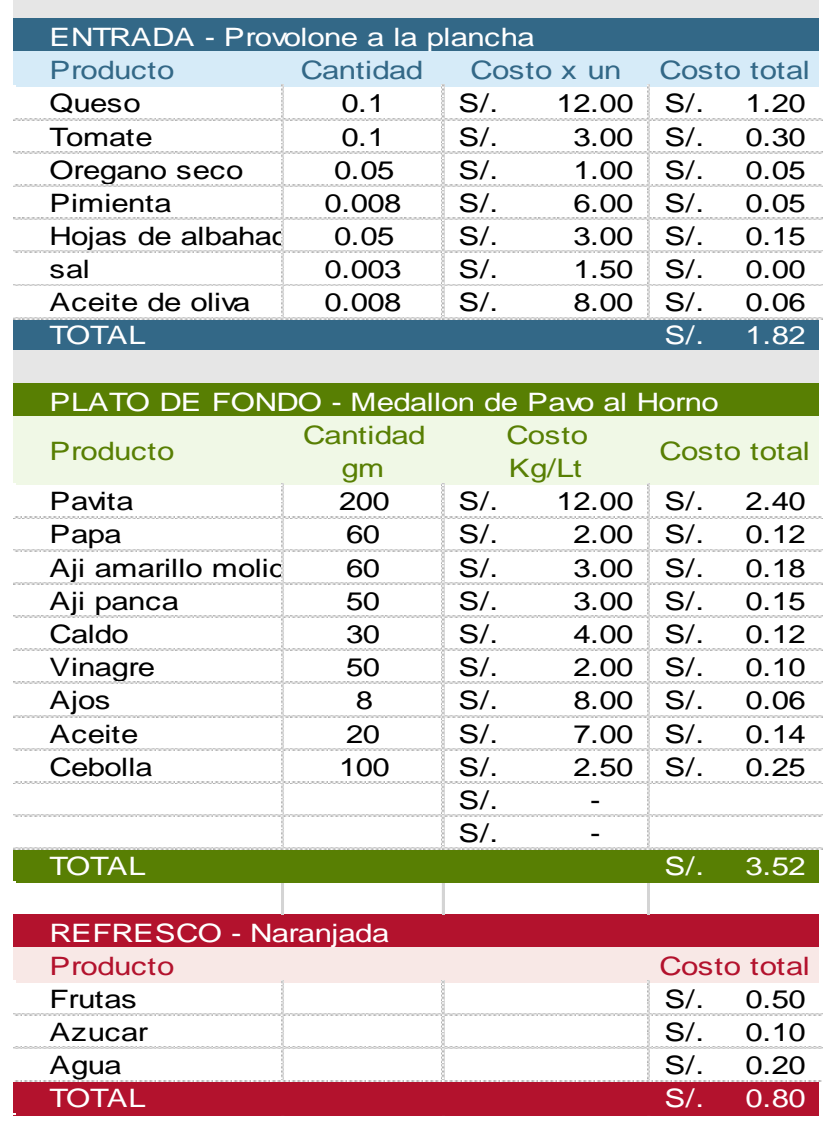

OPCION

3

Nombre del p ASADO DE RES CON PL

$\begin{array}{llr}\text { Precio estime S/. } & 25.00 \\ \text { Costo Total } & \text { S/. } & 6.18 \\ \text { Margen neto } & \text { S/. } & 18.82\end{array}$

\section{ENTRADA- Verduras a la parrilla}

\begin{tabular}{|c|c|c|c|c|c|}
\hline Producto & Cantidad & \multicolumn{2}{|c|}{ Costo $x$ un } & \multicolumn{2}{|c|}{ Costo total } \\
\hline Zapallo Itali & 0.1 & $\mathrm{~S} /$. & 8.50 & $\mathrm{~S} /$. & 0.85 \\
\hline Zanahoria & 0.15 & $\mathrm{~S} /$. & 2.00 & $\mathrm{~S} /$. & 0.30 \\
\hline Berengena & 2 & $\mathrm{~S} /$. & 1.00 & $\mathrm{~S} /$. & 0.20 \\
\hline Alba & & $\mathrm{S} /$. & 0.50 & $\mathrm{~S} /$. & 0.05 \\
\hline Aceite de C & 0.005 & $\mathrm{~S} /$. & 7.00 & $\mathrm{~S} /$. & 0.04 \\
\hline sal & 0.003 & $\mathrm{~S} /$ & 1.50 & $\mathrm{~S} /$. & 0.00 \\
\hline Pimienta & 0.008 & $\mathrm{~S} /$. & 6.00 & $\mathrm{~S} /$. & 0.05 \\
\hline TOTAL & & & & S/. & 1.49 \\
\hline
\end{tabular}

\section{PLATO DE FONDO - Asado de Res con Pure} Producto Cantidad Costo

\begin{tabular}{lllllll} 
& $\mathrm{gm}$ & \multicolumn{3}{l}{$\mathrm{Kg} / \mathrm{Lt}$} & & \\
Asado de $\mathrm{r}$ & 200 & $\mathrm{~S} / \mathrm{c}$ & 14.00 & $\mathrm{~S} /$. & 2.80
\end{tabular} \begin{tabular}{|ll|rr|rr} 
Asado de re & 200 & $\mathrm{~S} /$ & 14.00 & $\mathrm{~S} /$. & 2.80 \\
\hline Papa amari & 120 & $\mathrm{~S} /$ & 3.00 & $\mathrm{~S} /$ & 0.36 \\
\hline
\end{tabular} \begin{tabular}{l|l|ll|l|l|l} 
Papa amari & 120 & $\mathrm{~S} /$. & 3.00 & $\mathrm{~S} /$ & 0.36 \\
\hline Zanahoria & 10 & $\mathrm{~S} /$. & 2.00 & $\mathrm{~S} /$. & 0.02
\end{tabular} \begin{tabular}{llllllll} 
Zanahoria & 10 & $\mathrm{~S} /$. & 2.00 & $\mathrm{~S} /$. & 0.02 \\
\hline Leche & 50 & $\mathrm{~S} /$. & 3.50 & $\mathrm{~S} /$. & 0.18 \\
\hline
\end{tabular} \begin{tabular}{l|c|cc|c|c|} 
Cebolla & 100 & $\mathrm{~S} /$. & 2.50 & $\mathrm{~S} /$. & 0.25 \\
\hline
\end{tabular} \begin{tabular}{l|l|lll|ll} 
Laurel & 10 & $\mathrm{~S} /$. & 2.00 & $\mathrm{~S} /$. & 0.02 \\
\cline { 1 - 3 } & & 10 & $\mathrm{~S} /$. & 8.00 & $\mathrm{~S} /$. & 0.08 \\
\hline
\end{tabular} \begin{tabular}{l|l|ll|ll} 
Vino & 10 & $\mathrm{~S} /$. & 8.00 & $\mathrm{~S} /$. & 0.08 \\
\hline
\end{tabular} $\begin{array}{lllllll}\text { Mantequilla } & 20 & \mathrm{~S} / & 6.00 & \mathrm{~S} / . & 0.12\end{array}$ \begin{tabular}{l|l|ll|ll} 
Ajos & 8 & $\mathrm{~S} /$. & 8.00 & $\mathrm{~S} /$. & 0.06 \\
\hline
\end{tabular} \begin{tabular}{l|l|ll|ll} 
Sal & 5 & $\mathrm{~S} /$. & 1.50 & $\mathrm{~S} /$. & 0.01
\end{tabular}

TOTAL S/. 3.90

\begin{tabular}{l|ll|}
\hline REFRESCO - Limonada & \multicolumn{2}{c|}{} \\
\hline Producto & \multicolumn{2}{c|}{ Costo total } \\
\hline Limon & $\mathrm{S} /$. & 0.30 \\
\hline Azucar & $\mathrm{S} /$. & 0.20 \\
\hline Agua & $\mathrm{S} /$. & 0.30 \\
\hline TOTAL & $\mathrm{S} /$. & 0.80 \\
\hline
\end{tabular}




\begin{tabular}{|c|c|c|c|}
\hline OPCION & & 4 & \\
\hline \multicolumn{4}{|c|}{ Nombre del platctSAÑA DE VERDURAS } \\
\hline Precio estimado & \multicolumn{2}{|r|}{25.00} & \\
\hline Costo Total & $\mathrm{S} /$. & 6.25 & \\
\hline Margen neto & $\mathrm{S} /$. & 18.75 & \\
\hline \multicolumn{4}{|c|}{ ENTRADA-Ensalada Cesar } \\
\hline Producto & \multicolumn{2}{|c|}{ lada Cesar } & Costo total \\
\hline Lechuga americe & 0.12 & 1.50 & S/. $\quad 0.18$ \\
\hline Espinaca & 0.05 & 2.00 & S/. $\quad 0.10$ \\
\hline Aceite de Oliva & 0.02 & 8.00 & $\mathrm{~S} / . \quad 0.16$ \\
\hline Queso parmesar & 0.05 & 13.00 & $\mathrm{~S} / . \quad 0.65$ \\
\hline Crutones al ajo & 0.1 & 3.00 & S/. $\quad 0.30$ \\
\hline Tocino picado & 0.05 & 8.00 & $\mathrm{~S} / . \quad 0.40$ \\
\hline Huevos & 0.05 & 4.50 & $S / . \quad 0.23$ \\
\hline Sal & 0.05 & 1.50 & $\mathrm{~S} / . \quad 0.08$ \\
\hline \multicolumn{3}{|l|}{ TOTAL } & S/. 2.09 \\
\hline \multicolumn{4}{|c|}{ PLATO DE FONDO } \\
\hline Producto & \multirow{2}{*}{\multicolumn{2}{|c|}{$\begin{array}{l}\text { Cantidad } \\
\quad \mathrm{gm}\end{array}$}} & Costo total \\
\hline Lasaña & & & $S / . \quad 0.75$ \\
\hline Queso & 100 & 12.00 & $\mathrm{~S} / . \quad 1.20$ \\
\hline Espinaca & 50 & 2.50 & $\mathrm{~S} / . \quad 0.13$ \\
\hline Cebolla & 100 & 3.50 & $\mathrm{~S} / . \quad 0.35$ \\
\hline Salsa de tomate & 30 & 3.00 & $\mathrm{~S} / . \quad 0.09$ \\
\hline Aceite de Oliva & 30 & 8.00 & $S / . \quad 0.24$ \\
\hline Harina & 35 & 3.00 & $\mathrm{~S} / . \quad 0.11$ \\
\hline Leche & 100 & 3.50 & $S / . \quad 0.35$ \\
\hline Mantequilla & 10 & 6.00 & $\mathrm{~S} / . \quad 0.06$ \\
\hline Ajos & 10 & 8.00 & $\mathrm{~S} / . \quad 0.08$ \\
\hline Sal & 5 & 1.50 & $\mathrm{~S} / . \quad 0.01$ \\
\hline \multicolumn{3}{|l|}{ TOTAL } & S/. 3.36 \\
\hline \multicolumn{4}{|l|}{ REFRESCO } \\
\hline \multicolumn{3}{|l|}{ Producto } & Costo total \\
\hline Frutas & & & S/. $\quad 0.50$ \\
\hline Azucar & & & $\mathrm{S} / . \quad 0.10$ \\
\hline Agua & & & $\mathrm{S} / . \quad 0.20$ \\
\hline TOTAL & & & S/. $\quad 0.80$ \\
\hline
\end{tabular}

\begin{tabular}{|c|c|}
\hline OPCION & \\
\hline & LLA/PAF \\
\hline Precio estimado & 25.00 \\
\hline Costo Total & 5.31 \\
\hline Margen neto & 19.69 \\
\hline
\end{tabular}

\section{ENTRADA- Verduras a la parrilla}

Producto Cantidad Costo x un Costo total \begin{tabular}{l|l|ll|ll} 
Zapallo Italiano & 0.1 & $\mathrm{~S} /$. & 8.50 & $\mathrm{~S} /$. & 0.85 \\
\hline
\end{tabular} \begin{tabular}{l|l|llll} 
Zanahoria & 0.15 & $\mathrm{~S} /$. & 2.00 & $\mathrm{~S} /$. & 0.30
\end{tabular} \begin{tabular}{l|c|cc|cc} 
Zanahoria & 0.15 & $\mathrm{~S} /$ & 2.00 & $\mathrm{~S} /$. & 0.30 \\
\hline Berengena & 0.2 & $\mathrm{~S} /$. & 1.00 & $\mathrm{~S} /$. & 0.20 \\
\hline
\end{tabular} \begin{tabular}{l|llllll} 
Berengena & 0.2 & $\mathrm{~S} /$. & 1.00 & $\mathrm{~S} /$. & 0.20 \\
\hline Albahaca & 0.1 & $\mathrm{~S} /$. & 0.50 & $\mathrm{~S} /$. & 0.05
\end{tabular} \begin{tabular}{l|l|llll} 
Aceite de Oliva & 0.005 & $\mathrm{~S} /$. & 7.00 & $\mathrm{~S} /$. & 0.04
\end{tabular} $\begin{array}{llllll}\text { sal } & 0.003 & \mathrm{~S} / . & 1.50 & \mathrm{~S} / & 0.00\end{array}$

\begin{tabular}{l|l|llll} 
Pimienta & 0.008 & $\mathrm{~S} /$. & 6.00 & $\mathrm{~S} /$. & 0.05
\end{tabular}

$\begin{array}{llll}\text { TOTAL } & \text { S/. } & 1.49\end{array}$

\begin{tabular}{|c|c|c|c|c|}
\hline \multicolumn{5}{|c|}{ PLATO DE FONDO } \\
\hline Producto & $\begin{array}{c}\text { Cantidad } \\
\text { gm }\end{array}$ & & & Costo total \\
\hline Pollo & 300 & $\mathrm{~S} /$. & 7.50 & 2.25 \\
\hline Papas & 250 & $\mathrm{~S} /$ & 2.00 & 0.50 \\
\hline Mantequilla & 5 & $\mathrm{~S} /$. & 5.00 & 0.03 \\
\hline Ajos & 8 & $\mathrm{~S} /$. & 8.00 & 0.06 \\
\hline Sal & 5 & $\mathrm{~S} /$. & 1.50 & 0.01 \\
\hline Pimienta & 10 & $\mathrm{~S} /$. & 2.00 & 0.02 \\
\hline Aceite de Oliva & 20 & $\mathrm{~S} /$. & 8.00 & $\mathrm{~S} / . \quad 0.16$ \\
\hline TOTAL & & & & S/. 3.03 \\
\hline
\end{tabular}

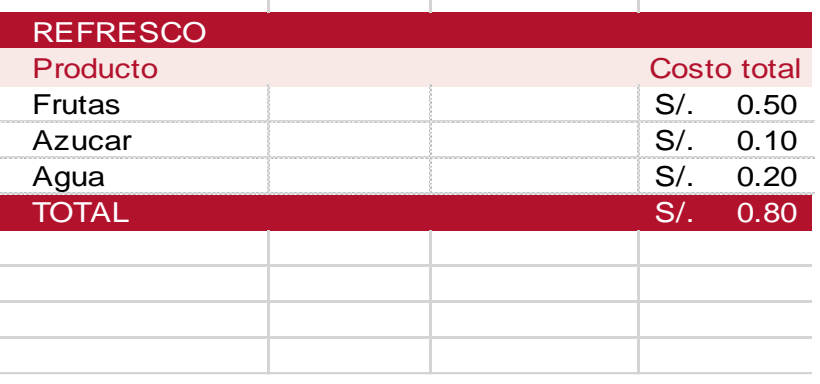

OPCION

6

Nombre delLETE POLLO AL VAPOR

Precio estir S/.

Costo Total S/. $\quad 5.95$

Margen net $\mathrm{S} /$

\section{ENTRADA-Ceviche de champiñones}

Producto Cantidad Costo $x$ un Costo total \begin{tabular}{ll|ll|ll} 
Cahmpiñon & 0.2 & $\mathrm{~S} /$. & 7.00 & $\mathrm{~S} /$. & 1.40
\end{tabular}

\begin{tabular}{l|l|lllll} 
Cebolla & 0.2 & $\mathrm{~S} /$. & 2.00 & $\mathrm{~S} /$. & 0.40 \\
\hline
\end{tabular}

\begin{tabular}{l|c|c|c|c|c} 
Cebolla & 0.2 & $\mathrm{~S} /$. & 2.00 & $\mathrm{~S} /$. & 0.40 \\
\hline Limon & 0.05 & $\mathrm{~S} /$. & 4.00 & $\mathrm{~S} /$. & 0.20
\end{tabular}

\begin{tabular}{lll|ll|lll} 
Limon & 0.05 & $\mathrm{~S} /$. & 4.00 & $\mathrm{~S} /$. & 0.20 \\
Aceite de C & 0.005 & $\mathrm{~S} /$. & 8.00 & $\mathrm{~S} /$. & 0.04
\end{tabular} \begin{tabular}{l|l|lllll} 
sal & 0.003 & $\mathrm{~S} /$. & 1.50 & $\mathrm{~S} /$. & 0.00 \\
\cline { 1 - 3 } & & 0.008 & $\mathrm{~S} /$ & 3.00 & $\mathrm{~S} /$ & 0.02
\end{tabular}

$\begin{array}{lllllll}\text { Jenjibre } & 0.008 & \mathrm{~S} / . & 3.00 & \mathrm{~S} / . & 0.02\end{array}$

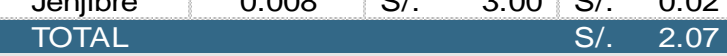

\begin{tabular}{l|c|cc|c|c|c}
\hline $\begin{array}{l}\text { PLATO DE FONDO } \\
\text { Producto }\end{array}$ & $\begin{array}{c}\text { Cantidad } \\
\text { gm }\end{array}$ & \multicolumn{2}{c}{$\begin{array}{c}\text { Costo } \\
\text { Kg/Lt }\end{array}$} & \multicolumn{2}{c}{ Costo total } \\
Pollo & 250 & $\mathrm{~S} /$. & 7.50 & $\mathrm{~S} /$. & 1.88 \\
\hline Papas & 200 & $\mathrm{~S} /$. & 2.00 & $\mathrm{~S} /$. & 0.40 \\
\hline Mantequilla & 5 & $\mathrm{~S} /$. & 5.00 & $\mathrm{~S} /$. & 0.03 \\
\hline Arroz & 150 & $\mathrm{~S} /$. & 3.50 & $\mathrm{~S} /$. & 0.53 \\
\hline Ajos & 8 & $\mathrm{~S} /$. & 8.00 & $\mathrm{~S} /$. & 0.06 \\
\hline Sal & 5 & $\mathrm{~S} /$. & 1.50 & $\mathrm{~S} /$. & 0.01 \\
\hline Pimienta & 10 & $\mathrm{~S} /$. & 2.00 & $\mathrm{~S} /$. & 0.02 \\
\hline Aceite de C & 20 & $\mathrm{~S} /$. & 8.00 & $\mathrm{~S} /$. & 0.16 \\
\hline TOTAL & & & & $\mathrm{S} /$. & 3.08 \\
\hline
\end{tabular}

\begin{tabular}{|c|c|}
\hline \multicolumn{2}{|c|}{ REFRESCO } \\
\hline \multicolumn{2}{|r|}{ Costo total } \\
\hline Frutas & 0.50 \\
\hline Azucar & 0.10 \\
\hline Agua & 0.20 \\
\hline \multirow{2}{*}{\multicolumn{2}{|c|}{ TOTAL }} \\
\hline & \\
\hline & \\
\hline & \\
\hline
\end{tabular}




\begin{tabular}{|c|c|c|c|}
\hline OPCION & & 7 & \\
\hline \multicolumn{4}{|c|}{ Nombre del platc FILETE DE CARNE/PAF } \\
\hline Precio estimado & $\mathrm{S} /$. & 25.00 & \\
\hline Costo Total & $\mathrm{S} /$ & 6.51 & \\
\hline Margen neto & $\mathrm{S} /$. & 18.49 & \\
\hline \multicolumn{4}{|c|}{ ENTRADA - Ensalada Capresse } \\
\hline Producto & Cantidad & Costo $\mathrm{x}$ un & Costo total \\
\hline Queso & 0.1 & S/. $\quad 12.00$ & S/. 1.20 \\
\hline Tomate & 0.15 & 2.00 & S/. $\quad 0.30$ \\
\hline Berengena & 0.2 & 1.00 & $\mathrm{~S} / . \quad 0.20$ \\
\hline Albahaca & 0.1 & 0.50 & S/. $\quad 0.05$ \\
\hline Aceite de Oliva & 0.005 & 7.00 & S/. $\quad 0.04$ \\
\hline sal & 0.003 & 1.50 & S/. $\quad 0.00$ \\
\hline Pimienta & 0.008 & 6.00 & S/. $\quad 0.05$ \\
\hline \multicolumn{3}{|l|}{ TOTAL } & S/. 1.84 \\
\hline \multicolumn{4}{|c|}{ PLATO DE FONDO } \\
\hline Producto & $\begin{array}{c}\text { Cantidad } \\
\text { gm }\end{array}$ & $\begin{array}{l}\text { Costo } \\
\mathrm{Kg} / \mathrm{Lt}\end{array}$ & Costo total \\
\hline Carne de res & 200 & S/. $\quad 17.00$ & S/. $\quad 3.40$ \\
\hline Papas & 100 & 2.00 & S/. $\quad 0.20$ \\
\hline Mantequilla & 5 & 5.00 & S/. $\quad 0.03$ \\
\hline Ajos & 8 & 8.00 & S/. $\quad 0.06$ \\
\hline Sal & 5 & 1.50 & S/. $\quad 0.01$ \\
\hline Pimienta & 10 & 2.00 & S/. $\quad 0.02$ \\
\hline Aceite de Oliva & 20 & 8.00 & S/. $\quad 0.16$ \\
\hline \multicolumn{3}{|l|}{ TOTAL } & S/. 3.88 \\
\hline & & & \\
\hline \multicolumn{4}{|l|}{ REFRESCO } \\
\hline \multicolumn{3}{|l|}{ Producto } & Costo total \\
\hline Frutas & & & S/. $\quad 0.50$ \\
\hline Azucar & & & S/. $\quad 0.10$ \\
\hline Agua & & & S/. $\quad 0.20$ \\
\hline TOTAL & & & S/. $\quad 0.80$ \\
\hline
\end{tabular}

\begin{tabular}{|c|c|}
\hline OPCION & \\
\hline Nombre del plato & FILETE DE CARNE CON \\
\hline Precio estimado & 25.00 \\
\hline Costo Total & 6.60 \\
\hline Margen neto & 18.40 \\
\hline
\end{tabular}

\begin{tabular}{l|c|rr|r|r}
\hline \multicolumn{7}{l}{ ENTRADA - Provolone a la plancha } \\
\hline Producto & Cantidad & \multicolumn{2}{c}{ Costo $x$ un } & \multicolumn{2}{l}{ Costo total } \\
\hline Queso & 0.1 & S/. & 12.00 & S/. & 1.20 \\
\hline Tomate & 0.15 & $\mathrm{~S} /$. & 2.00 & $\mathrm{~S} /$. & 0.30 \\
\hline Berengena & 0.2 & $\mathrm{~S} /$. & 1.00 & $\mathrm{~S} /$. & 0.20 \\
\hline Albahaca & 0.1 & $\mathrm{~S} /$. & 0.50 & $\mathrm{~S} /$. & 0.05 \\
\hline Aceite de Oliva & 0.005 & $\mathrm{~S} /$. & 7.00 & $\mathrm{~S} /$. & 0.04 \\
\hline sal & 0.003 & $\mathrm{~S} /$. & 1.50 & $\mathrm{~S} /$. & 0.00 \\
\hline Pimienta & 0.008 & $\mathrm{~S} /$. & 6.00 & $\mathrm{~S} /$. & 0.05 \\
\hline TOTAL & & & & $\mathrm{S} /$. & 1.84 \\
\hline
\end{tabular}

\section{PLATO DE FONDO}

$\begin{array}{cccc}\text { Producto } & \text { Cantidad } & \text { Costo } & \\ & \mathrm{gm} & \mathrm{Kg} / \mathrm{Lt} & \text { Costo total }\end{array}$

\begin{tabular}{l|l|lr|rr} 
Carne de res & 200 & $\mathrm{~S} /$. & 17.00 & $\mathrm{~S} /$. & 3.40
\end{tabular} \begin{tabular}{l|l|llll} 
Ajos & 8 & $\mathrm{~S} /$. & 3.00 & $\mathrm{~S} /$. & 0.02
\end{tabular} \begin{tabular}{l|lllll} 
Sal & 5 & $\mathrm{~S} /$. & 2.00 & $\mathrm{~S} /$. & 0.01 \\
\hline
\end{tabular} \begin{tabular}{l|lllll} 
Pimienta & 10 & $\mathrm{~S} /$. & 2.00 & $\mathrm{~S} /$ & 0.02
\end{tabular} \begin{tabular}{l|lllll} 
Aceite de Oliva & 20 & $\mathrm{~S} /$. & 8.00 & $\mathrm{~S} /$. & 0.16 \\
\hline
\end{tabular}

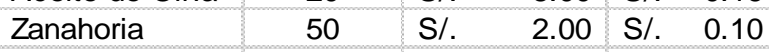

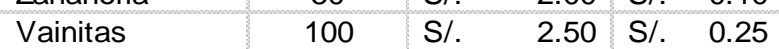
TOTAL S/. 3.96

\begin{tabular}{l|l|l} 
& & \\
\hline REFRESCO & & \\
\hline Producto & \multicolumn{3}{|c}{ Costo total } \\
\hline Frutas & S/. & 0.50 \\
\hline Azucar & S/. & 0.10 \\
\hline Agua & S/. & 0.20 \\
\hline TOTAL & S/. & 0.80 \\
\hline
\end{tabular}

OPCION

9

Nombre del TALLARINES AL PESTO

Precio estir S/.

Costo Total S/.

25.00

Margen net S/.

9.01

\begin{tabular}{|c|c|c|c|}
\hline \multicolumn{4}{|c|}{ ENTRADA - Ensalada Capresse } \\
\hline Producto & Cantidad & Costo $x$ un & Costo total \\
\hline Queso & 0.1 & S/. $\quad 12.00$ & $\mathrm{~S} / . \quad 1.20$ \\
\hline Tomate & 0.15 & 2.00 & $\mathrm{~S} / . \quad 0.30$ \\
\hline Berengena & 0.2 & 1.00 & $\mathrm{~S} / . \quad 0.20$ \\
\hline Albahaca & 0.1 & 0.50 & $\mathrm{~S} / . \quad 0.05$ \\
\hline Aceite de C & 0.005 & 7.00 & S/. $\quad 0.04$ \\
\hline sal & 0.003 & 1.50 & 0.00 \\
\hline Pimienta & 0.008 & 6.00 & 0.05 \\
\hline \multicolumn{3}{|l|}{ TOTAL } & 1.84 \\
\hline \multicolumn{4}{|c|}{ PLATO DE FONDO } \\
\hline Producto & $\begin{array}{c}\text { Cantidad } \\
\text { gm }\end{array}$ & $\begin{array}{l}\text { Costo } \\
\mathrm{Kg} / \mathrm{Lt}\end{array}$ & Costo total \\
\hline Fideos & 200 & 5.00 & $\mathrm{~S} / . \quad 1.00$ \\
\hline Albahaca & 50 & 3.50 & $\mathrm{~S} / . \quad 0.18$ \\
\hline Mantequilla & 5 & 5.00 & $\mathrm{~S} / . \quad 0.03$ \\
\hline Ajos & 8 & 8.00 & $\mathrm{~S} / . \quad 0.06$ \\
\hline Sal & 5 & 1.50 & 0.01 \\
\hline Queso parn & 100 & 13.00 & 1.30 \\
\hline Espinaca & 50 & 2.50 & 0.13 \\
\hline Pecanas & 50 & S/. $\quad 10.00$ & 0.50 \\
\hline Aceite de C & 20 & 8.00 & 0.16 \\
\hline \multicolumn{3}{|l|}{ TOTAL } & S/. $\quad 3.36$ \\
\hline \multicolumn{4}{|l|}{ REFRESCO } \\
\hline \multicolumn{3}{|l|}{ Producto } & Costo total \\
\hline Frutas & & & $S / . \quad 0.50$ \\
\hline Azucar & & & S/. $\quad 0.10$ \\
\hline Agua & & & $S / . \quad 0.20$ \\
\hline TOTAL & & & S/. $\quad 0.80$ \\
\hline
\end{tabular}




\begin{tabular}{|c|c|c|c|}
\hline OPCION & & 10 & \\
\hline \multicolumn{4}{|c|}{ Nombre del platc HAMBURGUESA CASE } \\
\hline Precio estimado & $\mathrm{S} /$. & 25.00 & \\
\hline Costo Total & $\mathrm{S} /$. & 6.29 & \\
\hline Margen neto & $\mathrm{S} /$. & 18.71 & \\
\hline \multicolumn{4}{|c|}{ ENTRADA - Ensalada Capresse } \\
\hline Producto & Cantidad & Costo $x$ un & Costo total \\
\hline Queso & 0.1 & 12.00 & $\mathrm{~S} / . \quad 1.20$ \\
\hline Tomate & 0.15 & 2.00 & $\mathrm{~S} / . \quad 0.30$ \\
\hline Berengena & 0.2 & 1.00 & $\mathrm{~S} / . \quad 0.20$ \\
\hline Albahaca & 0.1 & 0.50 & $\mathrm{~S} / . \quad 0.05$ \\
\hline Aceite de Oliva & 0.005 & 7.00 & $S / . \quad 0.04$ \\
\hline sal & 0.003 & 1.50 & $\mathrm{~S} / . \quad 0.00$ \\
\hline Pimienta & 0.008 & 6.00 & $\mathrm{~S} / . \quad 0.05$ \\
\hline \multicolumn{3}{|l|}{ TOTAL } & S/. 1.84 \\
\hline \multicolumn{4}{|c|}{ PLATO DE FONDO } \\
\hline Producto & $\begin{array}{c}\text { Cantidad } \\
\text { gm }\end{array}$ & $\begin{array}{l}\text { Costo } \\
\mathrm{Kg} / \mathrm{Lt}\end{array}$ & Costo total \\
\hline Carne molida & 180 & 17.00 & $\mathrm{~S} / . \quad 3.06$ \\
\hline Ajos & 8 & 8.00 & $\mathrm{~S} / . \quad 0.06$ \\
\hline Sal & 5 & 1.50 & $\mathrm{~S} / . \quad 0.01$ \\
\hline Pimiento & 100 & 2.50 & $\mathrm{~S} / . \quad 0.25$ \\
\hline Cebolla & 50 & 2.50 & $\mathrm{~S} / . \quad 0.13$ \\
\hline Tomate & 50 & 3.00 & $S / . \quad 0.15$ \\
\hline Aceite de Oliva & 20 & & \\
\hline \multicolumn{3}{|l|}{ TOTAL } & $\mathrm{S} / . \quad 3.66$ \\
\hline \multicolumn{4}{|l|}{ REFRESCO } \\
\hline \multicolumn{3}{|l|}{ Producto } & Costo total \\
\hline Frutas & & & $\mathrm{S} / . \quad 0.50$ \\
\hline Azucar & & & $\mathrm{S} / . \quad 0.10$ \\
\hline Agua & & & $\mathrm{S} / . \quad 0.20$ \\
\hline \multicolumn{3}{|l|}{ TOTAL } & S/. $\quad 0.80$ \\
\hline & & & \\
\hline & & & \\
\hline & & & \\
\hline
\end{tabular}

\begin{tabular}{|c|c|}
\hline OPCION & 11 \\
\hline Nombre del plato & LOMO SALTADO \\
\hline Precio estimado & 25.00 \\
\hline Costo Total & 6.44 \\
\hline Margen neto & 18.56 \\
\hline
\end{tabular}

\section{ENTRADA - Ensalada Capresse}

\begin{tabular}{|c|c|c|c|c|c|}
\hline Producto & Cantidad & & $x$ un & & tot \\
\hline Queso & 0.1 & $\mathrm{~S} /$. & 12.00 & $\mathrm{~S} /$ & 1.20 \\
\hline Tomate & 0.15 & $\mathrm{~S} /$. & 2.00 & $\mathrm{~S} /$ & 0.3 \\
\hline Berengena & 0.2 & $\mathrm{~S} /$. & 1.00 & $\mathrm{~S} /$ & 9.2 \\
\hline Albahaca & 0.1 & $\mathrm{~S} /$. & 0.50 & $\mathrm{~S} /$ & 0.0 \\
\hline Aceite de Oliva & 0.005 & $\mathrm{~S} /$. & 7.00 & $\mathrm{~S} /$ & 0.0 \\
\hline sal & 0.003 & $\mathrm{~S} /$. & 1.50 & $\mathrm{~S} /$ & 0.0 \\
\hline Pimie & 0.008 & $\mathrm{~S} /$. & 6.00 & $\mathrm{~S} /$ & .0 \\
\hline
\end{tabular}

\begin{tabular}{l|lllll} 
Pimienta & 0.008 & $\mathrm{~S} /$. & 6.00 & $\mathrm{~S} /$. & 0.05
\end{tabular}

$\begin{array}{lll}\text { TOTAL } & \text { S/. } & 1.84\end{array}$

\section{PLATO DE FONDO}

\begin{tabular}{l|c|c|c|c|c|} 
Producto & $\begin{array}{c}\text { Cantidad } \\
\text { gm }\end{array}$ & \multicolumn{2}{c}{$\begin{array}{c}\text { Costo } \\
\text { Kg/Lt }\end{array}$} & \multicolumn{2}{c}{ Costo total } \\
Carne de res & 170 & $\mathrm{~S} /$. & 17.00 & $\mathrm{~S} /$. & 2.89 \\
\hline Papa amarilla & 80 & $\mathrm{~S} /$. & 3.00 & $\mathrm{~S} /$. & 0.24 \\
\hline Tomate & 50 & $\mathrm{~S} /$. & 3.00 & $\mathrm{~S} /$. & 0.15 \\
\hline Cebolla & 50 & $\mathrm{~S} /$. & 2.50 & $\mathrm{~S} /$. & 0.13 \\
\hline Arroz & 30 & $\mathrm{~S} /$. & 3.50 & $\mathrm{~S} /$. & 0.11 \\
\hline Pimienta & 50 & $\mathrm{~S} /$. & 2.00 & $\mathrm{~S} /$. & 0.10 \\
\hline Comino & 50 & $\mathrm{~S} /$. & 2.00 & $\mathrm{~S} /$. & 0.10 \\
\hline Perejil & 10 & $\mathrm{~S} /$. & 2.00 & $\mathrm{~S} /$. & 0.02 \\
\hline Ajos & 8 & $\mathrm{~S} /$. & 8.00 & $\mathrm{~S} /$. & 0.06 \\
\hline Sal & 5 & $\mathrm{~S} /$. & 1.50 & $\mathrm{~S} /$. & 0.01 \\
\hline TOTAL & & & & $\mathrm{S} /$. & 3.80 \\
\hline & & & & & \\
\hline REFRESCO & & & & & \\
\hline Producto & & & & Costo total \\
\hline Frutas & & & & $\mathrm{S} /$. & 0.50 \\
\hline Azucar & & & & $\mathrm{S} /$. & 0.10 \\
\hline Agua & & & & $\mathrm{S} /$. & 0.20 \\
\hline TOTAL & & & & $\mathrm{S} /$. & 0.80 \\
\hline
\end{tabular}

OPCION

12

Nombre del PESCADO A LA PARRIL

Precio estir S/.

Costo Total S/.

25.00

Margen net $\mathrm{S} /$.

\section{ENTRADA-Ensalada de choclo de la casa}

Producto Cantidad Costo $\mathrm{x}$ un Costo tota

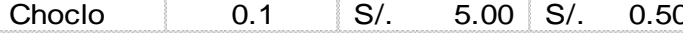

\begin{tabular}{llllllll} 
Tomate & 0.15 & $\mathrm{~S} /$. & 2.00 & $\mathrm{~S} /$. & 0.30 \\
\hline
\end{tabular}
\begin{tabular}{l|r|r|r|r|r|}
\hline Tomate & 0.15 & $\mathrm{~S} /$. & 2.00 & $\mathrm{~S} /$. & 0.30 \\
\hline Queso & 0.1 & $\mathrm{~S} /$. & 12.00 & $\mathrm{~S} /$. & 1.20 \\
\hline
\end{tabular} \begin{tabular}{l|r|rr|r|r} 
Queso & 0.1 & $\mathrm{~S} /$. & 12.00 & $\mathrm{~S} /$. & 1.20 \\
\hline Albahaca & 0.1 & $\mathrm{~S} /$. & 0.50 & $\mathrm{~S} /$. & 0.05 \\
\hline
\end{tabular} $\begin{array}{lllllll}\text { Aceite de } \mathrm{C} & 0.005 & \mathrm{~S} / . & 7.00 & \mathrm{~S} / . & 0.04\end{array}$ \begin{tabular}{l|llllll} 
sal & 0.003 & S/ & 1.50 & $\mathrm{~S} /$ & 0.00 \\
\hline
\end{tabular} Pimienta $\quad 0.008 \quad \mathrm{~S} / .26 .00 \mathrm{~S} / .0 .05$

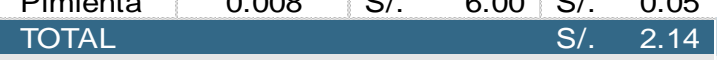

\begin{tabular}{|c|c|c|c|c|}
\hline \multicolumn{5}{|c|}{ PLATO DE FONDO } \\
\hline Producto & $\begin{array}{c}\text { Cantidad } \\
\text { gm }\end{array}$ & & $\begin{array}{l}\text { sto } \\
/ / \mathrm{Lt}\end{array}$ & Costo tot \\
\hline Pescado & 200 & $\mathrm{~S} /$. & 16.00 & 3.20 \\
\hline Papas & 150 & $\mathrm{~S} /$. & 2.00 & 0.30 \\
\hline Mantequilla & 5 & $\mathrm{~S} /$. & 6.00 & 0.03 \\
\hline Ajos & 8 & $\mathrm{~S} /$. & 8.00 & 0.06 \\
\hline Sal & 5 & $\mathrm{~S} / \mathrm{.}$ & 1.50 & 0.01 \\
\hline Pimienta & 10 & $\mathrm{~S} /$. & 6.00 & 0.06 \\
\hline TOTAL & & & & 3.66 \\
\hline
\end{tabular}

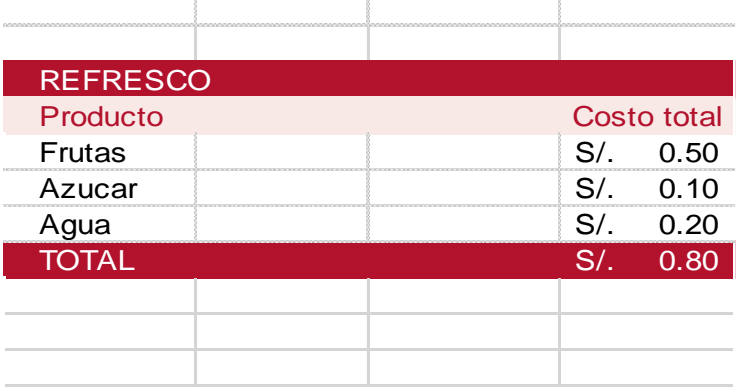




\begin{tabular}{|c|c|c|c|}
\hline OPCION & \multicolumn{3}{|c|}{13} \\
\hline \multicolumn{3}{|c|}{ Nombre del platc PASTEL DE QUINUA } & \\
\hline Precio estimado & $\mathrm{S} /$. & 25.00 & \\
\hline Costo Total & $\mathrm{S} /$. & 6.53 & \\
\hline Margen neto & $\mathrm{S} /$. & 18.47 & \\
\hline \multicolumn{4}{|c|}{ ENTRADA - Ensalada Capresse } \\
\hline Producto & Cantidad & Costo $x$ un & Costo total \\
\hline Queso & 0.1 & $\mathrm{~S} / . \quad 12.00$ & $\mathrm{~S} / . \quad 1.20$ \\
\hline Tomate & 0.15 & 2.00 & S/. $\quad 0.30$ \\
\hline Berengena & 0.2 & 1.00 & $S / . \quad 0.20$ \\
\hline Albahaca & 0.1 & 0.50 & S/. $\quad 0.05$ \\
\hline Aceite de Oliva & 0.005 & 7.00 & S/. $\quad 0.04$ \\
\hline sal & 0.003 & 1.50 & S/. $\quad 0.00$ \\
\hline Pimienta & 0.008 & 6.00 & S/. $\quad 0.05$ \\
\hline \multicolumn{3}{|l|}{ TOTAL } & S/. 1.84 \\
\hline \multicolumn{4}{|c|}{ PLATO DE FONDO } \\
\hline Producto & $\begin{array}{l}\text { Cantidad } \\
\text { gm }\end{array}$ & $\begin{array}{l}\text { Costo } \\
\mathrm{Kg} / \mathrm{Lt}\end{array}$ & Costo total \\
\hline Quinua & 70 & S/. $\quad 15.00$ & S/. 1.05 \\
\hline Papas & 150 & 2.00 & S/. $\quad 0.30$ \\
\hline Queso rallado & 120 & 12.00 & S/. 1.44 \\
\hline Espinaca & 50 & 2.50 & S/. $\quad 0.13$ \\
\hline Huevos & 150 & 5.00 & S/. $\quad 0.75$ \\
\hline Sal & 5 & 2.00 & S/. $\quad 0.01$ \\
\hline Pimienta & 10 & 6.00 & S/. $\quad 0.06$ \\
\hline Aceite de Oliva & 20 & 8.00 & S/. $\quad 0.16$ \\
\hline \multicolumn{3}{|l|}{ TOTAL } & S/. $\quad 3.90$ \\
\hline \multicolumn{4}{|l|}{ REFRESCO } \\
\hline \multicolumn{3}{|l|}{ Producto } & Costo total \\
\hline Frutas & & & S/. $\quad 0.50$ \\
\hline Azucar & & & S/. $\quad 0.10$ \\
\hline Agua & & & S/. $\quad 0.20$ \\
\hline \multicolumn{3}{|l|}{ TOTAL } & S/. $\quad 0.80$ \\
\hline
\end{tabular}

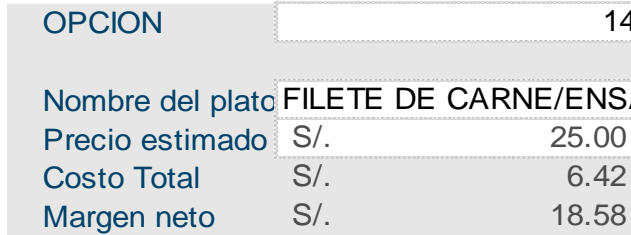

\section{ENTRADA - Ensalada Capresse}

Producto Cantidad Costo $\mathrm{x}$ un Costo total \begin{tabular}{l|l|ll|ll}
\hline Queso & 0.1 & $\mathrm{~S} /$. & 12.00 & $\mathrm{~S} /$. & 1.20 \\
\hline
\end{tabular}

\begin{tabular}{l|l|llll} 
Tomate & 0.15 & $\mathrm{~S} /$. & 2.00 & $\mathrm{~S} /$. & 0.30 \\
\hline
\end{tabular}

\begin{tabular}{l|l|llll}
\hline Berengena & 0.2 & $\mathrm{~S} /$. & 1.00 & $\mathrm{~S} /$. & 0.20 \\
\hline
\end{tabular}

\begin{tabular}{l|l|llll} 
Albahaca & 0.1 & $\mathrm{~S} /$. & 0.50 & $\mathrm{~S} /$. & 0.05 \\
\hline
\end{tabular}

\begin{tabular}{l|lllll} 
Aceite de Oliva & 0.005 & $\mathrm{~S} /$. & 7.00 & $\mathrm{~S} /$. & 0.04
\end{tabular}

\begin{tabular}{l|l|llll} 
sal & 0.003 & $\mathrm{~S} /$ & 1.50 & $\mathrm{~S} /$. & 0.00
\end{tabular}

\begin{tabular}{l|l|llll} 
& 0.003 & $\mathrm{~S} /$ & 1.50 & $\mathrm{~S} /$. & 0.00 \\
\hline Pimienta & 0.008 & $\mathrm{~S} /$. & 6.00 & $\mathrm{~S} /$. & 0.05
\end{tabular}

TOTAL S/. 1.84

\section{PLATO DE FONDO}

Producto Cantidad Costo Costo total \begin{tabular}{l|l|lr|rr} 
& $\mathrm{gm}$ & \multicolumn{3}{|c|}{$\mathrm{Kg} / \mathrm{Lt}$} \\
Zapallito Italiano & 250 & $\mathrm{~S} /$. & 3.00 & $\mathrm{~S} /$. & 0.75
\end{tabular} \begin{tabular}{lllllll} 
Carne molida & 120 & $\mathrm{~S} /$. & 18.00 & $\mathrm{~S} /$. & 2.16 \\
\hline
\end{tabular} \begin{tabular}{l|l|llll} 
Tomate & 50 & $\mathrm{~S} /$. & 3.00 & $\mathrm{~S} /$. & 0.15
\end{tabular} \begin{tabular}{l|c|cccc}
\hline Cebolla & 50 & $\mathrm{~S} /$ & 5.00 & $\mathrm{~S} /$ & 0.25 \\
\hline
\end{tabular} \begin{tabular}{l|lllll} 
Albahaca & 5 & $\mathrm{~S} /$. & 3.50 & $\mathrm{~S} /$. & 0.02 \\
\hline & 8 & $\mathrm{~S} /$. & 3.00 & $\mathrm{~S} /$. & 0.02
\end{tabular} \begin{tabular}{l|lllll} 
Ajos & $8 \mathrm{~L}$ & $\mathrm{~S} /$. & 3.00 & $\mathrm{~S} /$. & 0.02 \\
\hline
\end{tabular} \begin{tabular}{l|c|cccc} 
Sal & 5 & $\mathrm{~S} /$. & 2.00 & $\mathrm{~S} /$. & 0.01
\end{tabular} \begin{tabular}{l|lllll} 
Pimienta & 10 & $\mathrm{~S} /$. & 2.00 & $\mathrm{~S} /$. & 0.02
\end{tabular} \begin{tabular}{l|l|llll} 
Caldo de res & 100 & $\mathrm{~S} /$. & 4.00 & $\mathrm{~S} /$. & 0.40 \\
\hline
\end{tabular}

TOTAL S/. 3.78

\begin{tabular}{l|ll}
\hline REFRESCO & \multicolumn{2}{|c}{ Costo total } \\
\hline Producto & S/. & 0.50 \\
\hline Frutas & S/. & 0.10 \\
\hline Azucar & S/. & 0.20 \\
\hline Agua & S/. & 0.80 \\
\hline TOTAL
\end{tabular}

OPCION 15

Nombre del FILETE DE PESCADO Al

Precio estir S/.

Costo Total S/.

Margen net S/.

18.05

\section{ENTRADA-Portobello a la parrilla}

Producto Cantidad Costo $\mathrm{x}$ un Costo total \begin{tabular}{ll|llll} 
Hongos por & 0.3 & $\mathrm{~S} /$. & 6.00 & $\mathrm{~S} /$. & 1.80 \\
\hline
\end{tabular} $\begin{array}{lllllll}\text { Aceite de C } & 0.02 & \mathrm{~S} / . & 8.00 & \mathrm{~S} / & 0.16\end{array}$ \begin{tabular}{l|l|ll|lll} 
sal & 0.01 & $\mathrm{~S} /$. & 1.50 & $\mathrm{~S} /$. & 0.02 \\
\hline
\end{tabular} \begin{tabular}{l|l|lllll} 
Pimienta & 0.008 & $\mathrm{~S} /$. & 6.00 & $\mathrm{~S} /$. & 0.05 \\
\hline
\end{tabular} $\begin{array}{lllllll}\text { Verduras } & 0.1 & \mathrm{~S} / . & 1.50 \mathrm{~S} / . & 0.15\end{array}$

\section{TOTA}

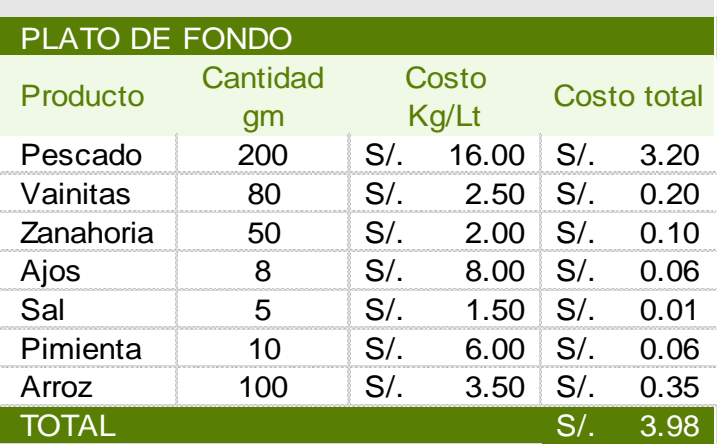

\section{REFRESCO}

Producto

Costo total

\begin{tabular}{l|l|l} 
Frutas & S/. & 0.50 \\
\hline
\end{tabular}

\begin{tabular}{l|lll} 
Azucar & & $\mathrm{S} /$. & 0.10 \\
\hline
\end{tabular}

Agua

$\begin{array}{ll}\mathrm{S} / . & 0.10 \\ \mathrm{~S} / . & 0.20\end{array}$

TOTAL 


\section{ANEXO 3: CUESTIONARIO.}

\section{CUESTIONARIO \\ ESTUDIO: RESTAURANTE CON INSUMOS SALUDABLES Y ORGÁNICOS}

Buenos días/ tardes, mi nombre es ....... y soy alumna de la Universidad San Ignacio de Loyola. Estamos haciendo una breve encuesta sobre restaurantes. ¿Podría ser tan amable de ayudarnos brindándonos su opinión sobre el proyecto que estamos presentando? La encuesta dura 10 minutos. Muchas Gracias

\section{FILTROS GENERALES}

\begin{tabular}{|l|l|l|}
\hline Chef de algún restaurante & 1 & $\rightarrow$ TERMINAR Y AGRADECER \\
\hline Estudiante de gastronomía & 2 & $\rightarrow$ TERMINAR Y AGRADECER \\
\hline Ninguno & 3 & $\rightarrow$ CONTINUAR \\
\hline
\end{tabular}

F2.- ¿Trabaja usted por esta zona de San Isidro? (E: MOSTRAR TARJETA NRO. 1)

\begin{tabular}{|l|l|}
\hline $\mathrm{Si}$ & $1 \rightarrow$ CONTINUAR \\
\hline No & $2 \rightarrow$ TERMINAR Y AGRADECER \\
\hline
\end{tabular}

F3.- ¿Suele usted comer en restaurantes de esta zona de San Isidro? (E:MOSTRAR TARJETA NRO. 1)

\begin{tabular}{|l|l|}
\hline $\mathrm{Si}$ & $1 \rightarrow$ CONTINUAR \\
\hline No & $2 \rightarrow$ TERMINAR Y AGRADECER \\
\hline
\end{tabular}

F4.- ¿Usted es un...

F5.- ¿En cuál de los siguientes rangos de edad se encuentra usted?

\begin{tabular}{|l|l|}
\hline Entre 26 y 35 años & 1 \\
\hline Entre 36 y 45 años & 2 \\
\hline Entre 46 y 55 años & 3 \\
\hline Otra edad & 4 \\
\hline
\end{tabular}

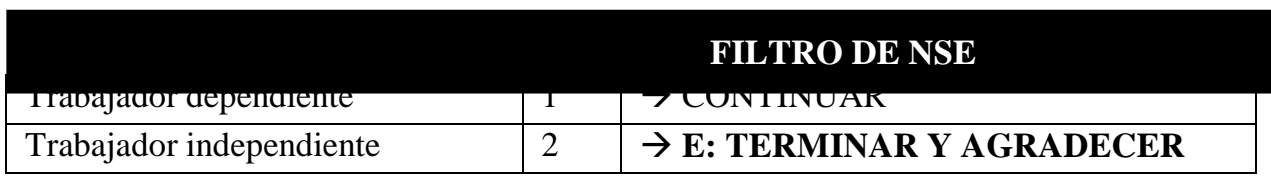

la finalidad de agrupar sus respuestas con las de otras personas de similares Joven, Con características a las de usted, nos gustaría que responda a las siguientes preguntas.

¿Quién es la persona que aporta MÁS al sostenimiento económico de su hogar? (E: 1. Si identifica a dos personas o más, preguntar por la de mayor edad. 2. Si la persona que más aporta no vive en el hogar, preguntar por la que administra los ingresos que recibe de la persona ausente.)

Las siguientes preguntas se refieren a... ......que es la persona que aporta MÁS al sostenimiento de su hogar (E: según pregunta 1)

N1. ¿Cuál es el último año o grado de estudios y nivel que aprobó el jefe de hogar (E: mencione el nombre según pregunta 1)? (ACLARAR “COMPLETA O INCOMPLETA”)

\begin{tabular}{|l|l|l|l|l|l|}
\hline Sin educación/ Educación Inicial & 0 & Superior Técnico Completa & 3 & Superior Univ. Completa & 5 \\
\hline $\begin{array}{l}\text { Primaria incompleta o completa/ Secundaria } \\
\text { incompleta }\end{array}$ & 1 & Superior Univ. Incompleta & 4 & Post-Grado Universitario & 7 \\
\hline Secundaria completa/ Superior Técnico Incompleta & 2 & & & & \\
\hline
\end{tabular}


N2. ¿Cuál de estos bienes tiene en su hogar que esté funcionando?

\begin{tabular}{|l|l|l|}
\cline { 2 - 3 } \multicolumn{1}{c|}{} & NO & SI \\
\hline $\begin{array}{l}\text { Computadora, laptop, tablet en } \\
\text { funcionamiento }\end{array}$ & 0 & 2 \\
\hline Lavadora en funcionamiento & 0 & 2 \\
\hline Horno microondas en funcionamiento & 0 & 2 \\
\hline $\begin{array}{l}\text { Refrigeradora/ Congeladora en } \\
\text { funcionamiento }\end{array}$ & 0 & 2 \\
\hline SUMAR PUNTAJE & & \\
\hline
\end{tabular}

N3. ¿Cuál de los siguientes bienes o servicios tiene en su hogar que esté funcionando?

\begin{tabular}{|l|l|l|}
\cline { 2 - 3 } \multicolumn{1}{c|}{} & NO & SI \\
\hline Auto o camioneta solo para uso particular (NO TAXI NI AUTO DE LA EMPRESA) & 0 & 5 \\
\hline $\begin{array}{l}\text { Servicio doméstico en el hogar pagado (MINIMO QUE VAYA AL HOGAR UNA VEZ } \\
\text { POR SEMANA) }\end{array}$ & 0 & 5 \\
\hline SUMAR PUNTAJES & & \\
\hline
\end{tabular}

N4. ¿Cuál es el material predominante en los pisos de su vivienda? (CONSIDERAR ÁREA

\section{CONSTRUIDA. RESPUESTA ÚNICA)}

\begin{tabular}{|l|l|l|l|}
\hline $\begin{array}{l}\text { Tierra / Otro material (arena y tablones sin } \\
\text { pulir) }\end{array}$ & 0 & Laminado tipo madera, láminas asfálticas o similares & 7 \\
\hline $\begin{array}{l}\text { Cemento sin pulir o pulido / Madera } \\
\text { (entablados)/ tapizón }\end{array}$ & 3 & $\begin{array}{l}\text { Parquet o madera pulida y similares; porcelanato, } \\
\text { alfombra, mármol }\end{array}$ & 8 \\
\hline $\begin{array}{l}\text { Losetas / terrazos, mayólicas, cerámicos, } \\
\text { vinílicos, mosaico o similares }\end{array}$ & 5 & & \\
\hline
\end{tabular}

N5. ¿A qué sistema de prestaciones de salud está afiliado el jefe de hogar? (SI TIENE MÁS DE UNO

CONSIDERAR EL DE MAYOR PUNTAJE. RESPUESTA ÚNICA)

\begin{tabular}{|l|l|l|l|}
\hline $\begin{array}{l}\text { No está afiliado a ningún seguro/ Seguro Integral de Salud } \\
\text { (SIS) }\end{array}$ & 0 & Seguro Salud FFAA/ Policiales & 4 \\
\hline ESSALUD & 2 & $\begin{array}{l}\text { Entidad prestadora de salud (EPS)/ Seguro privado de } \\
\text { salud }\end{array}$ & 6 \\
\hline
\end{tabular}

N6. ¿Cuál es el material predominante en las paredes exteriores de su vivienda? (NO

REVESTIMIENTO, ES EL MATERIAL. RESPUESTA ÚNICA)

\begin{tabular}{|l|l|l|l|}
\hline Estera & 0 & Piedra o sillar con cal o cemento & 4 \\
\hline Madera/ Piedra con barro/ Quincha (caña con barro)/ Tapia/ Adobe & 2 & Ladrillo o bloque de cemento & 6 \\
\hline
\end{tabular}

N7. El baño o servicio higiénico que tiene en su hogar está CONECTADO a:

\begin{tabular}{|c|c|c|c|}
\hline \multicolumn{2}{|c|}{$\begin{array}{l}\text { NO TIENE O NO ESTÁ CONECTADO A UN DESAGUE } \\
\text { (SIN RED PÚBLICA) }\end{array}$} & \multicolumn{2}{|l|}{$\begin{array}{l}\text { SÍ ESTÁ CONECTADO AL DESAGUE } \\
\text { ( CON RED PÚBLICA) }\end{array}$} \\
\hline No tiene baño & 0 & $\begin{array}{l}\text { Baño compartido fuera de la vivienda. (Ejem: quintas, } \\
\text { corralones, } \text { cuartos con baño compartido, } \text { etc.) }\end{array}$ & 3 \\
\hline $\begin{array}{l}\text { Baño que da a un pozo ciego, silo, letrina, pozo séptico, } \\
\text { río, acequia o canal dentro o fuera del hogar }\end{array}$ & 1 & Baño dentro de la vivienda & 5 \\
\hline
\end{tabular}

\begin{tabular}{|l|l|l|}
\hline .12 puntos o menos & NSE E & 8 \\
\hline .De 13 a 19 puntos & NSE D & 7 \\
\hline .De 20 a 22 puntos & NSE C2 & 6 \\
\hline .De 23 a 28 puntos & NSE C1 & 5 \\
\hline
\end{tabular}

\begin{tabular}{|l|l|l|}
\hline .De 29 a 33 puntos & NSE B2 & 4 \\
\hline .De 34 a 39 puntos & NSE B1 & 3 \\
\hline .De 40 a 47 puntos & NSE A2 & 2 \\
\hline .48 puntos a más & NSE A1 & 1 \\
\hline
\end{tabular}

\section{PERFIL DE GUSTOS Y PREFERENCIAS DE ALIMENTACIÓN DEL EJECUTIVO DE SAN ISIDRO}


A continuación vamos a hablar sobre su alimentación,

P1.- ¿Qué comida(s) suele consumir, con mayor frecuencia, en los restaurantes cercanos a su centro de labores? (RU)

\begin{tabular}{|l|l|}
\hline Pollo a la brasa & 1 \\
\hline Comida oriental & 2 \\
\hline Comida criolla & 3 \\
\hline Comida marina & 4 \\
\hline Comida rápida (Fast Food) & 5 \\
\hline Otro tipo & 6 \\
\hline
\end{tabular}

P2.- ¿Cuánto suele gastar aproximadamente en un almuerzo - menú ejecutivo, al acudir a estos restaurantes cercanos a su centro de labores? (RU)

\begin{tabular}{|l|l|}
\hline Menos de 15 soles & 1 \\
\hline De 15 a 25 soles & 2 \\
\hline De 26 a 35 soles & 3 \\
\hline Más de 36 soles & 4 \\
\hline
\end{tabular}

P3.- ¿Con qué frecuencia suele almorzar en lugares cercanos a su centro de labores?

\begin{tabular}{|l|l|}
\hline Todos los días (De lunes a viernes) & 1 \\
\hline Tres o cuatro veces por semana & 2 \\
\hline Una a dos veces por semana & 3 \\
\hline Una vez cada quince días & 4 \\
\hline Una vez al mes & 5 \\
\hline Otra frecuencia menor de consumo. & 6 \\
\hline No consume & 7 \\
\hline
\end{tabular}

EVALUACIÓN DEL CONCEPTO

A continuación le voy a leer una idea referente a un restaurante nuevo que ofrece un nuevo concepto y luego le pediremos su opinión a través de algunas preguntas.

(E: LEER) ANTE TODO PERMITAME LEERLE EL CONCEPTO DE "INSUMOS ORGÁNICOS”, ESTOS SON PRODUCTOS AGRÍCOLAS O AGROINDUSTRIALES, QUE SE PRODUCEN BAJO UN CONJUNTO DE PROCEDIMIENTOS DENOMINADOS "ECOLÓGICOS", ESTOS MÉTODOS EVITAN EL USO DE PRODUCTOS SINTÉTICOS, COMO PESTICIDAS, HERBICIDAS Y FERTILIZANTES ARTIFICIALES.

AL NO USAR PESTICIDAS SE CONTRIBUYE CON EL CUIDADO DEL MEDIO AMBIENTE. LAS PLANTAS, HORTALIZAS, ABSORVEN MAYORES MINERALES Y VITAMINAS. INCLUSO LOS ANIMALES CRIADOS BAJO ESTE SISTEMA ORGANICO, SE CRIAN EN UN ESTADO DE SEMI LIBERTAD, Y ALIMENTACIÓN NATURAL.

AHORA, LE COMENTAMOS SOBRE EL PROYECTO, DEL NEGOCIO PARA EL CUAL LE PEDIREMOS SU OPINIÓN. SE BASA EN LA CREACIÓN DE UN RESTAURANTE QUE ELABORE ALMUERZOS VARIADOS, BÁSICAMENTE DE COMIDA CRIOLLA, HACIENDO USO DE INSUMOS SALUDABLES Y ORGÁNICOS, Y DEBIDAMENTE MONITOREADOS POR UN NUTRICIONISTA. 


\section{EL RESTAURANTE ESTARÁ UBICADO EN EL DISTRITO DE SAN ISIDRO Y ATENDERÁ DESAYUNOS, ALMUERZOS, LONCHES Y CENAS, EN UN HORARIO DE 11 A 5 PM.}

P4.- De acuerdo al concepto que le acabo de leer, y haciendo uso de las alternativas de respuesta, que le muestro en la siguiente escala, cuan interesante o no, le parece esta idea a usted? (E: MOSTRAR TARJETA NRO. 2)

\begin{tabular}{|l|l|l|l|l|}
\hline Nada interesante & Poco interesante & Me es indiferente & Algo Interesante & Muy interesante \\
\hline 1 & 2 & 3 & 4 & 5 \\
\hline
\end{tabular}

P5.- Según el concepto que acabo de leer, en una escala de 1 al 5, donde 1 significa no me agrada nada y 5 me agrada mucho, cuánto le agradan o no, las siguientes características de nuestra propuesta:

No me agrada nada $\rightarrow$ Me agrada mucho

\begin{tabular}{|l|l|l|l|l|l|}
\hline Que utilice insumos orgánicos & $\mathbf{1}$ & $\mathbf{2}$ & $\mathbf{3}$ & $\mathbf{4}$ & $\mathbf{5}$ \\
\hline Que tenga reserva on line & $\mathbf{1}$ & $\mathbf{2}$ & $\mathbf{3}$ & $\mathbf{4}$ & $\mathbf{5}$ \\
\hline La ubicación del local & $\mathbf{1}$ & $\mathbf{2}$ & $\mathbf{3}$ & $\mathbf{4}$ & $\mathbf{5}$ \\
\hline Que cuente con la certificación de un nutricionista & $\mathbf{1}$ & $\mathbf{2}$ & $\mathbf{3}$ & $\mathbf{4}$ & $\mathbf{5}$ \\
\hline
\end{tabular}

P6.- Haciendo uso de la siguiente escala de respuestas y pensando en el RESTAURANTE DE ALMUERZOS CON INSUMOS ORGÁNICOS, en general cuál de estas respuestas que le voy a leer, representa mejor su intención de consumir o no, los almuerzos de este restaurante? (E:MOSTRAR

NRO.3)

\begin{tabular}{|l|l|l|l|l|}
\hline $\begin{array}{l}\text { Definitivamente NO } \\
\text { consumiría }\end{array}$ & $\begin{array}{l}\text { Probablemente NO } \\
\text { consumiría }\end{array}$ & $\begin{array}{l}\text { No sabría decir si iría } \\
\text { a consumir o no }\end{array}$ & $\begin{array}{l}\text { Probablemente SI } \\
\text { consumiría }\end{array}$ & $\begin{array}{l}\text { Definitivamente SI } \\
\text { consumiría }\end{array}$ \\
\hline 1 & 2 & 3 & 4 & 5 \\
\hline
\end{tabular}

P7.- El restaurante ofrecerá tres opciones de almuerzo (E: MOSTRAR TARJETA NRO. 4)

La OPCIÓN 1, contiene: entrada, sopa, plato de fondo, refresco.

La OPCIÓN 2, contiene: Entrada, plato de fondo y refresco.

La OPCIÓN 3, contiene: Plato de fondo y refresco.

¿Cuál de las siguientes combinaciones pediría con mayor frecuencia en el almuerzo? (E:RU)

\begin{tabular}{|l|l|}
\hline Opción 1 & 1 \\
\hline Opción 2 & 2 \\
\hline Opción 3 & 3 \\
\hline
\end{tabular}

\section{EVALUACIÓN DEL PRECIO}

en P7, de almuerzo, elaborado con insumos saludables y orgánicos, en este restaurante?

(E: MOSTRAR TARJETA NRO. 5)

\begin{tabular}{|l|l|}
\hline Menos de 14.99 soles & 1 \\
\hline Entre 15.00 y 19.99 soles & 2 \\
\hline Entre 20.00 y 24.99 soles & 3 \\
\hline Entre 25.00 y 29.99 soles & 4 \\
\hline De 30.00 a más soles & 5 \\
\hline
\end{tabular}

\section{PROYECCION DE LA FRECUENCIA DE COMPRA}

este restaurante que estamos evaluando? (E: MOSTRAR TARETA NRO.6)

\begin{tabular}{|l|l|}
\hline Todos los días de lunes a sábado & 1 \\
\hline Todos los días de lunes a viernes & 2 \\
\hline 4 veces a la semana & 3 \\
\hline 3 veces a la semana & 4 \\
\hline 2 veces a la semana & 5 \\
\hline 1 vez a la semana & 6 \\
\hline
\end{tabular}




\section{IDENTIFICAR CANALES DE COMUNICACIÓN}

P14.- Según las siguientes opciones, en qué medio(s) de comunicación, le gustaría ver, escuchar o leer información sobre el restaurante de alimentos orgánicos. (RM)

\begin{tabular}{|l|l|}
\hline Folletos/ volantes & 1 \\
\hline Mensaje de texto a su celular & 2 \\
\hline Mensajes por whatsapp & 3 \\
\hline Mensajes por el Facebook/ Twitter/ Instagram & 4 \\
\hline Degustaciones en el mismo restaurante & 5 \\
\hline Página web del restaurante & 6 \\
\hline Aplicación móvil del restaurante & 7 \\
\hline Mensaje de correo electrónico & 8 \\
\hline Otros (especifique) & 9 \\
\hline
\end{tabular}

\section{TARJETA 1}

\section{SECTOR 4: Dividido por 4 subsectores}

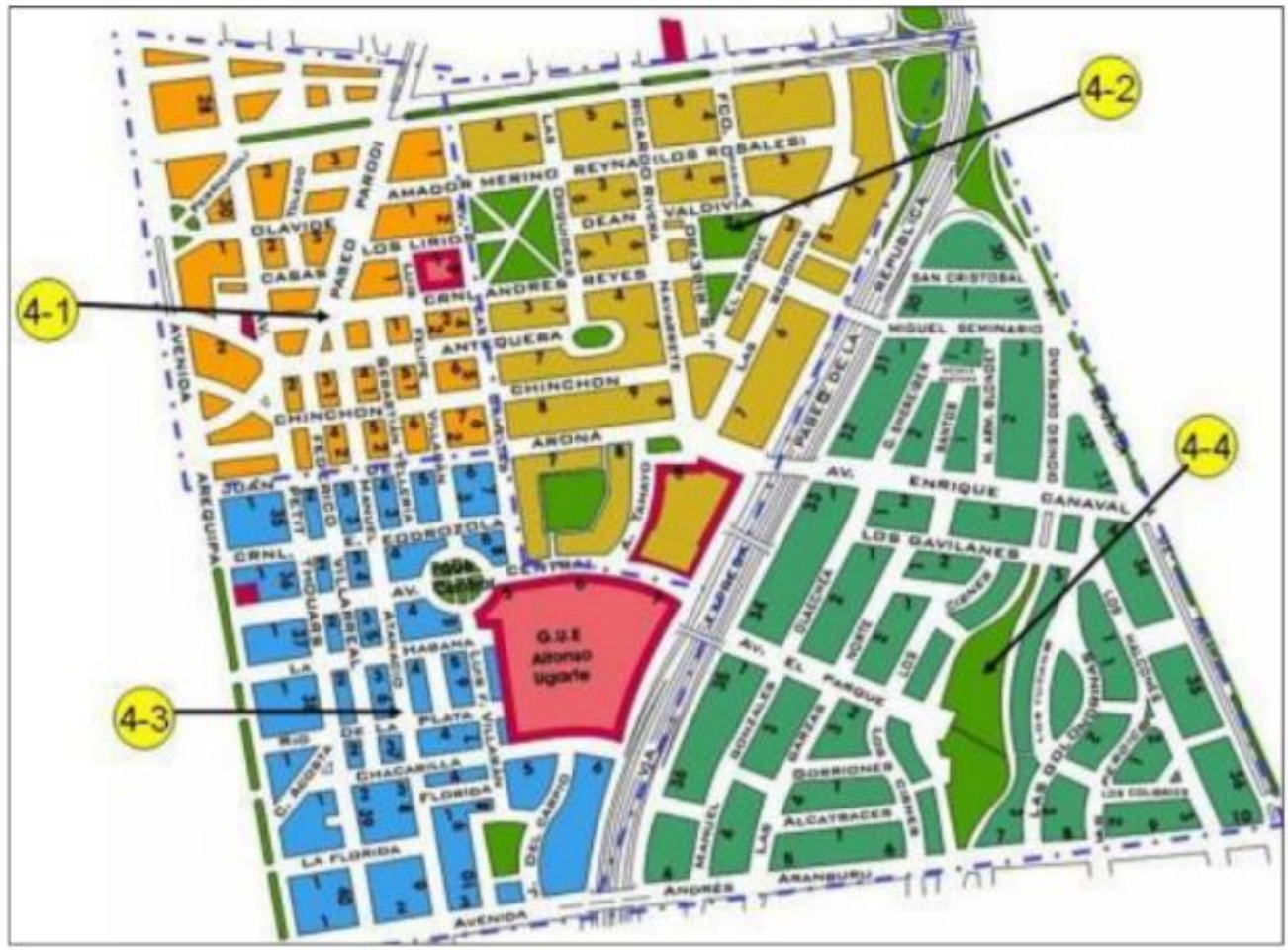

\section{TARJETA 2}

\begin{tabular}{|l|l|l|l|l|}
\hline Nada interesante & Poco interesante & Me es indiferente & Algo Interesante & Muy interesante \\
\hline
\end{tabular}

\section{TARJETA 3}




\begin{tabular}{|l|l|l|l|l|}
\hline $\begin{array}{l}\text { Definitivamente NO } \\
\text { consumiría }\end{array}$ & $\begin{array}{l}\text { Probablemente NO } \\
\text { consumiría }\end{array}$ & $\begin{array}{l}\text { No sabría decir si iría } \\
\text { a consumir o no }\end{array}$ & $\begin{array}{l}\text { Probablemente SI } \\
\text { consumiría }\end{array}$ & $\begin{array}{l}\text { Definitivamente SI } \\
\text { consumiría }\end{array}$ \\
\hline
\end{tabular}

\section{TARJETA 4}

La OPCIÓN 1, contiene: entrada, sopa, plato de fondo, refresco.

La OPCIÓN 2, contiene: Entrada, plato de fondo y refresco.

La OPCIÓN 3, contiene: Plato de fondo y refresco.

\section{TARJETA 5}

\begin{tabular}{|l|l|}
\hline Menos de 14.99 soles & 1 \\
\hline Entre 15.00 y 19.99 soles & 2 \\
\hline Entre 20.00 y 24.99 soles & 3 \\
\hline Entre 25.00 y 29.99 soles & 4 \\
\hline De 30.00 a más soles & 5 \\
\hline
\end{tabular}

\section{TARJETA 6}

\begin{tabular}{|l|l|}
\hline Todos los días de lunes a sábado & 1 \\
\hline Todos los días de lunes a viernes & 2 \\
\hline 4 veces a la semana & 3 \\
\hline 3 veces a la semana & 4 \\
\hline 2 veces a la semana & 5 \\
\hline 1 vez a la semana & 6 \\
\hline No consumiría & 7 \\
\hline
\end{tabular}




\section{BIBLIOGRAFÍA}

Altamirano, M., Dodero, G. Peña, J. (2001). Desarrollo del concepto e inicio de operaciones del establecimiento piloto de un restaurante con atención Fast-Casual y Fast-Food-Food netamente peruano con las características necesarias para ser franquiciado. Tesis de Executive MBA. Universidad San Ignacio de Loyola, Lima-Perú.

Angellotti, M.G., Carbone, V.R., Ventura, V.C. (2010). Plan de Negocios: Empresa de Cáterin "Sabores Delivery”. Seminario de Título Ingeniería Comercial Mención Administración. Universidad de Chile, Santiago-Chile.

Arlette Beltran y Hanny Cueva. (2013). Evaluación Privada de Proyectos (3a. ed.). Perú. Pearson.

Asociación Pro Bienestar y Desarrollo, Manual de Emprendedores -Raúl Diez Canseco Terry Fundador Asociación Pro Bienestar y Desarrollo.

Cesar A. Bernal (2010) Tercera edición "Metodología de la Investigación”.

Del Rosario, M.B., Santillana, C.V., Vidal, A.C., Yzarra, L.C. (2008). "Proyecto de reestructuración de procesos de un Restaurante en Surco Viejo". Tesis de Master of Science in Management. Universidad San Ignacio de Loyola, Lima-Perú.

Fernando D’Alessio Ipinza (2008) El proceso Estratégico: Un Enfoque de Gerencia. Perú. Pearson.

Forsyth, A. (2012) Finanzas Empresariales: Rentabilidad y valor. Perú. 
Flores, C.Y., Mora, E.P., Castro, Q.A., Santos, S.S. (2010). Almuerzos especiales. Proyecto de Inversión. Lima-Perú.

Leon, M.D., Nuñez, P.K., Villena, M.S., Bonilla, G.V. (2010). Restaurante de Comida Saludable "Fresh Food". Tesis de Master of Science in Management. Universidad San Ignacio de Loyola, Lima-Perú.

Lydia Arbaiza Fermini (2015) "Como elaborar un Plan de Negocios" (1a. ed.) Lima-Perú. Esan Ediciones.

Michael E. Porter (2015) Estrategia competitiva - Técnicas para el análisis de la empresa y sus competidores.

Oriol Amat (2008), Análisis De Estados Financieros Fundamentos y Aplicaciones (8a. ed.). Barcelona. Gestión 2000.

Porter, Michael E. (2008) Ventaja competitiva, creación y sostenimiento de un desempeño superior. $15^{\mathrm{a}}$ Ed. México: Compañía Editorial Continental, S.A. De C.V..

Porter, Michael E. (2013) Ser Competitivo Edición Actualizada y Aumentada. (6a. ed.) España. Ediciones Deusto.

Vidalon, J.J., Mondoñedo, T.C., Morales, Z.C., Pollet, G. (2002). “Estudio de Factibilidad para la implementación de un Café-Punto de Encuentro con estilo Mediterráneo Francés en Lima, Perú. Tesis de Executive MBA. Universidad San Ignacio de Loyola, Lima-Perú. 


\section{REFERENCIAS ELECTRÓNICAS}

"Un socio comercial muy importante". En: Diario Perú 21. [en línea]. (PE): 09/11/2016. [citado 14 abril 2017]. Microsoft HTML. Disponible "Las tendencias de la gastronomía peruana". En Semana Económica [en línea]. Lima: Masías, 2016 [Citado 19 Julio 2018]. Microsoft HTML. Disponible en: http://semanaeconomica.com/article/entreparentesis/estilo-de-vida/176373-las-tendencias-de-la-gastronomiaperuana-en-el-2016/

Adobe Acrobat. Disponible en:

https://www.inei.gob.pe/media/MenuRecursivo/publicaciones_digita les/Est/Lib1168/libro.pdf

Banco Mundial, "Facilidad para hacer negocios en Perú" [en línea]. Lima: BIRF, 2018. [citado 18 marzo 2018]. Microsoft HTML. Disponible en: http://espanol.doingbusiness.org/data/exploreeconomies/peru.

Banco Mundial. "Perú panorama General”. [en línea]. Lima: BIRF, 2018. [citado 18 marzo 2018]. Microsoft HTML. Disponible en: http://www.bancomundial.org/es/country/peru/overview.

Consultora internacional Mintel reporte Global Food and Drink Market. En: GASTRONOMÍA \& CÍA. [en línea]. (Republica): 2015. [citado 14 noviembre 2018]. Adobe Acrobat. Disponible en:

https://gastronomiaycia.republica.com/wp-content/uploads/2015/10/ informe mintel.pdf.

en: http://peru21.pe/economia/elecciones-estados-unidos-alfredo-thornecree-que-pais-seguira-siendo-socio-comercial-muy-importante$\underline{2261854}$ 
Instituto Nacional de Estadística e Informática. (Julio 2016). Encuesta

Instituto Nacional de Estadística e Informática. Informe Técnico 2016, [en línea]. Lima: INEI, 2016 [Citado 08 agosto 2018] Adobe Acrobat. Disponible en:

https://www.inei.gob.pe/media/MenuRecursivo/boletines/informetecnico-n10produccion-ago2016.pdf.

Instituto Nacional de Estadística e Informática. Una mirada a Lima

Mensual del Sector Servicios. Boletín Estadístico. (2), 1-14. [en línea]. Lima: INEI, 2016. [Citado 09 Setiembre 2017] Adobe Acrobat. Disponible en: https://www.inei.gob.pe/media/MenuRecursivo/boletines/boletinestadistico-del-sector-servicios-n-09-setiembre-2016.pdf

Metropolitana. [en línea]. Lima: INEI, 2014. [Citado 10 junio 2017].

Ministerio de Trabajo y promoción del empleo, Anuarios Estadísticos sectorial 2015. [en línea]. Lima: MTPE, 2015. [Citado 12 abril 2018]. Microsoft HTML. Disponible en: http://www2.trabajo.gob.pe/estadisticas/anuarios-estadisticos/.

Ministerio de Trabajo y Promoción del Empleo. Indicadores laborales a nivel distrital 2015. [en línea]. Lima: MTPE, 2015. [Citado 12 abril 2018]. Microsoft HTML. Disponible en: http://www2.trabajo.gob.pe/estadisticas/ind-lab-a-nivel-distrital/.

Municipalidad de San Isidro, Licencia de funcionamiento 2017. [en línea]. Lima: MSI, 2017. [Citado 10 noviembre 2017]. Microsoft HTML. Disponible en: 
http://datosabiertos.msi.gob.pe/dataviews/226709/licencias-defuncionamiento/.

Municipalidad de San Isidro, Restaurante Saludables 2017. [en línea]. Lima: MSI, 2017. [Citado 10 noviembre 2017]. Microsoft HTML. Disponible en: http://msi.gob.pe/portal/nuestro-distrito/turismodistrital/restaurantes-saludable/.

World Travel Awards. World's Leading Culinary Destination 2016. [en línea]. Lima:, WORLD TRAVEL AWARDS 2016. [Citado 30 abril 2018]. Microsoft HTML. Disponible en:

https://www.worldtravelawards.com/award-worlds-leading-culinarydestination-2016 